\title{
MACROINVERTEBRATE COMMUNITY RESPONSES \\ TO MAMMAL CONTROL - EVIDENCE FOR \\ TOP-DOWN TROPHIC EFFECTS
}

BY

OLIVIA EDITH VERGARA PARRA

A thesis submitted to the Victoria University of Wellington in fulfilment of the requirements for the degree of Doctor of Philosophy in Conservation Biology

Victoria University of Wellington

2018 
Para mi sobrina Violeta Orellana Vergara y su sonrisa hermosa.

Tu llegada remeció mi corazón de amor de una manera inimaginable.

¡Sueña en grande! 
Nothing in nature stands alone... (John Hunter 1786) 


\section{AbSTRACT}

New Zealand's invertebrates are characterised by extraordinary levels of endemism and a tendency toward gigantism, flightlessness and longevity. These characteristics have resulted in a high vulnerability to introduced mammals (i.e. possums, rats, mice, and stoats) which are not only a serious threat to these invertebrates, but have also altered food web interactions over the past two-hundred years. The establishment of fenced reserves and the aerial application of 1080 toxin are two methods of mammal control used in New Zealand to exclude and reduce introduced mammals, respectively. Responses of ground-dwelling invertebrates to mammal control, including a consideration of trophic cascades and their interactions, remain unclear. However, in this thesis, I aimed to investigate how changes in mammal communities inside and outside a fenced reserve (ZEALANDIA, Wellington) and before-and-after the application of 1080 in Aorangi Forest, influence the taxonomic and trophic abundance, body size and other traits of ground-dwelling invertebrates on the mainland of New Zealand. I also tested for effects of habitat variables (i.e. vegetation and elevation), fluctuations in predator populations (i.e. mice, rats and birds) and environmental variables (i.e. temperature). Additionally, I investigated how squid-bait suspended over pitfall traps influenced the sampling of ground weta and other invertebrates in Aorangi and Remutaka Forests. Contrary to my expectations, there were no differences in abundance or body size of invertebrates within ZEALANDIA (which excludes introduced mammals except mice) relative to the outside, except for Staphylinidae which were more abundant outside the fence. Differences in the agents of predation pressure from mainly mammals, outside the reserve, to mostly birds within ZEALANDIA, but potentially little change in net predation pressure, may explain this apparent similarity in ground-invertebrates. No differences in invertebrate communities were also recorded in the 1080-treated area (Aorangi Forest) after one year of the aerial application of 1080. It could imply that the use 
of this toxin does not produce any apparent detriment to invertebrates at a population level. The application of 1080 usually leads to changes in insectivorous predator (birds and introduced mammals) dynamics in the short-term mainly due to meso-predator release, which may affect invertebrate communities as a result. Temporal and spatial variation of different components of the ecosystem appear to be more significant drivers of invertebrate dynamics, than 1080 mammal control. For example, rats (Rattus spp.) limited the abundance and body size of large invertebrates (i.e. ground weta, cave weta and spiders) in Aorangi and Remutaka Forests. Smaller invertebrates such as gastropods, weevils and springtails were affected directly by spatial factors such as vegetation, while dung beetles responded to an increase in mouse density. Based on a comparison of pitfall trapping methods, I suggest the use of squid baiting as an effective method for sampling ground weta (Hemiandrus spp.) in New Zealand, as they responded positively to these baits. Finally, I propose ground weta and spiders as suitable indicators of rat predation, as they are abundant in forests and easily recognised by non-specialists, and they respond negatively to rat densities. This thesis underlines the importance of studying the effect of introduced mammal dynamics derived from mammal control in an ecosystem approach, to achieve conservation goals both in the short- and long-term, especially considering the New Zealand Government's ambitious goal of eradicating three of the most prevalent mammal predators (rats, possums and stoats) by 2050 . 


\section{ACKNOWLEDGEMENT}

We do not say "thank you" as often as we should. Most of the time we take others help, love and encouragement for granted, like if it was their obligation to be there when you need it. One of the many things I realized during this journey, was that we must be grateful for all of the people who willingly decide to walk the path alongside you. It has been a long journey and many people were part of it. To all of them, my deepest gratitude, because this thesis would not have been the same without them.

To begin with, I would like to thank my supervisors, Dr. Stephen Hartley and Dr. Nicky Nelson from Victoria University of Wellington (VUW), for their trust, commitment, feedback, support, and dedication. It has been a pleasure to work under their supervision. Their experience and knowledge inspired me along the way and I would be forever grateful for all their help and support.

I would like to thank: Leslie Milicich (VUW), Melissa Harward (VUW) and Alexandra Whyte (VUW) for their assistance with the laboratory work; to Sean Rudman for his assistant with the mammal footprint identification in Chapter 2; Dr. Mike Dickison (Whanganui Regional Museum), Dr. George Gibbs (VUW), Dr. Briar Smith (Massey University), Dr. Mike Fitzgerald (Te Papa Museum), Dr. Olivier Ball (Northtec) for their assistance with the identification of insects; to Dr Heiko Wittmer (VUW) for camera traps in Chapter 2, and Dr. Mandy Barron (Landcare Research) for her advice and feedback.

My gratitude to the people who participated in the identification of vegetation in the Aorangi and Remutaka: Dan Crossett, Asher Cook, Sean Rudman, Barrett Pistol, Alex Whyte, Bart Cox, Nancy Collis, Ella Buckley and Nyree Fea. To Cong Zeng and Edith Calixto for their 
assistance with map in Chapter 2. To members of the "Bug Club" (VUW) especially Nyree Fea, Charlie Clark, Victor Anton, Samhita Bose, Sarah Herbert, Alex Bonnar-Coles for their advice and feedback.

I would like to thank many people for field assistance in ZEALANDIA, Aorangi and Remutaka Forests, especially: Melissa Harward, Sean Bates, Simon Ingram, Claudia Hurtado, Asher Cook, Valentina Garcia, Ma Jose Silva, Ignacio Silva, Adrian Pike, Rachel Wilcox, Neville Higgson, Shaun Graham, Dan Crossett, Nyree Fea, Balam Jimenez and Catalina Silva. I would also like to thank rangers and conservation managers at ZEALANDIA that I encountered along the way and aided my job when I needed it.

To my colleagues and friends for their emotional and physical support during this journey, both in Wellington and around the world. To my friends: Kimberley Maxwell, Daniela Pavez, Connie Toth, Andrea Glockner, Catherine Davis and Patricia Ramirez who read and offer their advice about my thesis, and were also willing to share a cup of tea when I most needed it. To the 416KK team, Kim, Maren, Andrea, Sergio, Pop, Cong, Edi and Amy for all the good laugh and friendship.

To my Latin-American family in New Zealand, especially: Lili Guerra, Claudia Hurtado, Paty Lara, Balam Jimenez, Mauro Cifuentes and Pato Quintana. To my friends: Patricia Bocaz, Laura Callaghan and Leslie Roa (RIP) for their love. To members of Radio MIA at Wellington Access Radio, and Mujeres In Aotearoa (MIA) for bringing me back to my roots. To Joanna and Phil, angels on my way, who become my parents in Wellington. To Mary Murray and Patricia Stein for their help and conversations. 
I would like to thank my family, specially my mom (Raquel Parra) and dad (Isaac Vergara) who believe in this dream and support me emotionally and financially at all the times, even when they did not fully understand what was happening. To my brother, Javier Vergara and sister, Viviana Vergara for their love, jokes and conversations. To my grandparents: Abuela Eliana, Tata Juan and Tia Chalo and to the ones who already left this world: Abuela Carmela, Tata Dago, Abuela vieja and Tata Ramon. I acknowledge their kindness, patience and wisdom. Thank you for teaching me to love nature and my roots. To Hugo Moyano (Briozoologist), RIP, the best teacher in the world, who once taught me about the wonderful nature of New Zealand while I was still an undergrad student.

I acknowledge financial support from the Aorangi Restoration Trust, the Centre of Biodiversity and Restoration Ecology from Victoria University of Wellington, Submission scholarship at Victoria University of Wellington, and my PhD scholarship "Becas Chile" from the "Comisión Nacional de Ciencia y Tecnología (Conicyt)", Chilean Government, which made this research possible.

To the forests and invertebrates of New Zealand for teaching me so much. To the land that ignited my passion and guided this thesis in the highs and lows, making me feel alive and in love with this adventure. My gratitude and respect, especially to the forests of ZEALANDIA, Aorangi and Remutaka for guiding my path and allowing me the entrance and way out safe, sound and happy. This thesis is also yours. 


\section{Table of Contents}

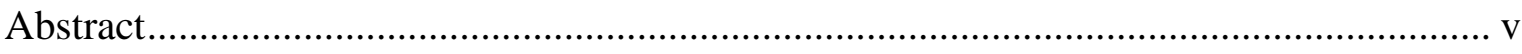

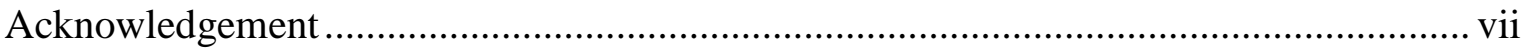

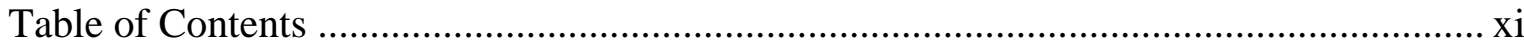

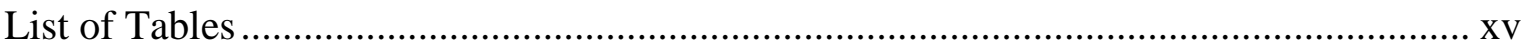

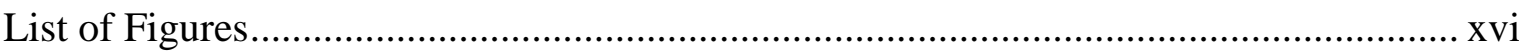

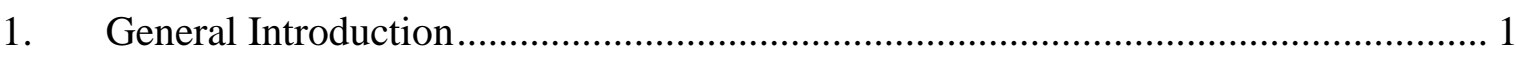

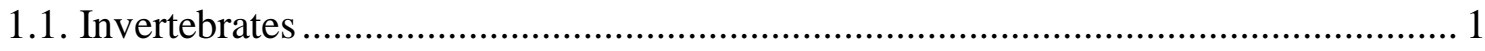

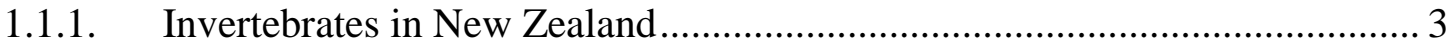

1.2. Human influences on invertebrate communities ....................................................... 5

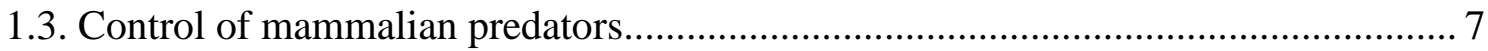

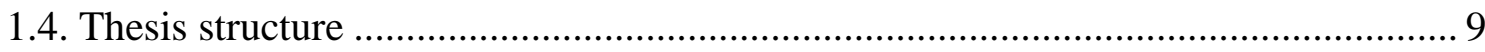

Chapter 2: Effects of mammal exclusion on invertebrate communities in New Zealand

Chapter 3. Neutral responses of ground-dwelling invertebrate communities to aerial 1080 operations in New Zealand.

Chapter 4. Top down effects on ground-dwelling invertebrates in Aorangi and Remutaka Forests, New Zealand.

Chapter 5. The efficiency and biases of squid-baited pitfall traps used for collecting ground weta and other ground-dwelling invertebrates in New Zealand..................... 12

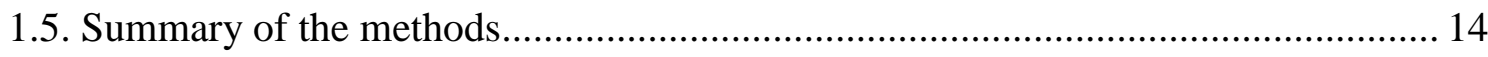

2. Effects of mammal exclusion on invertebrate communities in New Zealand .......... 17

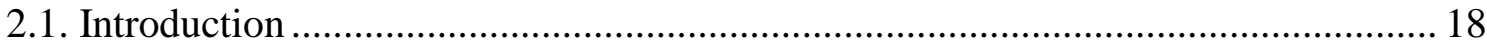

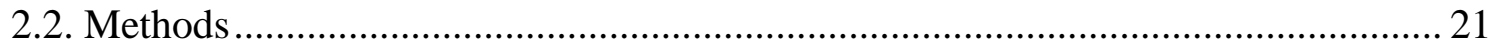

2.2.1. Invertebrate diversity, body size and composition ....................................... 22

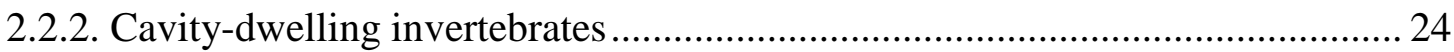

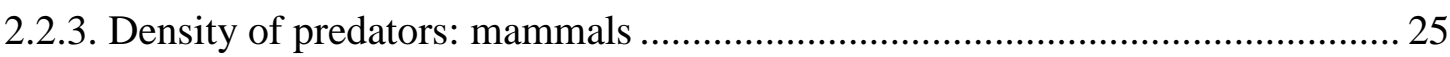

2.2.4. Predator pressure measured via exclosures................................................. 25

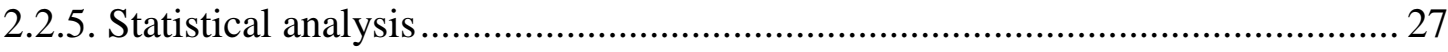

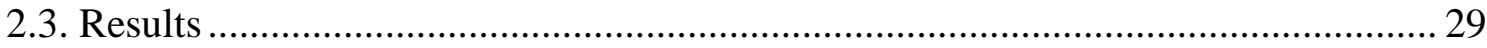

2.3.1. Composition and diversity of ground-dwelling invertebrates .......................... 29

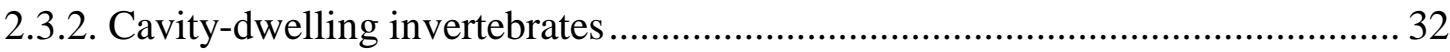




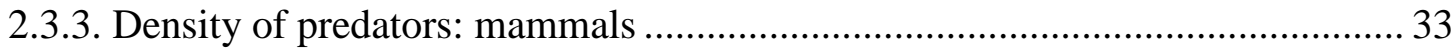

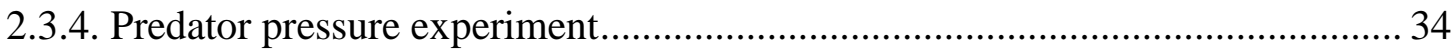

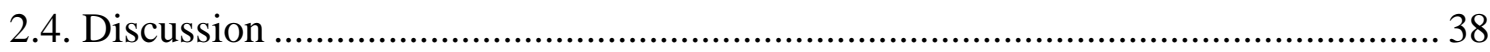

2.4.1. Invertebrate abundance and fence exclusion .................................................. 38

2.4.2. Abundance and body size of spiders and year ................................................ 40

2.4.3. Predator pressure measured by enclosures .................................................... 41

3. Neutral responses of ground-dwelling invertebrate communities to aerial 1080

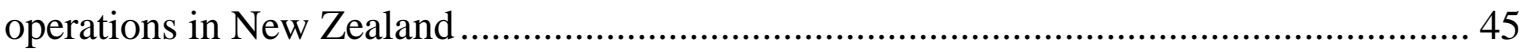

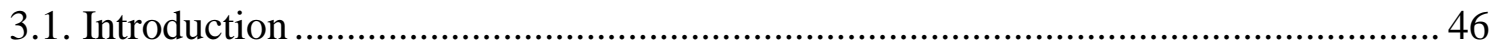

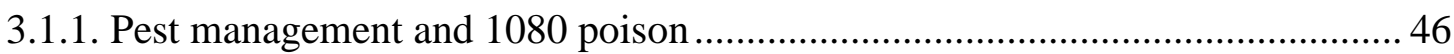

3.1.2. 1080 application and invertebrate communities .......................................... 48

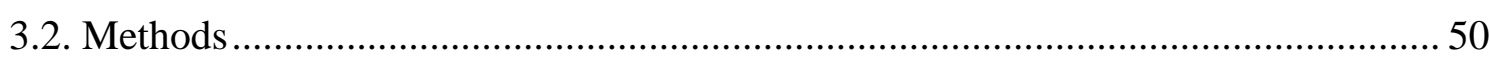

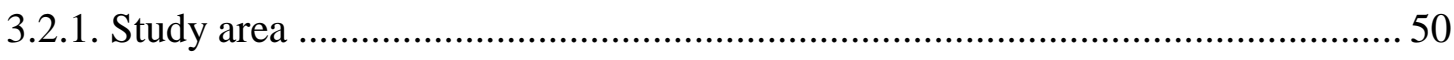

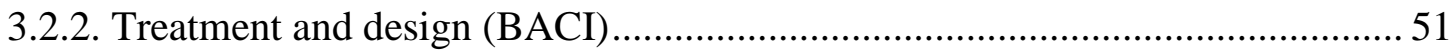

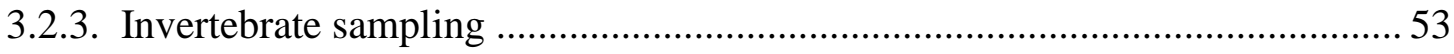

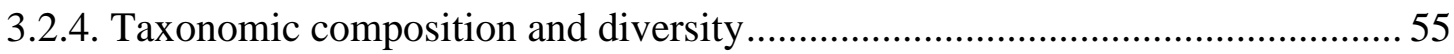

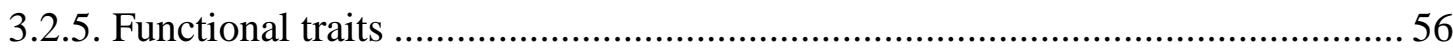

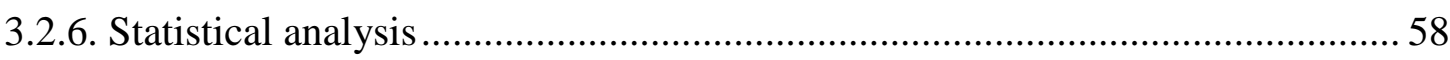

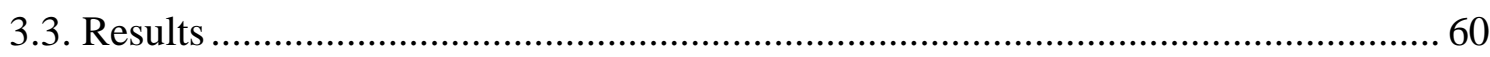

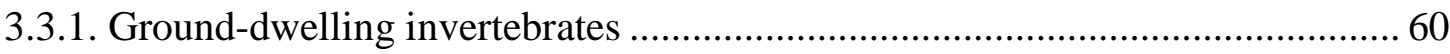

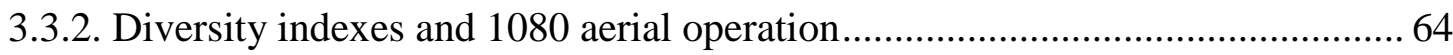

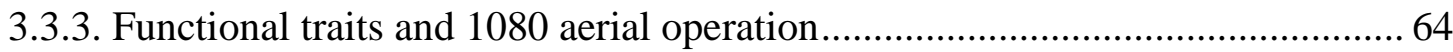

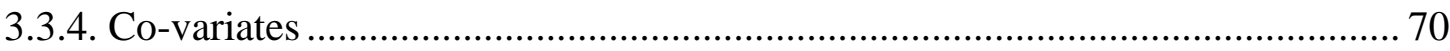

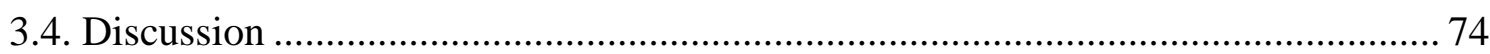

3.4.1. Ground-dwelling invertebrates and 1080 aerial operation ............................. 74

3.4.2. Abundance of ground-dwelling invertebrates and Time (both forests) ............. 75

3.4.3. Body size of ground-dwelling invertebrates and Time (both forests) ............... 76

3.4.4. Ground beetle assemblage and Time (both forests)....................................... 78

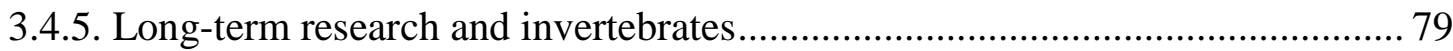

4. Top down effects on ground-dwelling invertebrates in Aorangi and Remutaka

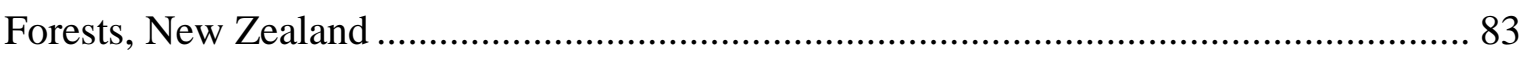

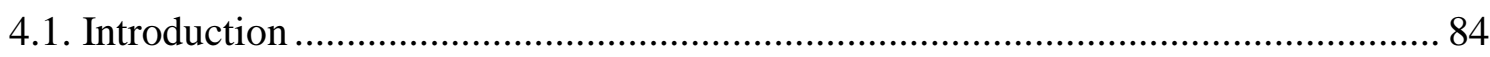

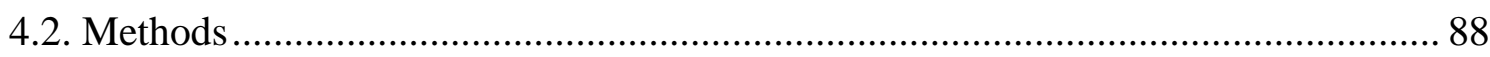

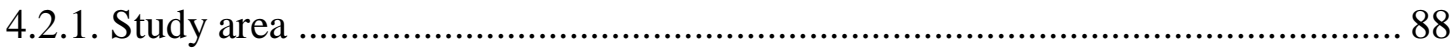




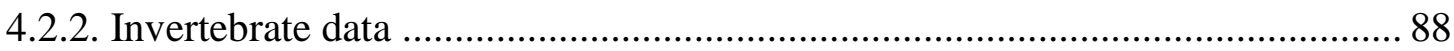

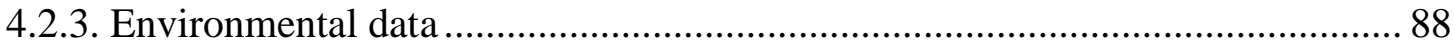

4.2.4. Top down effects on invertebrate communities ............................................... 89

4.2.5. Habitat and elevation effects on invertebrates and mammals.......................... 91

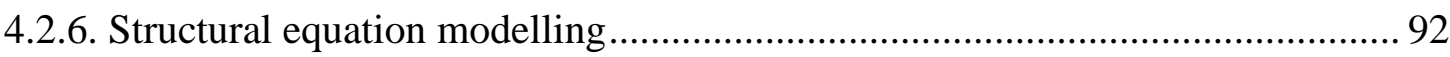

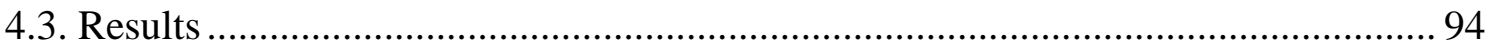

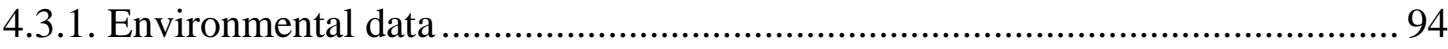

4.3.2. Top down effects on invertebrates ................................................................. 95

4.3.3. Habitat and elevation effects on invertebrates .................................................. 104

4.3.4. Structural equation modelling (SEM) ........................................................... 107

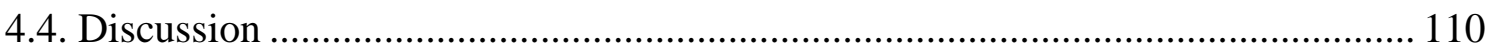

4.4.1. Effect of temperature and elevation on ground-dwelling invertebrates........... 110

4.4.2. Top down effects on invertebrates ............................................................... 111

4.4.3. Effect of habitat on ground-dwelling invertebrates ...................................... 114

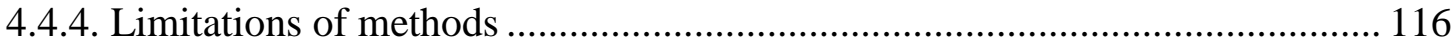

4.4.5. Which of the above factors explain the greatest amount of variation in invertebrate abundance and body size?

5. The efficiency and biases of squid-baited pitfall traps used for collecting ground weta (Orthoptera: Anostostomatidae) and other ground-dwelling invertebrates in New

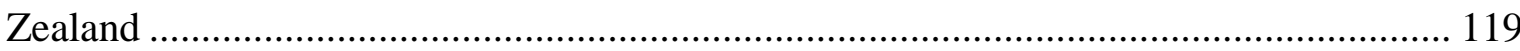

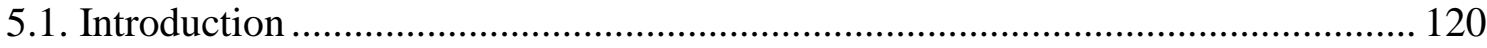

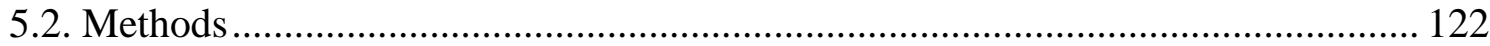

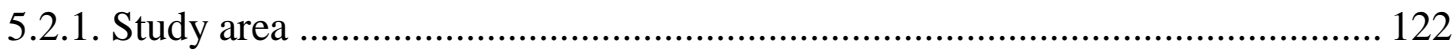

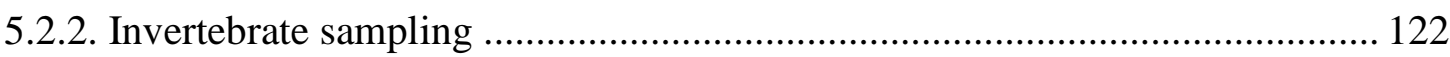

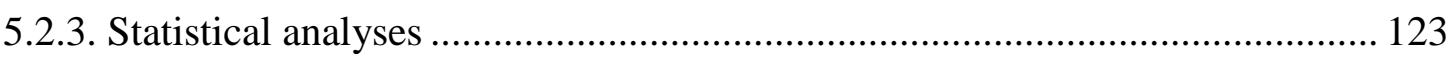

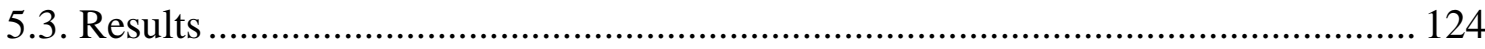

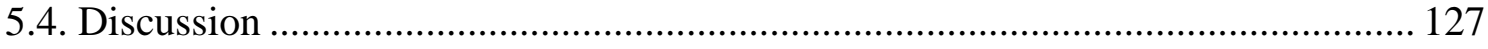

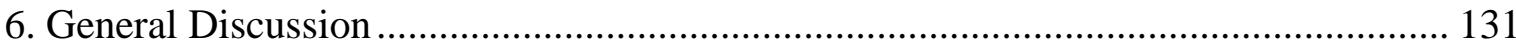

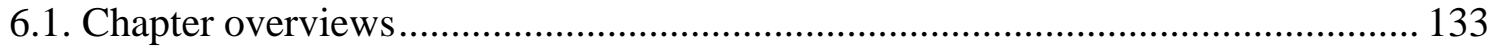

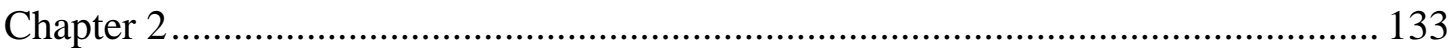

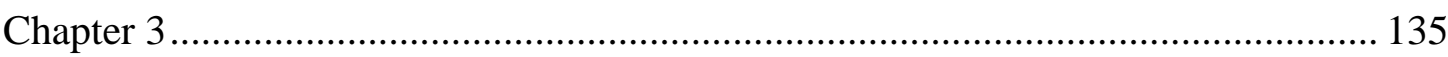

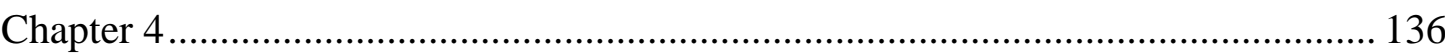

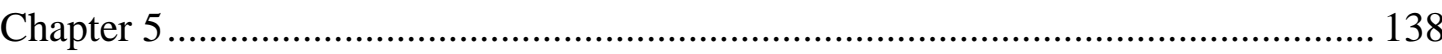

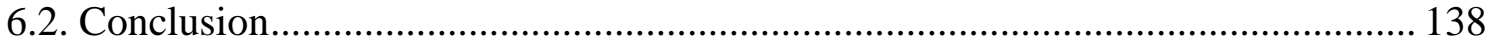




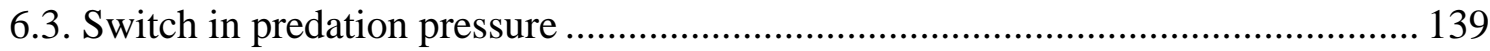

6.4. Complexity of trophic cascades of invertebrates ................................................ 141

6.5. Invertebrate indicators of mammal predation ........................................................ 143

6.6. Limitations, recommendations and future research ............................................... 146

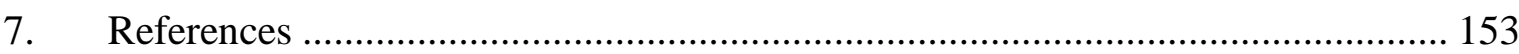

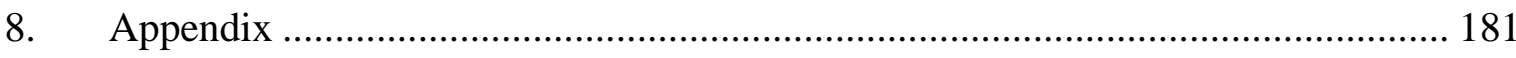




\section{LIST OF TABLES}

Table 1.1 Summary of factors analysed in each data chapter.

16

Table 2.1 Summary of analysis of Variance (Type III, chi-square test) fitting linear mixedeffects models for the effects of a fenced reserve mammal exclusion. 31

Table 2.2 Total number of all visits of predators inside and outside cages for each treatment inside and outside the fenced reserve. 37

Table 3.1 Sampling periods for each forest relative to 1080 treatment in the Aorangi...... 53

Table 3.2 Total number of sets of five pitfall traps and sets of seven pitfall traps $\left(\mathrm{n}^{\circ} / \mathrm{n}^{\circ}\right)$ per site and season across the Aorangi and Remutaka.................................................. 55

Table 3.3 Categorisation of functional traits for ground-dwelling invertebrate taxa........ 56

Table 3.4 Summary of Analysis of Deviance (Type III, chi-square tests) fitting a LME model for the effects of 1080 mammal control.

Table 4.1 Absolute value of the coefficient of correlations (r) and their relative strength. 89 Table 4.2 Cover-classes applied to ground (vegetation) and leaf litter cover .................... 91

Table 4.3 Environmental influences on the invertebrate community.............................. 106 Appendix Table 8.1 Taxonomic composition and total abundance of invertebrate communities inside and outside the fenced reserve, ZEALANDIA, in 2014 and 2015... 182 Appendix Table 8.2 Taxonomic composition and total abundance of invertebrates in Aorangi and Remutaka Forests from November 2013 to November 2015. 185 Appendix Table 8.3 Structural Equation Modelling (SEM) summary of the best model for invertebrate abundance. 


\section{LIST OF FIGURES}

Figure 1.1 Conceptual diagram of the research questions and predictions of each chapter.

Figure 2.1 Map of the fenced reserve, ZEALANDIA in Wellington Region, New Zealand..

Figure 2.2 Mean $( \pm \mathrm{SD})$ of invertebrates by Class, found inside and outside the fenced reserve in 2014 and 2015.

Figure 2.3 Principal Component Analysis (PCoA) for the Bray-Curtis dissimilarities of trophic guild of invertebrates among sites in 2014 and 2015.

Figure 2.4 Average detection rate of mammals and insects inside and outside fenced reserve using tracking tunnels.

Figure 2.5 Total proportion of predation of larvae and adult mealworms for each treatment inside and outside the fenced reserve.

Figure 2.6 First encounter predation on mealworms for mammal exclusion, bird exclusion, and control treatments, inside and outside the fenced reserve..

Figure 2.7 Diagram of predator pressures on invertebrates inside and outside the fenced reserve in 2014 and 2015

Figure 3.1 Map of monitoring lines within sites established in November 2012 in Aorangi

and Remutaka Forests.

Figure 3.2 Diagram of monitoring lines set up for catching ground-dwelling invertebrates in the Aorangi and Remutaka..

Figure 3.3 Examples of ground beetles (Carabidae) used for the mean trait value (mT) analysis.

Figure 3.4 Total abundance of classes of ground-dwelling invertebrates in Aorangi and Remutaka Forests.

Figure 3.5 Mean number $( \pm \mathrm{SE})$ of the twelve most abundant ground-dwelling invertebrate taxa collected across the Aorangi and Remutaka monitoring sites. 63 Figure 3.6 Mean number ( \pm SE) of richness and order-level diversity (Shannon) of grounddwelling invertebrates recorded across Aorangi and Remutaka monitoring sites. 64 Figure 3.7 Principal Coordinate Analysis (PCoA) for the Bray-Curtis dissimilarities of the invertebrate square-root abundance classified as trophic guilds among sites in the Aorangi and Remutaka. 65

Figure 3.8 Mean number $( \pm \mathrm{SE})$ of ground-dwelling invertebrates classified as predators, detritivores and omnivores recorded across the Aorangi and Remutaka monitoring sites. 66 Figure 3.9 Mean body sizes $(\mathrm{mm})( \pm \mathrm{SE})$ of Ctenognathus sp1, Ctenognathus $\mathrm{sp} 2$, Scarabaeidae (dung beetles), Araneae (total length), cave weta and ground weta (females, males and juveniles)..

Figure 3.10 Frequency of the body size of Araneae (spiders) recorded in Aorangi and Remutaka monitoring sites before and after 1080.

Figure 3.11 Principal Coordinate Analysis of the Euclidean similarity of the mean number of the dominance of traits (mT) of beetle assemblages collected from November 2013 to November 2015 among sites in the Aorangi and the Remutaka.

Figure 3.12 Mean trait values $( \pm \mathrm{SE}$ ) of ground beetle assemblages (Carabidae) recorded across Aorangi and Remutaka monitoring sites.. 
Figure 4.1 Invertebrate abundance and body size as a function of mean daily temperature in Aorangi and Remutaka Forests.

Figure 4.2 Invertebrate abundance as a function of rat density in Aorangi and Remutaka

Forests for all seasons.

Figure 4.3 Invertebrate abundance as a function of invertebrate predator abundance in Aorangi and Remutaka Forests all seasons.. 100

Figure 4.4 Correlations between invertebrates in Aorangi and Remutaka Forests all seasons.

Figure 4.5 Invertebrate body sizes as a function of mammalian predator density in Aorangi and Remutaka Forests all seasons..

Figure 4.6 Final Structural Equation Model revealing the direct and presumably some indirect effects of mice and rats on invertebrate abundances in Aorangi and Remutaka Forests

Figure 4.7 Final Structural Equation Model testing the direct and presumably some indirect effects of mice and rats on the body size (BZ) of invertebrates and guild abundances in Aorangi and Remutaka Forests....

Figure 4.8 Summary diagram of the effects of vegetation on invertebrate and mammal communities from Linear Mixed Models and/or Structural Equation Modelling (SEM). 115 Figure 5.1. Female (a) ground weta (Hemiandrus pallitarsis) and (b) cave weta (unidentified species) collected in Aorangi and Remutaka Forests. Figure 5.2. Relative attraction of individuals per trap-night caught on baited pitfall traps to un-baited pitfall traps in the Aorangi and Remutaka Forests.

Figure 5.3. Body-length distribution of ground weta specimens (Hemiandrus spp.) in

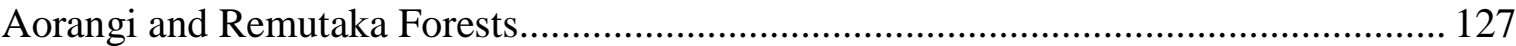

Figure 6.1 Diagram of the main findings of each chapter.......................................... 132

Appendix Figure 8.1 Details of each treatment and control for predation pressure

experiment inside and outside the fenced reserve..

Appendix Figure 8.2 Detection average $( \pm \mathrm{SD})$ rate of mammals inside and outside the fenced reserve using chew card devices for 2014 and 2015

Appendix Figure 8.3 Details of monitoring lines at each site in the Aorangi and Remutaka

Forests

Appendix Figure 8.4 Mean daily minimum temperature (MinT) and mean daily maximum temperatures (MaxT) as a function of Elevation (m) in Aorangi and Remutaka Forests for

Summer 2013/2014, 2014/15, 2015/16.

Appendix Figure 8.5 Detection rates of a) rats and b) mice across the Aorangi and

Remutaka monitoring sites.... 189

Appendix Figure 8.6 Matrix of all possible correlations between abundance of rats and mice from the previous season [t-1] and invertebrate abundance [t] in Aorangi and Remutaka Forests..

Appendix Figure 8.7 Mean number of invertebrate abundance per TN [t] and rat density $[\mathrm{t}-1]$ per site in the Aorangi and Remutaka across seasons.

Appendix Figure 8.8 Matrix of all possible correlations between abundance of invertebrate predators from the previous season [t-1] and invertebrate prey abundance in Aorangi and Remutaka Forests..

Appendix Figure 8.9 Matrix of all possible correlations between abundance $(\mathrm{AB})$ of rats and mice from the previous season [t-1] and invertebrate body sizes (BZ) in Aorangi and 
Remutaka Forests. Colours and slope represent coefficient intervals for positive, neutral or negative relationships. 


\section{GENERAL INTRODUCTION}

Food webs describe the trophic relationships between communities of co-occurring taxa. The links can represent both the flow of nutrients from the bottom upwards (bottom-up influence), and the predatory behaviours of natural enemies (top-down influence) (Power 1992, Amarillo-Suárez 2010, Bennett 2010). Ecological concepts such as bottom-up and top-down impacts have been well described in trophic cascades in many ecosystems, and they explain how particular taxa, or even entire trophic levels, are potentially limited by the availability of food resources or the density of predators, respectively (e.g. Hairston et al. 1960, Fox 2007, Gripenberg and Roslin 2007, Hicks et al. 2007, Rogers et al. 2012, Stoler and Relyea 2013, Hunter et al. 2015). Abiotic conditions also regulate food webs via changes in temperature, water availability, and soil chemistry, among others (Schowalter 2011). In these webs, two species or taxa may be directly or indirectly related depending on the participation of a third species in the interaction (Tscharntke and Hawkins 2002). A direct effect would occur when there is a physical interaction between two species. On the other hand, an indirect effect occurs when an intermediary species interacts between two species, or when one species modifies the availability of nutrients in the system, which subsequently may affect another consumer or producer (Wootton 1994). Food webs can be conceptualised at different levels of taxonomic and guild resolution. For example, Bennett (2010) showed how plant diversity may directly influence not only the guild of invertebrate herbivores but also, may indirectly affect guilds of invertebrate predators and parasitoids.

\subsection{Invertebrates}

Terrestrial invertebrates are, without question, substantial components of the diversity of any ecological system. Estimates about the global number of species indicate that 
arthropods, which include insects and arachnids, represent more than $60 \%$ of global diversity (Kim 2009, Gaston 2010). Invertebrates are involved in several processes above and below the ground as providers (serving as food or hosts for other organisms), eliminators (removing waste products, and dead organisms, recycling live plant material and eating other animals) and facilitators (helping in the processes of transmission of pathogens, pollination, seed dispersal and phoresy) (Erwin and Geraci 2009, Schowalter 2011).

Invertebrates occupy microhabitats such as living vegetative surfaces, bank and wood surfaces, herbaceous and plant tissues, leaf-litter and ground debris, animal nests, caves, soil, fungi, carrion and dung (Erwin and Geraci 2009). Based on their habitat preferences for forests, invertebrates, mainly insects, may be classified into four different groups: canopy-, ground-, litter- and soil-dwelling invertebrates. Foliage invertebrates (canopy and sub-canopy feeders), for example, utilise all imaginable parts of the trees above the ground (most of the flying and herbivore insects), while ground-, litter-, and soil-dwelling invertebrates use the different layers of the forest floor (Speight et al. 1999, Erwin and Geraci 2009). However, invertebrates may inhabit one or more layers of the forest depending on their life stage. For example, beetles, millipedes and centipedes may live in well-aerated litter but also, use the soil and subsoil for burrowing. Others, such as spiders and cave weta, may forage above the ground and lay their eggs on the soil (Dawson and Lucas 2000). Varying habitat requirements depending on life stages, the abundance of generalist feeders, the widespread habit of omnivory and the vital importance of belowground organisms on nutrient cycling over above-ground food webs, are the main reasons why soil communities (both above and below the ground) are complex (Tscharntke and Hawkins 2002). 


\subsubsection{Invertebrates in New Zealand}

The loss of endemic and irreplaceable invertebrates, and their vulnerability, their isolation and the fragmentation of their habitats are the main concern in insect conservation on islands (Dennis et al. 2008, New 2008). Island invertebrates are generally characterised by a high level of endemicity. For example, the largest known butterfly in the world, the Queen Alexandra's birdwing (Ornithoptera alexandrae), lives in Papua New Guinea which is globally ranked 12th in terms of endemism of large butterflies (Cranston 2009). In New Caledonia, endemism of Trichoptera is especially high, where 109 out of the 111 described species by 2003 are endemic (Cranston 2009). New Zealand's invertebrates are no exception as its fauna comprises five endemic families (Mystacinobiidae, Mnesarchaeidae, Huttoniidae, Synthetonychidae and Chathamiidae) and more than 20,000 endemic species of invertebrates to the country (Gibbs 2006, Gibbs 2016). Furthermore, in New Zealand there is a complete absence of scorpions, six families of butterflies and 61 families of land snails that are otherwise widespread (Gibbs 2016).

Characteristics that have influenced the New Zealand invertebrate fauna include: 1) the fauna of New Zealand evolved their ancient origin in the supercontinent Gondwana confirmed by entire communities of freshwater invertebrates which are considered Gondwanan descendants (Gibbs 2016). 2) Plate movements, the split of Zealandia Continent and the opening of the Tasman Sea have shaped the landscape of New Zealand and impacted climate and animal and plant dispersal (Gibbs 2016). 3) After this separation from Gondwana, New Zealand has been estimated to be isolated for 80 million years, which may explain why some taxa are missing while others are over-represented (Gibbs 2016). 4) Terrestrial mammals are an example of missing taxa as monotreme, marsupial and placental 
(except bats) mammals are not represented in the original fauna of New Zealand (Klimaszewski and Watt 1997, Gibbs 2006).

Over millions of years, many insects in New Zealand have evolved to become flightless (i.e. brachypterous, with reduced or rudimentary wings) and to have a longer life cycles with lower rates of reproduction mainly due to the absence of terrestrial mammals in New Zealand (Cranston 2009). As a result, invertebrates have become sedentary and developed strict associations with native plants, specific habitat requirements, longer juvenile stage and larger bodies (Meads 1990). Some examples of apterous (wingless) organisms are described in a quarter of the Hemiptera fauna, all endemic Blattodea and many Coleoptera and Orthoptera (Cranston 2009). Many of them are also large and long-lived organisms such as the giant weta or wetapunga (Deinacrida heteracantha) which is one of the largest insects recorded in the world and an example of gigantism for the New Zealand's fauna (Meads 1990, Gibbs 2006). Beetles are also large-bodied and flightless as they have strong and fused elytra. For example, the predatory and nocturnal ground beetle, Megadromus sp., can live to three years; and the long-lived, flightless and largest stag beetle, Dorcus helmsi, can reach $42 \mathrm{~mm}$ length (body and jaws) in rat-free islands (Meads 1990).

These characteristics have resulted in a higher vulnerability of New Zealand's terrestrial invertebrate fauna to the introduction of predatory vertebrates, and even the extinction of invertebrates when organisms have failed to cope with this disturbance (i.e. the local extinction of the Middle Island tusked weta (Motuweta isolata)) (St Clair 2011). The fragility of invertebrate fauna is also shown by the poor defence mechanisms against the predation by vertebrates other than birds, reptiles and frogs in New Zealand. Cryptic bodies and stillness when predators are nearby have been effective mechanisms against visual 
predation (e.g. birds) but seem to be weak defences against predators which locate their prey through olfactory clues (e.g. mammals) (Dent 2016).

\subsection{Human influences on invertebrate communities}

Major disturbances derived from the arrival of humans include habitat destruction and modification, and the deliberate or accidental introduction of species, which are threats to the conservation of diversity worldwide (New 2008, Cranston 2009, St Clair 2011). Human arrival in New Zealand made a huge impact on the native flora and fauna compromising all aspects of the island diversity (Cranston 2009), as disturbance may reduce the abundance of vulnerable or intolerant species and thereby affect their interactions with other species (Schowalter 2011). After human arrival in New Zealand, more than 80 percent of the natural vegetation has disappeared, comprising now only 23\% of the total land area (Meads 1990, Klimaszewski and Watt 1997). Habitat loss not only affects invertebrate consumers but also may affect invertebrate predators. This is the case of Mecodema punctellum (Carabidae), the largest ground beetle, which has become locally extinct on Stephens Island after the decrease of their main prey (large land snails) due to the forest clearing on this island (Meads 1990).

Ecosystems have changed in New Zealand after the arrival of pests and mammalian predators by human immigration (Meads 1990). For example, introduced species may produce several impacts on native species and their ecosystems involving habitat and vegetation modification, competition for resources, aggressive behaviour, predation of native species, introduction of diseases via pathogens and parasites, hybridisation and invasive meltdown, which occurs when the interaction of two or more invasive species enhances the population of one of them (Simberloff 2010). 
Since the arrival of non-native vertebrates approx. 800 years ago with the introduction of the Pacific rat or kiore (Rattus exulans) and waves of other mammal arrivals (St Clair 2011), several large forest invertebrates, who lack behavioural mechanisms against the direct predation, became vulnerable or even extinct in New Zealand (Gibbs 2006, Watts et al. 2011). Large invertebrate species have suffered the most to the subsequent introduction of mammals (Klimaszewski and Watt 1997, Gibbs 1998, St Clair 2011). Evidence of predation of introduced mammals (mainly rodents) has been documented on weta species (e.g. cave weta, Deinacrida heteracantha, D. rugosa, D. carinata, Hemiandrus sp.), ground beetles, numerous spiders, weevils (Heterexis seticostatus, Anagotus fairburni, A. stephensis, A. rugosus, A. turbotti, Lyperobius huttoni, Hadramphus stilbocarpae), land snails (e.g. Powelliphanta traversi), giant centipede (Cormocephalus rubriceps) and giant pill millipede (Procyliosoma tuberculata), among others (Ramsay 1978, Meads 1990, Kuschel and Worthy 1996, Craddock 1997, Berry 1999, Bennett et al. 2002, St Clair 2011).

The decline of invertebrates' abundance due to mammal predation have been reported on offshore islands of New Zealand, including the land snail Placostylus hongii and the beetles Mimopeus elongatus and Ctenognathus novaezealandiae on Motuhoropapa Island (Watt 1983, Moors 1985). Also, probable extinction has been described for Dorcus helmsi on Breaksea Island (Bremner et al. 1984) and on Big South Cape Island (Ramsay 1978), while local extinctions have been confirmed for the Middle Island tusked weta (Motuweta isolata) on Mercury Islands (Gibbs 2002), the flightless beetle Hadramphus stilborcarpae on Big South Cape Island (Kuschel and Worthy 1996), and endemic land snails Amborhytida tarngensis and Placostylus hongii on the Lady Alice Island (Brook 2000), among others. 
Fortunately, others have developed some avoidance behavioural adaptations to mammal predation, including the capability of hiding when predators are active, or the improvement of their escape responses (Gibbs 1998, Dent 2016). For example, tree weta (Hemideina spp.) shelter within natural galleries during the day and as well as at night when they share habitats with rats, and may also detect movements of predators through substrate vibrations and acoustic signals (Gibbs 2009).

\subsection{Control of mammalian predators}

A variety of methods have been used around the world to reduce populations of introduced mammals for both conservation and economic reasons. These activities include stopping the entrance of invaders, eradicating populations once they are already established, and maintaining introduced populations at lower numbers via mechanical, physical, chemical or biological control (Simberloff 2010).

In New Zealand, eradication of mammalian pests has been one of the main approaches to conservation management (St Clair 2011), especially on offshore islands, to protect endangered species and their habitats. Some studies have documented the positive effects of rodent eradications on the abundance of invertebrates on islands in New Zealand. For example, the abundance of ground weta (Hemiandrus sp.), large spiders (Miturga sp.), stag beetles (Hemidorcus spp.) and scale insects (Coelostoma zealandica) increased after rat eradication (Atkinson and Towns 2001, Green 2002, McClelland 2002, Towns 2002). Other invertebrates showed positive responses to mouse eradication including spiders (Uliodon sp. and Meringa sp.), moth larvae (Grypotheca sp.), various beetles (Leiodidae, Carabidae, Staphylinidae, Nitidulidae and Corticariidae), Cook Strait giant weta (Deinacrida rugosa) and exotic land snail (Helix aspersa) (Newman 1994, McIntyre 2001, Ruscoe 2001). 
Contrasting patterns were reported for tree weta (Hemideina crassidens) which did not show any clear population effect after rat eradication on Nukuwaiata Island (Rufaut and Gibbs 2003), and Carabidae and Amphipoda which decreased in abundance after rat eradication on Kapiti Island (see Table 1 Sinclair et al. 2005).

As mammal eradication is extremely difficult on large scale and complexity of the mainland, fenced reserves have been suggested as an alternative method for exclusion of introduced mammals in patches on the mainland. These reserves may be considered as an island within another island, a concept called Mainland Islands by the Department of Conservation, New Zealand (Saunders and Norton 2001, Department of Conservation 2017b). However, few studies have investigated how ground-invertebrates have responded to mammal-exclusion in fenced reserves. These involve positive responses of weta (Watts et al. 2011) and negative responses of beetles after 6 years of mammal eradication before stabilising (Watts et al. 2014).

Another effective method to temporarily reduce the density of mammals on the mainland of New Zealand is the aerial application of 1080 toxin (sodium fluoroacetate) (Byrom et al. 2016). This poison has been used mainly to control possums, rats and stoats, aiming to reduce predation of native fauna (Elliott and Kemp 2016). Few studies have examined the responses of invertebrates to 1080 pest control (Byrom et al. 2016). Canopy invertebrates (beetles, spiders, cockroaches and cave and tree weta) have been the main focus of the studies (Hutcheson and Crabtree 1994, Powlesland et al. 2005, Ruscoe et al. 2013). However, little is known about the effect of 1080 mammal control on litter- and grounddwelling invertebrates on the New Zealand mainland where eradication is not achieved (Hunt et al. 1998, Sherley et al. 1998, Didham et al. 2009, Rate 2009). The use of 
standardised biodiversity indicators across multiple studies is essential to fully understand the effect of this poison on native fauna in the long-term (Byrom et al. 2016).

To assess the potential benefit of these alternative methods of mammal control for the conservation of invertebrates and the maintenance of their functional roles in New Zealand, it is necessary to implement short- and long-term studies about the responses of grounddwelling invertebrates to mammal eradication and control, including a consideration of trophic cascades and interactions. This should be a priority due to 1) the vulnerability and high level of endemism of New Zealand's terrestrial invertebrates, 2) the huge and diverse impact of introduced mammals on ground-dwelling invertebrates, 3) the increasing number of projects aiming to control and eradicate introduced mammals, and 4) few attempts to understand the complex interactions between invertebrates, nutrients and introduced predators on the mainland of New Zealand.

\subsection{Thesis structure}

The main goal of my thesis was to assess how invertebrate communities respond to mammal control by: 1) comparing invertebrate communities in areas with and without mammal exclusion, and before and after 1080 mammal control (i.e. a reduction in top-down influences by reductions in natural enemies); and 2) measuring the effects of habitat (vegetation), temperature and elevation on invertebrate communities, in order to determine which of the above factors explain the greatest amount of variation in invertebrate abundance and community structure on the mainland. In particular, I investigated how changes in mammal communities inside and outside a fenced reserve, and before and after 1080 aerial mammal control, influence the taxonomic and trophic abundance, body size and 
other traits of ground-dwelling invertebrates on the mainland of the North Island, New Zealand.

The following thesis is divided into six chapters, four of which are written in the format of more-or-less stand-alone, publishable manuscripts (Chapter 2-5) followed by a final discussion. For the most part, this thesis is written in the first person singular as I was the primary investigator responsible for the majority of the project work, all of the analysis and all of the writing. However, as with any modern scientific undertaken, I received support and assistance in many forms (this is acknowledged more specifically in methods Chapters 3, 4 and 5) and hence some sections are written in the first-person plural (we) to acknowledge the broader team that contributed to the research. The Figure 1.1 shows a summary of the research questions and predictions of each chapter, which are explained in more extent along my thesis.

Chapter 2: Effects of mammal exclusion on invertebrate communities in New Zealand (A modified version of this chapter is ready for submission to Oikos)

My $\mathrm{PhD}$ thesis began with a study on the effects of mammal exclusion on ground-dwelling invertebrates. This study was conducted inside and outside a fenced mainland reserve (ZEALANDIA, Wellington), where non-native mammals (except mice) are excluded. Invertebrate communities were sampled inside and outside this fenced reserve over two summers and, a manipulative field experiment was conducted to measure levels of predator pressure exerted by different components of the vertebrate community inside versus outside the reserve. My specific research question was: is there a greater abundance and larger mean body size of ground-dwelling invertebrates inside the fence compared with the surrounding of the reserve? (Figure 1.1) 
Chapter 3. Neutral responses of ground-dwelling invertebrate communities to aerial 1080 operations in New Zealand.

This chapter investigated the short-term effects of 1080 aerial pest control on grounddwelling invertebrates. A sampling study was conducted in Aorangi and Remutaka* Forests to investigate how invertebrate communities differ before and after the aerial application of 1080. The study followed a BACI design (before-after, control-impact) where the Aorangi Forest was identified as the treatment area while Remutaka Forest was considered the lowtreatment zone (control). Invertebrate responses were evaluated as a change in taxon and guild abundance, mean body sizes and other traits. My research question was: is there a decrease in invertebrate abundance after the application of 1080 in the Aorangi compared with the Remutaka due to a negative effect of 1080 drop on invertebrate populations? Changes in traits such as mean body size and colouration across the invertebrate community, before versus after 1080 application, would most likely indicate a response to selective predation pressures in the Aorangi and the Remutaka (Figure 1.1).

(*) I have used the name Remutaka Forest along my thesis as the name Rimutaka Forest Park has changed and became Remutaka as per the Deed of Settlement (October 2017). The name Remutaka comes from Haunui a Nanaia. He was a Rangitāne rangatira who travelled through Wairarapa in pursuit of his wife who had fled with two men from another iwi. When he got to the top of Remutaka hill, he saw Lake Wairarapa and because it sparkled so much, it was hard to look at, then kua taka tōna remu (his brow dropped to shield his eyes) hence Remutaka (Bart Cox pers. comm., Department of Conservation, New Zealand). 
Chapter 4. Top down effects on ground-dwelling invertebrates in Aorangi and Remutaka Forests, New Zealand.

This chapter aimed to describe the main mechanisms underlying invertebrate community responses observed in the previous chapter. The effects of temperature, elevation, habitat (vegetation cover and type of forests) and mammal predation (top-down impact) on the taxonomic and guild abundance, and body sizes of invertebrates were tested in Aorangi and Remutaka Forests. Invertebrate abundance was tested to relationships with temporal variables such as mammal density (rats and mice) and temperature, and spatial variables like elevation, cover of vegetation and type of forests. My research questions were: are larger invertebrates more affected by mammal predation and smaller individuals more affected by other factors such as vegetation cover? Also, does the type of vegetation have more impact on detritivore and herbivore invertebrates compared with predatory and omnivorous invertebrates? (Figure 1.1).

Chapter 5. The efficiency and biases of squid-baited pitfall traps used for collecting ground weta and other ground-dwelling invertebrates in New Zealand (A modified version of this chapter is ready for submission to New Zealand Entomologist)

The aim of this chapter was to investigate how squid-bait influenced the sampling of ground weta individuals to find a tool for collecting these individuals in a quicker and standardised way. In this Chapter, weta individuals and other invertebrates which responded positively or negatively to squid-baiting from the previous Chapter (3) were re-analysed. My research questions were: is there a greater abundance of ground weta (more attraction) in squid-baited pitfall traps, compared with un-baited traps? Also, is there a positive response of carrion and scavengers (detritivores) invertebrates to squid baits? (Figure 1.1) 


\section{How do ground-dwelling invertebrates respond to mammal management on the mainland, New Zealand?}

\section{Chapter 2}

Q. Has the removal of introduced mammals and the suppression of mice within a fenced reserve, resulted in changes in the community composition, body sizes and diversity of invertebrates?

Hypothesis: Greater abundance, larger body sizes and greater diversity of invertebrates will be found inside ZEALANDIA compared to the outside.

Q. How does the predation pressure experienced by insects (from birds and mammals) differ on either side of the fence?

Hypothesis: There will be more vertebrate predation outside

ZEALANDIA compared with inside.

\section{Chapter 3}

Q. Does an aerial 1080 drop have a positive, neutral or negative effect on the abundance, body size and other traits of ground-dwelling invertebrates?

Hypothesis: The aerial application of 1080 will have a negative effect on the composition, abundance, and diversity of invertebrates in the treated area (Aorangi Forest). Body sizes of Orthoptera, Araneae and Coleoptera, and composition and diversity of ground beetles (Carabidae) will change after 1080 application in the same Forest.

Chapter 4
Q. Does temperature have a strong effect on the abundance and body size of invertebrates in
the Aorangi and Remutaka? Do variations in habitat and elevation influence invertebrate
communities?
Hypothesis: Invertebrates related to the soil (e.g. Acari, Collembola) will be more affected by
temperature, habitat and elevation than invertebrates related to the ground (e.g. Carabidae).
Q. What are the effects of vertebrate (rats and mice) and invertebrate predators (Carabidae
and Araneae) on the taxonomic and guild abundance, and body size of invertebrates?
Hypothesis: Predators will have a negative effect on invertebrate abundance and body sizes.
Q. Which of the above factors (temperature, habitat, elevation or predation) explain the
greatest amount of variation in invertebrate abundance and body size?
Hypothesis: Larger invertebrates will be more affected by vertebrate predation than smaller
invertebrates which will be more affected by vegetation, and/or temperature.

\section{Chapter 5}

$Q$. What are the effects of squid baits on sampling weta species and other invertebrates in New Zealand forests?

Hypothesis: There will be a greater abundance of weta species, scavengers and predators in squid-baited pitfall traps compared with un-baited pitfall traps.

FIGURE 1.1 Conceptual diagram of the research questions and predictions of each Chapter $Q$ denotes questions. 
Despite the fact that each of the described stand-alone chapters is distinct, there is overlap in methods which requires some repetition. The standardised methods used for all chapters are described as follows.

\subsection{Summary of the methods}

Individual methods for field and laboratory protocols are given in each data chapter (2-5). The following paragraphs provide further details regarding generalised laboratory methods.

Invertebrates: In this thesis, only adult stages of homometabolous insects (complete metamorphism) and all life-stages of hemimetabolous insects (e.g. Orthoptera) were analysed. Due to the difficulty in identifying between juvenile and adult stages of other noninsect invertebrates, their life stages were combined and incorporated into analyses.

The response measures of ground-dwelling invertebrates used in this thesis to test for impacts of introduced mammals via predation, and/or attraction to squid baits included a change in abundance, diversity and body size. These assumptions of response measures, although common for most of invertebrates, may not represent the total variability of invertebrates inhabiting the ground forest, as it may fail in measuring the success of rare taxa which are scarce in their habitats.

Top-down effects were considered here as the spatial/temporal population-level correlations or individual behavioural effects of mammalian predators and well-known invertebrate predators (Carabidae and Araneae) on other invertebrates. Due to the challenge of taxonomic identifications and paucity of natural history information with which to define food web interactions among invertebrates, the only interaction among invertebrates that 
was considered in this thesis was the effect of well-known predators (Carabidae and Araneae) on potential prey. All other interactions among invertebrates remained unresolved.

Sampling techniques: Ground-dwelling invertebrates were collected using pitfall traps. Canopy or soil invertebrates were not included in this thesis, except Collembola and Acari, which are considered soil arthropods. These two taxa were highly represented in our samples. Sampling techniques for collecting canopy invertebrates were not included in this thesis, except in Chapter 2 (mammal exclusion), where tree weta were sampled using weta houses to provide complementary information for the conservation plans in ZEALANDIA.

Data analysis: Data was analysed differently based on the aims of each chapter (Table 1.1). In Chapter 2, invertebrates were analysed as the average number per pitfall trap for the total of the three nights-four days sampling period, along monitoring lines for different factors (Exclusion, Season). In Chapter 3, invertebrates were analysed as the average per pitfall trap-night (TN) along monitoring lines for Squid, Season, Forest, and 1080 application (Time) as the exposure time of the traps differed among seasons (one-night in late spring (November), and three-nights in late-summer, February). Invertebrates were analysed as the average per pitfall trap-night (TN) along monitoring lines for Season and Forest in Chapter 4. While in Chapter 5, invertebrates (mainly weta) were analysed as the average of individuals per pitfall trap-night (TN) along monitoring lines for squid baiting. 
TABLE 1.1 Summary of factors analysed in each data chapter. TN=pitfall trap night.

\begin{tabular}{|c|c|c|c|c|}
\hline & Chapter 2 & Chapter 3 & Chapter 4 & Chapter 5 \\
\hline Invertebrates & $\begin{array}{l}\text { Average number } \\
\text { per trap ( } 3 \text { nights) }\end{array}$ & $\begin{array}{l}\text { Average number per } \\
\text { TN }\end{array}$ & $\begin{array}{l}\text { Average number per } \\
\text { TN }\end{array}$ & $\begin{array}{l}\text { Average number per } \\
\text { TN }\end{array}$ \\
\hline Forest & Zealandia & Aorangi/Remutaka & Aorangi/Remutaka & Aorangi/Remutaka \\
\hline Factors & $\begin{array}{l}\text { Mammal } \\
\text { Exclusion, Season }\end{array}$ & $\begin{array}{l}1080 \text { application } \\
\text { (Time), Forest, } \\
\text { Squid bait, Season }\end{array}$ & $\begin{array}{l}\text { Mammal abundance } \\
\text { index, Temperature, } \\
\text { Elevation, Type of } \\
\text { forests, Ground } \\
\text { cover, Litter cover, } \\
\text { Invertebrate } \\
\text { Predators }\end{array}$ & Squid bait \\
\hline $\mathbf{N}^{\circ}$ of sites & 4 & 7 & 7 & 7 \\
\hline $\mathbf{N}^{\circ}$ of seasons & 2 & 5 & 5 & 7 \\
\hline $\begin{array}{l}N^{\circ} \text { of pitfall sets } \\
\text { per site }\end{array}$ & $4-8$ & $3-6$ & 3 & 3 \\
\hline
\end{tabular}


2. EFFECTS OF MAMMAL EXCLUSION ON INVERTEBRATE COMMUNITIES IN NEW ZEALAND 


\subsection{Introduction}

The evolutionary history of invertebrates inhabiting isolated islands has shown that insular species tend to be larger and more often flightless in the absence of mammalian predators (Gibbs 2009). These particular evolutionary patterns contribute to the high vulnerability of an island's entomofauna to the introduction of novel predators, especially those with nocturnal habits and a well-developed olfactory sense (Gibbs 1998, McIntyre 2001, New 2008).

New Zealand is a large continental island, which evolved without terrestrial mammals except for two extant bat species (Chalinolobus tuberculatus and Mystacina tuberculata) (O'Donnell et al. 2013). Since the introduction of mammals to New Zealand, many large invertebrates have not coped with this new predation pressure, and have become threatened, or even extinct (Gibbs 1998, Stringer and Chappell 2008, Watts et al. 2008). Rats (Rattus spp.), mice (Mus domesticus) and hedgehogs (Erinaceus europaeus) are considered the main threats to invertebrates in native New Zealand forests (Fitzgerald et al. 1996, Alley et al. 2001, Watts et al. 2014). These introduced predators diminish invertebrate populations directly by predation, or indirectly by habitat modification and competition for food, among others (Gibbs 2009, Simberloff 2010)

Across the globe, governmental, non-governmental organisations and local community groups, have been involved in conservation projects to manage introduced mammals (Simberloff 2010). Activities include translocation of threatened species to areas free of these pests, intensive and extensive use of predator control and the construction of fenced reserves to maintain and restore areas of high conservation value (Green 2004, Connolly et al. 2009, Burns et al. 2012, Watts et al. 2012a) 
The strongest evidence of mammal disturbance to native ecosystems has been shown on New Zealand's offshore islands (St Clair 2011). These areas may be viewed as large-scale experimental sites, for comparisons among invertebrate communities on rat-free and ratinfested islands (Towns et al. 1997). However, our knowledge in this matter is still incomplete and results vary among studies. Ground-dwelling invertebrates respond to diverse fluctuations in predator pressures (i.e. introduced mammals and native and nonnative birds), and physical and soil parameters on islands (Towns et al. 2009). There is strong evidence of an increase in large (>10 mm long) invertebrate abundance after rat and rabbit eradications from Korapuki Island (Towns et al. 1997), whereas a decline in invertebrate species richness was observed after rat eradication on Kapiti island (Sinclair et al. 2005). Lower densities of Cook Strait giant weta (Deinacrida rugosa) were noticed on Stephens Island, a free-pest island, due to predation pressure from tuatara (Sphenodon punctatus) and changes in vegetation and nutrients transported by seabirds (McIntyre 2001).

Fencing areas for wildlife protection and pest eradication had a long history in Australia and South Africa (De Tores et al. 2011, Dickman 2012, Ferguson et al. 2012) to reduce the use of chemical pest control, and to provide secure sites for translocation of endangered species (Burns et al. 2012). In New Zealand, several studies have been conducted to understand how native communities have responded to mammal removal and exclusion within fenced reserves (e.g. Berndt 1998, Blick et al. 2008 for ZEALANDIA fenced reserve). Few of these attempts have characterised the effect of mammal exclusion on ground-dwelling invertebrate communities and variable results have been obtained. Watts et al. (2011) reported an increase in weta abundance after two years of mammal eradication inside and outside enclosure zones in Maungatautari reserve whilst Watts et al. (2014) recorded a 
decline in beetle abundance after 6 years of mammal eradication (and mouse control) inside ZEALANDIA fenced reserve.

Manipulative experiments are powerful methods for studying predator's effects on ecosystems (top-down effects) (Rogers et al. 2012). Most studies on macroinvertebratevertebrate relationships have focused on responses of canopy invertebrates (Borkhataria et al. 2006, Morrison and Lindell 2012). Research on the responses of understory invertebrates to mammals, via exclusion experiments are less common. For instance, unclear effects of mouse predation on the abundance, biomass and community structure of eight soilinvertebrate prey has been reported in a long term experiment on Marion island (Van Aarde et al. 2004). Another experiment has shown negative effects of wild boars (Sus scrofa) on ground-dwelling invertebrates in Mediterranean ecosystem (Carpio et al. 2014). Thus, there is a need to evaluate the impact of fenced reserves on ground-dwelling invertebrates on the mainland of New Zealand, to further understand their potential role on the conservation of large-bodied invertebrates that are thought to be vulnerable to predation by rodents and hedgehogs.

We aimed to answer the following questions: has the removal of introduced mammals and the suppression of mice within a fenced reserve, resulted in changes in the community composition, body sizes and diversity of ground-dwelling invertebrates? And more specifically, how does the predation pressure experienced by insects (from birds and mammals) differ on either side of the fence? 


\subsection{Methods}

The study was carried out in and around the fenced mainland reserve, ZEALANDIA ( $41^{\circ} 17^{\prime}$ $\mathrm{S}-174^{\circ} 45^{\prime} \mathrm{E}$ ) in Wellington, New Zealand (Figure 2.1). The construction of a $2.2 \mathrm{~m}$ high, $8.6 \mathrm{~km}$ long fence was completed in 1999 (Connolly et al. 2009), and it encloses 225 ha that protects kiwi (Apteryx owenii), robin (Petroica longipes) and tuatara (Sphenodon punctatus), among other species. It is surrounded by a mixture of rural land, city council reserve, open space and residential suburbs. The dominant vegetation includes native species, such as, fivefinger (Pseudopanax arboreus), fuchsia (Fuchsia excorticata), wineberry (Aristotelia serrata), rangiora (Brachyglottis repanda), broadleaf (Griselinia lucida); and some introduced species such as pine (Pinus sp.) and barberry (Berberis darwinii) (Karori Sanctuary Trust 2016).

The reserve is free of non-native mammals (e.g. rats, possums and stoats), except for mice, which are controlled annually using Pestoff® baits (20 ppm brodifacoum). Outside the reserve, Wellington City Council (WCC) and community groups carry out some pest control, but mice, rats, possums and other non-native mammals are still present.

To characterise the diversity and composition of mammal predators and invertebrates, we set up eight $250 \mathrm{~m}$ long transects paired inside and outside the fenced reserve during January-February 2014 and 2015 (Figure 2.1). Transects were placed $50 \mathrm{~m}$ away from the fence on both sides. This separation (i.e. $100 \mathrm{~m}$ between inside and outside traps), combined with the fence, should be beyond the short-term dispersal capability of most surface-active invertebrates, including flightless Carabidae (Coleoptera) and cursorial spiders, then we could assume some independence of the data. We placed each transect-pair according to the following criteria: 1) proximity to each other (>600 m apart), 2) similar vegetation, 3) 
topography and accessibility, and 4) management characteristics (placing transects away from human settlement).

\subsubsection{Invertebrate diversity, body size and composition}

We sampled composition, abundance and diversity of ground-dwelling invertebrates using pitfall traps (110 mm mouth diameter plastic container) protected with a plastic lid (170x170 $\mathrm{mm}$ ) raised $20 \mathrm{~mm}$ above ground-level to keep out rain and large vertebrates. Pitfall traps were active in the field during three consecutive nights and four days. In 2014, we used a total of 80 non-lethal pitfalls (40 inside the reserve and 40 outside it), without preservative, in order to avoid killing endangered species, and checked them daily in case of unintentional by-catch (lizards or giant weta). During this first summer, we set up two sets of five nonlethal pitfall traps per transect at the $50 \mathrm{~m}$ and $150 \mathrm{~m}$ from the beginning of each transect. Five traps per set were placed at the four corners and the centre of a $5 \times 5 \mathrm{~m}$ square. In 2015 , we used lethal pitfall traps because of the absence of any endangered species in our traps in 2014. We filled traps to one third of their volume with salt solution $(5.6 \% \mathrm{NaCl})$ and a few drops of detergent to kill and preserve invertebrates. In 2015, sampling intensity also increased from two to four sets of five pitfall traps per transect ( 80 traps inside the reserve and 80 traps outside it). Sets of five pitfall traps were placed at $0 \mathrm{~m}, 50 \mathrm{~m}, 150 \mathrm{~m}$ and 225 $\mathrm{m}$ from the beginning of each transect. 


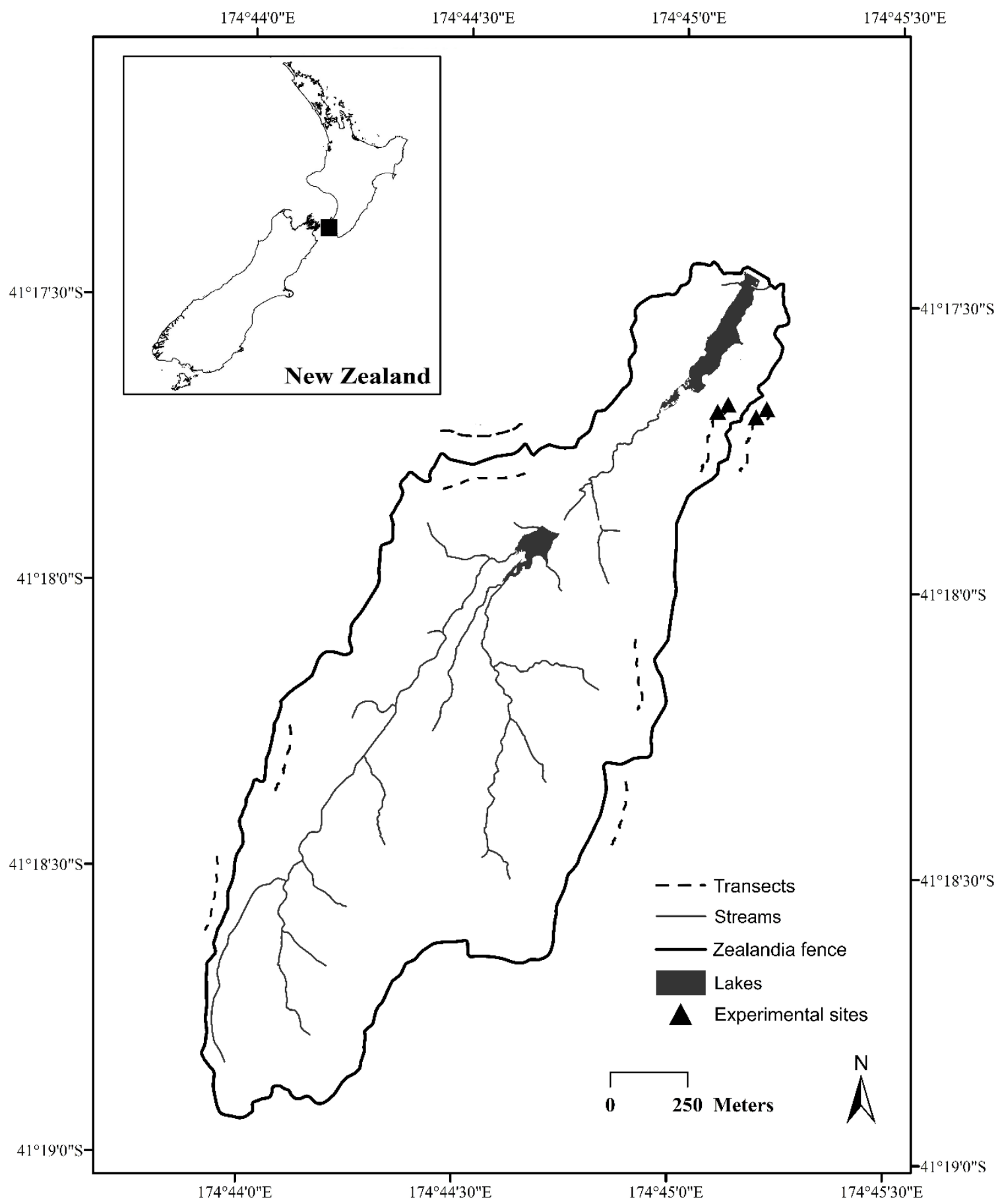

FIGURE 2.1 Map of the fenced reserve, ZEALANDIA in Wellington Region, New Zealand.

Sampling transects are represented by dashed lines and experimental sites by triangles inside and outside the fenced reserve.

Coleoptera and Orthoptera were sorted to family and/or species levels using nomenclature provided by Johns (2001), Gwynne (2005), Larochelle and Larivière (2007), and other 
invertebrates were classified to ordinal or class level. We measured the body sizes of Coleoptera, Araneae and Orthoptera (weta) as the total body length from the anterior part of the head to the posterior part of the abdomen, excluding appendages, using callipers for weta individuals and metric paper $(1 \mathrm{~mm})$ for other taxa. Also, we classified identified specimens into trophic guilds to investigate differences in trophic interactions. The guilds were, detritivores: organisms that feed on dead organic matter (including fungivores, saprophagous, scavengers and xylophages) (Schowalter 2011); omnivores: organisms that may eat both plant or animal matter; herbivorous or phytophagous: invertebrates that feed on any part of plants (foliage, stems, roots, flowers, fruits or seeds) (Schowalter 2011); and predators: invertebrates which locate and capture other organisms (Gillott 2005). When our taxonomic identifications were not as specific as required for a guild classification the taxon was not included in the guild analysis (Appendix Table 8.1).

\subsubsection{Cavity-dwelling invertebrates}

We placed four weta houses, artificial tree cavities used to monitor cavity-dwelling fauna (Bowie et al. 2006, Bowie et al. 2014), at each transect to test differences in tree weta (Orthoptera; Anostostomatidae) densities inside and outside the reserve. Our weta houses were $200 \times 70 \mathrm{~mm}$ with two entrances $(10 \mathrm{~mm}$ and $17 \mathrm{~mm}$ diameters $)$ and a front plate that can be swivelled to the side to allow inspection of occupants. Weta houses were tied to a tree trunk at approx. $170 \mathrm{~cm}$ high using a screw and installed at each set of pitfall traps. These devices were checked daily during four days after setting up in 2014 to check initial colonisation, and one day in 2015 to measure establishment. 


\subsubsection{Density of predators: mammals}

To confirm differences in mammal density and/or composition inside and outside the fenced reserve, we obtained an index of mammal abundance through identification of footprints on tracking tunnels baited with peanut butter, and teeth marks on chew cards baited with commercial paste (ferafeed, Connovation Ltd.) (Sweetapple and Nugent 2011, Gillies and Williams 2013). Ten tracking tunnels were set up at $25 \mathrm{~m}$ intervals along transects and ten chew cards at 5-10 m adjacent to each tracking tunnel. All devices were active for $72 \pm 2 \mathrm{hrs}$ (i.e. spanning three consecutive nights).

\subsubsection{Predator pressure measured via exclosures}

To estimate predator pressure upon invertebrates, we carried out a vertebrate enclosure experiment at two sites inside and two outside the fenced reserve, in February-March 2015 (Figure 2.1). We established four treatments for this experiment: bird-exclusion, mammalexclusion, joint exclusion of both birds and mammals and an open-access control at each site. Each treatment (except the control) consisted of 600x600 mm square cages, plus one plastic container of $150 \times 100 \times 30 \mathrm{~mm}$ buried at ground level in the middle of each cage. No cage was set up at the control site, but a plastic container was used, in which to place mealworms (Tenebrio monitor, Tenebrionidae).

We baited the plastic containers of treatments and control with two adult and two larval mealworms. They were set-up in either the morning or the afternoon (depending on date and location) and left in situ for two days, followed by replacement whenever at least two consecutive non-rainy days were forecast. In total, each treatment was baited eight times across the total experimental period. 
We set up passive infrared triggered cameras (Bushnell, model: 119537) beside each treatment throughout the experiment. Cameras were attached to trees approx. at 500 to 700 $\mathrm{mm}$ from the ground and angled downwards at approximately 20 degrees to cover the cage areas and their surroundings. When triggered, they recorded 15 seconds of video with a five second latency before the next video could be triggered. The presence of any vertebrate in a video was considered as one count. Successive triggers were counted as separate observations for quantification purposes as we could not always determine whether it was the same or a different individual, as there is no clear time elapsed which defines full independence of visits.

The specific design of control and treatments were as follows (Appendix Figure 8.1):

Control: plastic container $(150 \times 100 \times 30 \mathrm{~mm})$ buried at ground level that allows small and large vertebrates to take mealworms. No physical cage was involved here, only one stick was set up near the container to mark its position when recording.

Bird and mammal exclusions (BME): cage of double (square and hexagonal) $13 \mathrm{~mm}$ chicken wire mesh for walls and roof stopping the entrance of vertebrates, except very young mice.

Bird-reduced entry treatment (BE): cage of $13 \mathrm{~mm}$ mesh on the roof, $100 \mathrm{~mm}$ mesh on the walls and one door of $200 \mathrm{~mm}$ square per wall. It prevents the entrance of large birds (kiwi, Apteryx owenii) and large mammals (cats). It deters most other birds wary of confined spaces, but allows small mammals (and some inquisitive birds) to access to mealworms. Mammal exclusion (ME): cage of $13 \mathrm{~mm}$ double mesh (walls) with an open roof, and an external overhang $(150 \mathrm{~mm})$ that allows the entrance of birds from above, but excluded mammals from approaching the baits (except possibly small mice). 
We extracted all invertebrates from each container before the next set of experiments was run to reduce the attractiveness of caught invertebrates to vertebrate predators. We recorded the number of mealworms remaining alive or dead on each container.

Treatments were active for two periods: 13 consecutive days (18 February-2 March 2015) and 23 consecutive days (9-30 March 2015). The location of treatments was re-randomised between the two periods to guard against site-specific influences. We switched the cage position swapping the control with BE and BME with ME, as well as the hour of baiting inside vs outside the fenced reserve for the second period. During the first period, we baited containers located inside the reserve during mornings and outside it during afternoons, and vice versa during the second period.

For the propose of this research, we counted and analysed 1) the number of first encounters from videos showing predators directly foraging mealworms from containers, and 2) all visits (combining first encounters and all extra visits) when predators were displayed foraging or visiting cages or their surroundings within the field of camera detection, regardless of whether or not they consumed mealworms (in most instances the mealworms were no longer present). In this way, we obtained the number of predators eating mealworms and their foraging activities as well as an index for the total number of potential predators that could be influencing the invertebrate abundance inside and outside the fenced reserve.

\subsubsection{Analysis}

We compared taxonomic and guild abundance, body size and alpha diversity (ShannonWiener $\left.\left(H^{\prime}\right)\right)$ of ground-dwelling invertebrate taxa inside and outside the fenced reserve over two time periods. We fitted Linear Mixed Effect (lmer) models to test for an effect of 
the fenced reserve upon invertebrates with mammal-exclusion (inside vs. outside the reserve), year of sampling (2014 vs. 2015), and their interaction as fixed-effect variables. Site and transect were included as nested random effects.

We performed a multivariate ordination, principal coordinate analysis (PCoA), using the Bray-Curtis dissimilarities of the square-root transformed abundance of invertebrates per trap. This was done four times: first at the level of taxonomic order for all invertebrates sampled, secondly at the level of family for beetles, thirdly at the level of morphospecies of Carabidae, and fourthly based on a trophic guild classification of all invertebrates. We compared community structure among sites for each year separately and then combined. We excluded Dermaptera, Archaeognatha and Diplura from the first analysis and Lucanidae (Coleoptera) from the second, due to their very low abundance. We used biplots to indicate the invertebrate taxa contributing most strongly to the separation of sites. An analysis of variance (ANOVA) was performed using distance matrices and permutation tests (Adonis from the Vegan package adopted by J. Oksanen) for partitioning distance matrices among sites and fitting linear models (Exclusion*Year interaction, site $=$ random effect) to distance matrices.

We analysed the proportion of insectivorous birds and mammals feeding on mealworms (first encounters), as a measure of predation upon invertebrates and also compared the number of all vertebrate visits (both, inside and outside cages) inside and outside the fenced reserve and among treatments. We fit Generalized Linear Mixed Models (GLMMs) using Binomial family error distribution for first encounter $(\%)$ of vertebrate predators with mealworms, and Poisson family error distribution for all visits, tested by Analysis of Deviance with Type III sums of squares. Vertebrate predator visit was the response variable; 
broad-scale mammal-exclusion (inside vs outside fenced reserve) was the predictor; and site was a random effect. Analyses were performed using the statistical software $\mathrm{R}$ version (Version 0.99.902, (C) 2009-2016 RStudio, Inc.), and packages lme4 (Bates et al. 2015) and vegan (Oksanen et al. 2018).

\subsection{Results}

\subsubsection{Composition and diversity of ground-dwelling invertebrates}

In total, 2,988 invertebrates were collected in 2014, and 1,910 individuals in 2015 (Appendix Table 8.1). Malacostraca (30\%), Collembola (24\%), Insecta (23\%) and Arachnida (16\%) were the most abundant classes (Figure 2.2). Staphylinidae and Carabidae accounted for the most abundant Coleoptera families. Mammal exclusion and year of sampling made no significant difference to the abundance of most of these common taxa (all P > 0.05 after Holm-Bonferroni correction, Table 2.1)

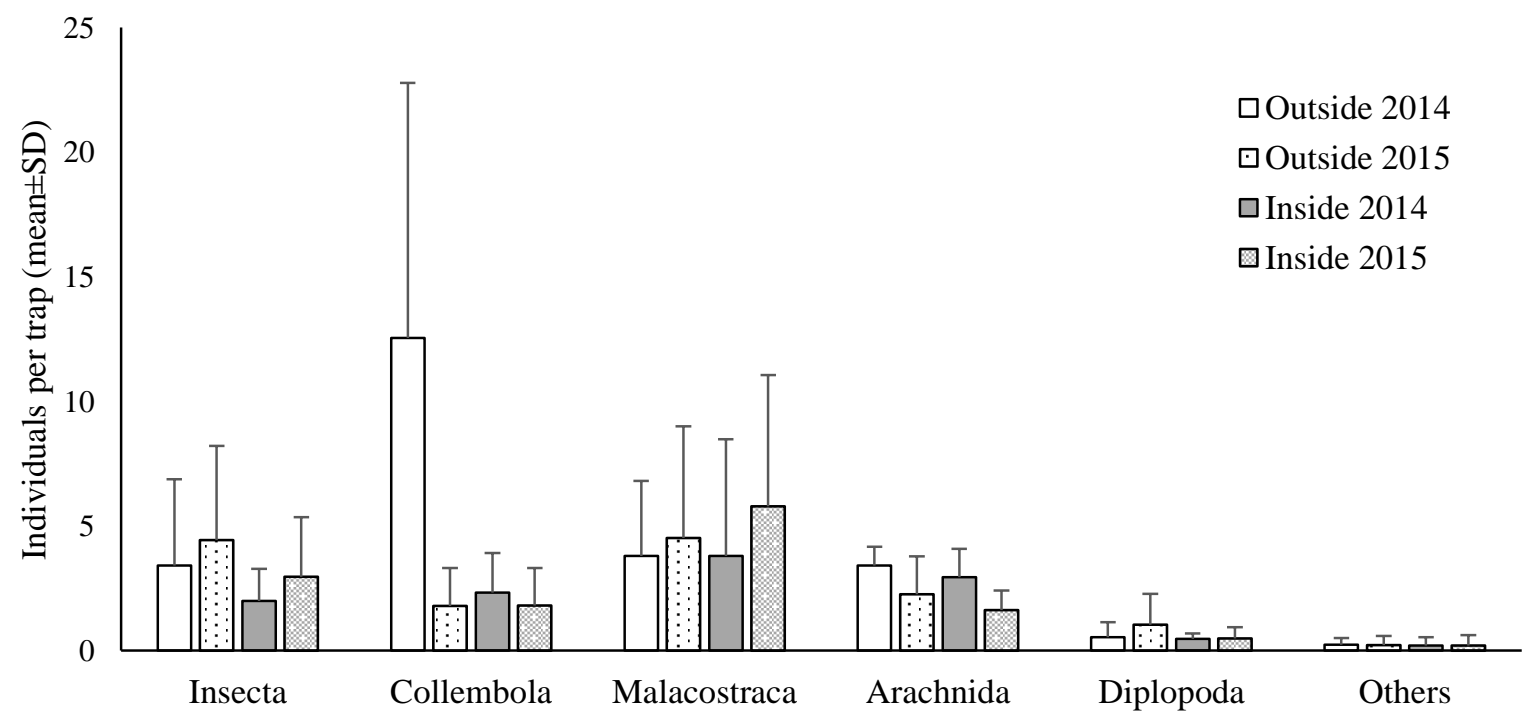

FIGURE 2.2 Mean ( \pm SD) of invertebrates by Class, found inside (grey bars) and outside (white bars) the fenced reserve in 2014 and 2015. $n=40$ pitfall traps on either side of the fenced reserve in 2014 , or $\mathrm{n}=80$ pitfalls in 2015 . 
Collembola (springtails) was the only taxon of epigeous invertebrates that showed response to mammal exclusion. They were exceptionally abundant outside the reserve in 2014 , compared to the inside in the same year, but with little difference compared inside to outside in 2015 (interaction; $\chi^{2}(1)=18.47, p=0.00002$ ) (Table 2.1). There was a slight difference (only apparent before Holm-Bonferroni correction) on the abundance of Staphylinidae (rove beetles) due to mammal exclusion. Rove beetles seem to be more abundant outside the fenced reserve compared to the inside (exclusion; $\left.\chi^{2}(1)=5.39, p=0.02\right)$. Araneae (spiders) were significantly more abundant in 2014 compared to 2015 (year; $\chi^{2}(1)=13.22, p=0.00028$ ) with no effect of mammal exclusion. There were no significant differences in the mean of Shannon-Wiener diversity at ordinal level for mammal exclusion or year of sampling. Herbivores were more abundant outside the fenced reserve in 2014, and inside it in 2015 $\left(\chi^{2}(1)=18.584, p=0.0014\right)$ (Table 2.1). No significant differences were found in body sizes of beetles or weta due to mammal exclusion, or year of sampling. Spiders seem to be smaller in 2014 and larger in 2015, but this size difference was only apparent before HolmBonferroni correction (Year, $\left.\chi^{2}(1)=5.39, p=0.04\right)$.

Multivariate ordinations (PCoA) did not show any distinguished differences between the sites inside and outside the fenced reserve due to the abundance of ground-dwelling invertebrates at order level or morphospecies of Carabidae (Adonis, exclusion, $p>0.05$ ). However, there was a tendency for sites to show higher dissimilarity in ground-dwelling invertebrate guilds inside and outside the fenced reserve but this was only evident for samples collected in 2014 (Adonis, exclusion, $\mathrm{F}=6.280, \mathrm{df}=1,14 ; p=0.002$ ). In this year, herbivores were higher relative abundant outside the fenced reserve while predators and detritivores were abundant inside it (Figure 2.3). 
TABLE 2.1 Summary of analysis of Variance (Type III, chi-square test) fitting linear mixed-effects models for the effects of a fenced reserve mammal exclusion and year on the mean abundance, body sizes, Shannon diversity, richness and guild abundance of ground-dwelling invertebrates. Values shown are beta coefficients with significance indicated by asterisks. $+=$ significant difference at $p<0.05$ before Holm-Bonferroni correction, and $* p<0.05$, ** $p<0.01$ and $* * * p<$ 0.001 after Holm-Bonferroni correction, NS = non-significant effect $(p>0.05) . \mathrm{CW}=$ Cave weta and $\mathrm{GW}=$ Ground weta.

\begin{tabular}{|c|c|c|c|}
\hline Taxon & Fenced reserve (in vs out) & Year & ReservexYear \\
\hline DIPLURA & $\mathrm{NS}$ & NS & NS \\
\hline COLLEMBOLA & $-1.7806^{* *}$ & $-2.0493 * * *$ & $1.8092 * *$ \\
\hline INSECTA & NS & NS & NS \\
\hline Coleoptera & NS & NS & NS \\
\hline Carabidae & NS & NS & NS \\
\hline Curculionidae & NS & NS & NS \\
\hline Staphylinidae & $(-0.9679)^{+}$ & & NS \\
\hline Pselaphidae & NS & NS & NS \\
\hline Lucanidae & NS & NS & NS \\
\hline Other beetles & NS & NS & NS \\
\hline Orthoptera & NS & NS & NS \\
\hline Rhaphidophoridae (CW) & NS & NS & NS \\
\hline Anostostomatidae (GW) & NS & NS & NS \\
\hline Diptera & NS & NS & NS \\
\hline \multicolumn{4}{|l|}{ Hymenoptera } \\
\hline Formicidae & NS & NS & NS \\
\hline Psocoptera & NS & NS & NS \\
\hline ARACHNIDA & NS & $(-0.4002)^{+}$ & NS \\
\hline Acari & NS & NS & NS \\
\hline Araneae & NS & $-0.5641 *$ & NS \\
\hline Opiliones & NS & NS & NS \\
\hline Pseudoscorpiones & NS & NS & NS \\
\hline DIPLOPODA & NS & NS & NS \\
\hline CHILOPDA & NS & NS & NS \\
\hline MALACOSTRACA & NS & NS & NS \\
\hline ISOPODA & NS & NS & NS \\
\hline AMPHIPODA & NS & NS & NS \\
\hline GASTROPODA & NS & NS & NS \\
\hline \multicolumn{4}{|l|}{ Diversity } \\
\hline Shannon (Order-level) & NS & NS & $(-0.1459)^{+}$ \\
\hline \multicolumn{4}{|l|}{ Guilds } \\
\hline Predator & $(0.1688)^{+}$ & NS & $(-0.2520)^{+}$ \\
\hline Herbivore & $-0.2419 *$ & $(-0.1839)^{+}$ & $0.3665^{* *}$ \\
\hline Detritivore & NS & NS & NS \\
\hline Omnivore & NS & $(0.1134)^{+}$ & NS \\
\hline \multicolumn{4}{|l|}{ Body size } \\
\hline Carabidae & NS & NS & NS \\
\hline Araneae & NS & $(0.4740)^{+}$ & NS \\
\hline
\end{tabular}




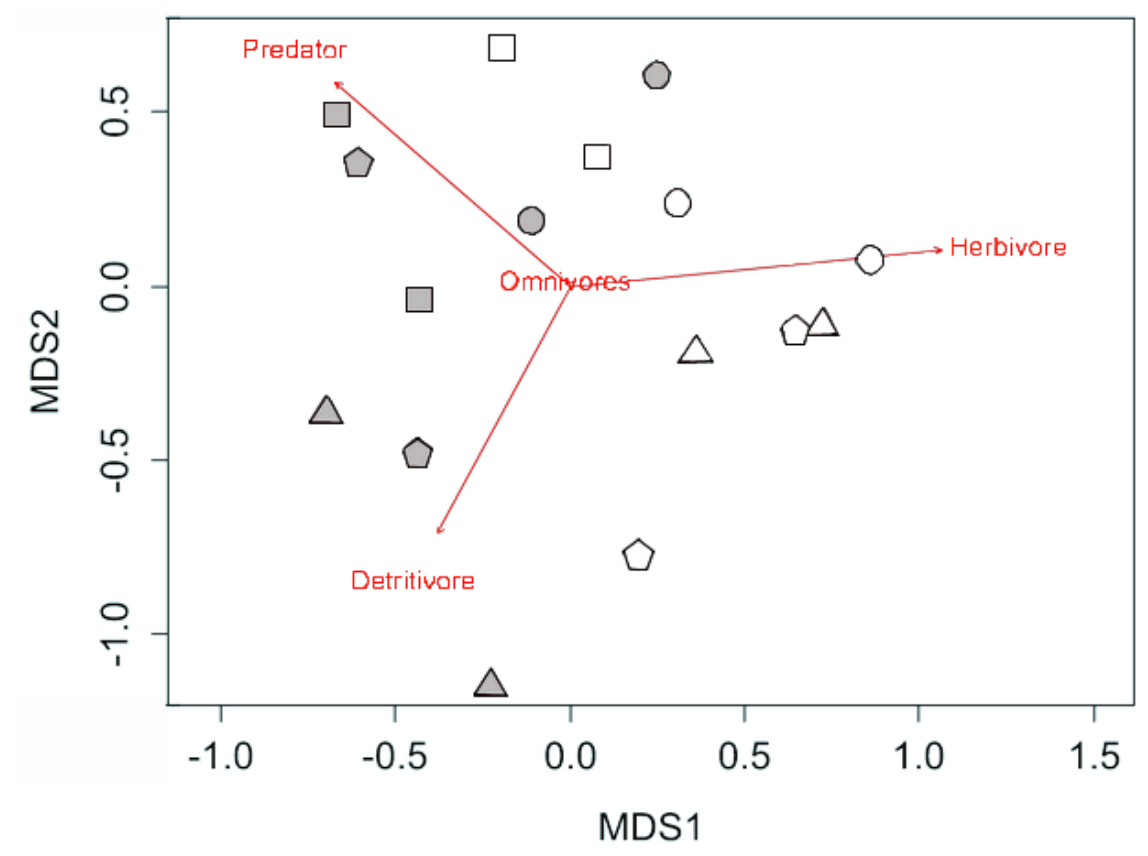

$\mathrm{a}$

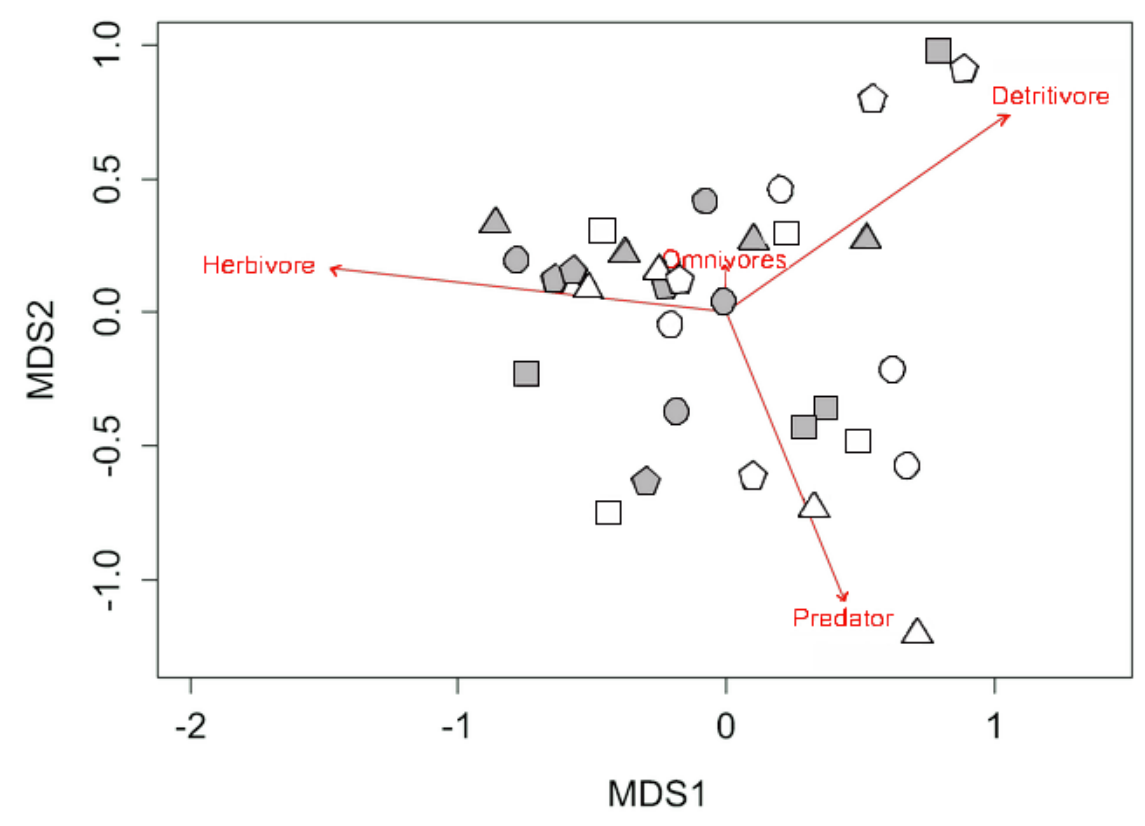

b

FIGURE 2.3 Principal Component Analysis (PCoA) for the Bray-Curtis dissimilarities of trophic guild of invertebrates among sites in (a) 2014 and (b) 2015. Grey figures represent sampling sites inside the fenced reserve, ZEALANDIA, and white figure, outside it. Shapes denote different transects within a site.

\subsubsection{Cavity-dwelling invertebrates}

Wellington tree weta (Hemideina crassidens), and multiple species of cave weta (Rhaphidophoridae), beetles (Coleoptera), spiders (Araneae), cockroaches (Blattodea) and 
slugs (Gastropoda) were found inhabiting weta houses both inside and outside the fenced reserve. One year after setting up, all weta houses $(n=16)$ placed inside the reserve were occupied by invertebrates, compared with $87 \%$ occupancy outside of the reserve. Tree weta were most abundant species inhabiting weta houses. There were no significant differences in total abundance, total occupancy rates or body sizes (male, female or juvenile) of tree weta in weta houses placed inside vs outside the fenced reserve.

\subsubsection{Density of predators: mammals}

Hedgehogs were the mammals most commonly detected outside of the fenced reserve, as indicated by the tracking tunnels (Figure 2.4). Hedgehog density remained high in both years $(70 \%$ and $73 \%$ ), while the detection of mice diminished from $10 \%$ (inside) and $15 \%$ (outside) in 2014 to zero in 2015 (both inside and outside of the reserve). Rat detections increased from zero (inside and outside) to 5\% (outside) during the same period. Mice were the only mammal recorded inside the fenced reserve. Insect footprints were also recorded in tracking tunnels, being more evident in $2014($ mean $=50 \%)$ related to $2015($ mean $=13 \%)$ $\left(\chi^{2}(1)=4.01, p=0.04\right)$.

Chew-cards detected similar trends to tracking tunnels. In addition, they detected possums outside the fenced reserve (15\% in 2015 compared to 5\% in 2014). Inside the fenced reserve, a higher occupancy rate of mice was recorded in 2014 (23\%) but non-detection in 2015 (Appendix Figure 8.2). 


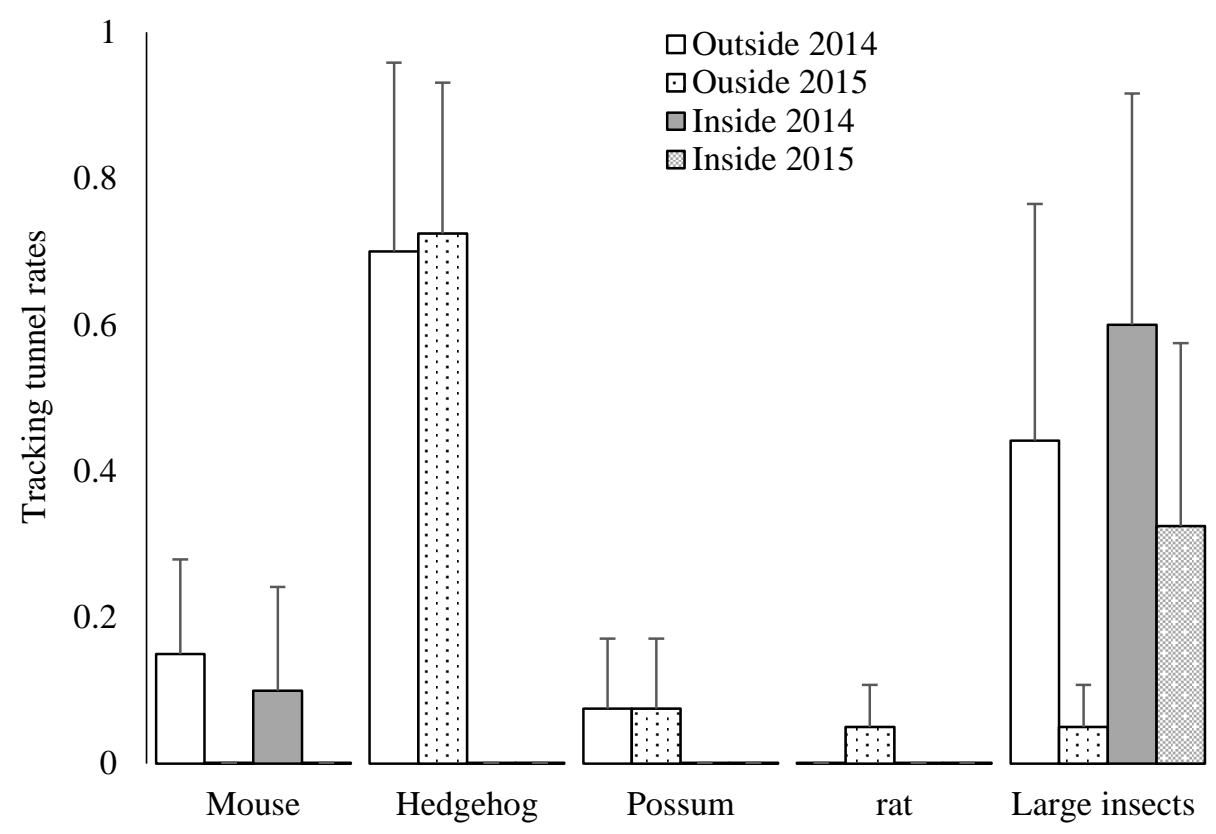

FIGURE 2.4 Average detection rate of mammals and insects inside (closed patterns) and outside (white patterns) fenced reserve using tracking tunnels. Mean \pm SD.

\subsubsection{Predator pressure experiment}

A total of 1295 videos of visitations to predator exclosure treatments were recorded across 36 days of monitoring. More videos were recorded during the day $(n=426$ inside; $n=524$ outside the fenced reserve) than night ( $n=201$ inside; $n=144$ outside the reserve).

First encounter (predation of mealworms): there was $100 \%$ predation of larvae and adult mealworms ( $\mathrm{n}=16$ trials) within the fenced reserve across all exclusion treatments apart from the BME (bird and mammal exclusion) cages. In contrast, there was generally less predation of mealworms outside of the fenced sanctuary $\left(\chi^{2}(1)=11.91, p=0.0006\right)$ (Figure 2.5). 


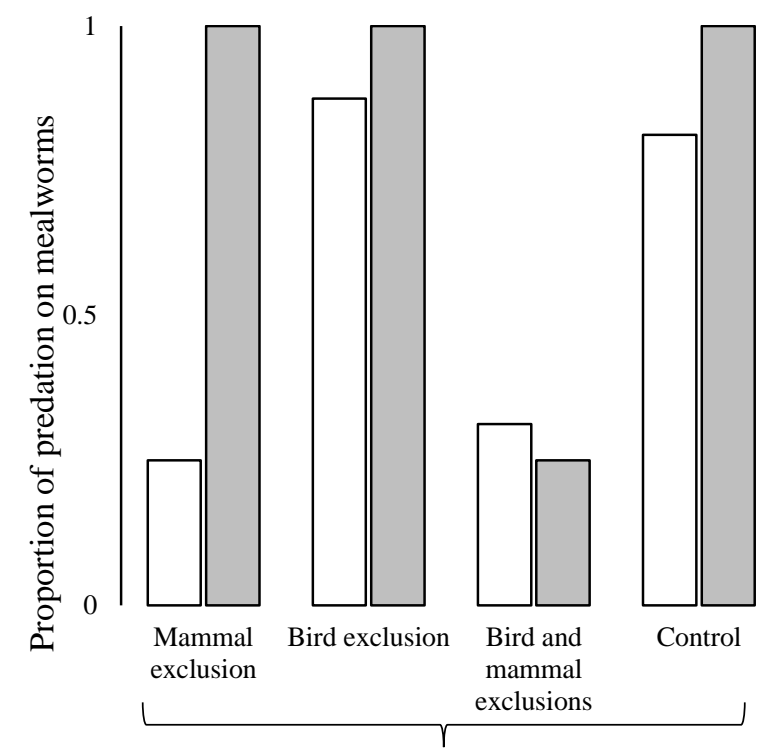

Larvae

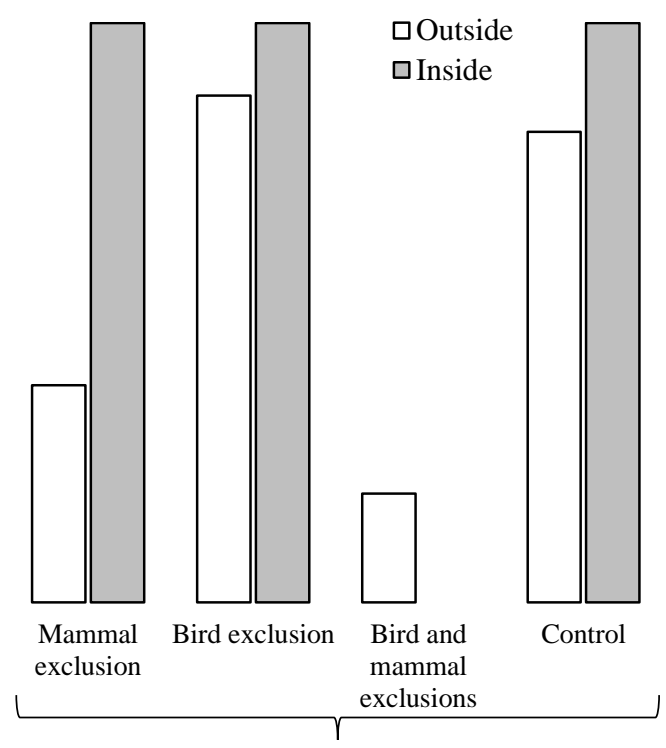

Adult

FIGURE 2.5 Total proportion of predation of larvae and adult mealworms for each treatment inside (closed bars) and outside (open bars) the fenced reserve.

Inside the fenced reserve, only robins and blackbirds were recorded to be the first predators eating mealworms, while outside it, blackbirds, dunnocks, chaffinches, mice, hedgehogs and unidentified predators were recorded as first predators (Figure 2.6). Robins were the main predators of mealworms inside the fenced reserve (75\% (ME and $\mathrm{BE}$ ) and $81.25 \%$ (Control) of predation) with no records of first encounter visits outside the fence. Blackbirds were significantly more often the first encounter predator outside the reserve compared to inside $\left(\chi^{2}(1)=12.98, p=0.0003\right)$. This species was responsible for $14 \%(\mathrm{ME}), 20 \%(\mathrm{BE})$ and $13 \%$ (control) of predation inside the fenced reserve, and 100\% (ME), 92\% (BE), 69\% (control) of predation outside it. 


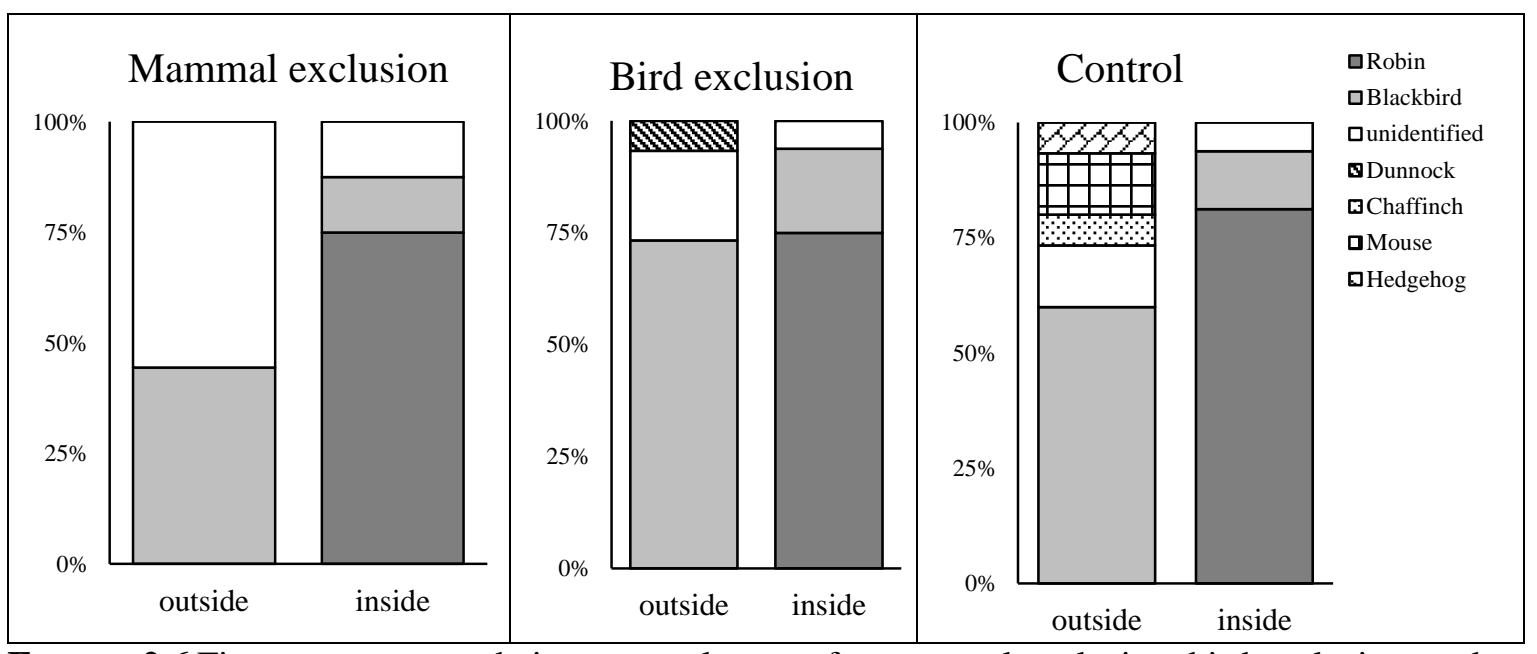

FIGURE 2.6 First encounter predation on mealworms for mammal exclusion, bird exclusion, and control treatments, inside and outside the fenced reserve. Unidentified denotes predation of mealworms with no apparent records of predators involved.

All visits: counting all visits (predation of mealworms plus other visits inside and outside cages), the predator pressure of birds (mainly blackbirds and robins) and mice upon invertebrates inside the fenced reserve (mean no. of visits $=1.09 \pm 0.17$ per day) seems to be similar to the predation pressure of birds (mainly blackbirds), mice and others mammals at treatments placed outside the fenced reserve (mean $\mathrm{n}^{\circ}$ of visits $=1.16 \pm 0.13$ per day) $\left(\chi^{2}(1)=0.003, p=0.956\right)($ Table 2.2). From these results, it was confirmed the observed trend for first encounters as blackbirds were more active outside the fenced reserve $\left(\chi^{2}{ }_{(1)}=16.95\right.$, $\left.p=3.843 \times 10^{-5}\right)$, while robins $\left(\chi^{2}(1)=52.54, p=4.226 \times 10^{-13}\right)$ were more highly detected inside it for all treatments. 
TABLE 2.2 Total number of all visits of predators inside and outside cages for each treatment inside and outside the fenced reserve.

\begin{tabular}{|c|c|c|c|c|c|c|c|c|c|c|c|}
\hline \multirow[b]{2}{*}{ Name } & \multirow[b]{2}{*}{ Species } & \multicolumn{5}{|c|}{ Inside the reserve } & \multicolumn{5}{|c|}{ Outside the reserve } \\
\hline & & BE & ME & Control & BME & Total & BE & ME & Control & BME & Total \\
\hline \multicolumn{12}{|l|}{ Birds } \\
\hline Kiwi & Apteryx owenii & 8 & 8 & 12 & 7 & 35 & 0 & 0 & 0 & 0 & 0 \\
\hline Robin & Petroica longipes & 66 & 57 & 47 & 37 & 207 & 1 & 0 & 1 & 2 & 4 \\
\hline Saddleback & Philesturnus rufusater & 1 & 1 & 0 & 0 & 2 & 0 & 0 & 0 & 0 & 0 \\
\hline Tui & Prosthemadera novaeseelandiae & 2 & 0 & 0 & 0 & 2 & 0 & 0 & 0 & 0 & 0 \\
\hline Bellbird & Anthornis melanura & 0 & 0 & 2 & 0 & 2 & 0 & 0 & 0 & 0 & 0 \\
\hline Song thrush & Turdus philomelos & 0 & 0 & 0 & 0 & 0 & 0 & 0 & 1 & 0 & 1 \\
\hline Blackbird & Turdus merula & 47 & 41 & 71 & 46 & 205 & 129 & 94 & 145 & 146 & 514 \\
\hline Chaffinch & Fringilla coelebs & 0 & 0 & 0 & 0 & 0 & 2 & 0 & 6 & 2 & 10 \\
\hline \multirow[t]{2}{*}{ Dunnock } & Prunella modularis & 3 & 1 & 0 & 0 & 4 & 4 & 0 & 5 & 3 & 12 \\
\hline & $\begin{array}{r}\text { Total of bird visits } \\
\end{array}$ & 127 & 108 & 132 & 90 & 457 & 136 & 94 & 158 & 153 & 541 \\
\hline \multicolumn{12}{|c|}{ Introduced mammals } \\
\hline Hedgehog & Erinaceus europaeus & 0 & 0 & 0 & 0 & 0 & 3 & 4 & 1 & 2 & 10 \\
\hline Mouse & Mus musculus & 54 & 28 & 83 & 0 & 170 & 53 & 12 & 27 & 10 & 102 \\
\hline \multirow[t]{2}{*}{ Rabbit } & Oryctolagus cuniculus & 0 & 0 & 0 & 0 & 0 & 5 & 1 & 5 & 4 & 15 \\
\hline & Total of mammal visits & 54 & 28 & 83 & $\mathbf{0}$ & 170 & 61 & 17 & 33 & 16 & 127 \\
\hline
\end{tabular}

$\mathrm{BE}=$ Bird-reduced entry treatment, $\mathrm{ME}=$ Mammal exclusion, Control, BME=Bird and mammal exclusions. 


\subsection{Discussion}

No major differences in invertebrate communities inside versus outside the fenced reserve were found. Similarities in the overall predation pressure, despite clear differences in the community composition of insectivorous vertebrates, were shown within and outside the reserve. Mammalian predators, hedgehogs, possums and rats, were only present outside the fenced reserve since their eradication from the reserve in 2000, while kiwi and tuatara were only present inside the reserve since their translocation there in 2000 and 2005, respectively (Karori Sanctuary Trust 2016) (Figure 2.7).
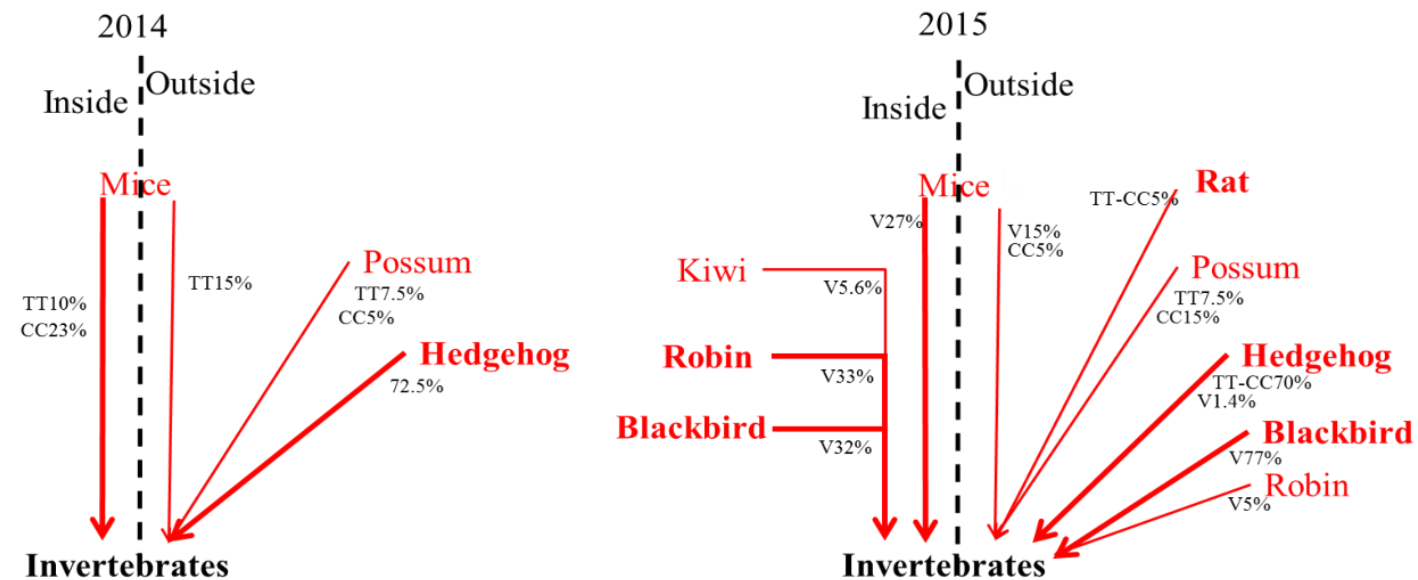

FIGURE 2.7 Diagram of predator pressures on invertebrates inside and outside the fenced reserve in 2014 and 2015. No data for birds in 2014 since birds were only investigated in 2015. Bold lines and large font symbolise strong influences. TT=tracking tunnel occurrence rates, $\mathrm{CC}=$ chew card occurrence rates, $\mathrm{V}=$ total number of visits from experiment sites. Red arrows= top-down forces upon invertebrates.

\subsubsection{Invertebrate abundance and fence exclusion}

None of ground-dwelling invertebrates showed any difference in abundance inside versus outside the fenced reserve. Only springtails (Collembola) showed greater abundance outside the reserve in 2014, but this difference was not apparent in the second year of sampling. Springtails are considered good indicators of soil quality and structure because of their 
edaphic adaptations (Vandewalle et al. 2010). Their higher abundance outside the reserve in 2014 may reflect temporal changes in nutrients and/or weather, i.e. a response to bottomup effects and environmental conditions or changes in macroinvertebrate predator pressures. A slight difference was recorded for Staphylinidae (rove beetles), which were more abundant outside the fenced reserve compared to the inside (difference only noted before Bonferroni correction). Staphylinidae are more likely to respond to bottom-up effects such as the availability of invertebrate prey and detritus based on their diet requirements, as rove beetles make up only a minor percentage of the diet of hedgehog, rat and mouse (Moeed and Fitzgerald 1982, Newman and McFadden 1990, Newman 1994, Hendra 1999, St Clair 2011).

The apparent similarity in the invertebrate communities inside and outside of the fenced reserve is consistent with the research by Watts et al. (2014). They monitored beetle communities for two years (two sampling periods) before mammal eradication and over a seven-year period after the eradication inside the reserve, and reported a decline in the abundance and body size distributions of beetles after mammal exclusion at ZEALANDIA before stabilising. These authors opened a discussion about the relative importance of predators, nutrients, invertebrate interactions and environmental factors in controlling invertebrate diversity, and the time required after mammal eradication to observe significant changes.

In all likelihood, vulnerable large-bodied flightless insects had already disappeared from the area that now comprises the fenced reserve 100 years ago, due to mammal predation and clearance of the forest (Karori Sanctuary Trust 2016). Thus, this lack of significant difference in the invertebrate communities inside versus outside the fenced reserve may be 
a result of the short period (17 years) since the creation of the reserve relative to the time needed for observing a recovery of their abundance inside the fence and the lack of source populations that could allow for recolonization of the now mammal-free reserve. In other words, creating a safe environment may not be a sufficient step towards restoration of natural ecosystems if there is no source of immigrants, the so-called "build it and they will come" field of dreams approach (Ahlering and Faaborg 2006).

Mice are omnivorous and their diet is biased towards invertebrates (Ruscoe 2001) including spiders which comprise from $44 \%$ to $58 \%$ of mice stomach contents in New Zealand (Fitzgerald et al. 1996, Miller and Webb 2001, Jones and Toft 2006). From our findings, mice represent an important threat to ground-dwelling invertebrates inside the fenced reserve as they seem to add pressure to the predation driven formerly by birds. This suggests that conservation management within fenced reserves should always incorporate a plan to control and reduce mouse populations. The construction of exclusion areas within protected areas might help threatened invertebrate species (i.e. Cook Strait giant weta), in particular, and ground-dwelling invertebrates, in general, to recover their populations inside fenced reserves where mice cannot otherwise be completely controlled.

\subsubsection{Abundance and body size of spiders, and year}

Significantly more spiders were caught in 2014 than in 2015. This suggests that either the summer distribution of spider abundances was different or there was a bias due to the variation in sampling methods. In our study, spiders may have an increased ability to discover and forage prey that remained alive in non-lethal pitfall traps in 2014, increasing our sampling abundance and suggesting that caught invertebrates could have acted as 
"baits" for spiders. In 2015, the use of lethal-pitfall traps killed potential invertebrate prey a few minutes after catching, which may have been the reason for reduced spider abundance. Spiders also tended to be larger in 2015 compared to 2014 (difference only apparent before Holm-Bonferroni correction). More evidence is needed to understand this pattern, as spiders would respond to availability of invertebrate prey, and/or predation pressure by vertebrates (e.g. mice) (Fitzgerald et al. 1996, Alley et al. 2001).

\subsubsection{Predator pressure measured by enclosures}

The negative impact of native and non-native birds on macroinvertebrate populations has been well described (Moeed and Fitzgerald 1982). Birds tend to increase their hatching and fledging successes and their breeding populations after the removal of introduced mammals (Smith et al. 2010). The population of robins has grown and remained high inside the fenced reserve since their translocation in 2000-2001 (Empson and Fastier 2013) and individuals have successfully dispersed into nearby parks and reserves (MacArthur et al. 2012). Although robins were not recorded eating mealworms outside the fenced reserve, they were observed on the videos after mealworms were gone. From our findings, native robins and also the non-native blackbirds, are exerting predation pressure upon invertebrates on both sides of the fence and might mainly affect soft and colourful invertebrates with diurnal behaviour, such as crickets, larvae of beetles, snails and most of the foliage invertebrates. Predation pressures of kiwi and tuatara (both protected species within the fenced reserve) could not be quantified in 2014, but kiwi were recorded foraging in 2015, and may also play a key role in controlling invertebrate populations inside the fence reserve. Whilst differences in bird predation pressure inside and outside the fence were not quantified in 2014, our results from 2015 indicate that the total predation pressure (measured as the total number of 
visits) on invertebrates was similar inside and outside the fenced reserve, although driven by different predators (Figure 2.7).

Our experiment had some biases: not all birds were excluded by the bird-reduced entry treatment $(\mathrm{BE})$ treatment. Inquisitive birds such as robins entered the cages through the walls and accessed baits (mealworms) in BE treatments, mainly inside the fenced reserve. Bird and mammal exclusions (BME) treatments also showed evidence of predation on mealworms (no mealworms were found on the containers) but no records of anything entering the cages were recorded on the videos. Either insects escaped their trays or a small animal entered but did not trigger the camera trap (e.g. mice or lizards). Predation pressure was measured as the total number of visits by birds and mammals to experimental sites whether or not they took the food (mealworms), and occurrence rates of mammals for all sampling sites (Figure 2.7). This approach has its own limitations: 1) a population estimate for each insectivorous bird predator was not measured over time, 2) even though all predator visits were considered for the experiment, their preference or dislike of mealworms and/or satiation could limit the number of visits, and 3) the inferred predation pressure by greater numbers of robins inside the fenced reserve should be interpreted carefully, as could have learnt quickly during the first few days of running the experiment that baits would be placed on the containers and therefore repeat visits by individuals are likely (Shaw et al. 2015).

In our study, we have focused on the interaction of vertebrate predation and invertebrate prey, in an attempt to understand a complex trophic cascade. This top-down effect involved only a section of the entire food web in soil systems in the forest. To completely understand the actual process that is occurring in the field we should further break down and include interactions between predatory invertebrates and their invertebrate prey, as well as the 
vertebrate predators; however, this was not possible within the scope of this project. It will be crucial for further studies to incorporate changes year by year in habitat quality (such as nutrient availability, soil properties) and other invertebrate interactions to take into account the effect of covariates, especially when the fenced reserve is in its early stages of management (Burns et al. 2012).

Fenced reserves are crucial conservation sites on the mainland of New Zealand to maintain and protect vegetation and endangered vertebrates (Connolly et al. 2009, Burns et al. 2012). However, their role in protecting invertebrates and generating an environment lacking mammalian predator for enhancing their reproduction and diversity, as measures of their success, remains uncertain. Larger invertebrates, such as spiders, some beetles (e.g. Carabidae, Lucanidae), snails, and weta species, are expected to be reduced in number by vertebrate predation inside and outside fenced reserves. These invertebrates are important components of the ecosystem and part of the diet of protected endangered vertebrates inside fenced reserves. Conservation management plans should not only address translocated vertebrates and invertebrates but also maintain nutrients and habitats within the reserve and outside it (if possible) to allow dispersal from the matrix to the surroundings and vice versa. Creating a mouse-free zone within fenced reserves is also key for recovering grounddwelling invertebrates when mouse control is not efficient across the reserve as a whole. Larger invertebrates and their trophic interactions should also be monitored seasonally within reserves to identify under which predation conditions they thrive, to successfully restore and conserve invertebrate communities. 
Creating mammal-free reserves may not be sufficient to restore invertebrate communities.

Both lack of dispersal, and complex trophic interactions involving native invertebrates and non-native birds make for a complex situation. 
3. NEUTRAL RESPONSES OF GROUND-DWELLING INVERTEBRATE COMMUNITIES TO AERIAL 1080 OPERATIONS IN NEW ZEALAND 


\subsection{Introduction}

The introduction of non-native species has caused a decline in diversity of many native communities and changes in their interactions with other organisms and their habitats worldwide (Byrom et al. 2016). This threat is particularly serious when introduced species are predators, and their eradication requires challenging financial, technical and social management (Courchamp et al. 2003).

In New Zealand, the introduction of Pacific rats (Rattus exulans), Norway rats ( $R$. norvegicus), ship rats ( $R$. rattus), mice (Mus musculus), brushtail possums (Trichosurus vulpecula), and stoats (Mustela erminea) has triggered the decline and led to local and total extinctions of many vertebrates and invertebrate species, both on the mainland as well as on offshore islands (Murphy and Dowding 1995, Towns et al. 1997, Atkinson 2001, Powlesland et al. 2005, Hoare et al. 2007, Watts et al. 2011, Norton and Warburton 2015, Barker 2016). Although the vulnerability of invertebrates to introduced predators is known, including the extinction of certain large-bodied invertebrates (Orthoptera: Anostostomatidae) such as Deinacrida rugosa and D. heteracantha (Gibbs 1998), other invertebrates have coped with these mammals. Tree weta (Hemideina spp.), for example, have been described as pre-adapted to rat invasion as they use refuges with narrow entrance holes during the day and night when both organisms share habitats (Gibbs 2009).

\subsubsection{Pest management and 1080 poison}

Pest management activities such as poisoning, trapping, and/or the construction of fenced conservation sites have been used as effective methods promoted by the Department of Conservation (DOC) and community groups in New Zealand in order to reduce and control top-down predatory forces on native fauna (Wright 2011). The success of these methods has 
been measured mainly by the response of bird communities to mammal control (Pryde et al. 2005, Hoare et al. 2007, Veltman and Westbrooke 2011, O'Donnell and Hoare 2012, Department of Conservation 2014, Schadewinkel et al. 2014).

The most common approach for widespread control of introduced mammals in New Zealand is the aerial application of sodium fluoroacetate (compound 1080), an effective poison found in several plants around the world that is used to control rodents, possums and stoats (Notman 1989, Elliott and Kemp 2016). In New Zealand, application of 1080 was initiated in the 1950s to suppress the possum population, and thus reduce damage to forest trees and prevent the spread of tuberculosis. Since then, this poison has been used across large areas to eradicate rats and other introduced mammals from islands; and to control rat, stoat and possum populations on the mainland New Zealand to reduce predation pressure on native fauna (Elliott and Kemp 2016). However, the effectiveness of this treatment depends on the frequency of the operations due to the rapid recovery of introduced mammals, particularly rats, after the application of 1080 (Ruscoe et al. 2011, Department of Conservation 2014, Byrom et al. 2016).

1080 poison affects cell metabolism via inhibition of the Kreb cycle in target animals. When delivered in cereal baits, it is ingested primarily by possums and rats. However, non-target species such as birds, reptiles and invertebrates, can get secondary poisoning by scavenging on poisoned carcasses due to the 1080 exposure of more than five days in the environment (Eisler 1995, Booth et al. 1999, Weaver 2003). Modern application procedures of this poison by aerial methods seems to result in a chemical exposure below 50\% Lethal Dose (LD50) for invertebrates (e.g., oral LD50: $91 \mu \mathrm{g} / \mathrm{g}$ for the Wellington tree weta (Hemideina 
crassidens) or oral LD50: $0.8 \mathrm{mg} / \mathrm{bee}$ for honey bees (Hymenoptera)) (Eisler 1995, Spurr and Berben 2004).

The 1080 poison has been a controversial method for mammal control in New Zealand (Department of Conservation 2017a) due its side effects. Its downsides include secondary poisoning of non-target species, expensive financial and management effort generated by its application, an extensive procedure to cover the whole infested area, and public sensitisation to the use of toxins (Courchamp et al. 2003).

\subsubsection{0 application and invertebrate communities}

Primary poisoning of invertebrates had been discussed in the early years following the first application of 1080 in New Zealand. It mainly reported mortality in several taxa in the field, such as adult beetles, mites, houseflies, moths, cockroaches, springtails, ants, aphids, bees, some weta species and larval stages of butterflies, possibly due to secondary poisoning (Notman 1989, Eisler 1995, Spurr and Drew 1999).

Abnormal behaviour due to intoxication (e.g. slow and lethargic movements) following 1080 application has also been noticed in native cockroaches in both the laboratory and field studies in the Wairarapa, New Zealand, which can increase their vulnerability to vertebrate predators and diminish the abundance of these insects as a result (McIntyre 1987, Lloyd 1994). However, Spurr and Berben (2004) found no evidence of 1080 poisoning affecting the abundance of cockroaches, slugs and spiders occupying artificial weta refuges in the short-term, and hence predicted no long-term effects on invertebrate populations. 
Most of the attempts to understand the effect of introduced mammals on invertebrates have been done on offshore islands in New Zealand, where mammals have been already excluded or reduced by a variety of control mechanisms. Negative, neutral or positive responses of invertebrates to mammal invasion seem to depend on the prevalence of top-down or bottom-up forces in island communities (Fukami et al. 2006). For example, uninvaded offshore islands are dominated by seabird communities which are the major drivers of nutrient variation on the soil and changes in invertebrate communities (Jones et al. 2011, Thoresen et al. 2017).

On the New Zealand mainland, predator pressure driven by insectivorous birds and introduced predators may trigger changes in invertebrate populations. There have been very few attempts to assess short- and long-term impacts of 1080 aerial pest control on invertebrate communities on the mainland of New Zealand. A review of the effects of pest control by Byrom et al. (2016), concluded that Auckland tree weta, a large-bodied and canopy invertebrate, is the only species that has shown benefits from 1080 aerial pest control application on the New Zealand mainland (Powlesland et al. 2005, Ruscoe et al. 2013). Explaining the effects of pest control on invertebrate communities is extremely difficult, due to their enormous diversity and complexity (Sinclair et al. 2005, Didham et al. 2009, Watts et al. 2014). Therefore, the extent of how 1080 mammal control directly or indirectly influences ground-dwelling invertebrates on the mainland, is still largely unknown.

Due to the need for increasing knowledge about the effects of aerial 1080 applications on invertebrates (Byrom et al. 2016), and given its widespread use for the control of possums, rodents and mustelids across New Zealand, it is crucial to monitor invertebrate diversity on the mainland over a time period of 1 to 5 years. In this Chapter, I aimed to answer the 
following question: Does an aerial 1080 drop affect ground-dwelling invertebrates? In particular:

1. Does 1080 application have a positive, neutral or negative effect on the composition, abundance, taxonomic and guild diversity of ground-dwelling invertebrates?

2. Does 1080 application have an indirect effect on the body size of Orthoptera, Araneae or Coleoptera?

3. Does 1080 application influence the composition and diversity of ground beetles (Carabidae)?

In this chapter, I present overall results of the effects of a 1080 pest control operation on ground-dwelling invertebrate populations, whilst trophic relationships between mammalian predators and invertebrates will be the subject of the next Chapter.

\subsection{Methods}

\subsubsection{Study area}

The study was conducted in the Aorangi Forest located in the Wairarapa $\left(41^{\circ} 25^{\prime} \mathrm{S}, 175^{\circ} 21^{\prime}\right.$ E), and the Remutaka Forest near Wainuiomata, North Island (41 $\left.{ }^{\circ} 5^{\prime} \mathrm{S}, 175^{\circ} 14^{\prime} \mathrm{E}\right)$. Aorangi Forest lies between Martinborough in the north and Cape Palliser in the south, covering a large part of the Aorangi Mountains. Remutaka Forest includes the Catchpool and the Orongorongo valleys, and joins the southern end of the Tararua Ranges (Department of Conservation, 2014) (Figure 3.1).

Both forests are protected mountainous areas with indigenous flora, dominated by broadleaf and podocarp species at lower elevations (e.g. Weinmannia racemosa (kamahi), Hedycarya arborea (pigeonwood), Cyatheales (tree ferns), Pseudopanax crassifolius (lancewood), 
Melicytus ramiflorus (whiteywood), Dacrydium cupressinum (rimu), Prumnopitys

ferruginea (miro), Podocarpus totara (totara)). They are mixed with small trees, shrubs, ferns, mosses, lichens, lianas and epiphytes. On the other hand, Nothofagaceae species (beech forest) (e.g. Fuscospora fusca (red beech) and Lophozonia menziesii (silver beech)) are dominant at higher elevations, in dry sites and/or infertile soils. The average monthly temperature varies between $8^{\circ} \mathrm{C}$ in July and $16^{\circ} \mathrm{C}$ in January and annual rainfall between $800 \mathrm{~mm}$ in Wairarapa and $7000 \mathrm{~mm}$ at the top of the Tararua range (ca.1500 $\mathrm{m}$ a.s.l.) (Dymond and Shepherd 2004).

\subsubsection{Treatment and design (BACI)}

A before-after control-impact (BACI) study was conducted in both forests. BACI is an effective method when large changes are predicted and when those changes are permanent after impact (Schwarz 2014). The main advantage of BACI analysis is that it can incorporate both time and the interaction of treatments (control versus impacted sites).

In the present chapter, richness, diversity (taxonomic and guild abundance, and Shannon index), and morphological traits of ground-dwelling invertebrates, were used as indicators of changes in the diversity in response to 1080 mammal control in Aorangi Forest (the treatment area) as compared to the low-treated control zone, the Remutaka Ranges (Figure 3.1). The aerial 1080 treatment was implemented in August 2014 by the Animal Health Board and the Department of Conservation in the southern Wairarapa area. This 1080 application covered over approximately 30,000 hectares of the Aorangi Forest to reduce the number of possums, stoats and rats. 


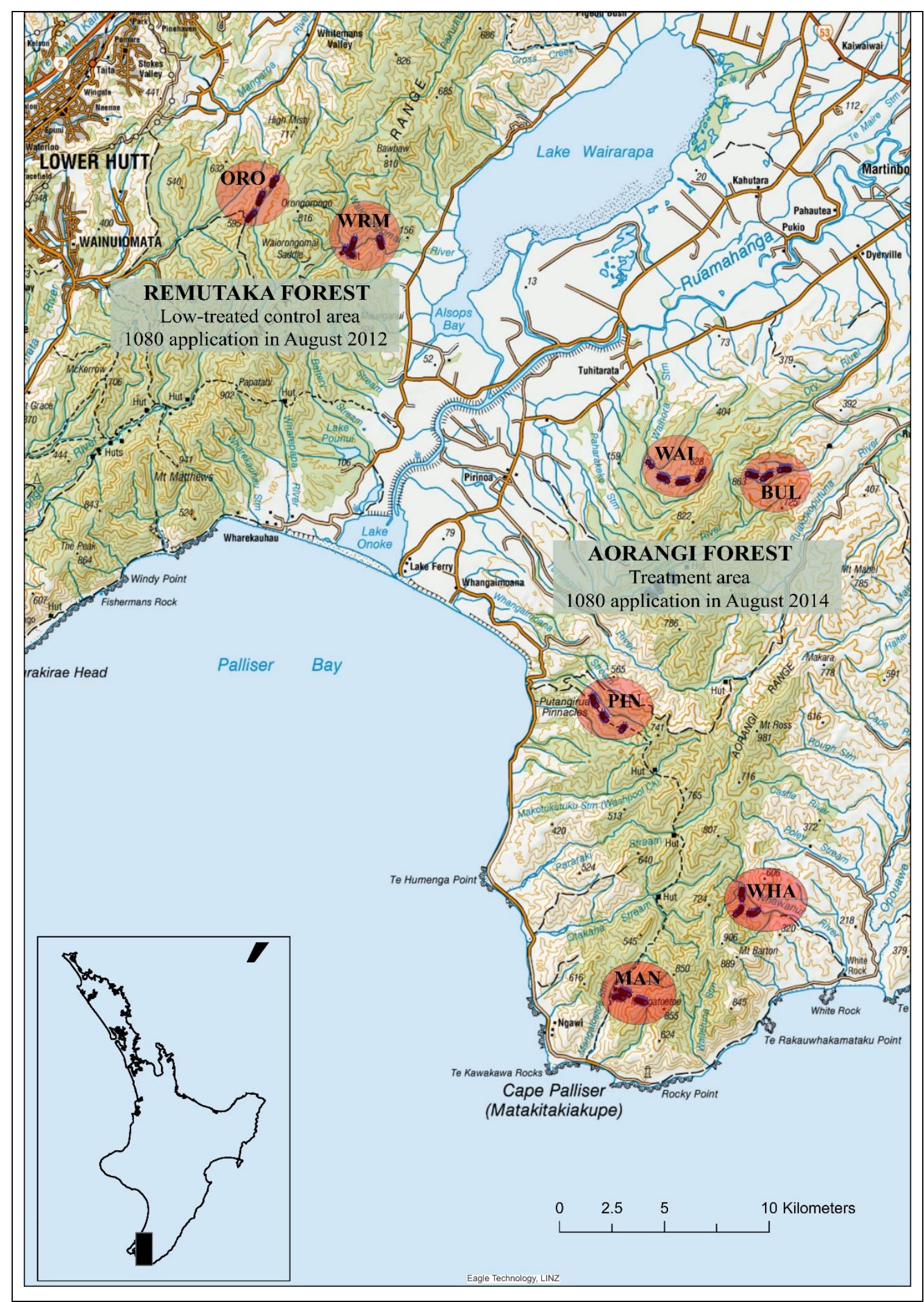

FIGURE 3.1 Map of monitoring lines within sites (red circles) established in November 2012 in Aorangi and Remutaka Forests. Sites in Aorangi Forest: BUL=Bull Hill, MAN=Mangatoetoe, WAI= Waihora,

PIN=Pinnacles and WHA=Whawanui; and sites in Remutaka Forest: ORO=Orongorongo and WRM=Wairongomai. For detailed maps of each site, refer to Appendix Figure 8.3. 


\subsubsection{Invertebrate sampling}

Sampling of ground-dwelling invertebrates was carried out from November 2013 to November 2015 in the Aorangi and Remutaka Forests; with two sampling events before 1080 mammal control and three sampling events after the treatment (Table 3.1). In the Aorangi Ranges, two extra seasons (November 2012 and February 2013) were sampled prior to 1080 treatment to improve baseline information on weta (see Chapter 5) (Table 3.1).

TABLE 3.1 Sampling periods for each forest relative to 1080 treatment in the Aorangi. Dashed line denotes 1080 application at the Aorangi.

\begin{tabular}{lllll|lll}
\hline Region & Nov-12 & Feb-13- & Nov13 & Feb 14 & Nov 14 & Feb 15 & Nov 15 \\
\hline Aorangi & Pre-treatment & Pre-treatment & Pre-treatment & Pre-treatment & Post-treatment & Post-treatment & Post-treatment \\
Remutaka & NA & NA & Non-treatment & Non-treatment & Non-treatment & Non-treatment & Non-treatment \\
\hline
\end{tabular}

The sampling was conducted once during the austral late spring (November) and once during summer (February) to account for seasonality. Fifteen $450 \mathrm{~m}$ faunal monitoring lines were placed across five sites in Aorangi Forest, and six lines across two sites in Remutaka Forest, set up by November 2012/13 (Figure 3.1). At each site, monitoring lines were set up at a distance of $250-500 \mathrm{~m}$ from the forest edge and an approximately $500 \mathrm{~m}$ gap was maintained between the start point and end point of consecutive monitoring lines (Figure 3.2). In most cases, monitoring lines followed an altitudinal gradient within sites (see Appendix Figure 8.3). 


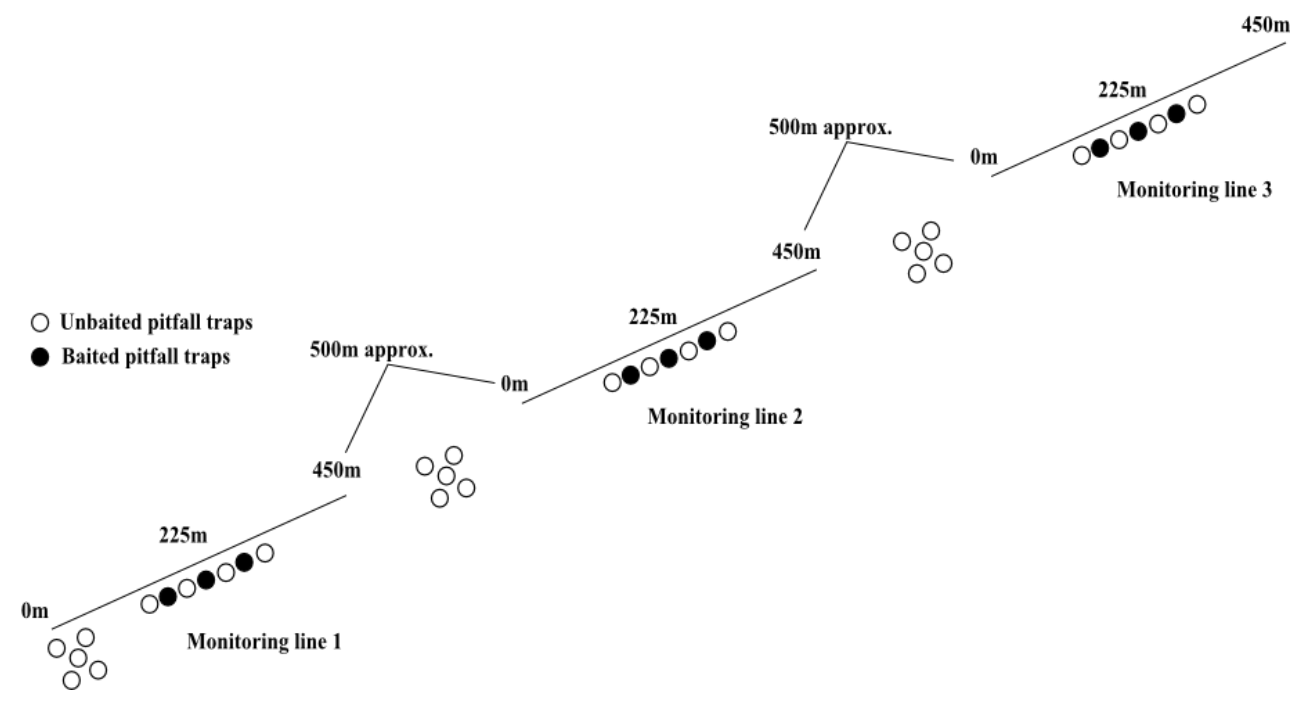

FIGURE 3.2 Diagram of monitoring lines set up for catching ground-dwelling invertebrates in the Aorangi and Remutaka. Open dots represent un-baited lethal pitfall traps, while black dots denote squid-baited lethal pitfall traps. Five un-baited pitfall traps were placed in a square design at $0 \mathrm{~m}$, at $500 \mathrm{~m}$ in between the first line and the second line, and at $500 \mathrm{~m}$ between the second and third lines. Three baited plus four un-baited traps were set up in a line half way along each monitoring line.

Composition, richness and abundance of surface-active invertebrates were assessed using arrays of baited and un-baited lethal pitfall traps. Invertebrates were caught using a transect of seven lethal pitfall traps placed halfway along each monitoring line and a square of five pitfall traps at the beginning $(0 \mathrm{~m})$, in between the first and second lines (at approx. $500 \mathrm{~m}$ ) and at the end of the second line $(500 \mathrm{~m})$ (Table 3.2, Figure 3.2). This was repeated when a third monitoring line was set up (i.e. five pitfall traps were placed in between line 2 and 3 ). Pitfall traps consisted of cylindrical polyethylene containers (110 $\mathrm{mm}$ mouth diameter), quarter-filled with salt solution $(\mathrm{NaCl})$ and a few drops of detergent. These were sunk into the ground so that the lip of the trap was flush with the ground-level. Pitfall traps were covered with a plastic lid (170x170 mm) raised $20 \mathrm{~mm}$ above ground-level to keep out the rain. In the middle of each transect, 3 out of 7 pitfall traps were baited with decomposing squid (1-2.5 days old) to attract carrion beetles (Seldon and Beggs 2010) and to compare its 
relative efficiency in catching other invertebrate species with un-baited traps (see Chapter 5, Figure 3.2).

TABLE 3.2 Total number of sets of five pitfall traps and sets of seven pitfall traps $\left(n^{\circ} / n^{\circ}\right)$ per site and season across the Aorangi and Remutaka. *extra sampling of weta species in Aorangi Forest.

\begin{tabular}{lllllllll}
\hline Site & Region & Nov-12* & Feb-13* & Nov-13 & Feb-14 & Nov-14 & Feb-15 & Nov-15 \\
\hline Bull Hill (BUL) & Aorangi & $0 / 3$ & $2 / 3$ & - & $3 / 3$ & $3 / 3$ & $3 / 3$ & $3 / 3$ \\
Mangatoetoe (MAN) & Aorangi & - & $3 / 2$ & $3 / 2$ & $3 / 2$ & $3 / 2$ & $3 / 2$ & $3 / 3$ \\
Waihora (WAI) & Aorangi & $0 / 1$ & $2 / 2$ & $2 / 2$ & $2 / 2$ & $2 / 2$ & $2 / 2$ & $2 / 3$ \\
Pinnacles (PIN) & Aorangi & - & - & $0 / 3$ & $0 / 3$ & $0 / 3$ & $0 / 3$ & $0 / 3$ \\
Whawanui (WHA) & Aorangi & $0 / 1$ & $0 / 3$ & $0 / 3$ & $0 / 3$ & $0 / 3$ & $0 / 3$ & $0 / 3$ \\
Orongorongo (ORO) & Remutaka & - & - & $3 / 2$ & $3 / 3$ & $3 / 3$ & $3 / 3$ & $3 / 3$ \\
Wairongomai (WRM) & Remutaka & - & - & $0 / 3$ & $0 / 3$ & $0 / 3$ & $0 / 3$ & $0 / 3$ \\
\hline & Total & $\mathbf{0 / 5}$ & $\mathbf{7 / 1 0}$ & $\mathbf{8 / 1 5}$ & $\mathbf{1 1 / 1 9}$ & $\mathbf{1 1 / 1 9}$ & $\mathbf{1 1 / 1 9}$ & $\mathbf{1 1 / 2 1}$ \\
\hline
\end{tabular}

In November, traps were set and left active for one night (22-24 hours) before the contents were collected. In February, traps were left active for three nights (70-72 hours). The total number of invertebrates collected per trap in February was divided by three to obtain numbers caught per trap night (TN). This study was carried out from November 2013 to November 2015 for all invertebrates, except for weta species, which were sampled from November 2012 to November 2015.

\subsubsection{Taxonomic composition and diversity}

All invertebrates caught were transferred into $70 \%$ ethanol, and subsequently processed and identified in the laboratory, following the taxonomic keys of Sutherland (2006), Klimaszewski and Watt (1997), Johns (2001), Gwynne (2005) and Larochelle and Larivière (2007), among others. Carabidae (Coleoptera) and weta species (Orthoptera) were identified to species and/or morphospecies levels. Other beetles were classified to family level if possible and other invertebrates to order or class level. Insect larvae as well as nymphs 
(when evident) were excluded from the analysis, except for weta juveniles, because their identification requires high degree of taxonomic expertise.

In this chapter, Mecodema sp1, Mecodema sp2, Megadromus sp2, Pentagonica vittipennis Chaudoir, 1877, Psegmatopterus sp1, Carabidae sp13, sp17 and sp9 (Coleoptera), Tenebrionidae (Coleoptera), Lucanidae (Coleoptera), Blattodea and Pseudoscorpiones were not analysed individually but as part as a guild due to their low abundance. Also, Chrysomelidae (Coleoptera), Elateridae (Coleoptera), Diptera and Hemiptera were excluded from all statistical analysis due to them not being primarily ground-dwelling. Within the Scarabaeidae (Coleoptera), epigeous dung beetles were separated from foliage non-dung beetles ( $\mathrm{n}=5$ individuals) and only dung beetles were analysed in this chapter.

\subsubsection{Functional traits}

Functional traits such as guild, body size, brightness and colouration, were measured in an attempt to describe and quantify changes at the community level (Table 3.3)

TABLE 3.3 Categorisation of functional traits for ground-dwelling invertebrate taxa.

\begin{tabular}{llll}
\hline Trait group & Trait & Taxa & Categories \\
\hline Trophic level & Guilds & All ground-dwelling invertebrates & Predators, herbivores, omnivores, detritivores \\
Morphology & Body length & Araneae, Coleoptera, Orthoptera & Continuous \\
Colouration & Body colouration & Morphospecies of Carabidae & $0=$ disruptive, 1=non-disruptive \\
& Body brightness & Morphospecies of Carabidae & $0=$ matte, 1=shiny \\
& Legs colouration & Morphospecies of Carabidae & $0=$ black, 1=red-brownish \\
\hline
\end{tabular}

\section{a) Trophic guilds:}

Identified specimens were classified as part of specific trophic guilds, such as detritivores, omnivores, herbivores and predators (see methods in Chapter 2), to account for differences in trophic interactions of ground-dwelling invertebrate communities before and after 1080 mammal control. Guild information was available and specified for 32 out of 36 taxa of 
ground-dwelling invertebrates and this subset formed the basis of the trophic guilds analysis.

\section{b) Morphology (body size):}

Body size was measured to the nearest $0.5 \mathrm{~mm}$ as the body length from the top of the head to the bottom of the abdomen, excluding appendages (such as antennae, mandibles and ovipositors) of adult Araneae (spiders) and Coleoptera (beetles), and juvenile and adult Orthoptera (cave and ground weta). The body size of spiders was also measured as the cephalothorax and abdomen lengths to discard variations in abdomen length due to availability of water and food (Gunnarsson and Hake 1999); although only the total and cephalothorax lengths were analysed statistically. To examine differences in body size distributions of each sex of ground weta before and after 1080, individuals were additionally classified as female, male or juvenile based on the presence of the secondary copulatory organ (Gwynne 2002, 2005) and the body length (>18mm being the threshold for adults).

\section{c) Colouration of ground-beetle assemblage:}

Body and leg colouration, and body brightness were assessed for 14 morphospecies of ground beetles (Carabidae) to estimate the visual appearance of the ground-beetle assemblage. In a simple approach, each trait was scored 0 or 1 depending on their quality to attract visual predators following patterns described for spiders (Godin and McDonough 2003, Cuthill et al. 2005, Fan et al. 2009). Individuals with disruptive colouration on their bodies (black and brownish patterns), black legs and matte bodies were scored 0 (assumed low visual appearance) while individuals with non-disruptive colouration (black, darkbrown or green-black bodies) and shiny bodies, and red-brownish legs were scored 1 (assumed high visual appearance) (Figure 3.3, Table 3.3). 


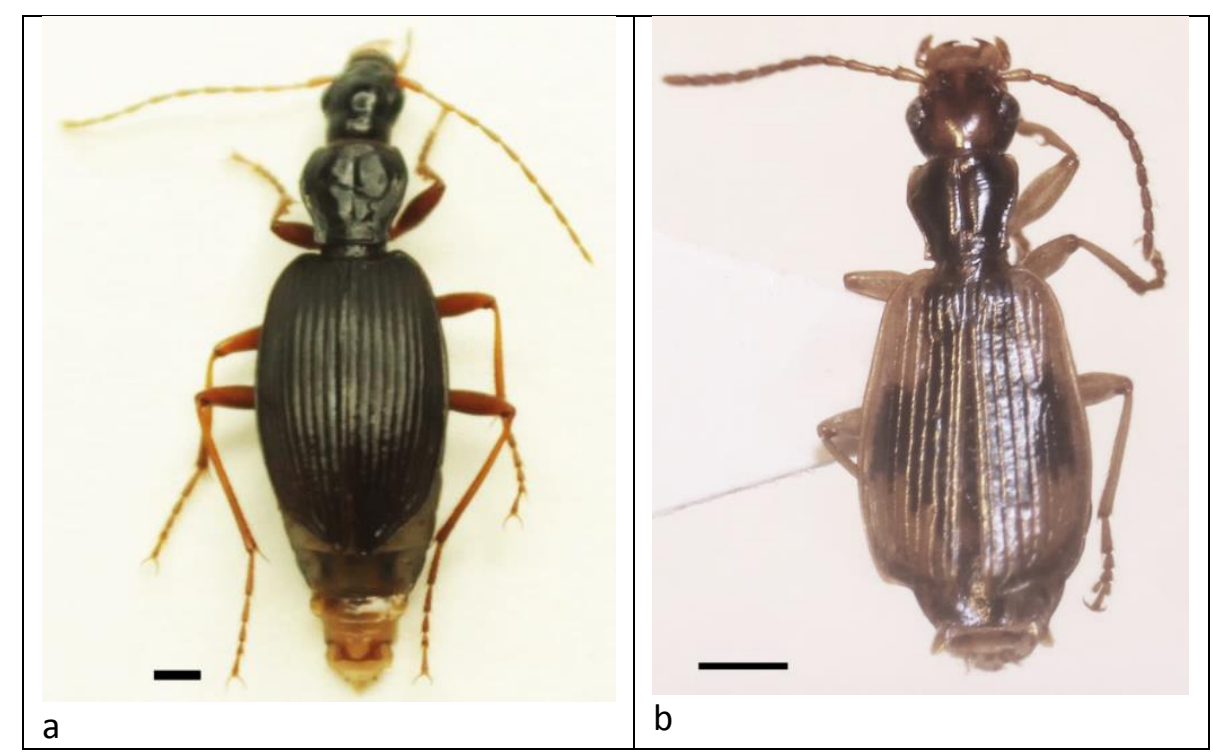

Figure 3.3 Examples of ground beetles (Carabidae) used for the mean trait value (mT) analysis. a) Ctenognathus sp1 (non-disruptive colouration) and b) Pentagonica vittipennis (disruptive colouration). Scale bar $=1 \mathrm{~mm}$.

\subsubsection{Statistical analysis}

Abundance of more common ground-dwelling invertebrates before and after the 1080 treatment within Aorangi Forest were compared with abundances in the low-treated control sites within the Remutaka over the same time periods. All analyses were performed using R program (Version 0.99.902, (C) 2009-2016 RStudio, Inc.). Richness (R) and evenness using Shannon-Wiener Index $\left(\mathrm{H}^{\prime}\right)$ of invertebrates at order level were calculated to obtain diversity indices.

Multivariate ordinations, Principal Coordinate Analysis (PCoA), were performed using Bray-Curtis distance of the square-root transformed abundance of taxa and taxonomic guilds, and the mean trait value (mT) of functional traits among sites and across seasons (from November 2013 to November 2015). Biplots were used to indicate the invertebrate guild and functional traits contributing most strongly to the separation of sites in each season. Analysis of variance (ANOVA) were performed using distance matrices and permutation tests (Adonis from the Vegan package, adapted by J. Oksanen) for partitioning 
distance matrices among sites and fitting linear models (Time*Forest interaction; Site= random effect) to distance matrices.

Functional traits are defined as indicators of biotic communities and were used in the current chapter to calculate the mean trait value $(\mathrm{mT})$ of ground-beetle assemblages and compare their diversity before and after 1080 in both forests. The mT was calculated following Garnier et al. (2004) as:

$$
m T=\sum_{i=1}^{s} p_{i} x_{i}
$$

where $x_{i}$ is the trait value of the $i$-th species (for binary traits $x_{i}$ can be either zero or one) and $p_{i}$ is the relative abundance of the $i$-th species (Moretti and Legg 2009, Vandewalle et al. 2010). Higher mT represents a greater proportion of individuals that were scored 1 for binary traits and assumes higher risk of predation by visual predators. For example, greater proportions of individuals with non-disruptive colouration, shiny-bodies and red-brownishlegs.

Linear mixed-effect models (lmer) tested by Analysis of Deviance with Type III sums of squares in package lme4 (Bates et al. 2015) were used to determine the statistical significance of differences in invertebrate communities before and after 1080 mammal control in Aorangi and Remutaka Forests. Separate analyses were undertaken for the mean number of ground-dwelling invertebrates; body sizes of Carabidae, weta and Araneae; trophic guild abundance; Shannon diversity at order level; richness at order level; and mean functional trait values (mT) of ground beetle assemblage as dependant variables. Abundance values per trap night $(\mathrm{TN})$ were square-root transformed to improve the normality of residuals. Time (before versus after 1080), Forest (impacted=Aorangi and low-treated control=Remutaka) and their interaction (Time $\mathrm{x}$ Forest) were set as fixed factors. Squid 
(baited versus un-baited pitfall traps) and season of sampling (February versus November) were considered as covariates, while sites and the set of pitfall traps within sites were counted as nested random effects. An example model formula is as follows:

lmer $(\operatorname{sqrt}($ abundance $) \sim$ Time $\times$ Forest + Squid + Season $+(1 \mid$ Sites $/$ Set $))$

p-values were adjusted using sequential Holm-Bonferroni correction (Holm 1979, Rice 1989) to reduce the probability of obtaining a statistically significant result (Type I error) when performing multiple tests for each response variable.

\subsection{Results}

\subsubsection{Ground-dwelling invertebrates}

a) Composition: Collembola $(n=7,768)$, Insecta $(n=3,703)$ and Arachnida $(n=2,903)$ were the most abundant classes of the 20,766 ground-dwelling invertebrates collected (Figure 3.4, Appendix Table 8.2). Scarabaeidae (Coleoptera) $(n=1,143$, excluding 5 canopy individuals), Anostostomatidae (Orthoptera) $(\mathrm{n}=590)$ and Carabidae (Coleoptera) $(\mathrm{n}=493)$ were the most abundant ground-dwelling taxonomic families within the insect group. We recorded >14 morphospecies of ground beetles (Carabidae). A large number of these beetles were Ctenognathus sp1 and sp2 ( $\mathrm{n}=134$ and $\mathrm{n}=189$, respectively) (see Appendix Table 8.2). 


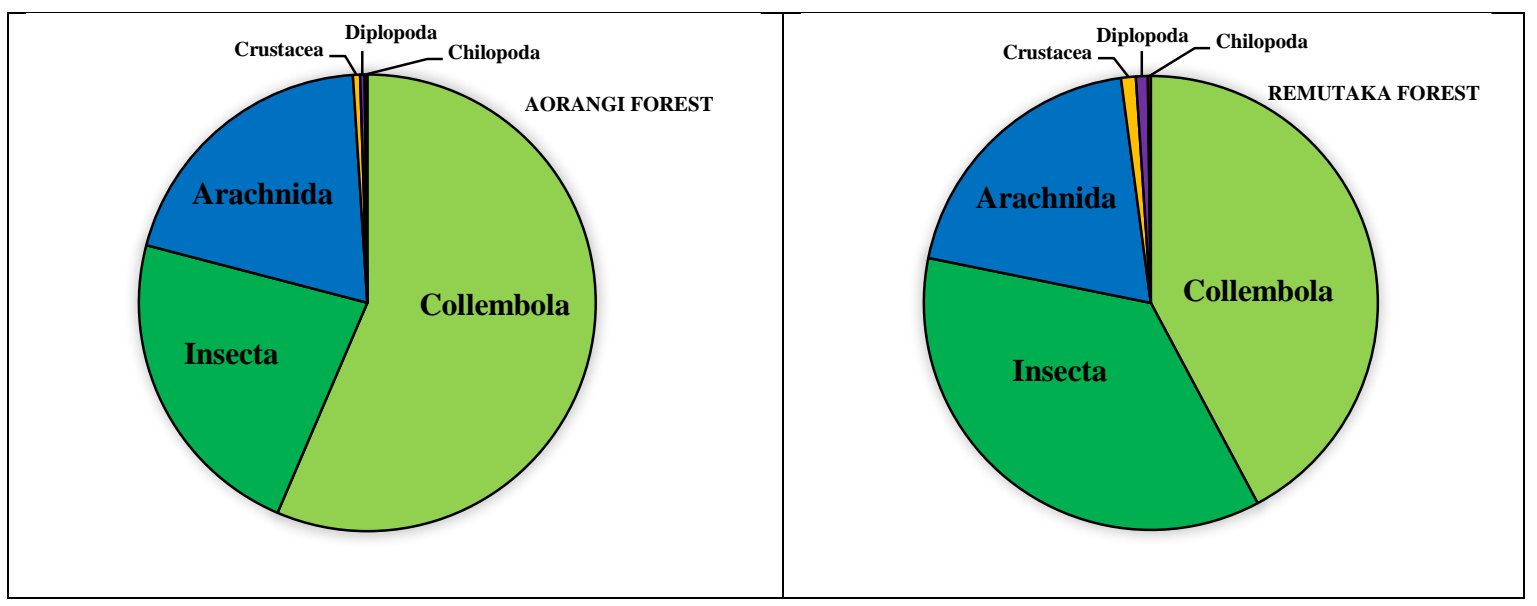

FIGURE 3.4 Total abundance of classes of ground-dwelling invertebrates in Aorangi and Remutaka Forests.

b) Abundance: None of the 25 taxonomic groups of invertebrates tested exhibited any significant effect for the interaction between Time (before and after 1080) and Forest (the Aorangi and Remutaka Forests) (Table 3.4). However, Collembola (springtails) and Acari (mites) exhibited different abundances before and after 1080 in both sites. Collembola (springtails) showed a 17 -fold increase after the 1080 operations in both sites $(p<0.05)$ (Figure 3.5). The abundance of Collembola peaked in the Remutaka in Feb-2015 (mean=18.29 per TN/site) and Aorangi in Nov-2015 (mean=18.45 per TN/site).

In addition, Acari (mites) increased four-fold over time ( $n=255$ before and $n=1,201$ after $1080 ; p<0.001)$ with slightly higher abundance in Aorangi Forest compared to the Remutaka along all seasons, except in November 2015. During this month, the difference between the mean abundance of mites per site increased when comparing both forests (mean $=3.73$ per $\mathrm{TN} /$ site in the Aorangi and mean=0.85 per TN/site in the Remutaka) (Figure 3.5). This taxon also exhibited a seasonal trend in their abundance: greater numbers of mites were caught in November compared to February $(p<0.001)$. Variations in the abundance of other groups of ground-dwelling invertebrates regarding any factors (Time or Forest) were not significant. 
Coleoptera and Araneae: We did not find significant differences in Coleoptera and Araneae abundance before and after 1080 operations except for Acari as previously explained (Figure 3.5). Most of differences were reported between sites (as error bars were large) and sampling dates. For example, dung beetles (Scarabaeidae) showed a shift in the mean abundance per TN/site before and after 1080 in both forests. This taxon decreased in the Aorangi from an average of 2.3 individuals per TN/site in Feb-14 (before 1080) to 0.9 individuals in Feb-15 (after 1080) while the opposite happened in the Remutaka, where the abundance increased from a mean of 0.6 to 4.7 individuals.

Orthoptera (weta): The mean number of ground and cave weta did not differ due to Time (before and after 1080) nor Forest (Table 3.4). However, ground weta (Hemiandrus spp.) abundance per site tended to follow a seasonal pattern in both forests $(p<0.0001)$ with greater numbers in February, except for the Feb-14 sampling when the number of individuals decreased to almost zero (mean=0.02 per TN/site) in the Remutaka (Figure 3.5). 

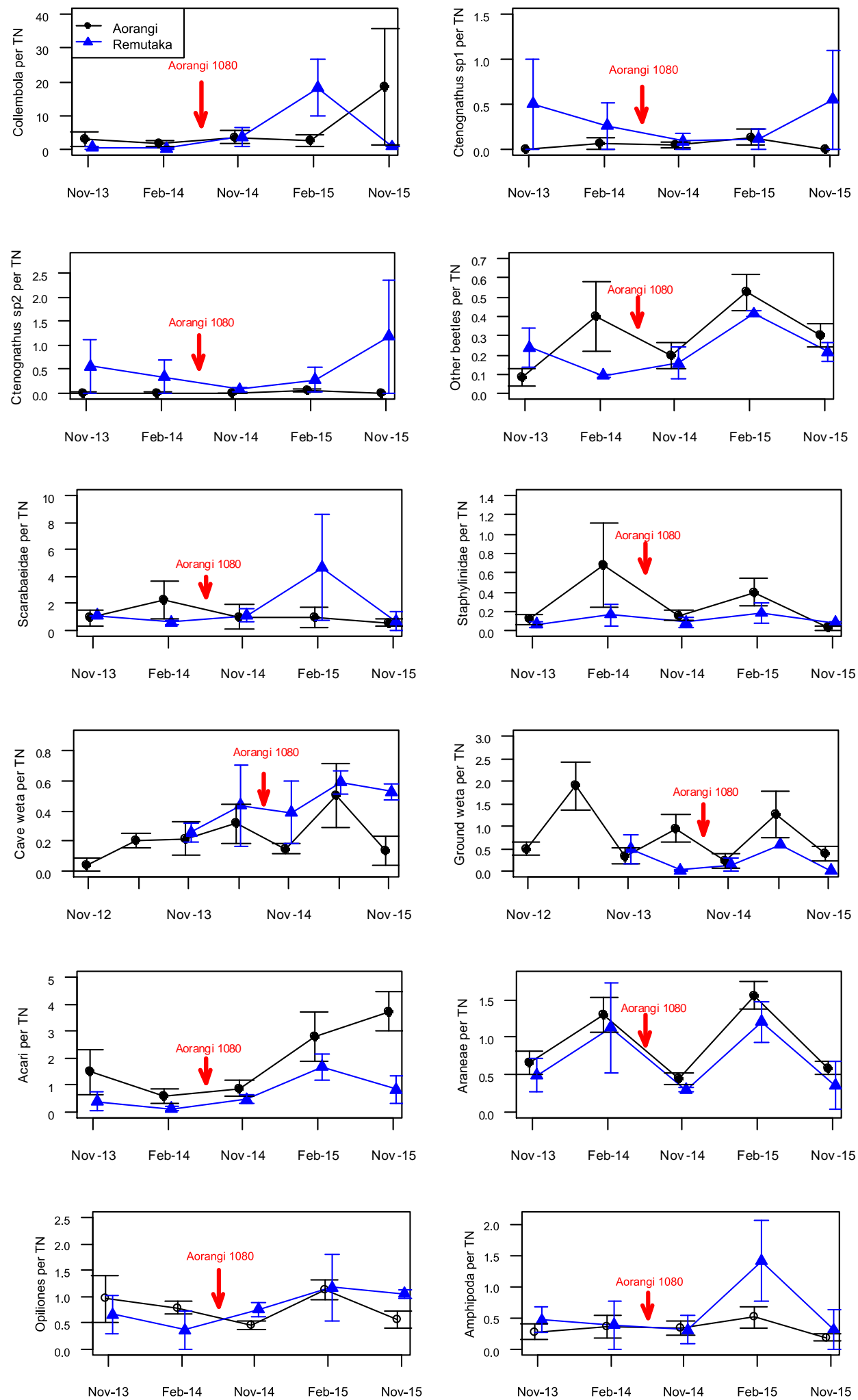

FIGURE 3.5 Mean number $( \pm \mathrm{SE})$ of the twelve most abundant ground-dwelling invertebrate taxa collected across the Aorangi and Remutaka monitoring sites. Symbols show the mean number per TN (pitfall Trap-Night) for five sites in the Aorangi (black circles) and two sites in the Remutaka (blue triangles). Arrow denotes the date of 1080 application in the Aorangi. 


\subsubsection{Diversity indexes and 1080 aerial operation}

There were no significant differences in the mean of order-level richness and Shannon diversity due to the application of 1080 in the Aorangi (see column for the non-significant interaction terms in Table 3.4, Figure 3.6).
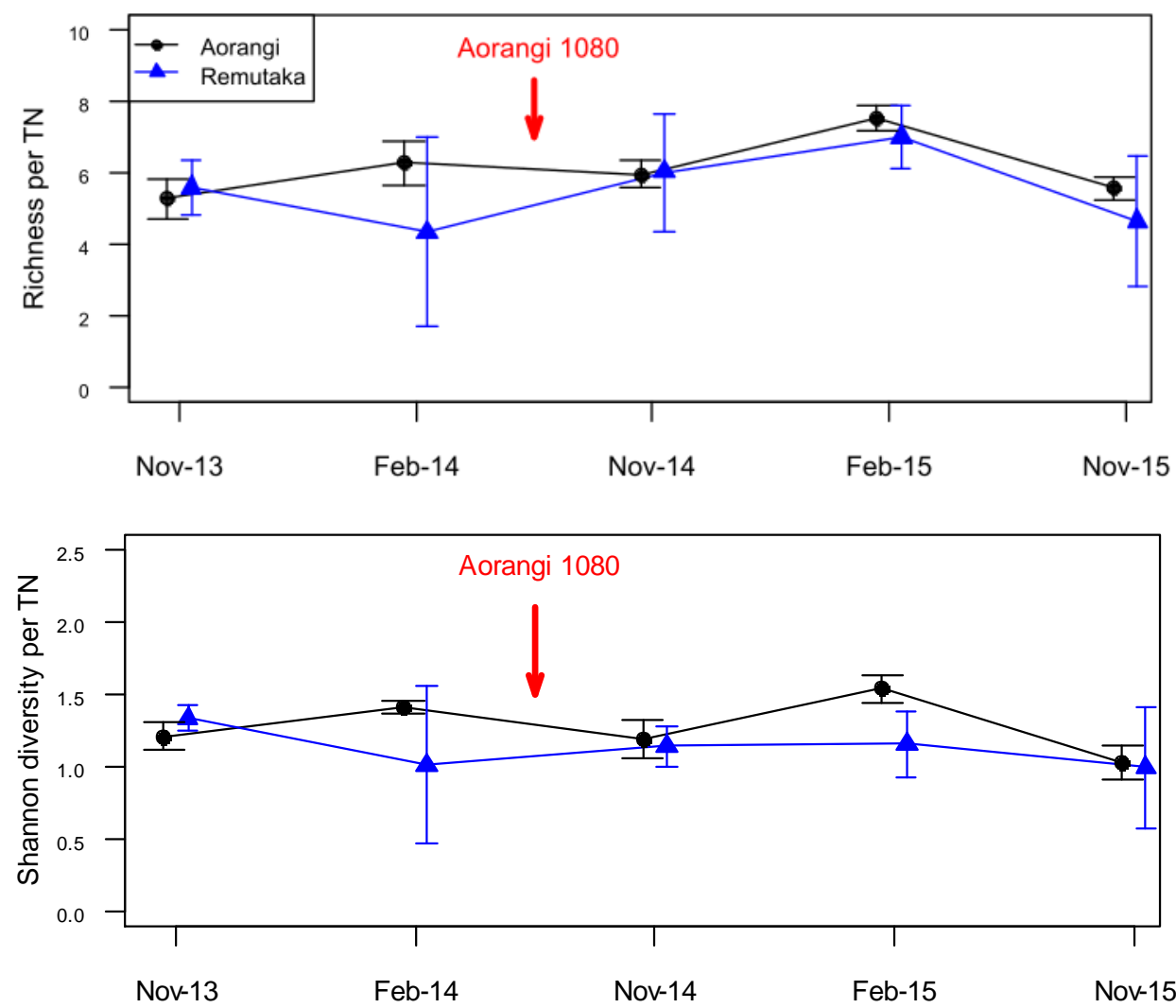

FIGURE 3.6 Mean number $( \pm \mathrm{SE})$ of richness and order-level diversity (Shannon) of grounddwelling invertebrates recorded across Aorangi and Remutaka monitoring sites. Symbols show the mean number of diversity for five sites in the Aorangi (black circles) and two sites in the Remutaka (blue triangles). Arrow denotes the date for 1080 application at the Aorangi.

\subsubsection{Functional traits and 1080 aerial operation}

\section{a) Trophic guilds}

Seven ground-dwelling taxa were classified as detritivores, five as predators, four as omnivores and one taxon as herbivores in Aorangi and Remutaka Forests (Appendix Table 8.2). The most abundant trophic guilds from Nov-13 to Nov-15 were detritivores. Sites were not clearly separated according to the similarity of guild abundance along time or between 
forests (Adonis $p>0.05$ ) (Figure 3.7). After excluding Collembola from the analysis no clear differences were found, neither due to Time, Forest or the interaction of both (Adonis $p>$ $0.05)$.

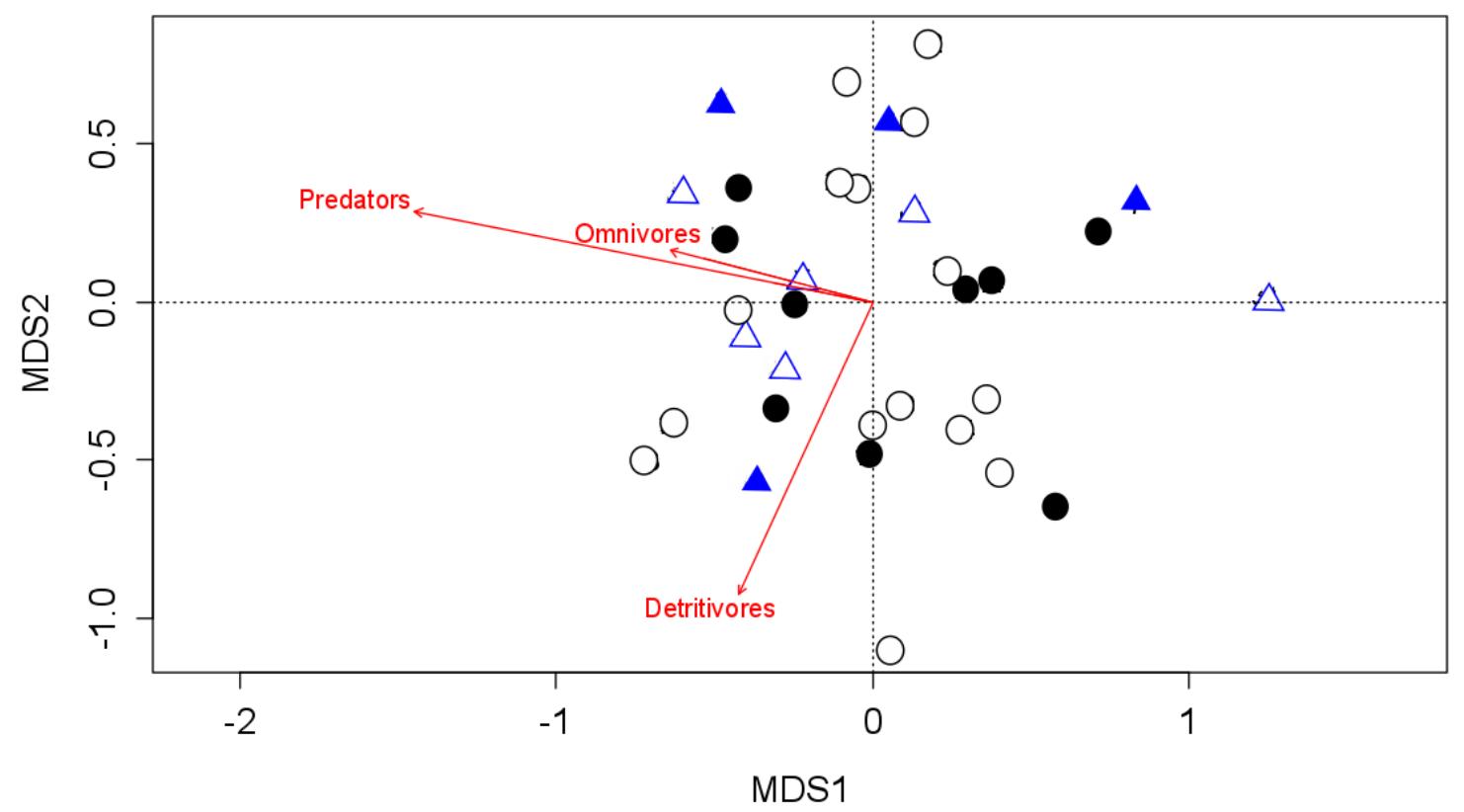

Figure 3.7 Principal Coordinate Analysis (PCoA) for the Bray-Curtis dissimilarities of the invertebrate square-root abundance classified as trophic guilds among sites in the Aorangi (black circles) and Remutaka (blue triangles). Filled symbols denote before 1080 while open symbols after 1080 control.

Only detritivores showed significant differences in abundance during the second-half of our sampling (i.e. after the 1080 application in the Aorangi) $(p<0.001)$ (Figure 3.8) with numbers peaking in the Remutaka in Feb-2015 (mean=24.6 per TN/site) and in Aorangi Forest in Nov-2015 (mean=24.0 per TN/site). Only two taxa (Hemiptera and Curculionidae) were classified as herbivores in our sampling. Bugs (Hemiptera) were not included in the analysis due to their canopy preference, therefore the herbivore guild was not statistically analysed as it is the same as the analysis of the taxonomic group Curculionidae (weevils). 

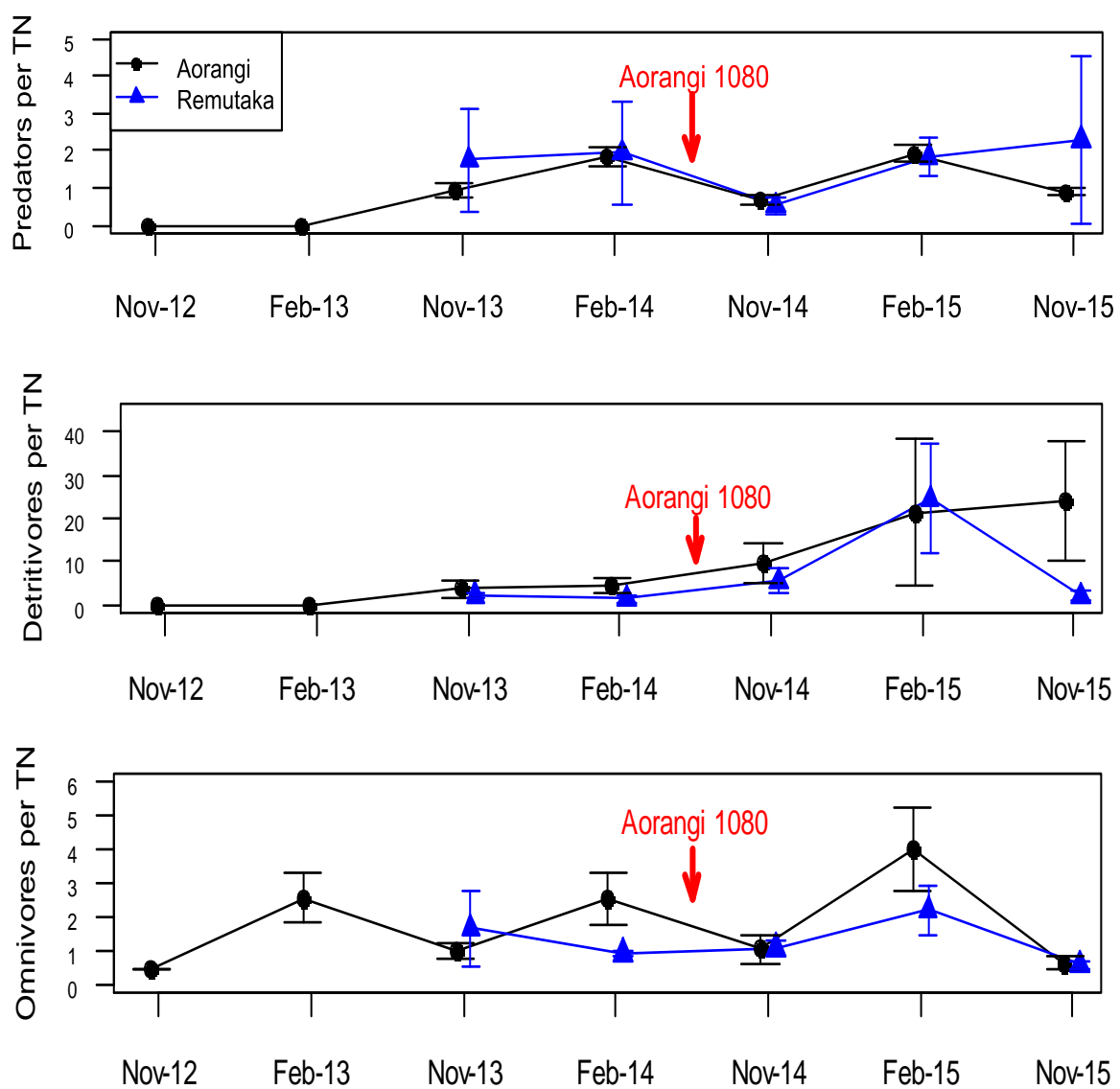

Figure 3.8 Mean number $( \pm \mathrm{SE})$ of ground-dwelling invertebrates classified as predators, detritivores and omnivores recorded across the Aorangi and Remutaka monitoring sites. Symbols show the mean number of each guild across five sites in the Aorangi (black circles) and two sites in the Remutaka (blue triangles). Arrow denotes the application of 1080 at Aorangi Forest.

\section{b) Morphology (Body size)}

Body sizes of Carabidae, Araneae and Orthoptera were not affected by 1080 application in the Aorangi (Table 3.4). However, some taxa showed interesting patterns across seasons, which are described in the following text:

Coleoptera: Scarabaeidae showed larger body sizes in both forests $(p<0.05)$ after 1080 mammal control (Figure 3.9). Significantly larger dung beetles were found in Remutaka Forest in Nov-2014 (Remutaka: mean=5.27 mm vs Aorangi: mean=2.86 mm per site) and 
in the Aorangi in Feb-2015 (Aorangi: mean=5.271 mm vs Remutaka: mean $4.78 \mathrm{~mm}$ per site).
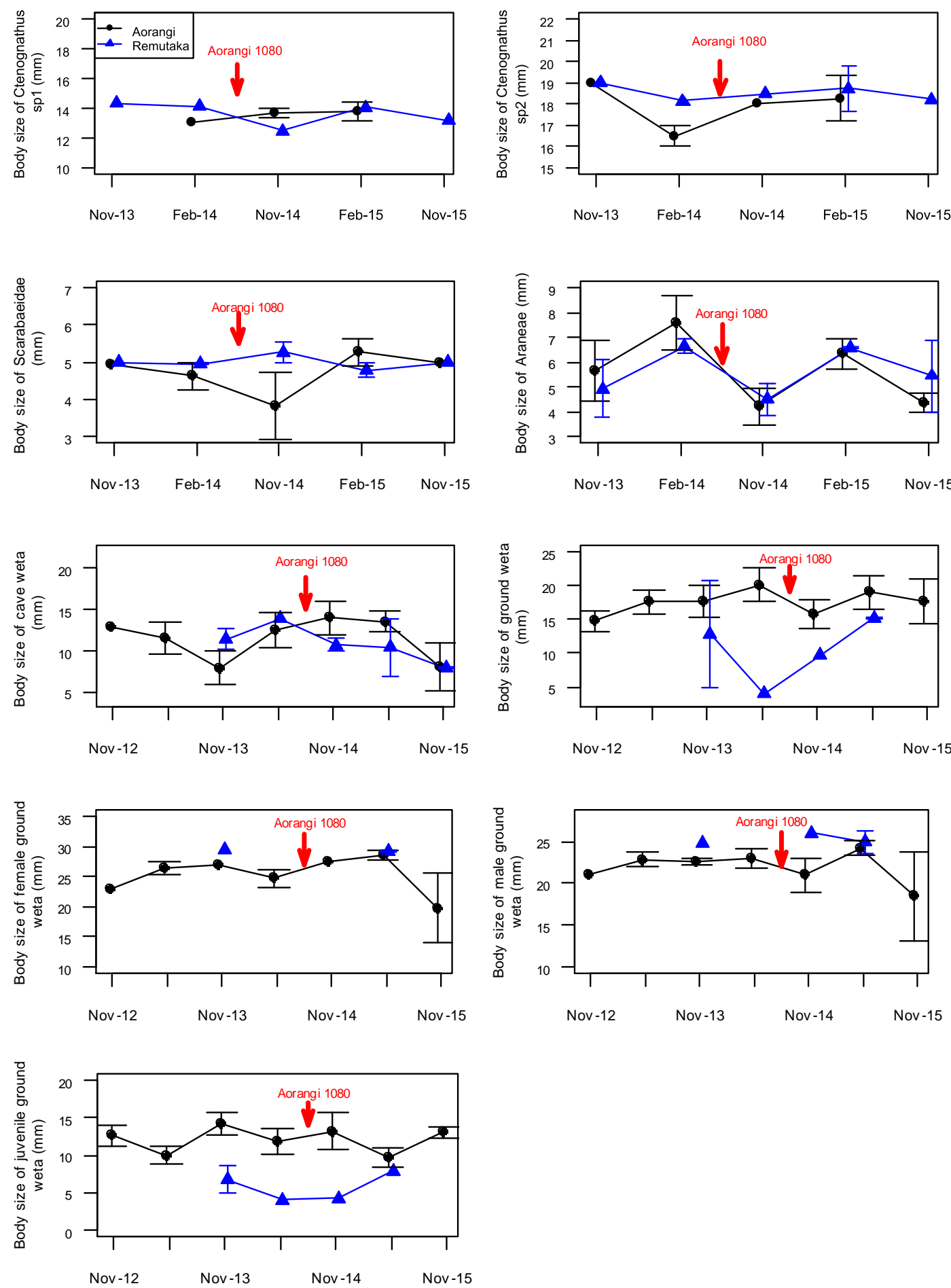

FIGURE 3.9 Mean body sizes (mm) ( \pm SE) of Ctenognathus sp1, Ctenognathus sp2, Scarabaeidae (dung beetles), Araneae (total length), cave weta and ground weta (females, males and juveniles). Symbols show the mean number of each guild across five sites in the Aorangi (black circles) and 
two sites in the Remutaka (blue triangles). Arrow denotes the application of 1080 at Aorangi Forest.

Araneae: No significant differences were found for the total body size and cephalothorax length of spiders due to Time and Forest or their interaction (Figure 3.10). However, there was a seasonality in the body size distribution of spiders. Spiders caught in February were significantly larger (as total length, $p<0.001$ ) than the ones caught in November in both forests across all years (Figure 3.9).
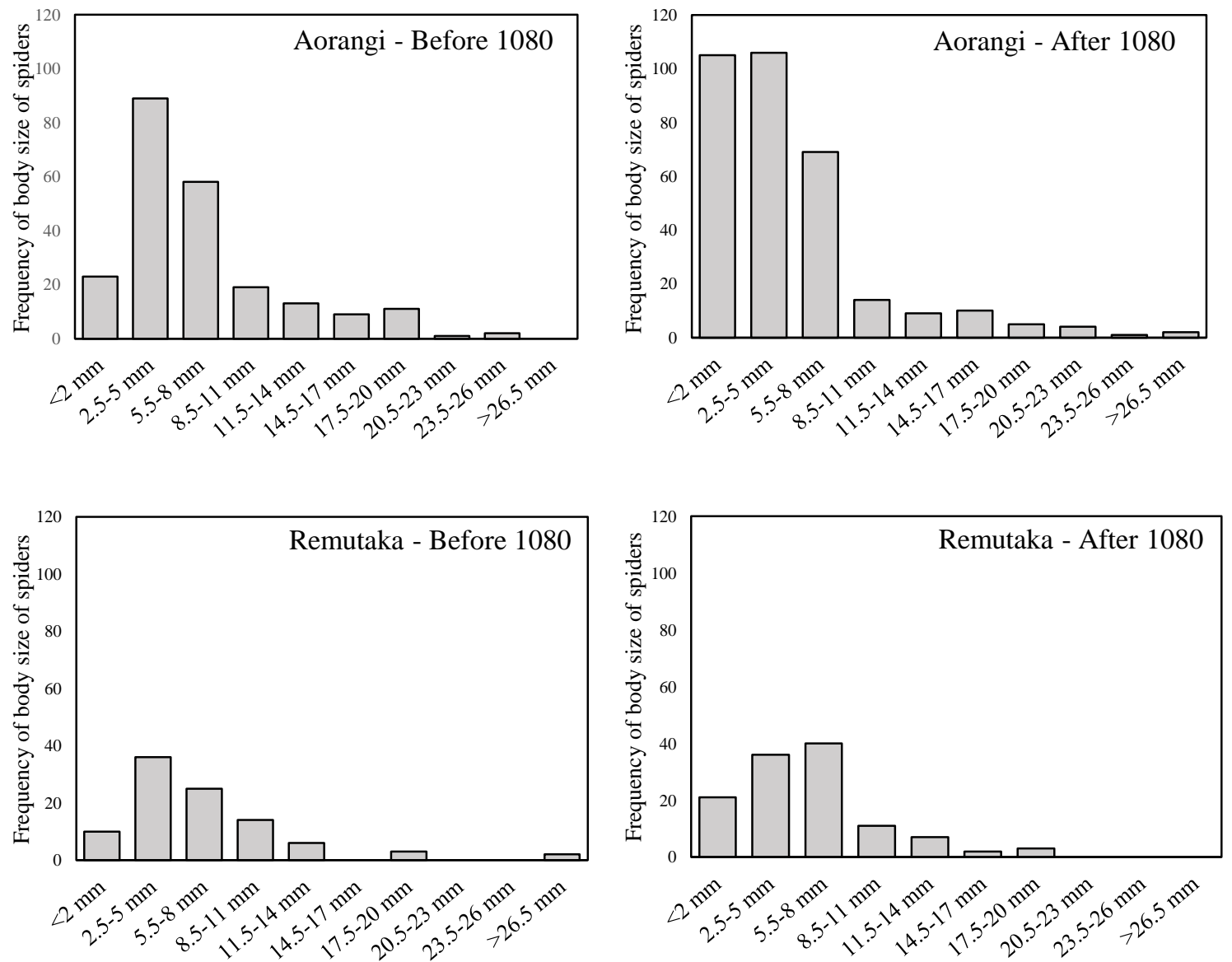

Figure 3.10 Frequency of the body size of Araneae (spiders) recorded in Aorangi and Remutaka monitoring sites before and after 1080. Body sizes were recorded in millimetres (mm) with precision to $0.5 \mathrm{~mm}$. 
Orthoptera: the body length of juvenile and adult cave weta were measured before and after 1080 in both forests and no significant interactions or differences were found. The body size distribution of cave weta showed two peaks over time with a peak of larger individuals collected in Nov-12 and Nov-14 in the Aorangi Forest (Figure 3.9). Female ground weta were significantly larger in both forests in samples taken after the 1080 drop $(p<0.05)$; although there were no significant differences in ground weta body sizes due to the application of 1080 in Aorangi Forest (interaction of Time and Forest). Female ground weta also varied in size between sampling seasons $(p<0.05)$; bigger females were observed in February compared to November (Figure 3.9).

\section{c) Colouration of ground-beetle (Carabidae) assemblage:}

Two out of 14 morphospecies were classified as matte-bodied ground beetles, one morphospecies with disruptive colouration on their bodies, and seven as black-legged specimens (all scored 0). There was no clear grouping on the dominance of traits (mT) of ground beetle assemblages for body colouration, body brightness and leg colouration among Forest and Time (Adonis, Time: $\mathrm{F}=-0.636 ; \mathrm{df}=1,27 ; p=0.90$ and Forest: $\mathrm{F}=0.053 ; \mathrm{df}=1,27$; $p=0.662$ ) (Figure 3.11). However, ground beetles with matte and disruptive colouration on bodies (one species; Pentagonica vittipennis) were mainly represented in the sites WRM (Nov-15), PIN (Nov-13) and PIN (Nov-13); sites represented by the three points on the right of the Figure 3.11. WRM (Nov-14) is mainly represented by matte-bodied ground beetles. Also, there were no significant differences in the brightness and colouration of bodies and legs of ground-beetles per TN (measured as $\mathrm{mT}$ ) due to Time and Forest or their interaction (Table 3.4, Figure 3.12). 


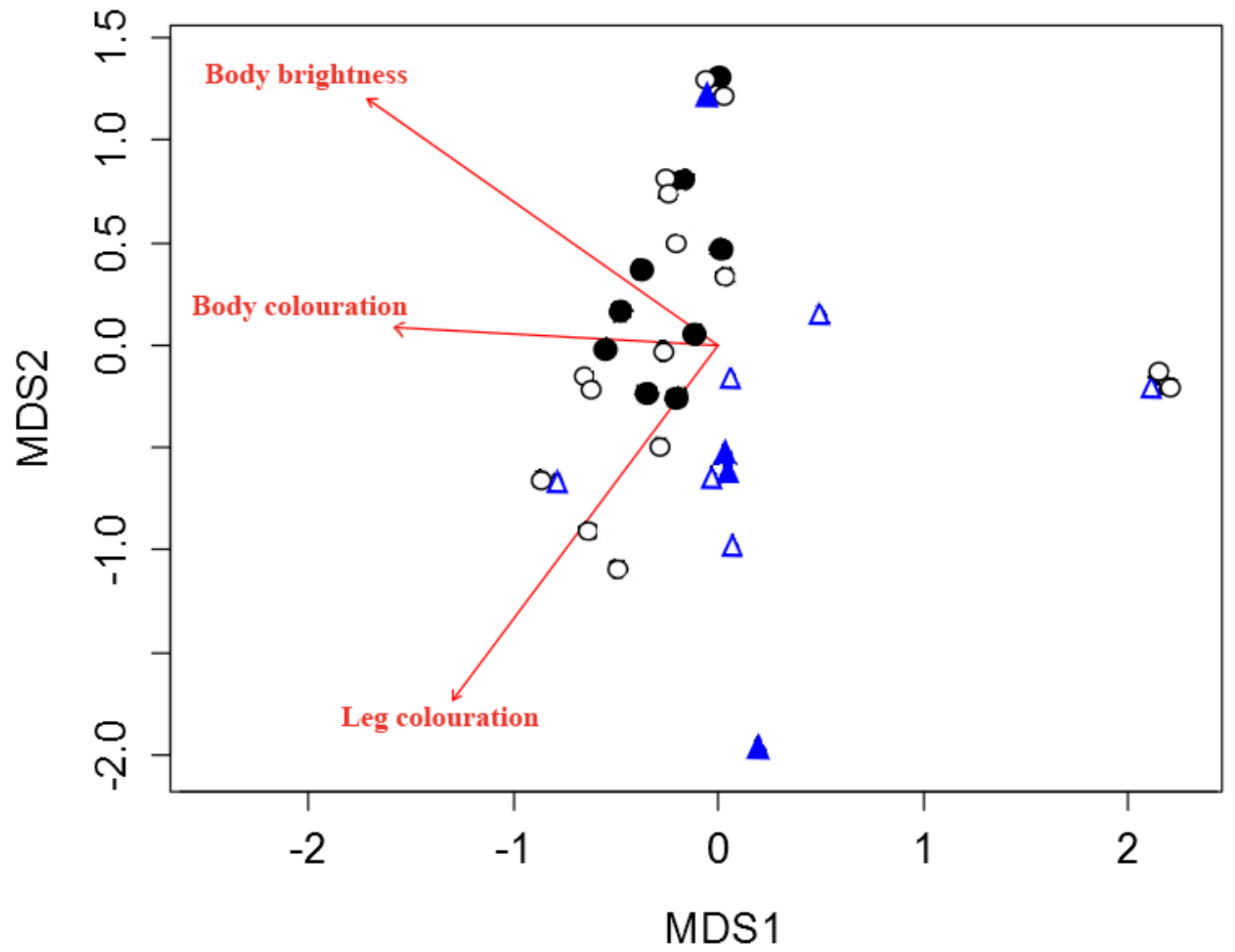

Figure 3.11 Principal Coordinate Analysis of the Euclidean similarity of the mean number of the dominance of traits (mT) of beetle assemblages collected from November 2013 to November 2015 among sites in the Aorangi and the Remutaka. Black circles denote Aorangi sites and blue triangles Remutaka sites while filled symbols denote before 1080 and unfilled symbols after 1080 .

\subsubsection{Co-variates}

Squid (baited versus un-baited traps): Many taxa showed a positive response in abundance to squid baiting. Coleoptera $(p<0.0001)$, Scarabaeidae (dung beetles) $(p<0.0001)$, Staphylinidae $(p<0.001)$, cave weta $(p<0.05)$, ground weta $(p<0.05)$, Hymenoptera $(p<0.01)$, Araneae $(p<0.001)$, and Opiliones $(p<0.001)$ were more attracted to squid-baited pitfall traps than un-baited traps. Predators $(p<0.01)$, omnivores $(p<0.0001)$ and larger ground weta $(p<0.01)$, were also more abundant in squid-baited pitfall traps than un-baited pitfall traps (Table 3.4). These results will be more fully explored in Chapter 5, but it was important to include this effect as a covariate in the present analysis. 

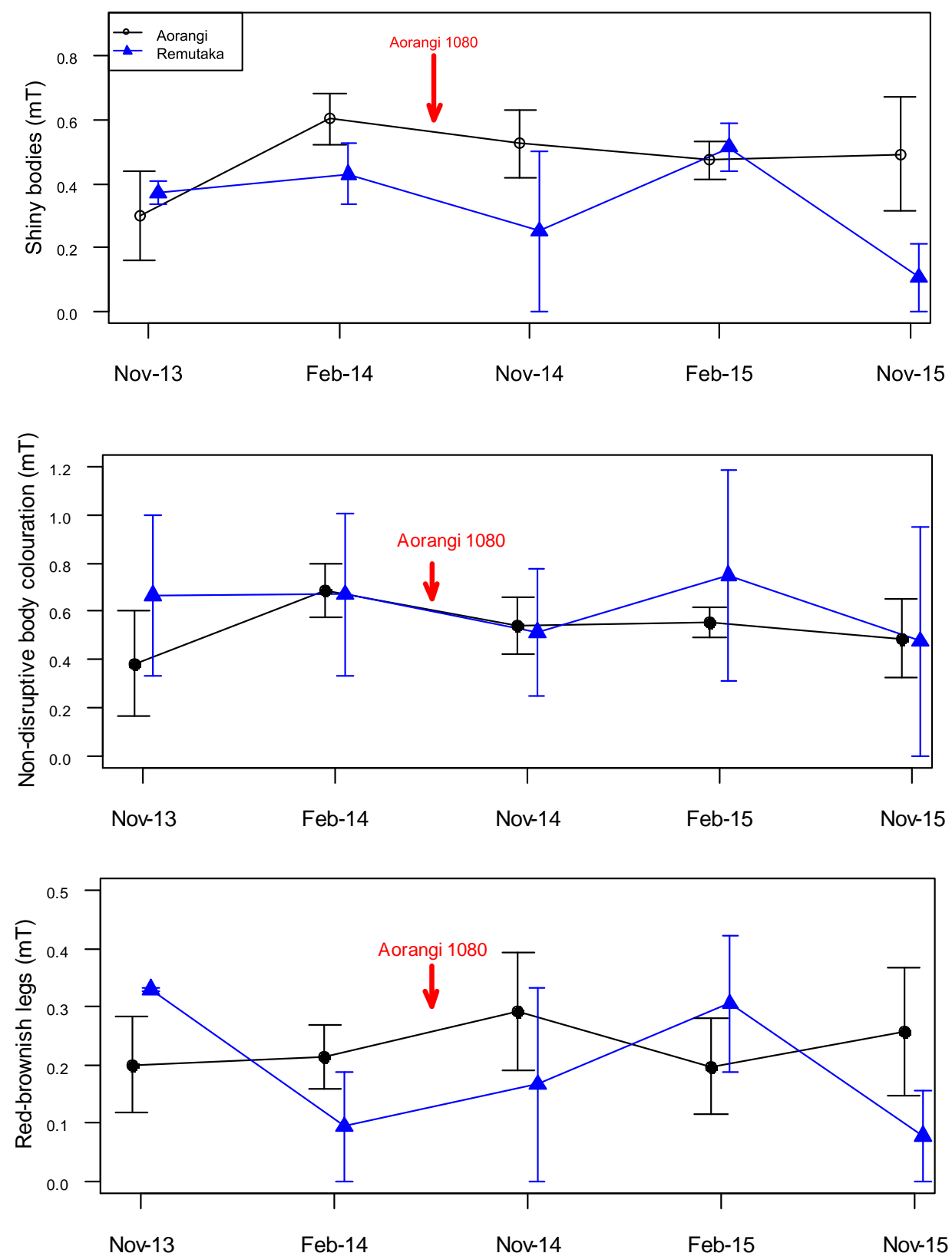

FIGURE 3.12 Mean trait values $( \pm$ SE) of ground beetle assemblages (Carabidae) recorded across Aorangi and Remutaka monitoring sites. Symbols show the mean number of each trait across five sites in Aorangi (black) and two sites in Remutaka (blue) from November 2013 to November 2015. Arrow denotes the application of 1080 at Aorangi Forest. Body brightness $(0=$ matte bodies and $1=$ shiny bodies), body colouration $(0=$ disruptive colouration and $1=$ non-disruptive colouration on bodies) and legs black ( $0=$ black and 1=red-brownish). 
TABLE 3.4 Summary of Analysis of Deviance (Type III, chi-square tests) fitting a LME model for the effects of 1080 mammal control (Time: before and after), the treatment (Forest: treated and low-treated control), interaction, squid baiting, and season of sampling (February vs November) on the mean number of grounddwelling invertebrates, richness and Shannon diversity at order level, guild abundance, body size of invertebrates and functional traits of ground beetle assemblage. Values shown are beta coefficients with significance indicated by asterisks. $+=$ significant difference at $p<0.05$ before Holm-Bonferroni correction, $* p<0.05$ after Holm-Bonferroni correction, $* * p<0.01$ after Holm-Bonferroni correction, $* * * p<0.001$ after Holm-Bonferroni correction, and $* * * * p<0.0001$ after Holm-Bonferroni correction.

\begin{tabular}{|c|c|c|c|c|c|}
\hline Taxon & $\begin{array}{l}\text { Time: } \\
\text { Before vs After } 1080\end{array}$ & $\begin{array}{l}\text { Forest: } \\
\text { Impacted (Aorangi) vs Low-treated Control } \\
\text { (Remutaka) }\end{array}$ & Time $\times$ Forest & $\begin{array}{l}\text { Squid: } \\
\text { Baited vs unbaited }\end{array}$ & $\begin{array}{l}\text { Season: } \\
\text { February vs November }\end{array}$ \\
\hline \multicolumn{6}{|l|}{ ABUNDANCE } \\
\hline COLLEMBOLA & $-1.2012 *$ & NS & NS & NS & NS \\
\hline \multicolumn{6}{|l|}{ INSECTA } \\
\hline Coleoptera (beetles) & NS & NS & NS & $0.6377 * * * *$ & $(0.257)^{+}$ \\
\hline Carabidae (ground beetles) & NS & NS & NS & $(0.118)^{+}$ & $(0.141)^{+}$ \\
\hline Ctenognathus sp1 & NS & NS & NS & NS & NS \\
\hline Ctenognathus sp2 & NS & $(0.349)^{+}$ & NS & NS & $(0.073)^{+}$ \\
\hline Megadromus sp1 & NS & NS & NS & NS & NS \\
\hline Morphospecies sp3 & NS & NS & NS & NS & NS \\
\hline Morphospecies sp16 & NS & NS & NS & NS & NS \\
\hline Curculionidae (weevils) & NS & NS & NS & NS & NS \\
\hline Scarabaeidae $(\text { Saphobius spp. })^{b}$ & NS & NS & NS & $0.6299 * * * *$ & NS \\
\hline Staphylinidae (rove beetles) & NS & NS & NS & $0.1612 * *$ & $(-0.089)^{+}$ \\
\hline Other beetles & $(-0.148)^{+}$ & NS & NS & $(0.114)^{+}$ & NS \\
\hline Epigeous beetles & NS & NS & NS & $0.6332 * * * *$ & $(0.197)^{+}$ \\
\hline Orthoptera (weta) & NS & NS & NS & $0.6509^{* * * *}$ & $-0.5658 * * * *$ \\
\hline Cave weta (multiple spp.) & NS & NS & NS & $0.2169 *$ & $(-0.180)^{+}$ \\
\hline Ground weta (Hemiandrus spp.) & NS & NS & NS & $0.3432 *$ & $-0.4053 * * * *$ \\
\hline Hymenoptera (mainly ants) & NS & NS & NS & $0.2925 * *$ & NS \\
\hline \multicolumn{6}{|l|}{ ARACHNIDA } \\
\hline Acari (ticks and mites) & $-0.5199 * * *$ & $(-0.508)^{+}$ & NS & NS & $0.4283^{* * *}$ \\
\hline Araneae (spiders) & NS & NS & NS & $0.2356^{* * * *}$ & NS \\
\hline Opiliones (harvestmen) & NS & NS & NS & $0.3291 * * *$ & $(0.161)^{+}$ \\
\hline DIPLOPODA (millipedes) & NS & NS & NS & NS & NS \\
\hline CHILOPDA (centipedes) & NS & NS & NS & NS & NS \\
\hline \multicolumn{6}{|l|}{ MALACOSTRACA } \\
\hline ISOPODA & NS & NS & NS & NS & NS \\
\hline AMPHIPODA & NS & NS & NS & $(-0.124)^{+}$ & NS \\
\hline GASTROPODA & NS & NS & NS & $(-0.052)^{+}$ & NS \\
\hline
\end{tabular}




\begin{tabular}{|c|c|c|c|c|c|}
\hline Shannon & NS & NS & NS & NS & $(-0.099)^{+}$ \\
\hline Richness & $(-0.191)^{+}$ & NS & NS & NS & $(-0.233)^{+}$ \\
\hline \multicolumn{6}{|l|}{ GUILDS of ground-dwelling invertebrates } \\
\hline Predators & NS & NS & NS & $0.2337 * *$ & $(0.191)^{+}$ \\
\hline Detritivores & $-1.2835 * *$ & NS & NS & NS & NS \\
\hline Omnivores & NS & NS & NS & $0.5365 * * * *$ & NS \\
\hline \multicolumn{6}{|l|}{ BODY SIZE } \\
\hline Coleoptera (Epigeous) & $\mathrm{NS}$ & NS & NS & NS & NS \\
\hline Carabidae & NS & NS & NS & NS & NS \\
\hline Ctenognathus sp1 & NS & NS & $(0.273)^{+}$ & NS & NS \\
\hline Ctenognathus sp2 & $(-0.200)^{+}$ & NS & $(0.221)^{+}$ & NS & NS \\
\hline Morphospecies sp. 16 & NS & NS & NS & NS & NS \\
\hline Curculionidae & NS & NS & NS & NS & NS \\
\hline Scarabaeidae $\left(\right.$ Saphobius spp.) ${ }^{b}$ & $-0.1067 *$ & NS & $(0.105)^{+}$ & NS & NS \\
\hline Staphylinidae & NS & NS & NS & NS & NS \\
\hline Other beetles & NS & NS & NS & NS & $(-0.428)^{+}$ \\
\hline \multicolumn{6}{|l|}{ Araneae } \\
\hline Total body size & $(0.306)^{+}$ & NS & NS & NS & $-0.3870 * * *$ \\
\hline Cephalothorax length & $(0.249)^{+}$ & NS & NS & NS & $-0.2704 * * *$ \\
\hline \multicolumn{6}{|l|}{ Orthoptera } \\
\hline Cave weta & NS & NS & NS & NS & $(-0.460)^{+}$ \\
\hline Ground weta (Hemiandrus spp.) & NS & NS & NS & $0.6539 * *$ & NS \\
\hline Female ground weta & $-0.2564 *$ & NS & $(0.750)^{+}$ & NS & $-0.4147^{*}$ \\
\hline Male ground weta & $(-0.198)^{+}$ & NS & NS & NS & NS \\
\hline $\begin{array}{r}\text { Juvenile ground weta } \\
\end{array}$ & NS & $(-0.477)^{+}$ & NS & NS & $(0.348)^{+}$ \\
\hline \multicolumn{6}{|c|}{ FUNCTIONAL TRAITS (ground beetle assemblages) } \\
\hline Body brightness & NS & $(0.295)^{+}$ & NS & NA & NS \\
\hline Body colouration & NS & NS & NS & NA & $(0.131)^{+}$ \\
\hline Leg colouration & NS & NS & NS & NA & NS \\
\hline
\end{tabular}

${ }^{\mathbf{b}}$ Dung beetles (excluding 5 individuals of non-dung beetle Scarabaeidae) 


\subsection{Discussion}

\subsubsection{Ground-dwelling invertebrates and 1080 aerial operation}

I found no indications that 1080 application benefits or harms invertebrate communities in New Zealand native forest. The taxonomic and guild abundance of ground-dwelling invertebrates did not change after 1080 application in Aorangi Forest. Also, taxonomical and functional diversity of ground-beetle assemblages did not differ before versus after the 1080 drop in the Aorangi Forest.

These neutral responses of ground-dwelling invertebrates concur with previous studies of the effects of 1080 on canopy invertebrates caught by Malaise traps (unpublished record, see Byrom et al. (2016)), and observed in artificial galleries (Powlesland et al. 2005, Ruscoe et al. 2013). Auckland tree weta (Hemideina thoracica) were the only canopy species that have shown a positive response to 1080 application on the New Zealand mainland. Similar results have been found on the mainland when assessing the direct effect of ground poisoning (baits) on the diversity of ground-dwelling invertebrates (Byrom et al. 2016). No clear trends have been found for leaf-litter invertebrates in podocarp-broadleaf fragments using ground pest control (Didham et al. 2009), and for ground-dwelling invertebrates in beech-podocarp forest (aerial and ground control) (Hunt et al. 1998) and in kanuka and podocarp-broadleaf forest in response to ground pest control (Rate 2009). Juvenile snails (Placostylus ambagiousus) have been the only invertebrates that show greater abundance in a Bromadiolone (anticoagulant unlike 1080) treatment zone in coastal shrub hardwood in response to ground pest control (Sherley et al. 1998). 
Neutral responses to the 1080 application suggest that this poison does not have any direct effect on the composition, abundance, diversity and body size of ground-dwelling invertebrates within one year following its application. Rather than responding to 1080 application, invertebrates could be responding to weather fluctuations, changes in nutrients, mast events and differences or similarities in predator pressures before and after mammal control (see Chapter 4).

\subsubsection{Abundance of ground-dwelling invertebrates and Time (both forests)}

Collembola (springtails) - the most abundant taxa in this study - and Acari (mites), exhibited an increase in abundance over time in the low-treated control forest as well as in the treated forest. Differences in composition and abundance of guilds in both forests are explained by the increase in number of Collembola (classified as detritivores) in our samples between seasons. They were extremely abundant in Waihora (WAI) and Mangatoetoe (MAN) in the Aorangi after 1080 drop. Collembola and Acari represent $60-80 \%$ of the individuals in the soil and litter layers (Oliver and Beattie 1996a). For instance, Collembola have been considered good indicators of soil condition (Moeed and Meads 1986, Vandewalle et al. 2010), resistant to urbanisation and sensitive to soil metal contamination (Santorufo et al. 2012), and secondary consumers (Fukami et al. 2006). They constitute a potential food for spiders (Araneae) (Lawrence and Wise 2000), ground-beetles (Carabidae) (Greenslade 1964), and mice (Miller and Webb 2001, Russell 2012), among others, but are unlikely to be preyed on by rats (Towns et al. 2009). On the other hand, Acari are less-active taxa compared to Collembola and are associated with moisture and sheltered areas (Sabu and Shiju 2010). They are present everywhere, weakly affected by soil metal contamination (Santorufo et al. 2012) and rarely considered as an indicator of quality of the soil, due to 
their generalist diet. They are more abundant in spring in broadleaf forests (Moeed and Meads 1986) and have been reported in the diet of hedgehogs (Hendra 1999) and possums (Forgie et al. 2014). Despite the fact that both taxa have been recorded on 1080 baits in low numbers (Spurr and Drew 1999), their greater abundance after 1080 (August 2014) in the Aorangi and the low-treated Remutaka may be explained by differences in soil conditions (e.g. temperature or moisture) and/or indirectly by a variation in invertebrate predation rather than as a result of the 1080 application.

Although not statistically significant, another interesting pattern observed was the abundance of Scarabaeidae (Saphobius spp.). Dung beetles decreased to half of their population from Feb-14 (before 1080) to Feb-15 (after 1080 mammal control) in the Aorangi Forest. Dung beetles are particularly important decomposers, recycling nutrients and improving soil quality by the decomposition of dung and carrion of a wide variety of animals in New Zealand (from invertebrates to mammals) (Jones et al. 2012, Stavert et al. 2014b). Their populations also vary between seasons, responding to rainfall seasonality (Andresen 2008b). Because they mainly feed on the dung of vertebrates and their abundance fluctuates over time, it would be interesting to test if this short-term fluctuation was directly correlated with environmental conditions between seasons, or indirectly with mammal or bird occurrences as a response to greater nutrient availability in the Aorangi just before the 1080 drop.

\subsubsection{Body size of ground-dwelling invertebrates and Time (both forests)}

Differences in the distribution of invertebrate body sizes may denote differences in the availability of nutrients, temperature and/or a variation in size-selective predation from one 
season to another (Byrom et al. 2016). More nutrients in the habitat could lead to greater abundance of larger invertebrates and a higher vulnerability to the attack of insectivorous predators as a result. Lower temperatures during larval development typically delay development times but result in larger individuals (Schowalter 2011). Also, body sizes of invertebrate prey are well known to be correlated with vertebrate predation pressure (i.e. larger individuals tend to be more consumed than smaller individuals) (Gibbs 1998).

In my study, only two invertebrate taxa showed significant differences in body size due to Time (before and after 1080), in both the low-treated control and treated forests. Scarabaeidae (dung beetles) and female ground weta showed larger body sizes after 1080 control in both forests. Larger dung beetles were found in the Remutaka in Nov-14 and in the Aorangi in Feb-15. Because dung beetles (Saphobious spp.) were not identified to species level in this study, the temporal variation in body sizes in both forests may be attributed to variations in community composition within our samples rather than other factors such as nutrient availability or predator pressure.

A more complex response was observed for weta species. Female ground weta (Hemiandrus spp.) were larger in both forests in samples collected after the 1080 drop and also during February. It is interesting to note that female ground weta showed an increase in size (of approx. $3 \mathrm{~mm}$ ) three months after 1080 application (Nov-14) in the Aorangi. However, this mean body size was not significantly different from Remutaka samples. Little is known about Hemiandrus ecology (Taylor-Smith et al. 2013). They are nocturnal, flightless, relatively abundant across New Zealand, and occupy holes in the ground during the day and emerge at night to forage and mate (Johns 2001). Their body size distributions differ 
between sexes as females tend to be larger than males (Taylor-Smith et al. 2013, Chappell et al. 2014, Chappell et al. 2015). Ground weta are components of the diet of introduced rodents (Rattus spp.), mustelids (Mustela spp.), hedgehogs (Erinaceus europaeus occidentalis) and cats (Felis catus), and can be found in both modified and natural habitats, mostly in the North Island (Chappell et al. 2014). Further studies about the correlation between ground weta body sizes and mammalian predator abundance is required to test if observed patterns of female ground weta body sizes are explained by predator pressure or respond to other factors.

\subsubsection{Ground beetle assemblage and Time (both forests)}

Relative abundance of ground beetles classified by their body brightness, and body and leg colouration did not show any variation across time in the Aorangi and Remutaka. Body trait distributions of invertebrates are good indicators of the adaptation of bio-indicators (e.g. springtails, ground beetles) to environmental and habitat disturbances (Vandewalle et al. 2010). In this chapter, functional traits were used to identify simple features associated with the attraction to visual vertebrate predators such as birds (except birds with a good sense of smell, e.g. Kiwi). Most of the studies about predators being attracted to invertebrate body colouration have been mainly assessed on spiders (Cuthill et al. 2005, Fan et al. 2009). These studies have reported a trade-off between a greater prey attraction (i.e. more food available for spiders) and a greater predator attraction (i.e. more predation pressure on spiders). In this chapter, I used a simple approach to classify traits (disruptive versus non-disruptive colouration on bodies; matte versus shiny bodies, and black versus red-brownish legs) based on the available information on spiders and their webs, in an attempt to understand the ground-beetle community in both forests. The results of body trait analysis should be taken 
carefully and revisited in further studies since: 1) black individuals were expected to be more visible to predators than brown-coloured bodies but the contrast between samples (individuals) and the ground cover was not measured among sites in the scope of this research, 2) the brightness of ground beetle individuals was measured through the use of compound microscopes but no software to detect light reflection was used, and 3) only one species was classified with disruptive colouration (Pentagonica vittipennis) which may influence the results for this trait.

\subsubsection{Long-term research and invertebrates}

Comparing ground-dwelling invertebrate communities before and after a control impact along multiple seasons and sites requires: 1) a multidisciplinary team, 2) financial and community support for the scope of the project, and most of all 3) a long time to process the huge number of invertebrates collected when pitfall traps are used (e.g. 10 to 15 minutes to process invertebrates from a single pitfall trap which requires further analysis if we want to identify to species level). Understanding the dynamics of invertebrate communities under mammal control at a broad scale should be one of the aims of mainland projects, especially after the New Zealand Government announced the goal for complete eradication of all rodents by 2050 (Department of Conservation 2017a). Community groups and nongovernmental organisations with low income could help to achieve this goal focusing on studying invertebrates before and after localised mammal control (baits or traps) in the short-term (1-2 years). From my findings, I recommend studying well-classified (i.e. large ground beetles) or large and abundant (i.e. ground weta and spiders) taxa, to understand the effects of mammal control on ground-dwelling invertebrates, and also sampling abiotic 
variables and changes in mammal populations. This will help to increase our knowledge and build up the network to understand complex responses in invertebrate communities.

Our control sites were placed in the Remutaka Forest which was not completely free from 1080. Part of this forest (around 28,000 ha), which comprises the Remutaka Forest Park, the Pakuratahi Forest, the Kaitoke Regional Park and Greater Wellington's Wainuiomata Orongorongo Water Collection Area, received 1080 treatment in August 2012 (OSPRI 2012). This control-site forest should be treated as a low-treatment area rather than a freefrom-treatment site. It was chosen based on the vegetation similarity, proximity to the treated area (the Aorangi), and the lower frequency of 1080 operations. The treatment area, the Aorangi, received 1080 for the first time in August 2014 and will receive treatments every three years (Aorangi Restoration Trust 2016) while the Remutaka is expected to receive repeat treatments approximately every six years. Thus, Remutaka Forest can be used as a suitable experimental control when looking at short-term population responses (1-3 years) as would be expected for most invertebrates.

Many studies have concluded that to completely understand the effects of mammal control on invertebrates, long-term studies are needed (> five years) (e.g. Hunt et al. 1998, Watts et al. 2014, Byrom et al. 2016). While this may be appropriate when studying long-lived invertebrates (e.g. weta), it is not clear how long or how many generations it will take for different species of invertebrates inhabiting the mainland to change after a 1080 application (if indeed they do change). This is especially noticeable when responses imply multiple species with different life expectancies and wide requirements of food and habitat. Despite the fact that my study may not be considered long enough, three seasons after 1080 
application, to observe changes in long-lived species (e.g. Hemiandrus spp. take two to three years to develop to adult in colder regions), it covered the previous gap about the effects of use of aerial 1080 on the abundance of ground-dwelling invertebrates on the mainland. The results of this chapter also may be used as baseline to guide future research in these broadleaf-beech forests, in particular, and in New Zealand in general, as research might focus on the most abundant, well-known and larger ground-dwelling taxa studied here.

From my findings, there was no evidence of the 1080 treatment having either negative or positive short-term effects on the invertebrate community, as measured by the abundance of 25 taxa and analysis of body size distributions and colouration. Other factors should be considered when studying ground-dwelling invertebrates as they may respond to interspecific relationships with other invertebrates and vertebrate predators, nutrients (e.g. vegetation) and environmental conditions (e.g. temperature). To fully understand invertebrate responses in these forests my next chapter will aim to understand the role of top-down forces (predation), habitat, temperature and elevation on these invertebrates. 
4. TOP DOWN EFFECTS ON GROUND-DWELLING INVERTEBRATES IN AORANGI AND REMUTAKA FORESTS, NEW ZEALAND 


\subsection{Introduction}

In natural ecosystems, two main forces control the abundance of species (Amarillo-Suárez 2010). The top-down concept predicts that the main forces controlling diversity and abundance of species at lower trophic levels are natural enemies such as predators or parasitoids (Nelson et al. 1960, Tscharntke and Hawkins 2002). The bottom-up concept suggests that species diversity is controlled by characteristics of trophic resources, such as temporal and spatial availability of prey and nutrients at each trophic level (Root 1973, Bennett 2010, Schowalter 2011). There is a consensus in ecology that ecosystems are affected by both, top-down and bottom-up influences, as negative or positive feedback loops which enable shifts from one dominant force to another over time (Bennett 2010). As ecosystems vary, top-down and bottom-up influences are also accompanied by other important factors that determine community structure such as climatic variables, habitat and inter-specific competitive interactions between organisms (Hunter and Price 1992).

Vertebrates such as insectivorous mammals, birds and reptiles are the main top-down predators associated with the decrease in invertebrate abundance. For example, in New Zealand, kiwi species (Apterygidae; Apteryx spp.), emblematic and endangered birds, feed on ground invertebrates and have behaved as top predators in the absence of mammals (Gibbs 2010). After the introduction of mammals to New Zealand, novel predators were incorporated into the ecosystem, modifying lower levels of food chains (Goldwater et al. 2012) and placing additional pressures on invertebrate communities (Gibbs 2009). For example, rats (Muridae: Rattus spp.) have had an enormous negative impact on large invertebrate species (Rufaut and Gibbs 2003, Powlesland et al. 2005, Ruscoe et al. 2013), especially on female individuals and large instar (stage) of weta species (Orthoptera: 
Anostostomatidae and Rhaphidophoridae), which may cause a long term negative impact on the survival of these species in New Zealand (Watts et al. 2011). As food webs are very dynamic, the control of higher-level predators sometimes allows an explosion of intermediate predators, a phenomenon called meso-predator release, which is also important in bio-control of invertebrate pests (Zavaleta et al. 2001). For instance, insect prey may be affected by an indirect rise of spider abundance (intermediate predator) as a response to lizard exclusion (higher-order predator) (Tscharntke and Hawkins 2002); or similarly, cereal aphid (Hemiptera: Aphididae) populations may decrease by a disruption of biological control by mesopredators: hoverflies (Syrphidae) and ladybird beetles (Coccinellidae), when birds are excluded in agroecosystems (Grass et al. 2017).

Indirect effects of predation via trophic cascades have rarely been measured (Ruscoe et al. 2013). Changes in insect communities due to modification of vegetation structure represent interesting examples of indirect effects of mammal grazing on insect populations (Tscharntke and Hawkins 2002). A study on the mainland New Zealand has reported an increase in leaf-litter invertebrates due to a short-term alteration in vegetation composition after a change in soil geochemistry in forest remnants where the livestock has been excluded and mammals controlled (Didham et al. 2009). More complex responses have been observed on islands in New Zealand where in presence of invasive rats, indirect effects on soil invertebrates can be positive ( (increased soil disturbance) and negative (decreased marinederived nutrients) because rats suppress seabird populations (Towns et al. 2009).

On the other hand, bottom-up influences are explained as the effect of the availability and quality of resources (Gunnarsson 1996) over the species success (e.g. greater abundance, 
larger individuals) and its transference to the upper levels of food webs (Tscharntke and Hawkins 2002, Bennett 2010). Responses of invertebrates to resources are well understood and have shown that mobile and generalist organisms tend to be less affected by this force than less mobile or specialist ones (Karban et al. 2012). Also, productive and complex areas characterised by greater availability of niches and additional resources, sustain greater abundance of beetles (Ruggiero et al. 2009) and spiders (Jiménez-Valverde et al. 2010). In early stages of plant species succession (build-up phase), invertebrate microbe-feeders appears to have high density in the litter layer supporting the finding that these invertebrates respond positively to high plant biomass (Doblas-Miranda et al. 2008). Other interactions have been reported in New Zealand beech (Nothofagus spp.) forests that undergo mast seeding approximately every two to four years as flower and seed density dramatically increases (Sutherland 2006). This event is followed by increases in invertebrates and mouse abundance (Murphy and Dowding 1995, Fitzgerald et al. 1996, Alley et al. 2001, Bowie and Frampton 2004) and a few months later a rise of stoats (Mustelidae: Mustela erminea), the main predator of mice (Muridae: Mus spp.) (Kelly et al. 2008, Griffiths et al. 2013).

In addition to previously explained influences, abiotic factors at micro and macro scales such as solar availability, precipitation and temperature, also influence the life-history processes of invertebrates (Speight et al. 1999) and food web interactions (Mazia et al. 2009). Many invertebrates are sensitive to changes in temperature (Schowalter 2011) and the strength of their responses depend on the development stage of organisms. Responses vary from changes in body size distributions at early stages to changes in fecundity and mating success at adult stages, among others (Nijhout 2003, Kingsolver and Huey 2008). Simultaneously, abiotic variables could indirectly mediate responses through trophic 
interactions if they affect host plant quality or population dynamics of the interacting species (Gripenberg and Roslin 2007).

I already demonstrated a nil effect of 1080 on invertebrates, and now I am going to test the effects of the other influences by re-analysed the data of ground-dwelling invertebrates inhabiting Aorangi and Remutaka Forests from the previous chapter. I will examine the possible links among the taxonomic and guild abundance, body size and other traits of invertebrates, and abiotic variables (elevation and temperature), predation (top-down effects) and habitat (vegetation). To further understand the mechanisms behind invertebrate responses, the aim of this chapter was to answer the following questions:

1. Does temperature have a strong effect on the abundance and body size of grounddwelling invertebrates in the Aorangi and Remutaka?

2. What are the effects of vertebrate (rats and mice) and invertebrate predators (Carabidae and Araneae) on the taxonomic and guild abundance, and body size of ground-dwelling invertebrates?

3. Do variations in habitat and elevation influence ground-dwelling invertebrate communities?

4. Which of the above factors explain the greatest amount of variation in invertebrate abundance and body size? 


\subsection{Methods}

\subsubsection{Study area}

The study was carried out in the Aorangi and Remutaka Forests (North Island, New Zealand) located at $41^{\circ} 27^{\prime} 45^{\prime}, \mathrm{S}-175^{\circ} 19^{\prime} 12^{\prime \prime} \mathrm{E}$ and $41^{\circ} 14^{\prime} 58^{\prime \prime} \mathrm{S}-175^{\circ} 04^{\prime} 52^{\prime \prime} \mathrm{E}$, respectively from November 2013 to November 2015 (see Chapter 3 for more details).

\subsubsection{Invertebrate data}

In this chapter, ground-dwelling invertebrates collected in the Aorangi and Remutaka from November 2013 to November 2015 were analysed to assess the mechanisms involved in their response to environmental variables (elevation and temperature), introduced predators (rats and mice), and habitat (ground and leaf-litter cover and type of forest). Field work methods for invertebrate sampling were thoroughly described in Chapter 3. Here, grounddwelling invertebrates per trap/night (TN) were summarised as the mean per monitoring line and season comprising only the seven pitfall traps placed at the middle $(250 \mathrm{~m})$ of each monitoring line (see Chapter 3 for more information). Season- and monitoring line-level data for all sites in both forests were used for the following analysis.

\subsubsection{Environmental data}

Elevation and temperature were calculated and analysed to study their direct or indirect effects on ground-dwelling invertebrate communities. Elevation (m) at each set of pitfall trap station was obtained via GIS (LINZ digital elevation model for New Zealand). Temperature $\left({ }^{\circ} \mathrm{C}\right)$ for each season at each station was recorded using TidbitT HOBO (Model UTBI-001) and HOBO pendant (Model UA-002-08) data loggers hang from the south (shady) side of a tree trunk at approximately $100 \mathrm{~cm}$ above the ground. Devices were set up 
to log temperatures every one hour and left in the field along the year or until batteries needed to be changed. Temperatures were summarised as the mean daily minimum (MinT) and mean daily maximum (MaxT) per month for each summer season (from November to February) along the duration of this study (i.e. summer 2013/14, 2014/15 and 2015/16). To assess the relationship between elevation and temperature and, the effect of temperature on invertebrate abundance, correlations were performed using pearson product-moment correlation coefficients (r) in R program (Version 0.99.902, (C) 2009-2016 RStudioInc.). Correlations were classified based on coefficients of correlations (r) (Table 4.1) and only moderate to very strong correlations were statistically analysed.

TABLE 4.1 Absolute value of the coefficient of correlations $(r)$ and their relative strength. Adopted from Evans (1996).

\begin{tabular}{ll}
\hline Absolute value of $\boldsymbol{r}$ & Strength \\
\hline $0.00-0.19$ & very weak \\
$0.20-0.39$ & weak \\
$0.40-0.59$ & moderate \\
$0.60-0.79$ & strong \\
$0.80-1$ & very strong \\
\hline
\end{tabular}

\subsubsection{Top down effects on invertebrate communities}

\section{Mammal abundance/ temporal analysis}

An index of density of rats and mice was obtained through identification of footprints on baited tracking tunnels along the monitoring lines $(450 \mathrm{~m}$ long) in all sites to estimate the effect of introduced mammal abundance on ground-dwelling invertebrates. Identifications of mammals and databases were supplied by Stephen Hartley's project "Biodiversity responses to possum-control in Aorangi and Haurangi Forests" from Victoria University of Wellington. Mammal sampling used the same standard operating procedures employed by DOC and Greater Wellington Regional Council (Gillies and Williams 2013), apart from the 
fact that peanut butter lure was placed in the centre of the card, not the ends. In Aorangi and Remutaka Forests, ten tracking tunnels baited with peanut butter were installed at each monitoring line at 50m intervals. Devices were left active for one night in winter season (July-August) and late spring (November), and three nights in late summer (February) from July 2013 to November 2015. Mammal occurrence rates were standardised by trap-night and summarised to the average occurrence rate of mammals per monitoring line at each site at each season.

Pearson product-moment correlation coefficients (r) were calculated to assess negative or positive relationships between rat and mouse density, and invertebrate communities. These correlations were fitted as the effects of rat and mouse density on: 1) invertebrate abundance; 2) invertebrate guild abundance, 3) body sizes of invertebrates, and 4) ground beetle's assemblage (body size categorisation, body and leg colouration and body brightness). Also, the relationship between potential prey and predator (Carabidae and Araneae) invertebrates were calculated. In this section, abundances of mammalian and invertebrate predators from the previous season [t-1] were correlated with prey abundance to represent the lag effect on prey-predator models (Lokta-Volterra, 1925) since populations oscillate cyclically and out of the phase. Invertebrate prey [t] collected in November and February were compared with mammal predators from the previous season [t-1]; JulyAugust and November, respectively. Due to the fact that invertebrates were not reported in winter season (July-August), potential prey invertebrates caught in November were compared with invertebrate predators collected in the prior February season. Only moderate to very strong correlations were described and analysed statistically in the current chapter $(r>0.4$, see Table 4.1) 


\subsubsection{Habitat and elevation effects on invertebrates and mammals}

\section{Vegetation/spatial analysis}

Vegetation identifications and databases were supplied by Stephen Hartley's project "Biodiversity responses to possum-control in Aorangi and Haurangi Forests" from Victoria University of Wellington (see Acknowledgments). Vegetation composition was achieved using a modified RECCE method (Hurst and Allen 2007) at each pitfall trap station, and simplified here as the ground vegetation and leaf-litter cover and forest type. Ground and leaf-litter cover were estimated visually and classified into six classes (Table 4.2). Ground cover was recorded as the total vegetation of the ground layer (below $0.3 \mathrm{~m}$ ) including foliage, tree trunks and exposed roots, while leaf-litter cover represented the percent of leaves, dead logs and branches on the ground (Hurst and Allen 2007). The forest type at each pitfall trap station was subsequently classified based on the canopy dominance of beech (1) or non-beech (0) species. Beech forest was defined when the greatest cover percentage (\%) at the higher tier was assigned to the Nothofagaceae family. In contrast, a station was classified as non-beech when other broadleaf families, podocarps or ferns represented the highest percentage cover of the canopy.

TABLE 4.2 Cover-classes applied to ground (vegetation) and leaf litter cover (extracted from Hurst and Allen 2007)

\begin{tabular}{cc}
\hline Cover-class & Percent (\%) of cover \\
\hline 1 & $<1$ \\
2 & $1-5$ \\
3 & $6-25$ \\
4 & $26-50$ \\
5 & $51-75$ \\
6 & $76-100$ \\
\hline
\end{tabular}

To assess the effect of elevation and habitat effects on ground-invertebrate and mammal communities, linear mixed models (lmer) tested by Analysis of Deviance with Type III sums 
of squares were performed for the mean abundance, guild abundance, diversity and body sizes of invertebrates and traits (mT) of ground-beetles; and rat and mouse density. Analysis of mean trait values (mT) were explained in Chapter 3. Mean trait values (mT) represented the proportion of ground beetles scored 1 (defined as coloured bodies, red-brownish legs and shiny bodies) and assumed greater attractiveness to visual predators.

Analyses were performed using R (Version 0.99.902, (C) 2009-2016 RStudiInc.) using the lme4 package (Bates et al. 2015). Abundance of invertebrates per trap-night were squareroot transformed to improve the normality of residuals. The type of forest (beech sites=1 and non-beech sites=0), elevation (continuous) and ground and leaf litter (1-6) cover were set as fixed factors. Sites and monitoring lines within sites were counted as nested random effects as follow:

$\operatorname{lmer}($ sqrt(invertebrates $) \sim$ Forest $_{\text {type }}+$ Elevation $_{+}$ground $_{\text {cover }}+$ leaf_litter $_{\text {cover }}+(1 \mid$ Site $/$ Set $\left.)\right)$

\subsubsection{Structural Equation Modelling}

A Structural Equation Modelling (SEM) was performed to discriminate the relative direct and indirect top-down and habitat effects on the taxonomic and guild abundance and body size of invertebrates. SEM was assessed to confirm trends identified through correlation and regression approaches from the previous sections. Data from both forests, the Aorangi and Remutaka, were analysed together due to the low numbers of site-level replicates in the Remutaka Forest. Abundances of invertebrates were square root transformed; and ground cover, leaf-litter cover and forest type divided by 10 to homogenise variances. 
As invertebrate communities did not show significant differences between Aorangi and Remutaka Forests (see Chapter 3), SEM was performed using all abundant ground-dwelling invertebrates that showed significant relationships with predators and nutrients from the previous sections in order to simplify and fit equations. Rat and mouse indices, ground and leaf-litter cover, and forest type were included in the analysis to inform hypotheses about mechanisms underlying invertebrate communities, their trophic cascades and habitat preference. Ground weta data were separated into the abundance and body size of females, males and juveniles to enable converge of the models. The most parsimonious model was chosen based on the Akaike Information Criterion (AIC) and values of estimates $(p>0.05$ for SEM). SEM was performed in R program (Version 0.99.902, (c 2009-2016 RStudiInc.) using the LAVAAN package (Rosseel et al. 2017).

Structural Equation Modelling (SEM) was performed to test the following hypotheses:

Links between top-down and habitat effects on the abundance of invertebrates:

Rat density recorded during the previous season [t-1], and ground and litter cover would have direct effects on the abundance of all invertebrates tested. Invertebrate predators (Carabidae and Araneae) [t] were also included as factors in equations. These top invertebrate predators would be expected to have direct trophic effects on Amphipoda, Staphylinidae and Scarabaeidae. To fit models, mouse density from the previous season [t1] was fitted as a direct effect on the most abundant invertebrates: cave weta, Staphylinidae and Scarabaeidae, Carabidae, Araneae; mice predation upon other invertebrates was also tested as part of correlations in the model. Type of forest (Beech sites) would also influence Scarabaeidae abundance (results from previous sections). In this analysis, Collembola and Acari abundances, temperature and elevation were excluded, as overly complex models 
failed to converge. Collembola and Acari, predominantly soil invertebrates are normally excluded when testing ground-dwelling invertebrates (e.g. Didham et al. 2009), showed enormous variation on the abundance throughout seasons and sites and when they were included, the model fit was unacceptable.

\section{Links between top-down and habitat effects on the body size and guild abundance of invertebrates:}

Rat and mouse density indices recorded during the previous season [t-1] were expected to have direct effects on the body size of large invertebrates and guild abundance due to previously recorded diet information (e.g. Rufaut and Gibbs 2003, Powlesland et al. 2005, Ruscoe et al. 2013). Leaf-litter and ground cover were expected to have a direct effect on the body size of cave weta, ground weta and on omnivores and detritivores abundances based on their diet (e.g. Speight et al. 1999). Forest type (beech or non-beech) was also included in this model as it would likely have a direct effect on spider body sizes (lmer results). For this analysis, only large invertebrates, such as Carabidae, Araneae and weta, were included.

\subsection{Results}

\subsubsection{Environmental data}

Strong negative correlations were found for the relationship between elevation, and minimum and maximum temperature (see Appendix Figure 8.4). Only Acari and Hymenoptera (mainly ants) showed significant changes in abundances due to mean daily temperature for summer sampling seasons. Acari showed strong negative relationship with the mean daily minimum temperature during summer $(t(76)=-2.65, p=0.009)$ while 
Hymenoptera showed positive relationship with the mean daily maximum temperature during summer $(t(76)=3.60, p=0.0005)$ (Figure 4.1). On the other hand, juvenile ground weta were significantly larger when the mean daily maximum temperature was high $\left(t_{(49)}=3.78\right.$, $p=0.0004$ ), this relationship was not apparent for adult ground weta (Figure 4.1).

\subsubsection{Top down effects on invertebrates}

\section{Invertebrate prey versus mammalian predators}

Data supplied by Stephen Hartley's project “Biodiversity responses to possum-control in Aorangi and Haurangi Forests" showed that rat numbers rose in both, the Aorangi and Remutaka Forests, from November 2013 to July 2014, reaching over 90\% tracking rate in the Remutaka by July 2015. In the Aorangi, the application of 1080 knocked down rat detections to very low numbers in November 2014 (below 5\% across all Aorangi sites) but tracking rates were back to pre-1080 level six months after 1080 operation. On the other hand, mouse detections were generally low over the past five years in the Aorangi and Remutaka Forests, expect for Pinnacles (PIN) and Waihora (WAI), where detections temporarily rose after the mast year (2014). The 1080 operation in August 2014 did not seem to depress mouse numbers in November 2014, however the most recent 1080 operation in June 2017 has had a noticeable effect, bringing mouse tracking rates down to 0\% as in July/August 2017 (see Appendix Figure 8.5) (Hartley 2017).

As expected, strong negative relationships were reported between rat density and 1) ground weta abundance $(\mathrm{r}=0.442 ; \mathrm{df}=34 ; p=0.007)$, specifically 2$)$ male ground weta $(\mathrm{r}=-0.373$; $\mathrm{df}=34 ; p=0.025)$, and 3) Araneae abundance $(\mathrm{r}=0.429 ; \mathrm{df}=30 ; p=0.014)$ (Figure 4.2). Contrary to what was expected, correlations showed moderate positive relationships 
between rat density and 1) Ctenognathus $\mathrm{sp} 2$ (Carabidae) ( $\mathrm{r}=0.384 ; \mathrm{df}=30 ; p=0.029), 2$ ) cave weta $(\mathrm{r}=0.479 ; \mathrm{df}=34 ; p=0.003)$ and 3$)$ Amphipoda $(\mathrm{r}=0.404 ; \mathrm{df}=30 ; p=0.021)$ abundance (see Appendix Figure 8.6 for all relationships tested and Appendix Figure 8.7 for changes in invertebrate and rat abundance through seasons). 

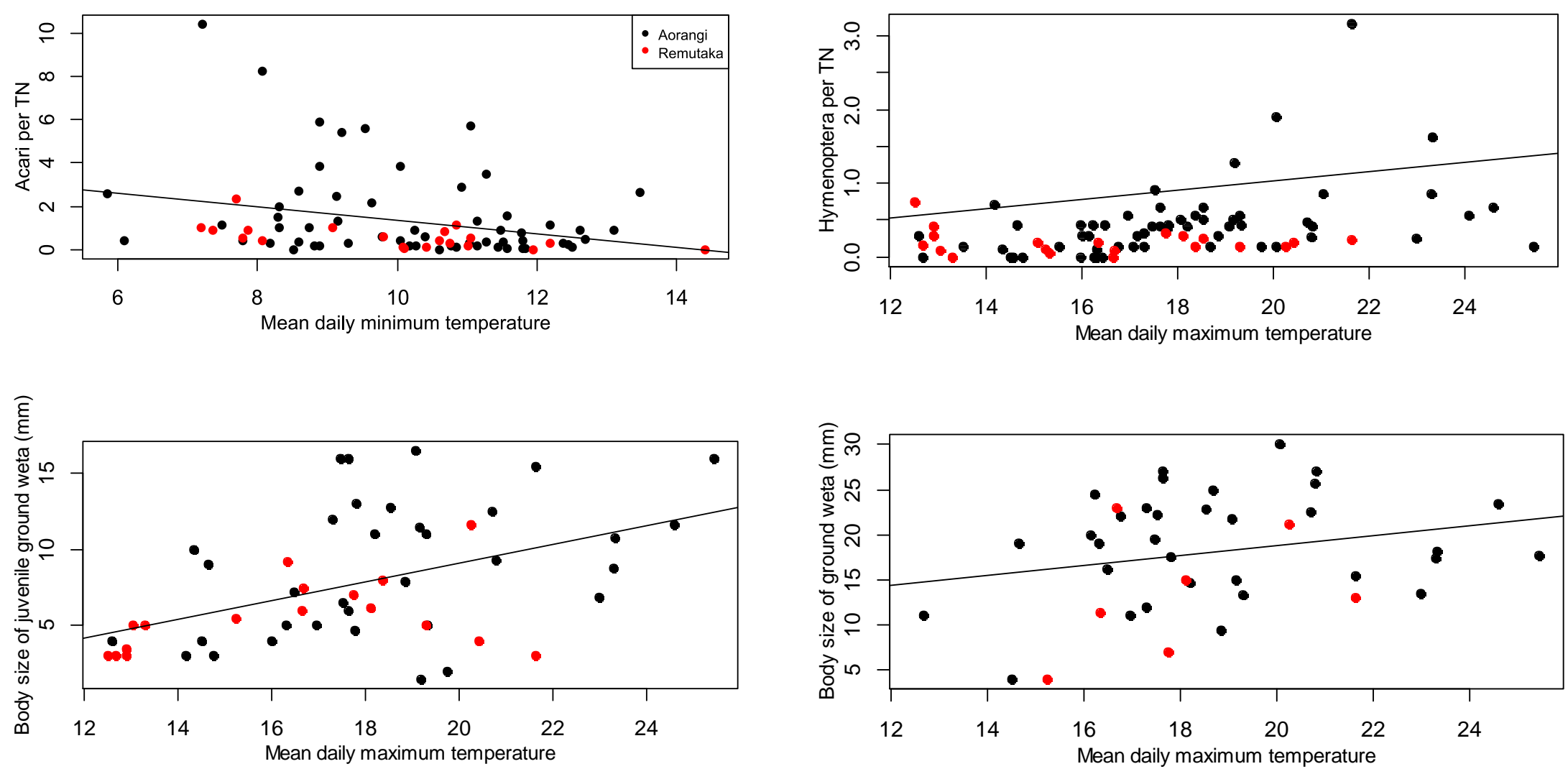

FIGURE 4.1 Invertebrate abundance and body size as a function of mean daily temperature in Aorangi (black) and Remutaka (red) Forests. Each point represents measurements for a particular monitoring line in a particular summer season. 

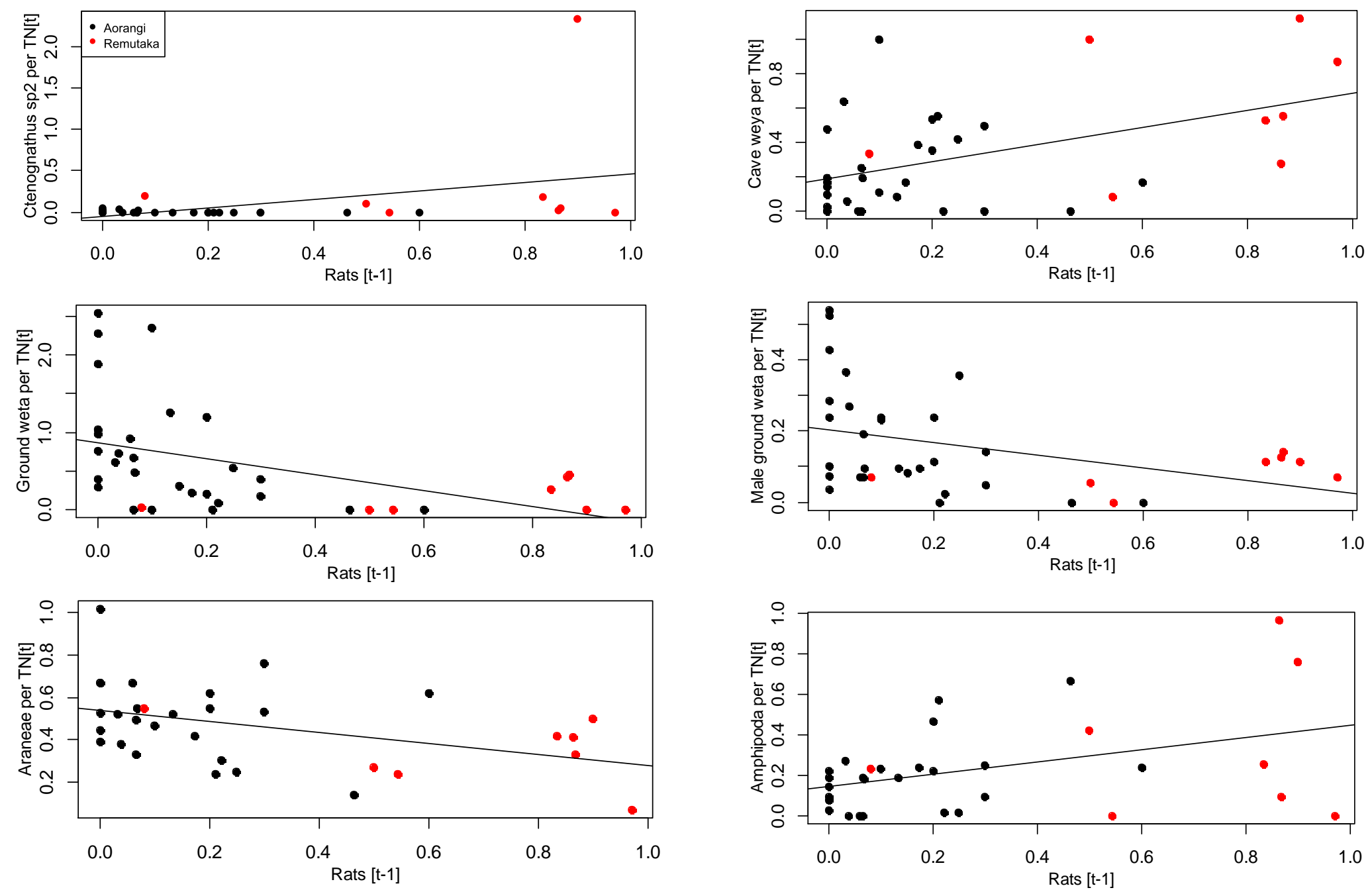

Figure 4.2 Invertebrate abundance as a function of rat density in Aorangi (black) and Remutaka (red) Forests for all seasons. [t-1] denotes abundances of predators the previous season. Each point represents the values for a particular site in a particular season. 


\section{Potential invertebrate prey versus invertebrate predator abundances}

Seven taxa were classified as invertebrate predators of other invertebrates: Araneae, Carabidae, Ctenognathus sp1, Ctenognathus sp2, Megadromus sp1, Carabidae sp3 and Carabidae sp16 (note that the latter five taxa are all Carabidae; see Chapter 3 for relative abundances). Moderate positive relationships were found between Carabidae sp16 (predator, [t-1]) and 1) male ground weta (Hemiandrus spp.) $(\mathrm{r}=0.427 ; \mathrm{df}=25 ; p=0.026)$ and 2$)$ Araneae (predator, $[\mathrm{t}-1])(\mathrm{r}=0.413$; $\mathrm{df}=25 ; p=0.032$ ). Negative moderate relationships were recorded between Araneae (predator, [t-1]) and the abundance of 1) Staphylinidae ( $\mathrm{r}=0.478 ; \mathrm{df}=25 ; p=0.012)$ and 2) Hymenoptera $(\mathrm{r}=0.449 ; \mathrm{df}=25 ; p=0.019)$ (Figure 4.3). Appendix Figure 8.8 shows the Pearson productmoment correlation coefficients of all possible relationships tested in this section but only moderate to very strong relationships $(r>0.4)$ were statistically tested.

Other significant relationships were reported among invertebrates during the same season $[\mathrm{t}]: \mathrm{a}$ strong positive correlation was found between Collembola and Acari abundance ( $\mathrm{r}=0.606$; $\mathrm{df}=32 ; p=0.0001)$ while moderate positive correlations were found between the abundance of Scarabaeidae and Hymenoptera $(\mathrm{r}=0.552 ; \mathrm{df}=32 ; p=0.0007)$, Scarabaeidae and Amphipoda $(\mathrm{r}=0.445 ; \mathrm{df}=32 ; p=0.008)$, Ground weta (Hemiandrus spp.) and Isopoda $(\mathrm{r}=0.439 ; \mathrm{df}=32$;

$p=0.009)$, specifically juvenile ground weta and Isopoda $(\mathrm{r}=0.453 ; \mathrm{df}=32 ; p=0.007)$, and male ground weta and Hymenoptera ( $\mathrm{r}=0.434 ; \mathrm{df}=32 ; p=0.010)$ (Figure 4.4). 

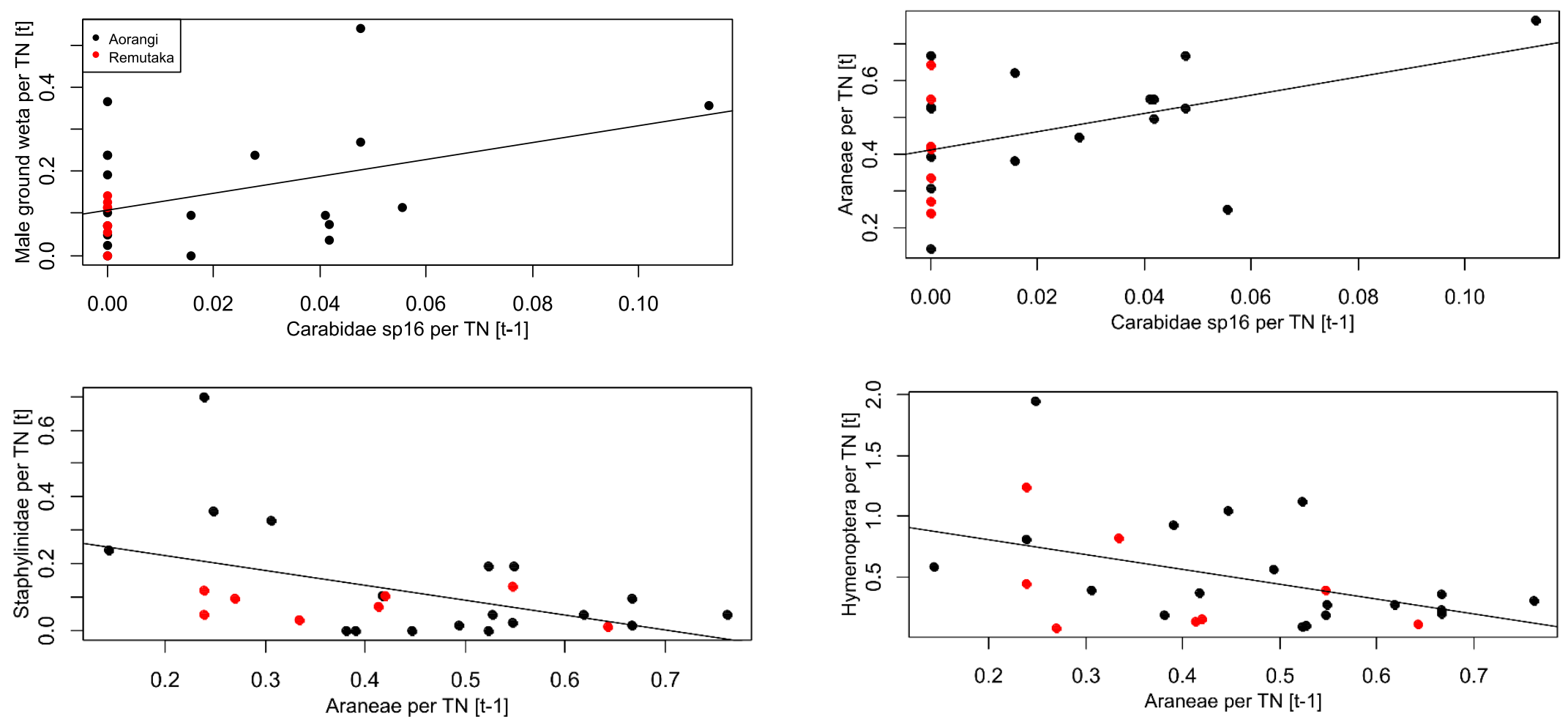

Figure 4.3 Invertebrate abundance as a function of invertebrate predator abundance in Aorangi (black) and Remutaka (red) Forests all seasons. [t-1] denotes abundances of invertebrate predators the previous season. Each point represents the values for a particular site in a particular season. 

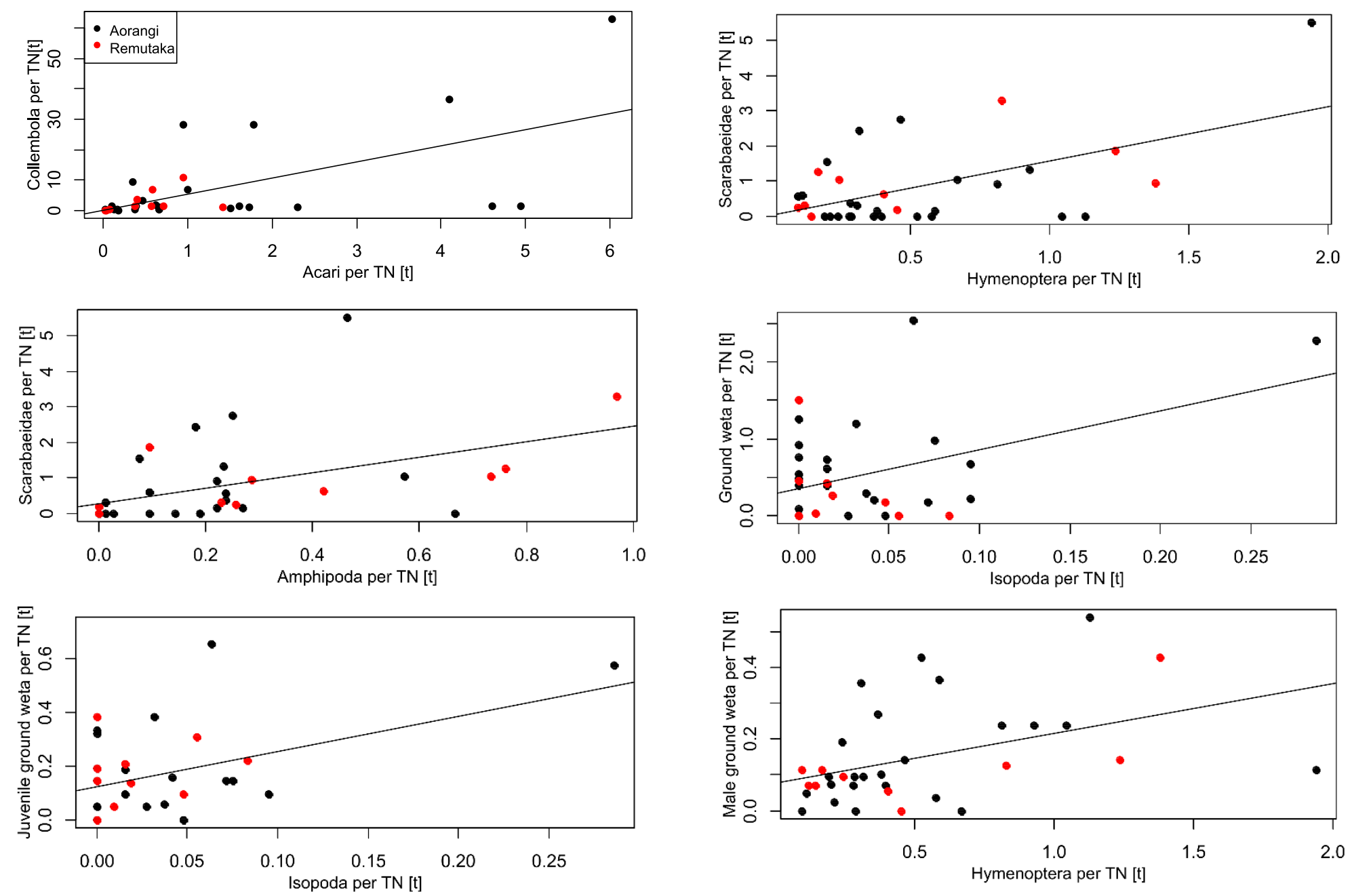

Figure 4.4 Correlations between invertebrates in Aorangi (black) and Remutaka (red) Forests all seasons. Note that invertebrates were compared within the same season [t]. Only moderate to very strong correlations were reported and statistically tested. Each point represents the values for a particular site in a particular season. 


\section{Traits (guilds and body sizes) of invertebrates versus mammalian predators}

No relationships were found between invertebrate guild abundance and mammal density. However, rat density was negatively related to the body size of cave and ground weta. Smaller

body sizes of cave weta $(\mathrm{r}=-0.379 ; \mathrm{df}=26 ; p=0.046)$, and female $(\mathrm{r}=-0.489 ; \mathrm{df}=25 ; p=0.009)$, male $(\mathrm{r}=-0.447 ; \mathrm{df}=30 ; p=0.010)$ and juvenile $(\mathrm{r}=-0.460 ; \mathrm{df}=30 ; p=0.008)$ ground weta were associated with greater density of rats (Figure 4.5). Mouse density was not significant related to the body size of the invertebrates tested. No relationships were found between mammal predation and body sizes of Carabidae, Ctenognathus sp1, Ctenognathus sp2, Carabidae sp16 and Scarabaeidae (see Appendix Figure 8.9 for all relationships tested).

\section{Ground beetle assemblage and mammal abundance}

No significant relationships were found between mammal density and 1) body colouration, 2) leg colouration, 3) body brightness and 4) body size of ground beetles. 

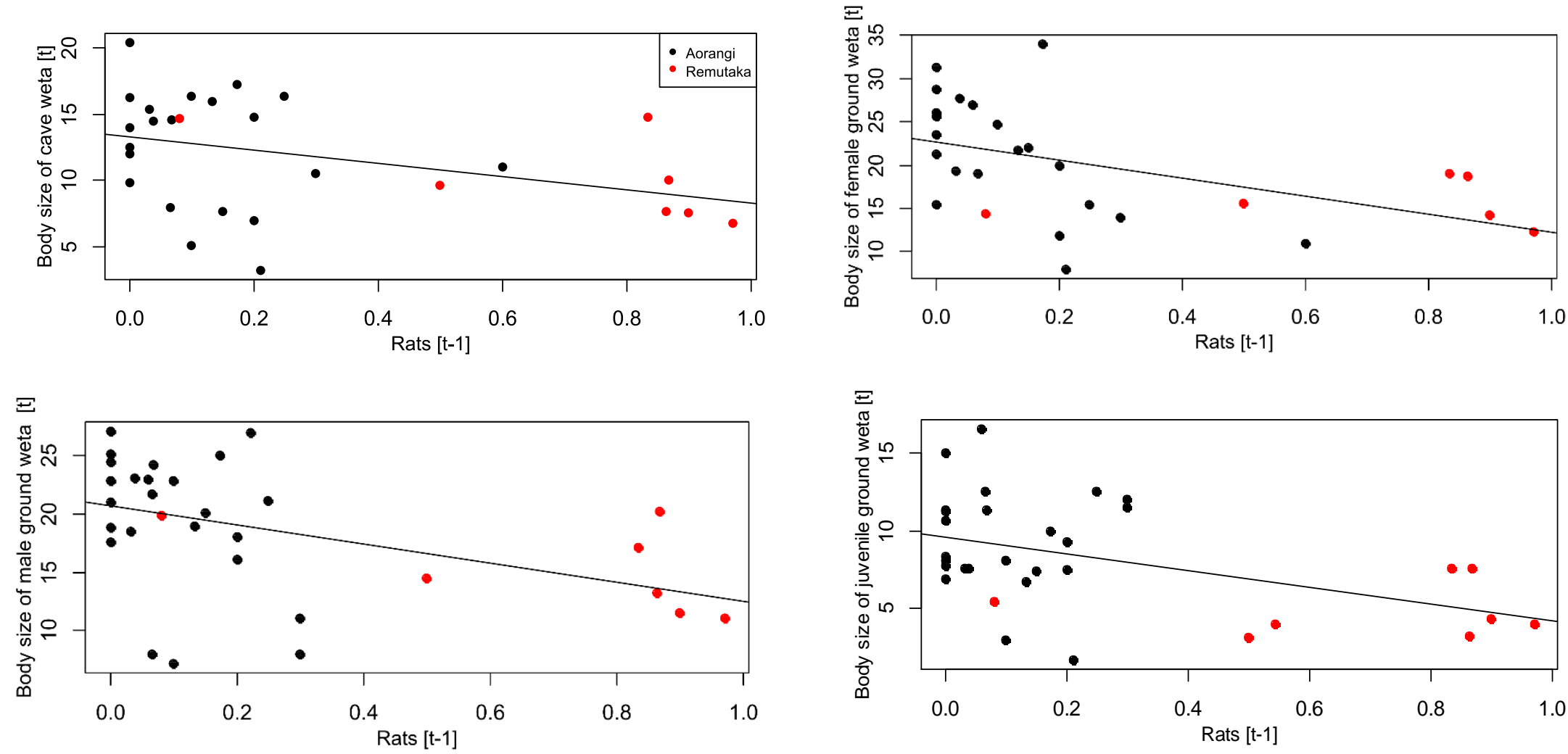

Figure 4.5 Invertebrate body sizes as a function of mammalian predator density in Aorangi (black) and Remutaka (red) Forests all seasons. [t1] denotes abundances of predators the previous season. Each point represents the values for a particular site in a particular season. 


\subsubsection{Habitat and elevation effects on invertebrates}

\section{Abundance and diversity}

Although low in abundance, Carabidae sp3 and Curculionidae showed significant differences based on the type of forest. Carabidae sp3 (mean=0.03 individuals $\pm 0.02 \mathrm{SE}$ for beech sites, versus mean $=0.006$ individuals $\pm 0.006 \mathrm{SE}$ for non-beech sites) were more abundant in sites represented primarily by beech species while Curculionidae were almost three time greater in sites dominated by broadleaf or other species (mean $=0.04$ individuals $\pm 0.02 \mathrm{SE}$ for non-beech sites versus mean $=0.02$ individuals $\pm 0.01 \mathrm{SE}$ for beech sites). An abundant taxon, Scarabaeidae, also showed greater abundance in sites dominated by beech species (mean $=1.09$ individuals $\pm 0.46 \mathrm{SE}$ for beech sites, versus mean $=0.32$ individuals \pm 0.14 SE for non-beech sites) (Table 4.3).

Collembola (mean $=16.58$ individuals \pm 13.18 SE for $76-100 \%$ versus mean $=1.10$ individuals \pm 0.37 SE for $1-5 \%$ cover) and Gastropoda (mean $=0.08$ individuals \pm 0.02 SE for $76-100 \%$ versus mean $=0.03$ individuals \pm 0.01 SE for $6-25 \%$ cover) showed greater abundance in sites where ground vegetation and leaf-litter cover, respectively, were higher. Elevation had a negative effect on the number of Megadromus sp1 (Carabidae) and Hymenoptera while a positive effect on Staphylinidae and Araneae abundance. No significant differences were found for Shannon diversity or Richness due to vegetation or elevation.

\section{Guilds and traits}

The only response of guilds to vegetation was reported for detritivores which were significantly more abundant in beech sites compared with non-beech sites (mean=7.64 
individuals $\pm 3.65 \mathrm{SE}$ versus mean=3.12 individuals $\pm 1.06 \mathrm{SE}$ ). On the other hand, shiny ground-beetles were well represented in sites where the percentage of leaf-litter cover was lower $(\mathrm{mT}=0.638 \pm 0.11 \mathrm{SE}$ for $6-25 \%$ cover versus $\mathrm{mT}=0.359 \pm 0.10 \mathrm{SE}$ for $75-100 \%$ cover $)$ (Table 4.3).

Body size

Only two taxa showed changes on their body sizes due to vegetation, but none to elevation. Ground cover had a positive effect on the body size of Ctenognathus sp1 (Carabidae) (mean=13.61 $\mathrm{mm} \pm 0.41 \mathrm{SE}$ for $26-50 \%$ cover and $12.75 \mathrm{~mm} \pm 0.75 \mathrm{SE}$ for $1-5 \%$ cover) while leaf-litter cover seems to have a negative effect on their body sizes (mean $=13.45 \mathrm{~mm}$ $\pm 0.35 \mathrm{SE}$ for $6-25 \%$ cover versus $13.14 \mathrm{~mm} \pm 1.13 \mathrm{SE}$ for $51-75 \%$ cover). These results should be taken with caution as lower abundance of Ctenognathus sp1 may affect these results. On the other hand, Araneae (spiders) tended to be larger in beech-dominated sites compared with non-beech sites (mean=6.44 $\mathrm{mm} \pm 0.55 \mathrm{SE}$ and $5.19 \mathrm{~mm} \pm 0.43 \mathrm{SE}$, respectively) (Table 4.3).

\section{Effect of vegetation on rats and mice}

Mice were more abundant on beech dominant sites in Aorangi and Remutaka Forests $\left(x_{(1)}^{2}=3.985, p=0.045\right)$. No significant differences were found for rat abundance due to vegetation or temperature. 
TABLE 4.3 Environmental influences on the invertebrate community. Summary of Analysis of Deviance (Type III, chi-square tests) fitting Lmer model for the effects of the type of forest (beech and non-beech), percentage of ground and leaf-litter cover and elevation (m) on the taxonomical and guild abundances, diversity, functional traits of ground beetle assemblage and body size of ground-dwelling invertebrates. Values shown are beta coefficients with significance indicated by asterisks: $* p<0.05, * * p<0.01, * * * p<0.001$. Only $* * * p<0.001$ was significant after Bonferroni correction (+).

\begin{tabular}{|c|c|c|c|c|}
\hline & $\begin{array}{c}\text { Forest-type (beech and } \\
\text { non-beech) }\end{array}$ & $\begin{array}{c}\text { Ground-cover } \\
(\%)\end{array}$ & $\begin{array}{c}\text { Leaf-litter cover } \\
(\%)\end{array}$ & $\begin{array}{c}\text { Elevation } \\
(\mathbf{m})\end{array}$ \\
\hline \multicolumn{5}{|l|}{ Abundance } \\
\hline Collembola & NS & $0.3675^{*}$ & NS & NS \\
\hline Insecta & NS & NS & NS & NS \\
\hline Coleoptera & NS & NS & NS & NS \\
\hline Carabidae & NS & NS & NS & NS \\
\hline Ctenognathus sp1 & NS & NS & NS & NS \\
\hline Ctenognathus $\mathrm{sp} 2$ & NS & NS & NS & NS \\
\hline Megadromus sp1 & NS & NS & NS & $-0.0004 * *$ \\
\hline Carabidae sp3 & $0.075^{*}$ & NS & NS & NS \\
\hline Carabidae sp16 & NS & NS & NS & NS \\
\hline Curculionidae & $-0.071 *$ & NS & NS & NS \\
\hline Scarabaeidae (Saphobius spp.) & $0.5337 *$ & NS & NS & NS \\
\hline Staphylinidae & NS & NS & NS & $0.0005^{*}$ \\
\hline Hymenoptera & NS & NS & NS & $-0.0006^{*}$ \\
\hline Orthoptera & NS & NS & NS & NS \\
\hline Rhaphidophoridae (Cave weta; CW) & NS & NS & NS & NS \\
\hline Anostostomatidae (Hemiandrus spp., GW) & NS & NS & NS & NS \\
\hline Female Hemiandrus spp. & NS & NS & NS & NS \\
\hline Male Hemiandrus spp. & NS & NS & NS & NS \\
\hline Juvenile Hemiandrus spp. & NS & NS & NS & NS \\
\hline Arachnida & NS & NS & NS & NS \\
\hline Acari & NS & NS & NS & NS \\
\hline Araneae & NS & NS & NS & $0.0005^{*}$ \\
\hline Opiliones & NS & NS & NS & NS \\
\hline Amphipoda & NS & NS & NS & NS \\
\hline Isopoda & NS & NS & NS & NS \\
\hline Chilopoda & NS & NS & NS & NS \\
\hline Diplopoda & NS & NS & NS & NS \\
\hline Gastropoda & NS & NS & $0.048 *$ & NS \\
\hline \multicolumn{5}{|l|}{ Diversity } \\
\hline Shannon diversity & NS & NS & NS & NS \\
\hline Richness & NS & NS & NS & NS \\
\hline \multicolumn{5}{|l|}{ Guilds } \\
\hline Omnivores & NS & NS & NS & NS \\
\hline Predators & NS & NS & NS & NS \\
\hline Detritivores & $0.9016^{*}$ & NS & NS & NS \\
\hline \multicolumn{5}{|l|}{ Functional traits of ground-beetles } \\
\hline Body colouration & NS & NS & NS & NS \\
\hline Body shiny & NS & NS & $-0.0879 *$ & NS \\
\hline Leg colouration & NS & NS & NS & NS \\
\hline \multicolumn{5}{|l|}{ Body size } \\
\hline Coleoptera & NS & NS & NS & NS \\
\hline Carabidae & NS & NS & NS & NS \\
\hline Ctenognathus sp1 & NS & $0.0479 * *$ & $-0.0692 * * *(+)$ & NS \\
\hline Ctenognathus sp2 & NS & NS & NS & NS \\
\hline Megadromus sp11 & NS & NS & NS & NS \\
\hline Carabidae sp3 & NS & NS & NS & NS \\
\hline Carabidae sp16 & NS & NS & NS & NS \\
\hline Orthoptera & NS & NS & NS & NS \\
\hline Rhaphidophoridae (Cave weta; CW) & NS & NS & NS & NS \\
\hline Anostostomatidae (Hemiandrus spp., GW) & NS & NS & NS & NS \\
\hline Female Hemiandrus spp. & NS & NS & NS & NS \\
\hline Male Hemiandrus spp. & NS & NS & NS & NS \\
\hline Juvenile Hemiandrus spp. & NS & NS & NS & NS \\
\hline Araneae & $0.259 *$ & NS & NS & NS \\
\hline
\end{tabular}




\subsubsection{Structural Equation Modelling (SEM)}

Links between top-down and habitat effects on the abundance of invertebrates

The final reduced model for invertebrate abundance in Aorangi and Remutaka is illustrated in Figure $4.6\left(x^{2}(26)=28.403, p=0.339\right)$ (see Appendix Table 8.3 for results). This model confirmed some of the relationships between invertebrates and their trophic cascades and revealed other possible associations. Rats from the previous season [t-1] seem to have a negative effect on the abundance of Araneae (spiders) while a positive effect on Rhaphidophoridae (cave weta), Scarabaeidae and Amphipoda abundance. On the other hand, mouse density played a moderate positive effect on the abundance of Scarabaeidae (dung beetles) while these insects were positively correlated to Staphylinidae (rove beetles) and Amphipoda abundance. Scarabaeidae were also more abundant at beech dominated sites. All weta taxa and stages represented in the models were positively associated with each other's abundances, except cave weta and juvenile ground weta which did not show any apparent relationship. Habitat effects were less important on this system. Leaf-litter cover showed positive effects on Hymenoptera (mainly ants) and is negatively related to ground vegetation cover. 


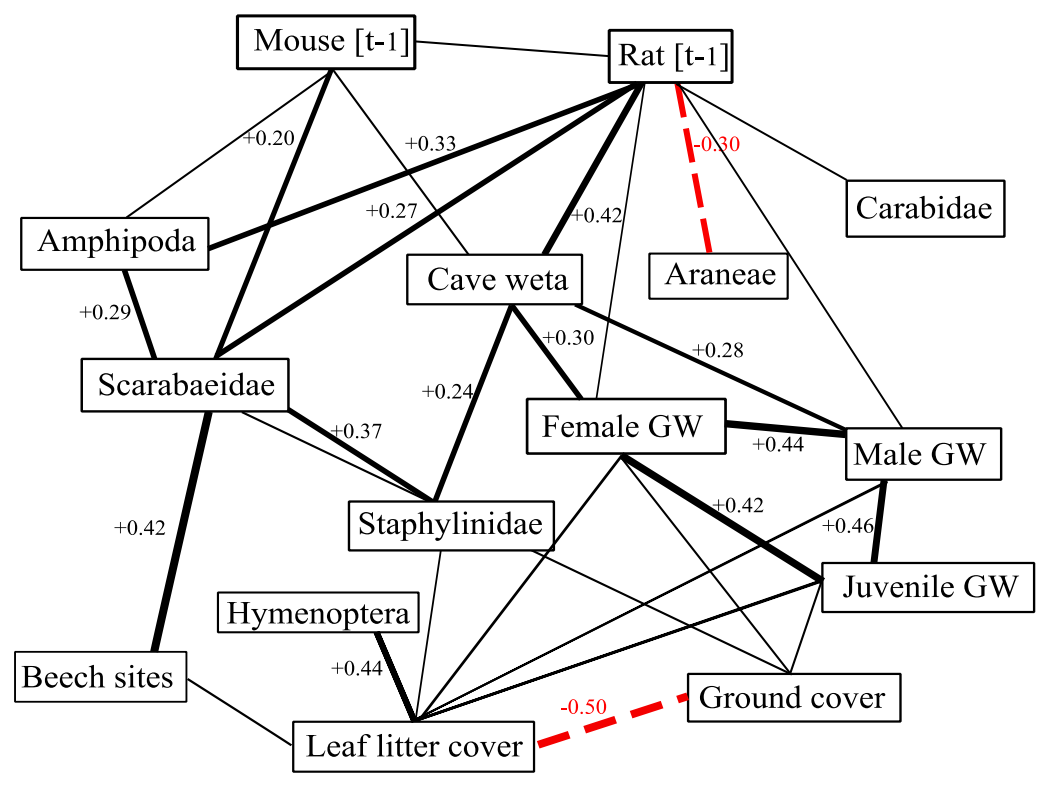

Figure 4.6 Final structural equation model revealing the direct and presumably some indirect effects of mice and rats on invertebrate abundances in Aorangi and Remutaka Forests, North Island. Approximate values for path coefficients are indicated by lines and numbers. Black and red lines denote statistical significance of regression coefficients at $p<0.05$. Negative relationships are indicated by red-broken lines. Grey lines denote additional non-significant tested relationships ( $p>0.05$ ). Relationships between 1) Amphipoda, Scarabaeidae, Carabidae and Araneae abundance, and leaf-litter and ground cover; 2) Staphylinidae and Hymenoptera, and ground cover; and 3) Carabidae and Araneae (predators) abundance and other invertebrates were excluded from the diagram to simplify figure. All these relationships have path coefficients $<0.3$ and $p>0.05$. GW= ground weta.

\section{Links between top-down and habitat effects on the body size and guild abundance of invertebrates}

In an attempt to understand the habitat and predation (top-down) effects on the body size and guild abundances of invertebrates, another structural equation model was performed. The final reduced model for invertebrate body sizes and guild abundance in the Aorangi and Remutaka is illustrated in Figure $4.7\left(x_{(14)}^{2}=14.704, p=0.399\right)$. This model confirmed trends described in our hypothesis for the effect of top-down forces. Thus, rat density from the previous season had a negative effect on the body size of male, female and juvenile ground weta (Hemiandrus spp.) as well as cave weta (Rhaphidophoridae). All weta body sizes were 
positively correlated with each other and the body size of ground beetles were positively related to cave weta, and female and male ground weta body size distributions. Vegetation and forest type did not have any apparent relationship to body sizes of invertebrates analysed here but had an effect on detritivores abundance. Ground vegetation cover had a positive effect on the abundance of invertebrate detritivores. This final model showed the same negative relationships between leaf-litter and ground cover as the SEM for invertebrate abundance but added a new correlation into the system: beech dominated sites seems to have less percentage of ground vegetation cover. No other relationships were apparent.

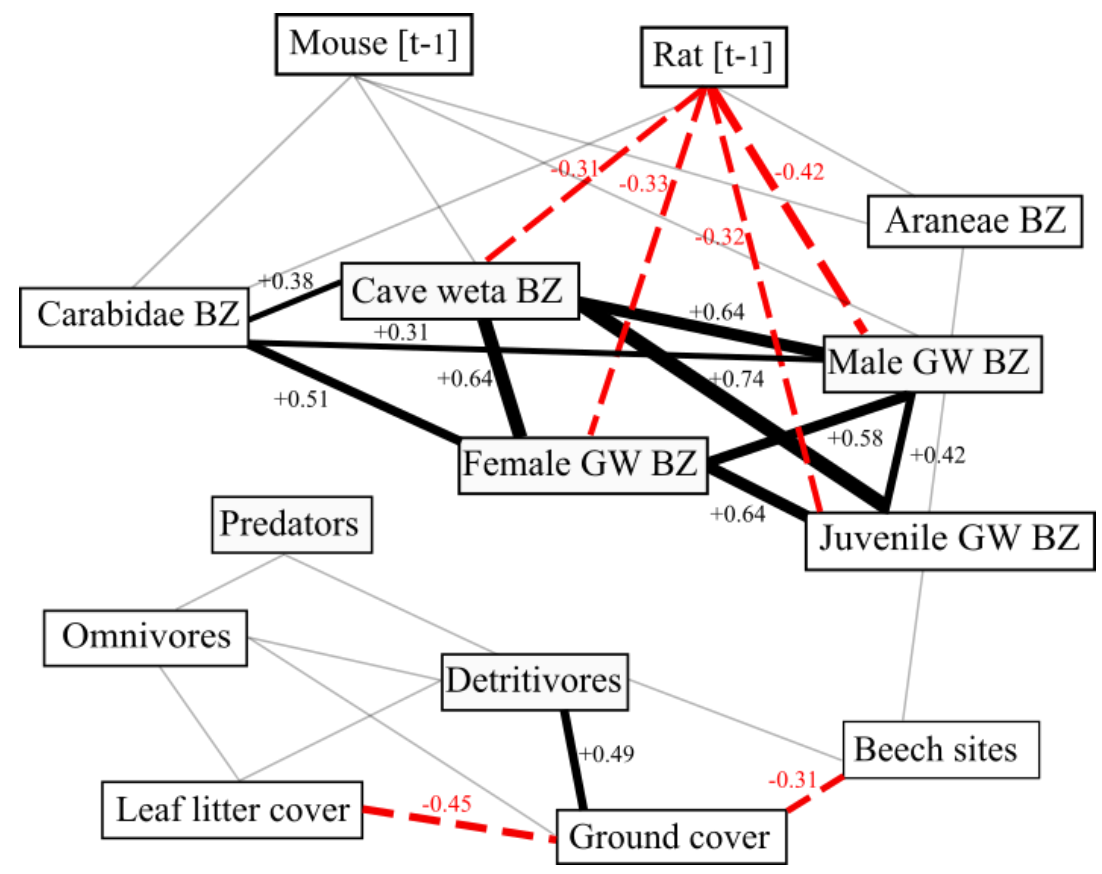

Figure 4.7 Final structural equation model testing the direct and presumably some indirect effects of mice and rats on the body size (BZ) of invertebrates and guild abundances in Aorangi and Remutaka Forests, North Island. Approximate values for path coefficients are indicated by thickness of lines and numbers. Black and red lines denote statistical significance of regression coefficients at $p<0.05$. Negative relationships are indicated by red-broken lines. Grey lines represent additional non-significant tested relationships at $p>0.05$. Relationships between 1) cave weta and ground weta (GW) body sizes, and leaf-litter and ground cover and 2) invertebrate guild abundance and rat and mouse density were excluded from the diagram to simplify figure. All these relationships have path coefficients $<0.3$ and $p>0.05$. 


\subsection{Discussion}

Some ground-dwelling invertebrates were noticeably affected by the combination of predation, nutrients, temperature and elevation factors in Aorangi and Remutaka Forests. Particular responses of these invertebrates were reported via correlations and linear mixed models, and then confirmed through Structural Equation Modelling (SEM), while others were only shown in one analysis. The strength of these relationships varies among invertebrates and are summarised and discussed below.

\subsubsection{Effect of temperature and elevation on ground-dwelling invertebrates}

First, temporal and spatial abiotic variables, such as temperature and elevation, appear to regulate six taxa in Aorangi and Remutaka Forests. The results varied among these taxa and may result from a response to different lifestyles. For example, temperature seems to positively regulate the abundance of Hymenoptera (mostly ants) and the body size of juvenile ground weta (Hemiandrus spp.) while negatively affecting the abundance of Acari. Temperature may regulate the survival, growth and development rates at early stages and fitness during adult stages of invertebrates (Speight et al. 1999, Kingsolver and Huey 2008). In my research, responses to temperature may reflect changes in daily activities (such as mobility, which resulted in a greater capture rates) and/or indirect effects on invertebrate fitness (such as survival, mating success, generation time or fecundity) from previous seasons. On the other hand, elevation positively influenced the abundance of Staphylinidae and Araneae, while negatively influencing Megadromus sp. (Carabidae) and Hymenoptera abundance. Megadromus, a genus that comprises at least 24 described species in New Zealand (Larochelle and Larivière 2007), were more abundant at lower elevations. Despite the fact that identification to species level was not achieved here, my findings concurred 
with traits described for Megadromus capito (Mike Dickison pers. comm.) which seems to switch habitat with Plocamostethus planiusculus (White, 1846) (Carabidae) at higher altitudes in other forests in New Zealand (Mike Dickison pers. comm.). Temperature and elevation, as well as Hymenoptera and Acari abundance could not be included in the SEM as their variances were too high to fit the models. The abundance of the fourth most abundant ground beetles, Megadromus sp., was included in the SEM as part of Carabidae abundance and body sizes.

\subsubsection{Top down effects on invertebrates}

Another factor influencing invertebrate communities was predation pressure measured as density of mammals and abundance of invertebrate predators. Rats were the main predators related to the decline in abundance of ground weta (Hemiandrus spp.) and spiders (Araneae) in Aorangi and Remutaka Forests. This is not surprising as these invertebrates are recognized as the main prey items of these rodents in New Zealand (e.g. Fitzgerald et al. 1996, Gibbs 1998, Atkinson and Towns 2001, Innes 2001, Rufaut and Gibbs 2003, Gibbs 2009). The negative responses of ground weta (all stages) were only shown on correlations, as in the SEM the abundance of ground weta were separately analysed as juvenile, males and females to facilitate convergence of the models (Figure 4.6).

Rats appeared to prey selectively on large male, female and juveniles ground weta (Hemiandrus spp.) and cave weta (Rhaphidophoridae) (Figure 4.5 and Figure 4.7). Structural Equation Modelling (SEM) confirmed the negative relationships between rat abundance and the body size of 1) female, 2) male and 3) juvenile ground weta showed on correlations. It also showed a negative relationship between rat abundance and cave weta 
body sizes. Rats are known to mainly feed upon large weta, beetles and arachnids ( $>7 \mathrm{~mm}$ long) but also upon small prey (Bremner et al. 1984), thus representing a threat to the survival of these organisms over time if predator abundance is not kept low by sustained control. This is especially important since there is some growing concern that regular 1080 application may cause changes (boom and bust cycles) in rat and mouse abundance which may be as damaging (or worse) for native organisms than no control.

In contrast to the negative predicted effects of rats upon invertebrates explained above, unexpected positive correlations were observed between rats and the abundance of 1) Amphipoda, 2) Ctenognathus sp2 (Carabidae) and 3) Rhaphidophoridae (cave weta). Interpretations of these relationships are still unresolved and may be as a response to factors such as soil characteristics (e.g. pH, moisture, and nutrient content), mast cycles, percentage of canopy cover, and/or changes in predation pressure driven by birds. One factor that may have played an important role in Aorangi and Remutaka Forests is the mast cycle. In beech and podocarp forests in New Zealand, mast cycles are the main factor responsible for mice irruptions (Fitzgerald et al. 1996, Ruscoe et al. 2004), and increases in the abundance of invertebrates (Fitzgerald et al. 1996, Alley et al. 2001) and, occasionally, ship rats (Kelly et al. 2008), in beech and podocarp forests, New Zealand. Beech mast happened in autumn 2014 in the Wellington region (Elliott 2016, Elliott and Kemp 2016) and may represent the most parsimonious explanation for the positive relationship between these invertebrates and rats.

Another factor that could have effects on invertebrate communities may be predation pressure driven by birds. In this research, the aim was to understand the effects of introduced 
mammals on invertebrate communities but it is likely that birds may have contributed to the observed patterns. The effects of avian predation upon invertebrates have been well described (e.g. Fitzgerald and Karl 1979, Moeed and Fitzgerald 1982, Gunnarsson 1996, Gunnarsson and Hake 1999). In the Aorangi Forest, bellbirds (Anthornis melanura (Sparrman 1786)), tomtit (Petroica macrocephala (Gmelin 1789)) and rifleman (Acanthisitta chloris (Sparrman 1787)) detections seem to increase after 1080 pest control (presumably due to a reduction of introduced mammals), while blackbird detections (Turdus merula Linnaeus 1758) have been reported to decrease during the same period relative to Remutaka Forest (Nyree Fea, pers. comm.). Although these birds move around different layers in the forest, all of them feed partially or completely upon invertebrates (Sherley 1985, Spurr et al. 2011). The underlying effects of these insectivorous birds on invertebrate communities would require further investigation.

Most notably for my results are the responses of Scarabaeidae (Saphobius spp.). They were the only ground-dwelling invertebrates that showed positive relationships with both introduced mammals, mice and rats, and beech dominated sites. There is evidence that these insects are generalists, use and are attracted in large numbers to avian and mammalian dung materials and carrion, and also are commonly found in leaf litter in New Zealand (Gibbs 2010, Jones et al. 2012, Stavert et al. 2014b). Thus, it is not surprising that these insects would have responded to an increase of mammals (and dung as a result) and to beech dominated sites where mice were more abundant.

Furthermore, correlations between different trophic groups of the invertebrate community were also found. For example, abundance of Araneae (predators) from the previous season 
[t-1] were negatively related to Staphylinidae and Hymenoptera (mainly ants) presumably because their predator-prey relationships. Soil invertebrates, Collembola and Acari, from the same season [t] were positively correlated; as well as Scarabaeidae (dung beetles) and Amphipoda (also detritivores) [t]. Explanations for these positive relationships remain tentative as they may also be responding to factors such as similarities on habitat (Collembola and Acari) and food requirements (Scarabaeidae and Amphipoda), or other factors. The negative correlations between Araneae [t-1] and 1) Staphylinidae [t] and 2) Hymenoptera [t] were not confirmed by SEM (Figure 4.6) most likely because data were analysed at different lags in the two methods. For example, in simple correlations, data from previous season [t-1] were used to test associations between invertebrate predators and invertebrate prey, while in the SEM data from the same season $[t]$ were used. This was because the aim of the SEM was to investigate the top-down effects upon invertebrates, mainly driven by mammalian predators rather than invertebrate predators (mammalian predators were always tested at [t-1]). Similarly, the predation pressure of invertebrate predators upon prey may be noisy and underestimated in my study as the poor level of taxonomical identification of some taxa which impeded a fine guild classification for correlations. Nevertheless, invertebrates included here, Carabidae and Araneae, represent the main confirmed and the most abundant classified predators in the Aorangi and Remutaka Forests (see Chapter 3).

\subsubsection{Effect of habitat on ground-dwelling invertebrates}

Another factor that has been shown to influence invertebrates was vegetation. Some taxa respond positively (Collembola, Gastropoda, Carabidae sp3, Scarabaeidae, Hymenoptera, detritivores, and Araneae), others negatively (Curculionidae) or both (Ctenognathus sp1 
(Carabidae)), to vegetation cover in the Aorangi and Remutaka Forests (Figure 4.8). The abundance of Collembola (soil-detritivores), Gastropoda (carnivores or herbivores), and Curculionidae (herbivores) may positive respond to vegetation (i.e. ground cover, leaf litter cover and beech forest, respectively) based on their diet and/or life-style. For example, close relationships have been reported between Collembola, soil and detritus (Lawrence and Wise 2000), and between herbivores and plants (Bennett 2010, Schowalter 2011). These taxa were not incorporated in the SEM analysis due to low abundances or very high variance between sites. Greater abundance of Carabidae sp3 and larger Araneae (spiders) in beechdominated sites and larger Ctenognathus sp1 inhabiting sites with low percentage of leaflitter may presumably reflect greater availability or good visibility of invertebrate prey on these sites. It is noteworthy that Ctenognathus sp1 tended to be larger in sites covered by a greater percentage of ground vegetation, but smaller when the percentage of leaf-litter was higher. Whether the body size distribution of these species responds to lower predation pressure (driven by birds or other mammals) or greater availability of food remains unclear.

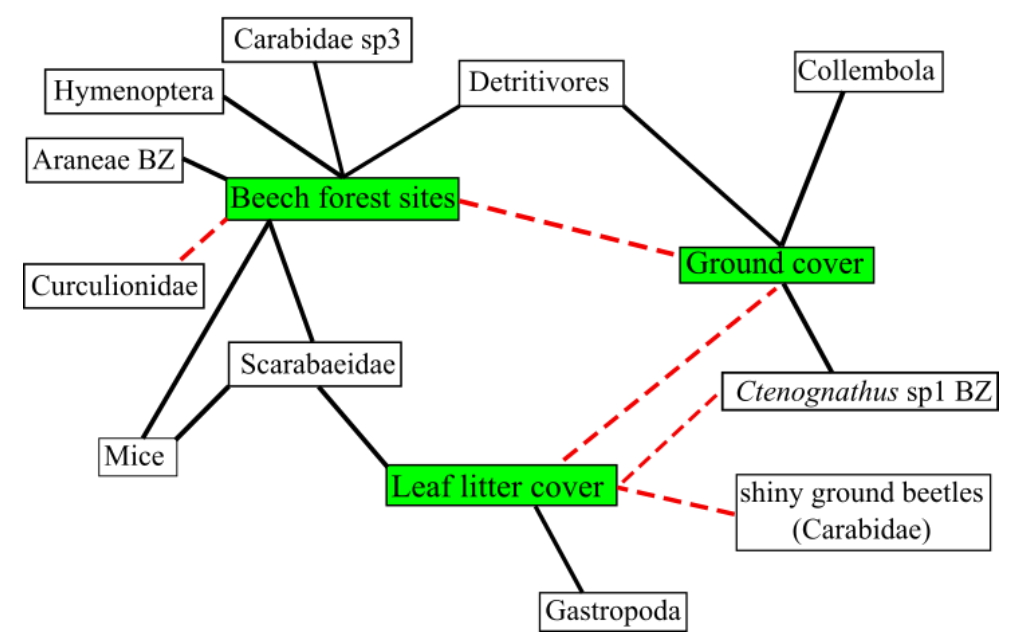

Figure 4.8 Summary diagram of the effects of vegetation on invertebrate and mammal communities from Linear Mixed Models and/or Structural Equation Modelling (SEM). This diagram does not show the strength of the relationships but their negative or positive correlations. Red-dashed lines denote negative interactions while black lines denote positive interactions. All these relationships were statistically significant at $p<0.05$ for correlations. $\mathrm{BZ}=$ body size. 
Within habitat effects, vegetation variables were also related to each other. Smaller percentages of ground vegetation cover were linked to a higher percentage of leaf-litter cover and beech dominated sites.

In this research, the effects of mast cycle on invertebrates and mammals (rats and mice) communities were not measured, thus the effects of vegetation upon these communities were analysed spatially but not temporally. Therefore, it is likely that temporal differences in vegetation in both forests may have also contributed to the observed patterns, and these variations would have a greater effect on herbivores, detritivores and mice.

\subsubsection{Limitations of methods}

Some responses were evident in correlations or linear models but not in the best SEM model. This may indicate that particular responses lose strength when models become complex and other responses (presumably affected by indirect effects) became more apparent.

Results for the mouse density index may have some bias as the activity of mice in tracking tunnels, and thus their detectability, is highly limited by the presence of rats (Innes et al. 1995, Harper and Cabrera 2010). Also, the use of tracking tunnels does not allow identification of the different species of rats (Morgan et al. 2009), hence species-specific conclusions could not be made for rat communities. 


\subsubsection{Which of the above factors explain the greatest amount of variation in invertebrate}

abundance and body size?

From my findings, there was not a clear pattern that identifies which of the influences, predation (top-down effects), habitat and environmental variables (temperature and elevation) dominates all ground-dwelling invertebrate communities inhabiting Aorangi and Remutaka Forests. Furthermore, the strength of one factor upon another varies among invertebrates and seems to depend on their body sizes, abundance of their predators, the relationships with other invertebrates, and their habitat and diet requirements, among others. For example, large invertebrates were more affected by top-down forces (i.e. ground weta, cave weta and spiders were affected by rat density) and habitat (i.e. the second more abundant ground beetle (Ctenognathus sp1) was affected by the percentage of leaf-litter cover). Smaller invertebrates tended to be more affected by habitat and temperature (i.e. Acari and Collembola respond negatively to temperature and positively to ground cover, respectively). Dung beetles (Scarabaeidae), small organisms, were positively affected by both, habitat (type of forests and leaf litter cover) and top-down forces (mouse and rat abundance). Thus, ground dwelling invertebrates respond differently to variations in temperature and predators (i.e. rats and mice), and spatial factors such as elevation, ground and litter cover and type of forest, confirming that invertebrate communities are diverse and complex. 
5. THE EFFICIENCY AND BIASES OF SQUID-BAITED PITFALL TRAPS USED FOR COLLECTING GROUND WETA (ORTHOPTERA: ANOSTOSTOMATIDAE) AND OTHER GROUND-DWELLING INVERTEBRATES IN NEW ZEALAND 


\subsection{Introduction}

Invertebrates are important indicators of species diversity and are often used to monitor the ecological effects of land-use practices and conservation management globally (Keesing and Wratten 1998, McGeoch 1998, Johns 2001). They are well represented in forest habitats and are indispensable for any ecosystem (Bowie and Frampton 2004) due to their ability to pollinate, disperse seeds, and recycle nutrients (Wilson 1987, Keesing and Wratten 1998), as well as forming part of the diet of many vertebrates (Wilson 1987, Williams 1993).

New Zealand's invertebrates are characterised by large-bodied, flightless, and long-lived species, many of them being ground-dwelling and nocturnal (Gibbs 2010). In particular, weta species (Orthoptera; Anostostomatidae and Rhaphidophoridae), are considered "flagship species" and iconic in translocation programs and conservation management in natural reserves in New Zealand (Johns 2001, Watts et al. 2008). Within the weta group, New Zealand's ground and cave weta are poorly classified and in need of taxonomic reviews and ecological studies (Taylor-Smith et al. 2013, Fitness et al. 2015, Trewick and MorganRichards 2015, Taylor-Smith et al. 2016). Recent studies are starting to fill this gap (TaylorSmith 2015, Carpenter et al. 2016, Fitness 2017).

One method commonly applied for an efficient sampling of ground-dwelling invertebrates is the use of lethal pitfall traps (Sutherland 2006). However, the traps may not effectively retain some saltatorial invertebrates (e.g. cricket or weta species) which can escape from the traps. This problem highlights the need for a more effective way to detect and monitor the diversity of saltatorial ground-dwelling invertebrates, especially in isolated or still unprospected sites. 
The effectiveness of pitfall traps as a sampling method may be enhanced by modifications of the standard technique. For example, the number of individuals caught may be increased with baits as attractants and/or by modifying the sampling area using fences, polythene barriers or cages for exclusion of vertebrate and invertebrate predators (e.g. Walker 1957, Brennan et al. 2005, Woodcock 2005, Carrillo et al. 2007).

The use of baits in pitfall traps to attract target species has its own bias since they may usefully increase the relative proportion of some taxa over others depending on the bait type (Woodcock 2005). Seldon and Beggs (2010) reported that Diptera and mainly carrion Coleoptera (i.e. Agyrtidae, Hydrophilidae, Leiodidae, Scarabaeidae and Staphylinidae) were preferentially caught when squid was used as bait in lethal pitfall traps in Waitakere Range of northern New Zealand. Another study, from the Czech Republic, demonstrated that fish was a useful bait when the target taxon was Silphidae (Coleoptera) (Knapp et al. 2016). However, both studies concluded that neither squid nor fish were effective at increasing catches of Carabidae (Coleoptera), which are a common indicator taxon of habitat changes worldwide, and neither studies were attempting to capture Orthoptera. Understanding the bias and the efficiency of the use of baits across a range of taxa and environments would assist researchers to select the most appropriate method for particular survey or research aims.

The aim of our study was to compare the efficiency of squid-baited versus un-baited lethal pitfall traps as a mean of sampling weta species and other invertebrates in New Zealand forests. In particular, we examined the effect of squid baits in attracting different body sizes 
of male, female or juvenile ground weta, as mammals are reported to select larger invertebrates as we described in Chapter 4.

\subsection{Methods}

\subsubsection{Study area}

The study was carried out in Aorangi and Remutaka Forests (North Island, New Zealand) located at $41^{\circ} 27^{\prime} 45^{\prime \prime} \mathrm{S}-175^{\circ} 19^{\prime} 12^{\prime \prime} \mathrm{E}$ and $41^{\circ} 14^{\prime} 58^{\prime \prime} \mathrm{S}-175^{\circ} 04^{\prime} 52^{\prime \prime} \mathrm{E}$, respectively from November 2012 to November 2015 (see Chapter 3 for more information).

\subsubsection{Invertebrate sampling}

Surface-active invertebrates were caught using lethal pitfall traps (110 mm mouth diameter, $100 \mathrm{~mm}$ deep) containing c. $25 \mathrm{~mm}$ depth of salt-solution $(\mathrm{NaCl})$ and a few drops of detergent. Seven pitfall traps were placed in a line $5 \mathrm{~m}$ apart from each other at the mid-point of rodent and possum monitoring lines (450 m long) at five sites in the Aorangi and two sites in Remutaka Forest (see Figure 3.1 in Chapter 3). Three pitfall traps per line were baited with decomposing squid (1-2.5 days old), alternated between four un-baited traps. The squid bait $(\sim 10 \times 20 \times 3 \mathrm{~mm})$ was hung from a thin wire suspended beneath a raised lid 25-30 mm over the centre of the pitfall trap (see details in Chapter 3). A similar method was used previously to attract carrion and dung beetles in New Zealand (Seldon and Beggs 2010). Traps were active in the field for one night (November) and three nights (February) to coincide with the logistics of mammal monitoring protocols (see Chapter 4). 


\subsubsection{Statistical analyses}

The number of weta in the three baited traps and the four un-baited traps were averaged separately to create a standard-unit effort response variable of "weta per trap-night (TN)" at the level of monitoring lines (i.e. the total catch from four un-baited traps each run for three nights at a particular monitoring line was divided by 12). The data for ground and cave weta from Chapter 3 were re-analysed here to test the effects of squid-baits on the average number of individuals and the body size per trap-night of ground weta (males, females and juveniles analysed separately) and cave weta. Also, we tested the effects of squid and season (November and February) on the ratio of adult to juveniles of ground weta.

In this chapter, we also incorporated data from the statistically significant results for squid baits of other invertebrates previously reported in Chapter 3. Among the most abundant invertebrates collected in Aorangi and Remutaka Forests, Carabidae, Scarabaeidae, Staphylinidae (Coleoptera), Hymenoptera, Araneae and Opiliones showed bias towards squid baiting, while Collembola, Acari, Diplopoda, Amphipoda and Gastropoda did not show any significant difference related to squid baiting. Weta individuals were collected from November 2012 to November 2015 while other invertebrates from November 2013 to November 2015.

We used Linear Mixed Models (lmer) to study the effect of squid baiting on i) the average number of weta and other invertebrates per trap night, ii) body size of weta and iii) the ratio of adult to juvenile ground weta, using Analysis of Deviance with Type III sums of squares to determine the significance of baiting. Monitoring lines $(n=3)$ nested within sites $(n=7)$, were included as random effects. Average counts were square-root transformed to improve 
homogeneity of variances and normality of residuals. Statistical analyses were performed using R (Version 0.99.902, (C 2009-2016 RStudiInc.) and lme4 package (Bates et al. 2015).

\subsection{Results}

A large number of ground weta $(n=528)$ and a lesser amount of cave weta species $(194$ individuals) were found in summer from November 2012 to November 2015 in Aorangi and Remutaka Forests (Figure 5.1). Most of the ground weta were identified as Hemiandrus pallitarsis (Walker, 1869), and only one individual was noticed to be different (Hemiandrus, unidentified species). The sex ratio of the ground weta populations sampled considered across all seasons was male-biased, 0.635 in the Aorangi and 0.636 in the Remutaka.
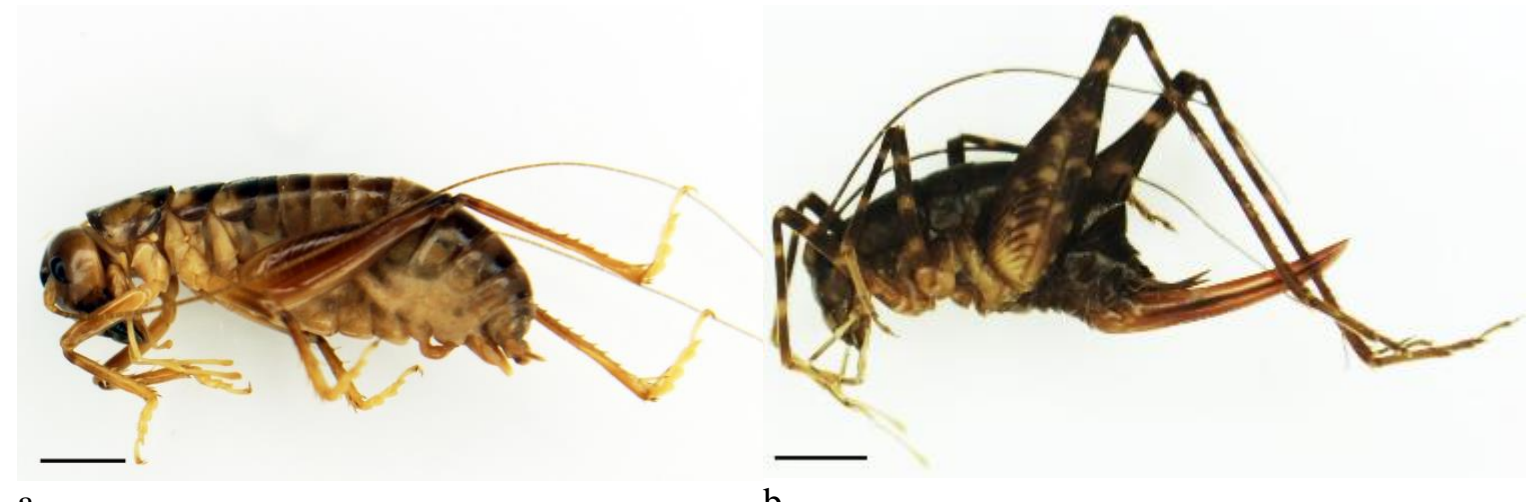

FIGURE 5.1. Female (a) ground weta (Hemiandrus pallitarsis) and (b) cave weta (unidentified species) collected in Aorangi and Remutaka Forests. Scale bar $=5 \mathrm{~mm}$.

The average number of ground weta (Hemiandrus spp.) caught in squid-baited pitfall trap was $0.52 \pm 0.077$ individuals per trap-night, more than two times the average number caught in un-baited pitfall traps (mean=0.24 \pm 0.05 individuals per trap-night) (lmer: $\chi_{(1)}^{2}=19.07$, $p<0.0001$ ) (Figure 5.2). This significant difference was confirmed when comparing sexes 
of ground weta: a six-fold increase on female abundance (lmer: $\chi^{2}(1)=26.33, p<0.0001$ ), a five-fold increase on male abundance (lmer: $\left.\chi_{(1)}^{2}=29.49, p<0.0001\right)$ and more than a twofold increase on juvenile abundance (lmer: $\left.\chi^{2}(1)=13.08, p=0.0003\right)$ were reported in squid baited pitfall traps compared with un-baited traps. Cave weta were three times as abundant in squid baited pitfall traps (mean $=0.26 \pm 0.04$ individuals per $T N$ ) compared with un-baited traps (mean $=0.1 \pm 0.02$ individuals per TN) (lmer: $\left.\chi_{(1)}^{2}=19.36, p<0.0001\right)$ (Figure 5.2). Cave weta were not analysed by sex because any trends were complicated by low taxonomic precision.

Significant differences were also found for the average number of other ground-dwelling invertebrates (Figure 5.2). Scarabaeidae (Coleoptera) were more than twenty times (lmer: $\left.\chi_{(1)}^{2}=60.53, p<0.0001\right)$ while Staphylinidae (Coleoptera) were four times (lmer: $\chi_{(1)}^{2}=14.45$, $p=0.0001$ ) more abundant in squid-baited than in un-baited pitfall traps. Opiliones (lme; $\left.\chi_{(1)}^{2}=18.02, p<0.0001\right)$ and Hymenoptera (lmer: $\left.\chi_{(1)}^{2}=16.413, p<0.0001\right)$ showed more than three-fold increase, and Araneae (lmer: $\chi^{2}(1)=30.31, p<0.0001$ ) showed more than two-fold increase in squid-baited pitfall traps compared with un-baited traps. Carabidae (Coleoptera) were 1.5 more abundant in baited compared with un-baited pitfall traps (lmer: $\chi^{2}(1)=4.74$, $p=0.03)$.

The ratio of adult to juvenile ground weta (Hemiandrus spp.) found in baited pitfall traps (mean ratio $=0.96 \pm 0.19$ individuals per $\mathrm{TN}$ ) was significantly different from the ratio caught in un-baited traps (mean ratio $=0.20 \pm 0.07$ individuals per TN) $\left(\operatorname{lmer}: \chi^{2}(1)=35.26\right.$, $p<0.0001$ ). Adult ground weta were also significantly more abundant in February (mean 
ratio $=0.94 \pm 0.20$ individuals per $\mathrm{TN}$ ) compared with November (mean ratio $=0.25 \pm 0.07$ individuals per TN) (lmer: $\left.\chi_{(1)}^{2}=4.40, p<0.0001\right)$.

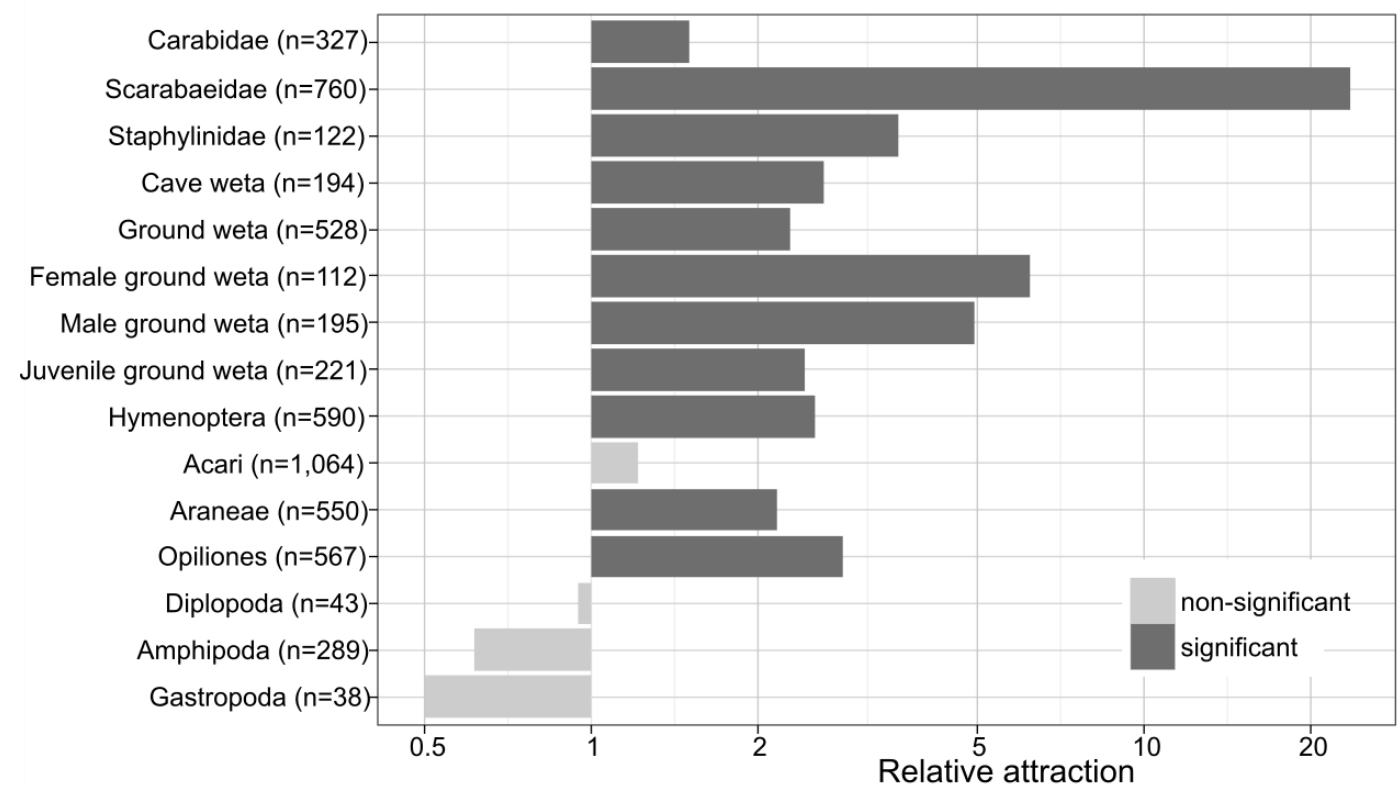

FIGURE 5.2. Relative attraction of individuals per trap-night caught on baited pitfall traps to unbaited pitfall traps in the Aorangi and Remutaka Forests. Dark grey bars denote significant differences on the average number of individuals as a function of squid baiting while light grey bars represent non-significant results. Ground weta (Hemiandrus spp.).

The body-size distributions of ground weta (Hemiandrus spp.) specimens, both adults and juveniles, differed between baited and un-baited pitfall traps (Figure 5.3). Ground weta were generally smaller in un-baited traps (mean $=16.07 \pm 0.7 \mathrm{~mm}$ ) than those found in squid-baited $($ mean $=19.2 \pm 0.4 \mathrm{~mm})$ pitfall traps $\left(\operatorname{lmer} ; \chi^{2}(1)=4.69, p<0.05\right)$. However, when separated by age and sex the average body size of females, males and juveniles did not differ due to squid-baiting. 


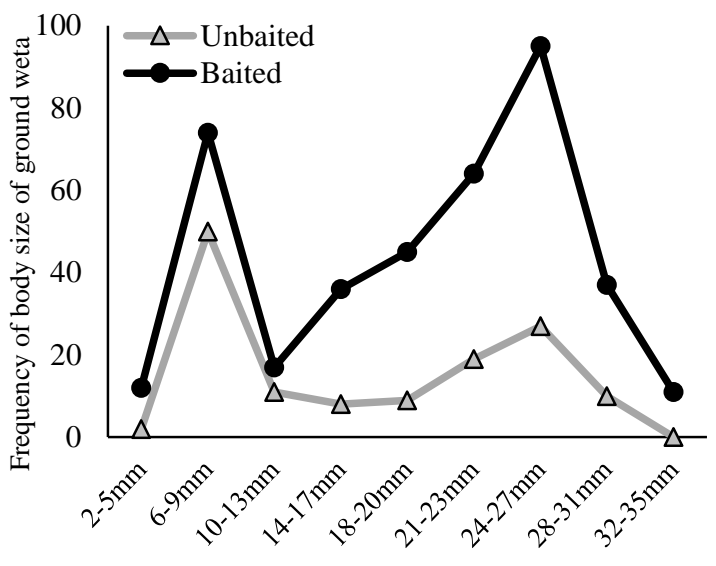

a

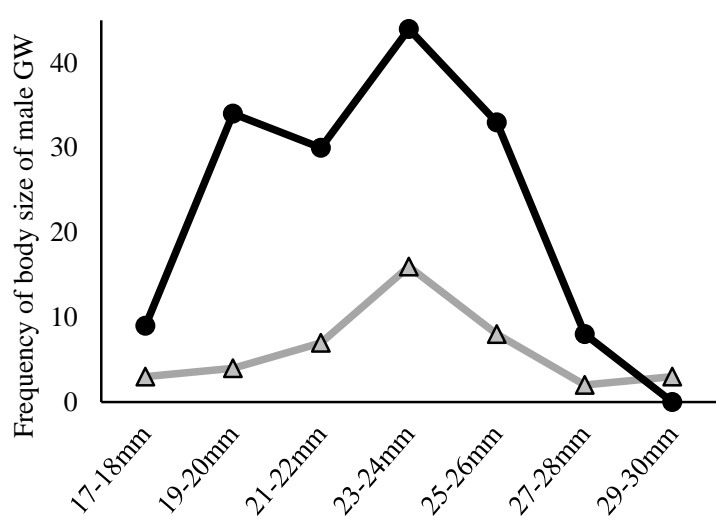

$\mathrm{C}$

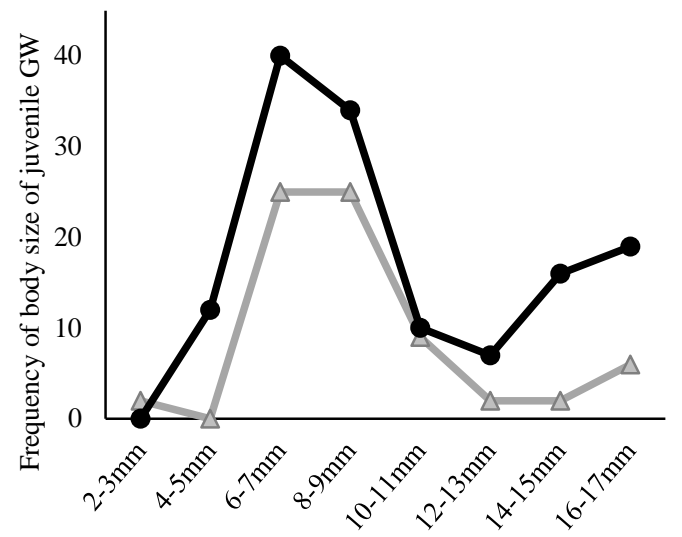

b

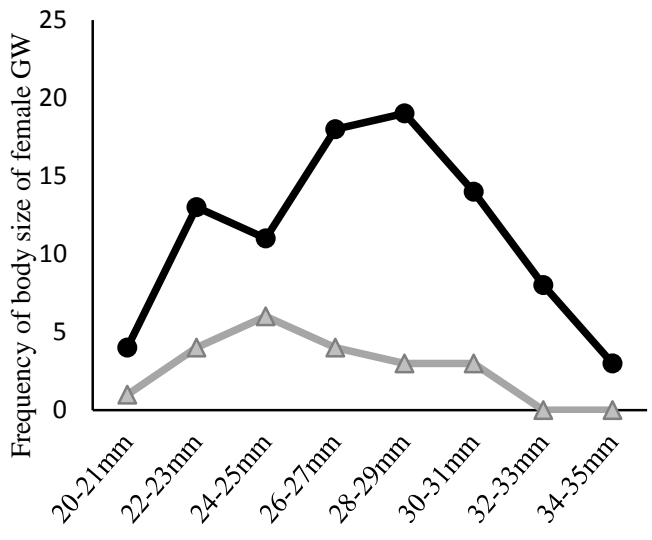

d

FIGURE 5.3. Body-length distribution of ground weta specimens (Hemiandrus spp.) in Aorangi and Remutaka Forests. A comparison between body size distributions of (a) all ground weta (GW), (b) juvenile, (c) male and d) female ground weta caught in baited (black lines) and un-baited (grey lines) pitfall traps is shown.

\subsection{Discussion}

Hemiandrus pallitarsis was the main ground weta collected in Aorangi and Remutaka

Forests. This species is widely spread across the North Island (Johns 2001, Trewick and Bland 2012), although to the best of our knowledge, our study is the first record from the 
Aorangi Forest. Previous studies have recorded at least two species of cave weta in Aorangi Forest: Pachyrhamma edwardsii (Scudder, 1869) and P. longipes (Colenso, 1887) (Cook et al. 2010), and three species in the Orongorongo catchment of the Remutaka Forest: Pallidoplectron sp., Pleioplectron hudsoni Hutton, 1897 and Pachyrhamma longipes (Colenso, 1887) (Moeed and Meads 1983). However, we could not confirm the presence of these species in either of these forests as it was not possible to clearly identify our specimens due to the taxonomic uncertainty within the family (Fitness et al. 2015).

The efficiency of pitfall traps is sensitive to the density of the population sampled, the behaviour of individuals, and the surrounding ground vegetation and its seasonal changes that impede or facilitate the catch of individuals (Greenslade 1964). Although this method has its limitations, pitfall trapping is the most frequently used approach to monitor grounddwelling invertebrates and offers a standard and quick solution to collect high numbers of individuals and species at low cost (Woodcock 2005, Knapp et al. 2016). Our findings have confirmed that lethal pitfall traps are useful in catching weta species despite their presumed limitations on preventing the escape of jumping species. The depth of the traps $(100 \mathrm{~mm})$, use of preservative and lid may all have contributed to retaining the catch of weta.

The use of squid baits in pitfall traps improves the catch of ground weta (Hemiandrus spp.) and cave weta (multiple species) by two and three times, respectively. Both, adult and juvenile ground weta, were observed to be attracted to baited pitfall traps and, in particular, larger individuals were more attracted to squid baits than smaller ones. This may imply that adult (female and male) ground weta (mainly 24 to $27 \mathrm{~mm}$ long) are more responsive to the volatiles of carrion than juveniles or differences in body sizes of ground weta would 
represent a seasonal trend of adults compared with juveniles in Aorangi and Remutaka Forests. In addition to these responses, Carabidae (ground beetles), Scarabaeidae (Saphobius spp. dung beetles), Staphylinidae (rove beetles), Hymenoptera (mainly ants), Araneae (spiders) and Opiliones (harvestmen) also showed preference to decomposing squid (1.5-3.5 days old). The use of baits in pitfall traps, such as carrion and dung, has been reported to be a successful method to increase the catch of flies (Diptera), carrion beetles (Seldon and Beggs 2010) and dung beetles (Halffter and Favila 1993, Andresen 2008a, Jones et al. 2012), as these baits emit volatiles that these invertebrates may detect and may be attracted to (Stavert et al. 2014a). Carabidae (predominantly Ctenognathus, Mecodema and Megadromus spp.) were significantly more abundant in baited traps, as was also observed by Seldon \& Beggs (2010). Our results concur with what was observed for the above invertebrates as well as provide further data confirming that ground and cave weta are also attracted to this bait.

Ground weta species have been classified as predominantly predatory (Taylor-Smith et al. 2013) as they may feed on Diptera in the field, but they have also been reported to feed on fruits (Burns 2006, Morgan-Richards et al. 2008). Their attraction to squid baits in our study indicates that ground weta ( $H$. pallitarsis) may also feed on dead or decaying animals suggesting that these insects should be considered omnivores rather than predators per se. The diverse range of food that comprises ground weta diet has been also reported for Hemiandrus maia Taylor-Smith et al. (2013) as this species feed on oats, fruits and flies without distinction. 
Ground and cave weta are solitary and nocturnal, and live in soil and moss cavities (TaylorSmith et al. 2013) requiring high sampling effort, this being one of the reasons for their poorly known taxonomy and ecology (Taylor-Smith et al. 2013, Trewick and MorganRichards 2015). The susceptibility of ground and cave weta to traps baited with squid provides some insight into their dietary preferences. The baited traps will also be a useful tool for future ecological studies as a valuable sampling method that may help to increase the number of these target species and reduce the sampling effort invested in collecting individuals in the forests. 


\section{GENERAL DisCUSSION}

New Zealand's terrestrial invertebrates are characterised by high level of endemism and vulnerability to introduced mammals (Meads 1990, Craddock 1997, Gibbs 2009, St Clair 2011, Gibbs 2016). However, despite the increasing number of mammal control projects, there have been few attempts to understand the complex interaction between invertebrates and mammalian predators (Byrom et al. 2016, Department of Conservation 2017b). In my thesis, I compared responses of ground-dwelling invertebrate communities to mammal control in Wellington and Wairarapa, New Zealand. This thesis comprises four studies that provide insight into the invertebrate responses to mammal exclusion via fenced reserves (Chapter 2), mammal control by aerial 1080 pest control (Chapter 3), and more specifically the effects of rodent density, habitat, elevation and temperature (Chapter 4). The study on the effectiveness of squid bait for catching ground weta and other invertebrates (Chapter 5) added extra information on reliable monitoring methods for sampling these taxa. Here, I review the findings of this thesis, summarized in the Figure 6.1, and the evidence for invertebrate community responses. I also discuss the conservation implications of my findings, propose two invertebrate taxa as indicators of rodent predation, and outline future research that would extend the work conducted for this thesis. 


\section{How do ground-dwelling invertebrates respond to mammal management on the mainland, New Zealand?}

\section{Chapter 2}

$Q$. Has the removal of introduced mammals and the suppression of mice within a fenced reserve, resulted in changes in the community composition, body sizes and diversity of invertebrates?

Findings: No evidence of any change in abundance, body sizes and diversity of invertebrates when comparing inside and outside ZEALANDIA, except for Collembola.

Q. How does the predation pressure experienced by insects (from birds and mammals) differ on either side of the fence?

Findings: Similar vertebrate predation pressure was found on the inside and outside of ZEALANDIA.

Chapter 3

Q. Does an aerial 1080 drop have a positive, neutral or negative effect on the abundance, body size and other traits of ground-dwelling invertebrates?

Findings: No evidence of any negative effect on the composition, abundance, and diversity of invertebrates in the treated area (Aorangi Forest). No changes in body sizes of Orthoptera, Araneae and Coleoptera, and composition and diversity of ground beetles (Carabidae) were found.

\section{Chapter 4}

Q. Does temperature have a strong effect on the abundance and body size of in the Aorangi and Remutaka? Do variations in habitat and elevation influence invertebrate communities?

Finding: Different taxa were affected by these variables. For example, temperature positively affected Hymenoptera abundance and ground weta body sizes while negatively regulated Acari abundance. Elevation had a positive effect on the abundance of Staphylinidae and Araneae; while negative affected Megadromus sp. (Carabidae) and Hymenoptera abundance. Vegetation cover influences Collembola, Gastropoda, Carabidae, Scarabaeidae, Hymenoptera, Detritivores, Araneae and Curculionidae.

$Q$. What are the effects of vertebrate (rats and mice) and invertebrate predation (Carabidae and Araneae) on the taxonomic and guild abundance, and body size of invertebrates?

Findings: Evidence for negative effect of rats upon ground and cave weta body sizes and spider abundance.

Q. Which of the above factors (temperature, habitat, elevation or predation) explain the greatest amount of variation in invertebrate abundance and body size?

Findings: No evidence of one variable dominating others to explain variation in invertebrates.

Chapter 5
Q. What are the effects of squid baits on sampling weta species and other invertebrates
in New Zealand forests?
Finding: There was a greater abundance of cave and ground weta, as well as
Scarabaeidae, Staphylinidae and Opiliones, in squid baited pitfall traps compared with
un-baited pitfall traps.

FIGURE 6.1 Diagram of the main findings of each chapter. $Q$ denotes questions. 


\subsection{Chapter overviews}

\section{Chapter 2}

A popular conservation method used to exclude introduced mammals on the mainland New Zealand in the long term, is the construction of fenced reserves (Burns et al. 2012). I conducted an in-situ predation pressure experiment inside and outside the fenced reserve, ZEALANDIA, to assess responses of ground-dwelling invertebrates to mammal exclusion. Different insectivorous vertebrate predators drive predation pressure on invertebrates inside and outside this reserve. North Island robins (Petroica longipes), blackbirds (Turdus merula), little spotted kiwi (Apteryx owenii), and mice (Mus musculus) appear to be the main predators inside the fence, while blackbirds, mice, brushtail possums (Trichosurus vulpecula) and hedgehogs (Erinaceus europaeus) are the main predators outside it. The presence of mice inside ZEALANDIA represents a threat to ground-dwelling invertebrates and together with birds such as robins, blackbirds and kiwi may exert similar total predation pressure as multiple species of mammals and birds outside the fence.

After 15 years of mammal eradication in ZEALANDIA, I would have expected some changes in abundance and/or body size of both short lifespan $(<1$ year, 15 generations approx.) and long-lived (2 to many years, 6 generations approx.) invertebrates because of the number of generations passed, in addition to the mammal preference for large-bodied prey (Meads 1990, Gibbs 1998, St Clair 2011). However, the establishment of the fence, which excludes most introduced mammals (except mice) and protects certain birds (e.g. kiwi, robins, saddlebacks, hihi) and translocated Cook Strait giant weta (Deinacrida rugosa) (Watts et al. 2008, Watts et al. 2012a, Empson and Fastier 2013), appears not to have resulted in an increase in abundance or diversity of invertebrate communities within the 
reserve relative to its surroundings, due to the similarity of predator pressure which impacts the invertebrate communities on both sides (Figure 6.1). There is some evidence for a slight difference in abundance of beetles and spiders, with Staphylinidae being more abundant outside the fence and larger spiders found both inside and outside the fence in 2015 . Staphylinidae are unlikely to suffer major changes by mammal predation, although they are preyed by hedgehogs, rats, mice and birds (Moeed and Fitzgerald 1982, Newman and McFadden 1990, Newman 1994, Hendra 1999, St Clair 2011). They are more likely to respond to bottom-up effects such as the availability of invertebrate prey and detritus based on their diet requirements. More evidence is needed to understand the seasonal trend observed in body size distribution of spiders at ZEALANDIA as they would respond to availability of invertebrate prey and/or predation pressure by vertebrates (e.g. mice) (Fitzgerald et al. 1996, Alley et al. 2001).

Few studies have investigated the effects of fenced reserves on ground-invertebrate communities in New Zealand, presumably because of the lack of suitable control sites adjacent to reserves. Unexpected results were reported by Eddowes (2007) who found higher invertebrate biomass in the control site (Bidwood reserve, outside ZEALANDIA) compared to the treatment area (inside ZEALANDIA). He concluded that the main factor limiting invertebrate biomass may have been the presence of mice and the greater abundance of insectivorous birds after mammal removal inside this fenced reserve. Most research has been focussed, however, on comparing invertebrates before and after mammal eradication within reserves. For example, positive responses of ground weta (Hemiandrus pallitarsis), cave weta (Gymnoplectron spp.) and tree weta (Hemideina thoracica) within two years after mammal eradication in Maungatautari Ecological Island (Watts et al. 2011) and negative 
responses of beetles in the valley of ZEALANDIA after six years of the establishment of the fence have been found (Watts et al. 2014).

Vertebrate predation would be a limiting factor inside and outside of fenced reserves if the recruitment (immigration) of invertebrates from outside the reserve is low or maintained to guarantee their enhancement within the matrix over time. In my study at ZEALANDIA, invertebrate communities were experiencing similar level of predation by different vertebrate predators on either side of the fence implying that the exclusion of most introduced mammals does not always lead to a change and recovery of invertebrate communities.

\section{Chapter 3}

Aerial 1080 pest control is an extensive method used for controlling introduced mammals (mainly possums) in the short-term (Green 2004, Wright 2011, Byrom et al. 2016). Invertebrates are potentially at risk of direct poisoning if they consume 1080 baits (McIntyre 1987, Notman 1989, Lloyd 1994, Eisler 1995), although whether this has any negative consequences at the population level remains doubtful. I conducted a Before and After Control Impact (BACI) study in the treated area (the Aorangi) and low-treated area (the Remutaka) to address the effects of the aerial 1080 pest control application on invertebrate communities. I found no evidence of any impact of 1080 operations on the abundance, diversity and body sizes of the ground-dwelling invertebrate communities in the treated area, in the year following application (Figure 6.1). My findings concur with what was reported in a pilot trial for ground-dwelling invertebrates (Hunt et al. 1998), but also for canopy invertebrates such as beetles (Hutcheson and Crabtree 1994), and cave weta, spiders 
and cockroaches inhabiting artificial galleries (weta houses) (Powlesland et al. 2005, Ruscoe et al. 2013).

Aerial 1080 pest control was applied during a mast year in Aorangi Forest, when there was an increase in seed production in beech-forests (Elliott 2016, Elliott and Kemp 2016). Timing 1080 application to coincide with mast years does not seem to have any detriment on ground-dwelling invertebrates which have been reported to increase during the same seed event (Fitzgerald et al. 1996, Alley et al. 2001, Kelly et al. 2008).

Neutral responses may be considered good news for the immediate survival of grounddwelling invertebrates during 1080 application in New Zealand. Temporal and spatial variations of different components of the ecosystem (e.g. habitat, predation, temperature) are likely to be more significant drivers of ground-dwelling invertebrate dynamics than the aerial application of 1080 poison (see Chapter 4).

\section{Chapter 4}

In this chapter, I assessed relationships between ground-dwelling invertebrates, and variables with high temporal variation, such as temperature and rodent density, and variables with high spatial variability such as vegetation cover, elevation and type of forest. There was no clear pattern of one variable dominating others to explain variation in grounddwelling invertebrates in the Aorangi and Remutaka Forests (Figure 6.1).

Larger invertebrates (i.e. ground weta, cave weta and spiders) were generally affected directly by temporal variation in top-down (predatory) influences while the opposite trend 
was observed for smaller invertebrates (i.e. gastropods, weevils, and springtails) which were more directly affected by spatial factors (vegetation). High abundance of rats (Rattus spp.) reduced the abundance of larger invertebrates (i.e. ground weta and spiders), and the body size of cave weta and female, male and juvenile ground weta in Aorangi and Remutaka Forests, as is generally understood to occur throughout New Zealand (Innes 2001, St Clair 2011, Barker 2016).

Other introduced mammals, such as hedgehogs, mustelids and possums, are known to be present in the Aorangi and Remutaka Forests (Hartley 2017). Detections of these mammals fluctuated from November 2012 to August 2017, with possum detections reduced following aerial 1080 operations in August 2014 and June 2017 in the Aorangi, and hedgehog detections showing a seasonal trend with more detections recorded in February (Hartley 2017). Mustelid (presumably stoats) detections were rare in both forests (Hartley 2017). These predators could also be affecting ground-dwelling invertebrates directly by predation and/or indirectly by changing abundance of direct predators, behaviour of invertebrates or by altering the habitat for invertebrates, for example, affecting their capacity to reproduce or feed (Cowan 2001, Moss and Sanders 2001, Ruscoe 2001).

Of particular interest was the potential positive indirect effect of mouse density on the abundance of smaller invertebrates, such as dung beetles (Saphobius sp., approx. $4 \mathrm{~mm}$ ). New Zealand dung beetles have evolved a generalist diet, feeding on dung and carrion before human arrival and the introduction of mammals (Stavert et al. 2014b). In this chapter, potential invertebrate prey from one season $[\mathrm{t}]$ were related to the mammal density from the previous season [t-1] (2-3 month interval). I discussed how these invertebrates may utilise 
the dung of these rodents as food but it is still unclear whether mammalian dung remains available and suitable for consumption and decomposition after 3 months on the ground.

\section{Chapter 5}

One of the most abundant taxa I found in Aorangi and Remutaka Forests was ground weta (Hemiandrus spp.), and probably the most abundant in terms of biomass in pitfall traps, although I did not measure biomass specifically. In this chapter, I showed that ground weta responded positively to squid baits suspended over pitfall traps (Figure 6.1). I suggested the use of squid baiting as an effective tool for sampling weta species and other invertebrates in New Zealand. The attraction of ground weta to squid (one to two days old) showed the interest of these species in carrion. Based on previous research about the predatory (TaylorSmith et al. 2013) and frugivory (Burns 2006) habits of ground weta and my findings, I suggest that Hemiandrus spp. could have a more generalist diet than what has been previously recorded.

\subsection{Conclusion}

My research has informed on the neutral effects of mammal exclusion (comparing inside and outside a fenced reserve, Chapter 2) and mammal control (comparing one or two years before and after 1080 application, Chapter 3) on ground-dwelling invertebrate communities on the mainland New Zealand. Rather than responding directly to these two methods used for reducing introduced mammals, invertebrates were positively and negatively affected by spatial variables (i.e. vegetation and elevation), fluctuations in predator populations (i.e. mice, rats and birds) and environmental variables (i.e. temperature) (Chapter 2 and 4). 
My thesis addresses gaps (2 out of 3) described by Byrom et al. (2016) in the diversity outcomes from mammal control in New Zealand. These include 1) monitoring population responses using paired non-treatment sites and 2) studying a range of taxonomic and functional groups of sensitive organisms to pest control. It may also represent a baseline for ongoing long-term monitoring of several ecosystem components at Aorangi and Remutaka Forests, and guide further insight into the long-term responses of invertebrates and their fluctuating communities.

In 2004, the Entomological Society of New Zealand identified knowledge gaps or areas to promote further research in the country (Lester et al. 2014). My research also incorporated recommendations on two of these high priority areas including exotic vertebrate predators of invertebrates and conservation of indigenous invertebrate diversity. For example, I investigated how native invertebrate fauna respond to mammal control (Chapters 2 and 3). Throughout my recommendations (see section 6.6.), I quantify and guide actions to mitigate the impact of mammalian predators on invertebrates. I followed a BACI design in open forests (Chapter 3), and I analysed resultant changes in an ecosystem framework (Chapters 2 and 4). I also propose invertebrate indicator taxa to monitor invasive pest effects (see section 6.5.)

\subsection{Switch in predation pressure}

Control of introduced mammalian browsers and predators by the establishment of fences or the use of chemicals can lead to a change in trophic interactions among non-targeted competitors or prey, sometimes allowing an intermediate predator release (Towns et al. 1997). For example, mice seem to benefit from rat removal (Innes et al. 1995, Hartley 2017), 
rats are also reported to increase after possum (Sweetapple and Nugent 2007) and cat removal (Fitzgerald 1990, Towns et al. 1997), and bird counts tend to increase after the decrease in possum, rat, mouse and stoat detections (Innes et al. 2010, Department of Conservation 2014).

Watts et al. (2014) hypothesised that periodic mouse irruptions in fenced reserves and high numbers of ground-feeding insectivorous birds may explain the lack of change in beetle communities over time (before and after the fence). My results confirm this hypothesis as the establishment of the fence at ZEALANDIA led to a change in the agents of predation pressure from mainly mammals outside to mainly birds within reserves, but potentially little change in net predation pressure relative to the outside (Chapter 2). This explanation also accounts for the relatively few differences in the composition of invertebrate communities, comparing both sides of the reserve. Predation pressure upon invertebrates is probably amplified within the reserve by the translocation of ground-feeding insectivorous birds (i.e. North Island robin and Kiwi) and irruptions of mouse populations.

A different phenomenon occurred in open forests on the mainland. Introduced mammals are not completely controlled after aerial 1080 application leading to changes in insectivorous predator dynamics in the short-term. Then, invertebrate responses to predators are more complex to be measured over time (Innes et al. 1995). While mouse irruptions are an important threat within fenced reserves (Chapter 2) (Innes et al. 2012), other introduced mammals can benefit from 1080 application in open forests after possum control (Sweetapple and Nugent 2007, Ruscoe et al. 2011, Department of Conservation 2014, Byrom et al. 2016) or prey-switching (Murphy and Bradfield 1992). This appears to have 
been evident in Aorangi Forest (Chapter 4) where rat populations recovered 6-12 months after 1080 drops, while possums remained low during the same period (Hartley 2017).

Studying multiple components of the ecosystem (e.g. vertebrate predators and invertebrate prey) is particularly important in determining how population fluctuations between introduced mammals and native and non-native birds affect invertebrate communities, and how these vertebrates (e.g. robins and mice) compete for food (Burns et al. 2012). It would be interesting to test whether these fluctuations may hide temporal shifts from mammal to bird predation of invertebrates, when mammals are controlled in the short-term. For example, I might not expect any major increase in the long-term in ground-dwelling invertebrates if insectivorous birds increase after frequent mammal control.

\subsection{Complexity of trophic cascades of invertebrates}

Terrestrial ecosystems are complex and dynamic as they involve multiple species which respond to autogenic changes and multiple external disturbances at different spatial and temporal scales (Lambin et al. 1998, Atkinson 2001, Saunders and Norton 2001). Soil invertebrates (above and below the ground) participate in crucial natural processes in these ecosystems (Tscharntke and Hawkins 2002). Understanding the interaction of these organisms with other components of the ecosystems including predator and prey, plant and herbivore, pollinator and dispersers, parasite and host, and competitive interactions, requires comprehensive studies on the taxonomy, biology and ecology of related organisms; which most of the time are poorly understood (Towns et al. 1997). 
Moreover, the overall outcomes are more difficult to interpret when these processes are disrupted by human-driven causes, such as the introduction of species (Saunders and Norton 2001, Towns et al. 2012). Mammal introductions and their control methods may produce several effects along food webs including chain reactions, irreversible changes or even novel successional trajectories (Atkinson 2001, Towns et al. 2012). For example, ground weta suffered negative effects from mesopredator release of rats after a decrease in possums by aerial 1080 application in Aorangi Forest (Chapter 4). These invertebrates also respond to local spatial variables such as vegetation cover and temperature (Chapter 4).

There is a call for conservation management programmes to incorporate both key species and related ecosystems in New Zealand (Atkinson 2001, Simberloff 2008, Innes et al. 2012, Fuller et al. 2013). However, information about the biology and ecology of many grounddwelling invertebrates and their trophic cascades is patchy or even absent (Towns et al. 1997, Buckley et al. 2012, Stringer and Hitchmough 2012), probably because studying these interactions is time-consuming and sometimes requires a high level of expertise. For example, most information on the effects of mammal predation on invertebrates is restricted to responses of canopy or iconic invertebrates (Sherley et al. 1998, Powlesland et al. 2005, Gibbs 2009, Ruscoe et al. 2013).

Despite these difficulties, I would recommend the following plans to achieve conservation goals in the short-term: 1) studying well-known, large-bodied and abundant species or taxa identified as indicators of predation by introduced mammals (section 6.5.) or indicators of habitat such as Collembola or Carabidae (Gardi et al. 2002, Vandewalle et al. 2010, Santorufo et al. 2012). When the investigation does not require information on particular 
species, I would recommend 2) the use of morphospecies or guilds/assemblages to cover ecological information of invertebrates (Oliver and Beattie 1996b, Derraik et al. 2002), 3) preserving the valuable entomological material in ethanol and pinning some common species to identify organisms in the future using morphological taxonomy and/or molecular systematics, and 4) monitoring and reporting changes on invertebrate communities and their food web interactions in both the short and long-term.

\subsection{Invertebrate indicators of mammal predation}

Given the limited funding for conservation management and the increase in community-led conservation projects aiming to reduce mammal pests, proposing indicator taxa will enable a more effective use of resources for research and more accurate outcomes (Speight et al. 1999, Bradshaw and Brook 2010, Watts et al. 2012b, Monks et al. 2013, Byrom et al. 2016). These two characteristics create an urgent need for identification of which taxa are susceptible or relatively invulnerable to mammal predation, and what traits contribute to vulnerability. In New Zealand, the selection of potential indicator species, from ecosystem health to population trend, has involved a panel of national experts who identified and scored taxa based on biological (abundance, biology, monitoring) and geographical (distribution, sensibility to changes) attributes (Monks et al. 2013). Monks et al. (2013) have proposed two invertebrates as indicators of introduced mammalian predation in the forests: Hemideina spp. (Orthoptera; tree weta) and Powelliphanta spp. (Gastropoda; giant landsnails). From my findings, I also propose the two following ground-dwelling invertebrate taxa: ground weta (Hemiandrus sp.) and spiders (Araneae), which may be used as potential indicators of rat predation in the forests (Chapters 2 and 4). 
Despite the fact that ground weta (Hemiandrus spp.) have not been normally used when studying the impacts of predators controlled by 1080 drop, they appear to be suitable indicators of rat predation because of three main attributes:

1. they can be of relatively high abundance in mature forests such as the Aorangi and the Remutaka, being the third most abundant large invertebrate $(4-35 \mathrm{~mm}$, juvenile and adults) (Chapter 3);

2. they responded negatively to rat density (threat) (Chapter 4, and other authors Gibbs 1998, Green 2002, and Gibbs 2009)

3. they could be easily identified by community groups and monitored based on their attraction to squid baits which offers a new reliable sampling technique in forests (Chapter 5).

Similarly, spiders (Araneae) could also be considered indicators of rodent predation, even though I could not identify them to genus or species level. Their attributes include:

1. they are abundant in mature forests, the first most abundant large invertebrates in Aorangi and Remutaka Forests (Chapter 3),

2. spiders can be relatively easily identified by community groups, although identifications to family or genus level require expert knowledge, and

3. they negatively respond to rat predation (Chapter 4, and others, Atkinson and Towns 2001, Innes 2001)

However, more comprehensive research is needed for these taxa. For example, developing studies to confirm aspects related to biology, ecology and demography of ground weta, and geographic distributions of both taxa in habitats different than forests (e.g. wetlands, 
alpine, coastal, scrubland, urban). A more accurate taxonomic identification of Araneae to species or genus level, could also offer insight into their more specific selection as potential indicators of predation (Monks et al. 2013).

The body size distribution of spiders seemed to statistically differ between years of sampling (at $p<0.05$ before Holm-Bonferroni correction) at ZEALANDIA and its surroundings with larger spiders being presumably related to the abundance of mice which are the only mammalian vertebrate recorded inside ZEALANDIA (Chapter 2, and other authors, Fitzgerald et al. (1996), Innes et al. (2014)). This observed trend needs to be confirmed by a more intensive sampling (e.g. seasonal sampling of both spiders and mice) inside and outside this fenced reserve, and may indicate whether spiders could be used as indicators of mouse predation as well (as seems likely from the work of Fitzgerald et al. (1996) analysing mouse stomach contents).

Carabidae are commonly used as indicators of diversity, land-use, climate change, forest soil, and environmental health worldwide (Speight et al. 1999, Larochelle and Larivière 2007, New 2007, Vandewalle et al. 2010). They may also be good indicators of vertebrate predation as they have been reported to be suppressed by rat and mouse predation on islands in New Zealand (Moors 1985, Towns et al. 1997, Marris 2000, Ruscoe 2001). However, I did not consider Carabidae as good indicators of predation as this diverse and well-known family did not show any responses to rat or mouse density in Aorangi and Remutaka Forests (Chapter 4) nor to mouse density inside and outside ZEALANDIA (Chapter 2). There was a tendency for Carabidae to be more abundant inside ZEALANDIA related to the surroundings. Although this difference failed at $p<0.05$ level of significance (exclusion 
effect $p=0.08$ ), these data provide insight into the effects of mammal predation on the abundance of these beetles that should be confirmed by further studies. Perhaps their defence mechanisms such as distasteful secretion of pungent odour may have been effective against vertebrate predation, or the particular species that inhabit the Aorangi, Remutaka or ZEALANDIA may not comprise the main diet items of rodents, or their responses to environmental factors (e.g. elevation, ground and litter cover, Chapter 4) may hide predation effects in these forests. I would expect that the list of potential indicators of mammal predation might increase after a more accurate taxonomic identification of spiders and other invertebrates and/or after a longer-term (more than 5 year) monitoring in Aorangi and Remutaka Forests.

\subsection{Limitations, recommendations and future research}

My research carried out in ZEALANDIA comprised collections in only one season (summer) in two different years (Chapter 2). Three main aspects could contribute to a stronger understanding of how ecological patterns of ground-dwelling invertebrates are influenced by the exclusion of introduced mammals:

1. investigating predation rates and prey choices of insectivores inside and outside the reserve to assess differential effects on invertebrates among seasons,

2. sampling vegetation and/or soil components inside and outside the reserve to inform responses of invertebrates to habitat and/or nutrients, similar to what was achieved in Aorangi and Remutaka Forests (Chapter 4), and

3. including additional sampling of invertebrates within the valley and along the elevational transect inside ZEALANDIA and relating them to similar habitats in the 
surrounding to compare the invertebrate diversity of the edge and interior of the forest.

This latter aspect would increase our understanding of whether neutral invertebrate responses observed near the fence (100 m away) are also replicated along different microhabitats in the reserve, or whether there is an edge-effect. The edges of ZEALANDIA, for example, tend to be ridges and different from the rest of the landscape where the habitat comprises sheltered gullies and terraces in the valley floor, both within and in the nearby forest outside the reserve (Polhill and Wrights Hill reserves) (Karori Sanctuary Trust 2016, Wellington City Council 2017). These differences in the landscape may have an effect on the composition and diversity of invertebrates at the edges of this forest depending on the different life styles of invertebrates (Ewers and Didham 2006).

I would suggest at least two ways to promote the increase of ground invertebrates within ZEALANDIA. From a top-down approach, establishing mouse- and bird-free zones (or enclosures) within fenced reserves may contribute to the decrease of predation pressure upon invertebrates, and set a source population of invertebrates within the forest. ZEALANDIA has a mouse exclosure area to conserve translocated tuatara populations within the fenced reserve. The tuatara diet comprises mainly insects, so this particular enclosure would not necessarily result in increased invertebrate diversity and abundance, but I did not study that specifically. Construction of zones for investigating various predation impacts on ground-dwelling vertebrates should include exclusion and/or separation of all predatory elements, and would best be dealt with in a "standard" crossed effects experimental design. 
From a bottom-up approach, the recovery and conservation of forests both inside and outside fenced reserves would enhance the habitat and nutrient availability for invertebrates and other communities. While flying insects can easily fly over a fence, increasing the capacity of external sources to contribute, ground-dwelling invertebrates are less vagile. Their movement and dispersal ability would be influenced by intrinsic factors such as their flight capability, body size and behaviour, and extrinsic factors such as ground properties (e.g. moisture, vegetation cover), physical barriers such as the fence itself and the road that goes along it, density of predators and/or prey availability. It is extremely important that actions like the maintenance of vegetation within ZEALANDIA (Blick et al. 2008), and outside it at George Denton Park \& Polhill, and Wrights Hill, are continued and enhanced to increase the buffer vegetation, and that mammal control around the reserve is maintained or scaled-up for better control. These actions are likely to contribute to increased interchange of invertebrates from and to the reserve and reduce potential edge effects of the reserve.

Dissimilarities in abundance of some ground-dwelling invertebrates were evident between ZEALANDIA and its surroundings, and the Aorangi and Remutaka, presumably due to the different forest structures and components related to site and successional stage that characterise these forests. For example, Amphipoda were more abundant inside and outside ZEALANDIA ( $\mathrm{n}=1,016$ and total number of 1.05 per trap-night) compared to the total abundance found in Aorangi and Remutaka ( $n=416$ and total number of 0.25 per trap-night). Amphipoda feed mainly on detritus including dead animal and plant material. Their greater abundance may suggest a greater accumulation of organic matter on the surface of the soil, which is generally observed in the early stages of forest developments (e.g. ZEALANDIA), 
but in mature forests (e.g. the Aorangi and Remutaka), this organic matter derived from litter decomposition, is distributed along the soil profile (Cotrufo et al. 2000). On the other hand, Scarabaeidae (dung beetles) $(\mathrm{n}=9)$ and ground weta (Hemiandrus spp.) $(\mathrm{n}=1)$ seemed to be rare at ZEALANDIA and its surroundings while they were highly abundant $(n=1,148$ and $n=590$, respectively) in the Aorangi and Remutaka Forests. These invertebrates respond to mammalian predator abundance (Chapter 4) but their differences between forests are more likely related to an association with mature forest habitat. Confirming differences in taxonomic composition of ground-dwelling invertebrates between the two forest types will require identifications to a finer taxonomic level.

I would expect rapid negative responses (via mortality and abundance decrease) of invertebrates to 1080 if there were taxa directly affected by this poison. However, positive responses would need time to develop, especially for longer-lived invertebrates (i.e. ground weta 2- 3 years). Thus, it remains unclear whether or not a year after 1080 application may be long enough to notice an increase of both short- and long-lived invertebrates, especially when 1080 poison is applied every 3 to 6 years and invertebrates seem to respond rapidly to rodent predation (Chapter 4). Two improvements could be made in monitoring invertebrate responses to mammal pests control in New Zealand. One way would be sampling immediate responses of targeted invertebrates throughout the year including winter, which may detect even faster negative responses to 1080 (if present). For example, monitoring detritivore abundance weeks before and weeks after the application of aerial 1080 may inform on whether any secondary poisoning is happening. Another way would be repeating pulsed short-term studies across multiple 1080 operations at different sites and 
years, but using standardised measures, which ultimately could contribute to understanding of invertebrate dynamics in a longer time frame e.g. over decades.

Invertebrates are reported to increase after beech flowering in mast cycle events (Fitzgerald et al. 1996, Alley et al. 2001), are affected by environmental variables and habitat changes (i.e. soil quality, percentage of canopy cover and distance to the nearest forest edge) (Speight et al. 1999), and they respond negatively to bird predation (Moeed and Fitzgerald 1982, Rogers et al. 2012). In addition, predation of individual species in a whole suite of mammals present in a system is not understood (i.e. hedgehogs, possums) (Berry 1999, Atkinson 2001). The findings from Chapter 4 would be informed further by measuring the relationship between ground-dwelling invertebrates and these covariates.

Invertebrates analysed here (Chapters 2-4) comprised a variety of taxa inhabiting the ground, from abundant soil invertebrates (Collembola and Acari) to larger and reasonably vagile invertebrates (Carabidae and Araneae). The level of taxonomic identification of individuals achieved in my research hindered the investigation of detailed interspecific relationships among invertebrates, except between Carabidae and Araneae (mainly predators) and potential prey (Chapter 4). Further invertebrate identifications are needed to increase our knowledge about the effects of 1080 pest control and predation along trophic cascades from nutrients, invertebrate prey, and primary invertebrate predators to toppredators (vertebrates) on the mainland to facilitate meta-analysis of the resulting data.

Predator-Free New Zealand is an ambitious plan to eradicate introduced mammals from the country (Department of Conservation 2017a). However, mammal control in New Zealand 
does not usually target mice or hedgehogs, so even if rats, mustelids and possums were completely eradicated from mainland, these mammals would remain. Hedgehogs mainly feed on insects and other invertebrates (Berry 1999, Atkinson 2001, Jones et al. 2005). In my thesis, I discussed the negative effects of mice on invertebrates within fenced reserves but not the effects of an increase in hedgehog detections when other mammals have been controlled. The implications for the conservation of ground-invertebrates in habitats dominated by mice and hedgehogs (after the control of others) remains unclear and should be one of the topics of future research in New Zealand. My outcomes provide valuable information on ground-dwelling invertebrate communities and their relationships with pest management to support and guide conservation management of these dynamic ground invertebrate communities on the mainland. 


\section{REFERENCES}

Ahlering, M. A., and J. Faaborg. 2006. Avian habitat management meets conspecific attraction: If you build it, will they come? The Auk 123:301-312.

Alley, J., P. Berben, J. Dugdale, B. Fitzgerald, P. Knightbridge, M. Meads, and R. Webster. 2001. Responses of litter-dwelling arthropods and house mice to beech seeding in the Orongorongo Valley, New Zealand. Journal of the Royal Society of New Zealand 31:425-452.

Amarillo-Suárez, Á. R. 2010. Top-down, bottom-up, and horizontal mortality variation in a generalist seed beetle. Revista Colombiana de Entomología 36:269-276.

Andresen, E. 2008a. Dung beetle assemblages in primary forest and disturbed habitats in a tropical dry forest landscape in western Mexico. Journal of Insect Conservation 12:639-650.

Andresen, E. 2008b. Short-term temporal variability in the abundance of tropical dung beetles. Insect Conservation and Diversity 1:120-124.

Aorangi Restoration Trust. 2016. Aorangi Trust. Retrieved from http://www.aorangitrust.org.nz/

Atkinson, I., and D. Towns. 2001. Advances in New Zealand mammalogy 1990-2000: Pacific rat. Journal of the Royal Society of New Zealand 31:99-109.

Atkinson, I. A. 2001. Introduced mammals and models for restoration. Biological Conservation 99:81-96.

Barker, G. M. 2016. Land snail communities respond to control of invasive rats in New Zealand forests. New Zealand Journal of Ecology 40:310-320. 
Bates, D., M. Mächler, B. Bolker, and S. Walker. 2015. Fitting linear mixed-effects models using lme4. Journal of Statistical Software 67.

Bennett, A. 2010. The role of soil community biodiversity in insect biodiversity. Insect Conservation and Diversity 3:157-171.

Bennett, S. J., R. J. Standish, and I. A. Stringer. 2002. Effects of rodent poisoning on Powelliphanta traversi. Science for Conservation 195C.

Berndt, L. 1998. Aspects of the ecology of ground-active spiders (Araneae) of the Karori Wildlife Sanctuary, Wellington. Unpublished Master Thesis. Victoria University of Wellington. $142 \mathrm{pp}$.

Berry, C. J. 1999. European hedgehogs (Erinaceus europaeus L.) and their significance to the ecological restoration of boundary stream mainland island, Hawkes Bay. Master Thesis. Victoria University of Wellington. 135 pp.

Blick, R., R. Bartholomew, T. Burrell, and K. Burns. 2008. Successional dynamics after pest eradication in the Karori Wildlife Sanctuary. New Zealand Natural Sciences 33:3-14.

Booth, L., S. Ogilvie, G. Wright, and C. Eason. 1999. Degradation of sodium monofluoroacetate (1080) and fluorocitrate in water. Bulletin of Environmental Contamination and Toxicology 62:34-39.

Borkhataria, R. R., J. A. Collazo, and M. J. Groom. 2006. Additive effects of vertebrate predators on insects in a Puerto Rican coffee plantation. Ecological Applications 16:696-703.

Bowie, M. H., W. J. Allen, J. McCaw, and R. van Heugten. 2014. Factors influencing occupancy of modified artificial refuges for monitoring the range-restricted Banks 
Peninsula tree weta Hemideina ricta (Anostostomatidae). New Zealand Journal of Ecology 38:132-138.

Bowie, M. H., and C. M. Frampton. 2004. A practical technique for non-destructive monitoring of soil surface invertebrates for ecological restoration programmes. Ecological Management \& Restoration 5:34-42.

Bowie, M. H., S. Hodge, J. C. Banks, and C. J. Vink. 2006. An appraisal of simple treemounted shelters for non-lethal monitoring of weta (Orthoptera: Anostostomatidae and Rhaphidophoridae) in New Zealand nature reserves. Journal of Insect Conservation 10:261-268.

Bradshaw, C. J., and B. W. Brook. 2010. The conservation biologist's toolbox-principles for the design and analysis of conservation studies. Pages 313-334 in N. S. Sodhi and P. R. Ehrlich, editors. Conservation Biology for All, Oxford University Press.

Bremner, A., C. Butcher, and G. Patterson. 1984. The density of indigenous invertebrates on three islands in Breaksea Sound, Fiordland, in relation to the distribution of introduced mammals. Journal of the Royal Society of New Zealand 14:379-386.

Brennan, K. E. C., J. D. Majer, and M. L. Moir. 2005. Refining sampling protocols for inventorying invertebrate biodiversity: influence of drift-fence length and pitfall trap diameter on spiders. Journal of Arachnology 33:681-702.

Brook, F. 2000. Prehistoric predation of the landsnail Placostylus ambagiosus Suter (Stylommatophora: Bulimulidae), and evidence for the timing of establishment of rats in northernmost New Zealand. Journal of the Royal Society of New Zealand 30:227-241. 
Buckley, T., R. Palma, P. Johns, D. Gleeson, A. Heath, R. Hitchmough, and I. Stringer. 2012. The conservation status of small or less well known groups of New Zealand terrestrial invertebrates. New Zealand Entomologist 35:137-143.

Burns, B., J. Innes, and T. Day. 2012. The use and potential of pest-proof fencing for ecosystem restoration and fauna conservation in New Zealand. Pages 65-90 in M. J. Somers and M. W. Hayward, editors. Fencing for conservation, restriction of evolutionary potential or a riposte to threatening processes?, Springer.

Burns, K. C. 2006. Weta and the evolution of fleshy fruits in New Zealand. New Zealand Journal of Ecology 30:405-406.

Byrom, A. E., J. Innes, and R. N. Binny. 2016. A review of biodiversity outcomes from possum-focused pest control in New Zealand. Wildlife Research 43:228-253.

Carpenter, J. K., J. M. Monks, and C. F. J. O'Donnell. 2016. Developing indices of relative abundance for monitoring cave and ground weta (Orthoptera) in southern beech forest, New Zealand. New Zealand Journal of Zoology 43:149-162.

Carpio, A. J., J. Castro-López, J. Guerrero-Casado, L. Ruiz-Aizpurua, J. Vicente, and F. S. Tortosa. 2014. Effect of wild ungulate density on invertebrates in a Mediterranean ecosystem. Animal Biodiversity and Conservation 37:115-125.

Carrillo, R., R. Alarcón, and M. Neira. 2007. The effects of carabid beetles (Coleoptera: Carabidae) on the arthropod fauna of wheat fields in Chile. Revista de Biología Tropical 55:101-111.

Chappell, E., D. Webb, A. Brown, and J. Tonkin. 2015. A preliminary survey of altitudinal variation in two ground weta species, Hemiandrus maculifrons (Walker) and Hemiandrus pallitarsis (Walker) (Orthoptera: Anostostomatidae). New Zealand Entomologist 38:1-6. 
Chappell, E., D. Webb, and J. Tonkin. 2014. Notes on sexual size dimorphism, sex ratio and movements of adult ground weta Hemiandrus maculifrons (Walker) (Orthoptera: Anostostomatidae). New Zealand Entomologist 37:83-92.

Connolly, T. A., T. D. Day, and C. M. King. 2009. Estimating the potential for reinvasion by mammalian pests through pest-exclusion fencing. Wildlife Research 36:410421.

Cook, L. D., S. A. Trewick, M. Morgan-Richards, and P. M. Johns. 2010. Status of the New Zealand cave weta (Rhaphidophoridae) genera Pachyrhamma, Gymnoplectron and Turbottoplectron. Invertebrate Systematics 24:131-138.

Cotrufo, M., M. Miller, and B. Zeller. 2000. Litter decomposition. Pages 276-297 in S. Ernst-Detlef, editor. Carbon and nitrogen cycling in European forest ecosystems: ecological studies, vol. 142, Springer, New York.

Courchamp, F., J. L. Chapuis, and M. Pascal. 2003. Mammal invaders on islands: impact, control and control impact. Biological Reviews 78:347-383.

Cowan, P. 2001. Advances in New Zealand mammalogy 1990-2000: brushtail possum. Journal of the Royal Society of New Zealand 31:15-29.

Craddock, P. 1997. The effect of rodent control on invertebrate communities in coastal forest near Auckland. Unpublished MSc-Zoology Thesis. University of Auckland. $132 \mathrm{pp}$.

Cranston, P. S. 2009. Biodiversity of Australasian insects. Pages 83-105 in R. Foottit and P. Adler, editors. Insect biodiversity: science and society. Blackwell Publishing Ltd.

Cuthill, I. C., M. Stevens, J. Sheppard, T. Maddocks, C. A. Párraga, and T. S. Troscianko. 2005. Disruptive coloration and background pattern matching. Nature 434:72-74. 
Dawson, J., and R. Lucas. 2000. Nature guide to the New Zealand forest. First edition. A Godwit Book published by Random House, New Zealand. 312 pp.

De Tores, P. J., D. R. Sutherland, J. R. Clarke, R. F. Hill, S. W. Garretson, L. Bloomfield, L. Strümpher, A. S. Glen, and J. Cruz. 2011. Assessment of risks to non-target species from an encapsulated toxin in a bait proposed for control of feral cats. Wildlife Research 38:39-50.

Dennis, R. L., L. Dapporto, T. G. Shreeve, E. John, J. G. Coutsis, O. Kudrna, K. Saarinen, N. Ryrholm, and W. B. Williams. 2008. Butterflies of European islands: the implications of the geography and ecology of rarity and endemicity for conservation. Journal of Insect Conservation 12:205-236.

Dent, E. 2016. The impacts of an introduced mammalian predator (Mus musculus) on tree weta (Hemideina trewicki) and skinks (Oligosoma polychroma, Oligosoma infrapunctatum and Oligosoma lineoocellatum) in Cape Sanctuary, Hawkes Bay. Unpublished Master Thesis. Victoria University of Wellington. 84 pp.

Department of Conservation. 2014. Project Kaka: Tararua nature recovery. Report. Wellington, New Zealand. 18 pp.

Department of Conservation. 2017a. Predator free 2050. Retrieved from http://www.doc.govt.nz/Documents/our-work/predator-free-2050

Department of Conservation, N. 2017b. Mainland islands. Retrieved from http://www.doc.govt.nz/our-work/mainland-islands/

Derraik, J. G., G. P. Closs, K. J. Dickinson, P. Sirvid, B. I. Barratt, and B. H. Patrick. 2002. Arthropod morphospecies versus taxonomic species: a case study with Araneae, Coleoptera, and Lepidoptera. Conservation Biology 16:1015-1023. 
Dickman, C. R. 2012. Fences or ferals? Benefits and costs of conservation fencing in Australia. Pages 43-63 in M. J. Somers and M. W. Hayward, editors. Fencing for conservation: restriction of evolutionary potential or a riposte to threatening processes?, Springer Science+Business Media.

Didham, R. K., G. M. Barker, J. A. Costall, L. H. Denmead, C. G. Floyd, and C. H. Watts. 2009. The interactive effects of livestock exclusion and mammalian pest control on the restoration of invertebrate communities in small forest remnants. New Zealand Journal of Zoology 36:135-163.

Doblas-Miranda, E., D. A. Wardle, D. A. Peltzer, and G. W. Yeates. 2008. Changes in the community structure and diversity of soil invertebrates across the Franz Josef Glacier chronosequence. Soil Biology and Biochemistry 40:1069-1081.

Dymond, J. R., and J. D. Shepherd. 2004. The spatial distribution of indigenous forest and its composition in the Wellington region, New Zealand, from ETM+ satellite imagery. Remote Sensing of Environment 90:116-125.

Eddowes, P. 2007. The impact of alien mammal exclusion on invertebrate food resources for native birds in New Zealand. Unpublished Master Thesis. University of Exeter, UK. 44 pp.

Eisler, R. 1995. Sodium monofluroacetate (1080) hazards to fish, wildlife, and invertebrates: A synoptic review Report. U.S. National Biological Service Laurel, MD 20708. $52 \mathrm{pp}$.

Elliott, G. 2016. The science behind the Department of Conservation's predator control response. Report. Department of Conservation. $10 \mathrm{pp}$.

Elliott, G., and J. Kemp. 2016. Large-scale pest control in New Zealand beech forests. Ecological Management \& Restoration 17:200-209. 
Empson, R., and D. Fastier. 2013. Translocations of North Island tomtits (Petroica macrocephala toitoi) and North Island robins (P. longipes) to Zealandia-Karori Sanctuary, an urban sanctuary. What have we learned. Notornis 60:63-69.

Erwin, T. L., and C. J. Geraci. 2009. Amazonian rainforests and their richness of Coleoptera, a dominant life form in the critical zone of the neotropics. Pages 49-67 in R. Foottit and P. Adler, editors. Insect biodiversity: science and society, Blackwell Publishing Ltd.

Evans, J. D. 1996. Straightforward statistics for the behavioral sciences. Brooks/Cole, Pacific Grove, California. 122 pp.

Ewers, R. M., and R. K. Didham. 2006. Confounding factors in the detection of species responses to habitat fragmentation. Biological Reviews 81:117-142.

Fan, C. M., E. C. Yang, and I. M. Tso. 2009. Hunting efficiency and predation risk shapes the color-associated foraging traits of a predator. Behavioral Ecology 20:808-816.

Ferguson, K., L. Adam, and F. Jori. 2012. An adaptive monitoring programme for studying impacts along the western boundary fence of Kruger National Park, South Africa. Pages 105-123 in M. J. Somers and M. W. Hayward, editors. Fencing for conservation: restriction of evolutionary potential or a riposte to threatening processes?, Springer Science+Business Media.

Fitness, J. 2017. Te Putaiao o Tokoriro: Taxonomy and diversity of New Zealand cave weta (Orthoptera: Rhapidophoridae). PhD Thesis. Massey University, New Zealand. 190 pp.

Fitness, J. L., M. Morgan-Richards, O. P. Ball, A. J. R. Godfrey, and S. A. Trewick. 2015. Improved resolution of cave weta diversity (Orthoptera: Rhaphidophoridae): 
ecological implications for Te Paki, Far North, New Zealand. New Zealand Journal of Zoology 42:1-16.

Fitzgerald, A. M., and B. J. Karl. 1979. Foods of feral house cats (Felis catus L.) in forest of the Orongorongo Valley, Wellington. New Zealand Journal of Zoology 6:107126.

Fitzgerald, B. 1990. House cat. Pages 330-348 in C. M. King, editor. The handbook of New Zealand mammals. Oxford University Press, Auckland.

Fitzgerald, B., M. Daniel, A. Fitzgerald, B. Karl, M. Meads, and P. Notman. 1996. Factors affecting the numbers of house mice (Mus musculus) in hard beech (Nothofagus truncata) forest. Journal of the Royal Society of New Zealand 26:237-249.

Forgie, S. A., J. J. Dymock, and D. M. Tompkins. 2014. No evidence that brushtail possums (Trichosurus vulpecula) forage on dung beetles (Coleoptera: Scarabaeidae) in New Zealand. New Zealand Journal of Zoology 41:95-102.

Fox, J. 2007. The dynamics of top-down and bottom-up effects in food webs of varying prey diversity, composition, and productivity. Oikos 116:189-200.

Fukami, T., D. A. Wardle, P. J. Bellingham, C. P. Mulder, D. R. Towns, G. W. Yeates, K. I. Bonner, M. S. Durrett, M. N. Grant-Hoffman, and W. M. Williamson. 2006. Above-and below-ground impacts of introduced predators in seabird-dominated island ecosystems. Ecology Letters 9:1299-1307.

Fuller, L., P. M. Johns, and R. M. Ewers. 2013. Assessment of protected area coverage of threatened ground beetles (Coleoptera: Carabidae): a new analysis for New Zealand. New Zealand Journal of Ecology 37:184-192.

Gardi, C., C. Menta, and V. Parisi. 2002. Use of microarthropods as biological indicators of soil quality: The BSQ sinthetic indicator. in International meeting on: soils with 
Mediterranean type of climate. 23-28 Sep 2001. CIHEAM-IAMB, Valenzano, Italy.

Garnier, E., J. Cortez, G. Billes, M. L. Navas, C. Roumet, M. Debussche, G. Laurent, A. Blanchard, D. Aubry, A. Bellmann, C. Neill, and J. P. Toussaint. 2004. Plant functional markers capture ecosystem properties during secondary succession. Ecology 85:2630-2637.

Gaston, K. J. 2010. Biodiversity. Pages 27-42 in N. S. Sodhi and P. R. Ehrlich, editors. Conservation Biology for All. Oxford University press.

Gibbs, G. W. 1998. Why are some weta (Orthoptera: Stenopelmatidae) vulnerable yet others are common? Journal of Insect Conservation 2:161-166.

Gibbs, G. W. 2002. A new species of tusked weta from the Raukumara Range, North Island, New Zealand (Orthoptera: Anostostomatidae: Motuweta). New Zealand Journal of Zoology 29:293-301.

Gibbs, G. W. 2006. Ghosts of Gondwana: the history of life in New Zealand. Craig Potton Publishing, Nelson, New Zealand. 132 pp.

Gibbs, G. W. 2009. The end of an 80-million year experiment: a review of evidence describing the impact of introduced rodents on New Zealand's 'mammalfree'invertebrate fauna. Biological Invasions 11:1587-1593.

Gibbs, G. W. 2010. Do New Zealand invertebrates reflect the dominance of birds in their evolutionary history? New Zealand Journal of Ecology 34:152.

Gibbs, G. W. 2016. Ghosts of Gondwana: the history of life in New Zealand. Fully revised edition. Potton \& Burton Nelson, New Zealand. 416 pp. 
Gillies, C., and D. Williams. 2013. DOC tracking tunnel guide v2.5.2: Using tracking tunnels to monitor rodents and mustelids. Report. Department of Conservation, Science \& Capability Group, Hamilton, New Zealand. 14 pp.

Gillott, C. 2005. Entomology. Springer Science \& Business Media, Netherlands. 832 pp.

Godin, J.-G. J., and H. E. McDonough. 2003. Predator preference for brightly colored males in the guppy: a viability cost for a sexually selected trait. Behavioral Ecology 14:194-200.

Goldwater, N., G. L. Perry, and M. N. Clout. 2012. Responses of house mice to the removal of mammalian predators and competitors. Austral Ecology 37:971-979.

Grass, I., K. Lehmann, C. Thies, and T. Tscharntke. 2017. Insectivorous birds disrupt biological control of cereal aphids. Ecology 98:1583-1590.

Green, C. 2002. Recovery of invertebrate populations on Tiritiri Matangi Island, New Zealand following eradication of Pacific rats (Rattus exulans). in Turning the tide: the eradication of invasive species. Proceedings of the international conference on eradication of island invasives. IUCN SSC Invasive Species Specialist Group. Gland, Switzerland and Cambridge, UK.

Green, W. 2004. The use of 1080 for pest control: a discussion document. Report. Animal Health Board and the Department of Conservation, New Zealand. 64 pp.

Greenslade, P. J. M. 1964. Pitfall trapping as a method for studying populations of Carabidae (Coleoptera). The Journal of Animal Ecology 33:301-310.

Griffiths, J., G. Elliott, D. Carlton, M. Barron, W. A. Ruscoe, and P. Crisp. 2013. Project Kaka; understanding the efficacy of 3 yearly pre-fed aerial 1080 applications for large scale forest restoration. VII Southern Connections Conference, Dunedin, New Zealand. 
Gripenberg, S., and T. Roslin. 2007. Up or down in space? Uniting the bottom-up versus top-down paradigm and spatial ecology. Oikos 116:181-188.

Gunnarsson, B. 1996. Bird predation and vegetation structure affecting spruce-living arthropods in a temperate forest. Journal of Animal Ecology 65:389-397.

Gunnarsson, B., and M. Hake. 1999. Bird predation affects canopy-living arthropods in city parks. Canadian Journal of Zoology 77:1419-1428.

Gwynne, D. T. 2002. A secondary copulatory structure in a female insect: a clasp for a nuptial meal? Naturwissenschaften 89:125-127.

Gwynne, D. T. 2005. The secondary copulatory organ in female ground weta (Hemiandrus pallitarsis, Orthoptera: Anostostomatidae): a sexually selected device in females? Biological Journal of the Linnean Society 85:463-469.

Hairston, N. G., F. E. Smith, and L. B. Slobodkin. 1960. Community structure, population control, and competition. The American Naturalist 94:421-425.

Halffter, G., and M. E. Favila. 1993. The Scarabaeinae (Insecta: Coleoptera) an animal group for analyzing, inventorying and monitoring biodiversity in tropical rainforest and modified landscapes. Biology International 27:15-21.

Harper, G. A., and L. F. Cabrera. 2010. Response of mice (Mus musculus) to the removal of black rats (Rattus rattus) in arid forest on Santa Cruz Island, Galápagos. Biological Invasions 12:1449-1452.

Hartley, S. 2017. Biodiversity responses to possum-control in Aorangi and Haurangi Forests. Activity report for 2016-17. Report. TbFree, New Zealand. 25 pp.

Hendra, R. 1999. Seasonal abundance patterns and dietary preferences of hedgehogs at Trounson Kauri Park. Conservation Advisory Science Notes No. 267. 
Hicks, B. J., D. P. Hamilton, N. Ling, and S. A. Wood. 2007. Top down or bottom up? Feasibility of water clarity restoration in the lower Karori Reservoir by fish removal. Report. The University of Waikato, Hamilton, New Zealand. 21 pp.

Hoare, J. M., L. K. Adams, L. S. Bull, and D. R. Towns. 2007. Attempting to manage complex predator-prey interactions fails to avert imminent extinction of a threatened New Zealand skink population. The Journal of Wildlife Management 71:1576-1584.

Holm, S. 1979. A simple sequentially rejective multiple test procedure. Scandinavian Journal of Statistics 6:65-70.

Hunt, M., G. Sherley, and M. D. Wakelin. 1998. Results of a pilot study to detect benefits to large-bodied invertebrates from sustained regular poisoning of rodents and possums at Karioi, Ohakune. Report. Department of Conservation, Wellington, New Zealand. 17 pp.

Hunter, D. O., T. Britz, M. Jones, and M. Letnic. 2015. Reintroduction of Tasmanian devils to mainland Australia can restore top-down control in ecosystems where dingoes have been extirpated. Biological Conservation 191:428-435.

Hunter, M. D., and P. W. Price. 1992. Playing Chutes and Ladders: Heterogeneity and the Relative Roles of Bottom-Up and Top-Down Forces in Natural Communities. Ecology 73:724-732.

Hurst, J., and R. Allen. 2007. The Recce method for describing New Zealand vegetationexpanded manual. Report. Landcare Research, New Zealand. 64 pp.

Hutcheson, J., and R. Crabtree. 1994. A preliminary comparison of malaise trapped beetles from tawa forest sites with varied management in the Onaia Ecological Area. Report. New Zealand Forest Research Institute. Lincoln, New Zealand. pp. 
Innes, J. 2001. Advances in New Zealand mammalogy 1990-2000: European rats. Journal of the Royal Society of New Zealand 31:111-125.

Innes, J., D. Kelly, J. M. Overton, and C. Gillies. 2010. Predation and other factors currently limiting New Zealand forest birds. New Zealand Journal of Ecology 34:86.

Innes, J., W. G. Lee, B. Burns, C. Campbell-Hunt, C. Watts, H. Phipps, and T. Stephens. 2012. Role of predator-proof fences in restoring New Zealand's biodiversity: a response to Scofield et al. (2011). New Zealand Journal of Ecology 36:232-238.

Innes, J., B. Warburton, D. Williams, H. Speed, and P. Bradfield. 1995. Large-scale poisoning of ship rats (Rattus rattus) in indigenous forests of the North Island, New Zealand. New Zealand Journal of Ecology 19:5-17.

Innes, J., C. Watts, D. Wilson, N. Fitzgerald, S. Bartlam, D. Thornburrow, M. Smale, M. Padamsee, G. Barker, and K. Frogley. 2014. Impacts of mice alone on biodiversity: interim report on a Waikato field trial. Report. Landcare Research New Zealand Ltd and Waikato Regional Council. New Zealand. 40 pp.

Jiménez-Valverde, A., A. Baselga, A. Melic, and N. Txasko. 2010. Climate and regional beta-diversity gradients in spiders: dispersal capacity has nothing to say? Insect Conservation and Diversity 3:51-60.

Johns, P. M. 2001. Distribution and conservation status of ground weta, Hemiandrus species (Orthoptera: Anostostomatidae). Report. Department of Conservation, Wellington, New Zealand. $250 \mathrm{pp}$.

Jones, A. G., S. A. Forgie, D. J. Scott, and J. R. Beggs. 2012. Generalist dung attraction response in a New Zealand dung beetle that evolved with an absence of mammalian herbivores. Ecological Entomology 37:124-133. 
Jones, C., K. Moss, and M. Sanders. 2005. Diet of hedgehogs (Erinaceus europaeus) in the upper Waitaki Basin, New Zealand: implications for conservation. New Zealand Journal of Ecology 29:29-35.

Jones, C., and R. Toft. 2006. Impacts of mice and hedgehogs on native forest invertebrates: a pilot study. Report. Science \& Technical Publishing, Department of Conservation, New Zealand. $32 \mathrm{pp}$.

Jones, H. P., D. R. Towns, T. W. Bodey, C. Miskelly, J. C. Ellis, M. J. Rauzon, S. W. Kress, and M. W. McKown. 2011. Recovery and Restoration on Seabird Islands. Pages 317-357 in C. P. H. Mulder, W. B. Anderson, D. R. Towns, and P. J. Bellingham, editors. Seabird Islands: Ecology, Invasion, and Restoration. Oxford Scholarship Online.

Karban, R., P. Grof-Tisza, J. L. Maron, and M. Holyoak. 2012. The importance of host plant limitation for caterpillars of an arctiid moth (Platyprepia virginalis) varies spatially. Ecology 93:2216-2226.

Karori Sanctuary Trust. 2016. Zealandia Sanctuary. Karori, Wellington, New Zealand. Retrieved from http://www.visitzealandia.com

Keesing, V., and S. D. Wratten. 1998. Indigenous invertebrate components in ecological restoration in agricultural landscapes. New Zealand Journal of Ecology 22:99-104.

Kelly, D., W. D. Koenig, and A. M. Liebhold. 2008. An intercontinental comparison of the dynamic behavior of mast seeding communities. Population Ecology 50:329342.

Kim, K. C. 2009. Taxonomy and management of insect biodiversity. Pages 561-574 in R. G. Foottit and P. H. Adler, editors. Insect biodiversity: science and society, Blackwell Publishing Ltd. 
Kingsolver, J. G., and R. B. Huey. 2008. Size, temperature, and fitness: three rules. Evolutionary Ecology Research 10:251-268.

Klimaszewski, J., and J. C. Watt. 1997. Coleoptera: family-group review and keys to identification. Fauna of New Zealand. Manaaki Whenua Press, Landcare Research, Lincon, Canterbury, New Zealand. 199 pp.

Knapp, M., E. Baranovská, and P. Jakubec. 2016. Effects of bait presence and type of preservative fluid on ground and carrion beetle samples collected by pitfall trapping. Environmental Entomology 45:1022-1028.

Kuschel, G., and T. Worthy. 1996. Past distribution of large weevils (Coleoptera: Curculionidae) in the South Island, New Zealand, based on Holocene fossil remains. New Zealand Entomologist 19:15-22.

Lambin, X., D. A. Elston, S. J. Petty, and J. L. MacKinnon. 1998. Spatial asynchrony and periodic travelling waves in cyclic populations of field voles. Proceedings of the Royal Society of London B: Biological Sciences 265:1491-1496.

Larochelle, A., and M.-C. Larivière. 2007. Carabidae (Insecta: Coleoptera): synopsis of supraspecific taxa. Fauna of New Zealand. Manaaki Whenua Press, Landcare Research, Lincoln, New Zealand 188 pp.

Lawrence, K. L., and D. H. Wise. 2000. Spider predation on forest-floor Collembola and evidence for indirect effects on decomposition. Pedobiologia 44:33-39.

Lester, P., S. Brown, E. Edwards, G. Holwell, S. Pawson, D. Ward, and C. Watts. 2014. Critical issues facing New Zealand entomology. New Zealand Entomologist 37:113.

Lloyd, B. 1994. Evaluating the potential hazard of aerial 1080 poison operations to shorttailed bat populations. Report. Department of Conservation, New Zealand. 11 pp. 
MacArthur, N., S. Moylan, and P. Crisp. 2012. Baseline survey of the diversity, abundance and distribution of birds in Wellington City reserves. Report. Greater Wellington Regional Council, New Zealand. 25 pp.

Marris, J. W. M. 2000. The beetle (Coleoptera) fauna of the Antipodes Islands, with comments on the impact of mice; and an annotated checklist of the insect and arachnid fauna. Journal of the Royal Society of New Zealand 30:169-195.

Mazia, C. N., E. J. Chaneton, T. Kitzberger, and L. A. Garibaldi. 2009. Variable strength of top-down effects in Nothofagus forests: bird predation and insect herbivory during an ENSO event. Austral Ecology 34:359-367.

McClelland, P. 2002. Eradication of Pacific rats (Rattus exulans) from Whenua Hou Nature Reserve (Codfish Island), Putauhinu and Rarotoka Islands, New Zealand. Pages 173-181 in C. Veitch and M. Clout, editors. Turning the tide: the eradication of invasive species. IUCN SCC Invasive Species Specialist Group, IUCN, Gland, Switzerland \& Cambridge, UK.

McGeoch, M. A. 1998. The selection, testing and application of terrestrial insects as bioindicators. Biological Reviews of the Cambridge Philosophical Society 73:181201.

McIntyre, M. E. 1987. Ecological and Behavioural Relationships of Some Native Cockroaches (Dictyoptera: Blattidae). PhD Thesis. Victoria University of Wellington, New Zealand. 199 pp.

McIntyre, M. E. 2001. The ecology of some large weta species. Pages 225-242 in L. Field, editor. The biology of wetas, king crickets and their allies. CABI Publishing UK.

Meads, M. 1990. Forgotten fauna: the rare, endangered, and protected invertebrates of New Zealand. DSIR Publishing, Wellington, New Zealand 95 pp. 
Miller, A. P., and P. I. Webb. 2001. Diet of house mice (Mus musculus L.) on coastal sand dunes, Otago, New Zealand. New Zealand Journal of Zoology 28:49-55.

Moeed, A., and B. Fitzgerald. 1982. Foods of insectivorous birds in forest of the Orongorongo Valley, Wellington, New Zealand. New Zealand Journal of Zoology 9:391-403.

Moeed, A., and M. Meads. 1986. Seasonality of litter-inhabiting invertebrates in two native-forest communities of Orongorongo Valley, New Zealand. New Zealand Journal of Zoology 13:45-63.

Moeed, A., and M. J. Meads. 1983. Invertebrate fauna of four tree species in Orongorongo Valley, New Zealand, as revealed by trunk traps. New Zealand Journal of Ecology 6:39-53.

Monks, J. M., C. F. O'Donnell, and E. F. Wright. 2013. Selection of potential indicator species for measuring and reporting on trends in widespread native taxa in New Zealand. Publishing Team, Department of Conservation, New Zealand. pp.

Moors, P. 1985. Norway rats (Rattus norvegicus) on the Noises and Motukawao Islands, Hauraki Gulf, New Zealand. New Zealand Journal of Ecology 8:37-54.

Moretti, M., and C. Legg. 2009. Combining plant and animal traits to assess community functional responses to disturbance. Ecography 32:299-309.

Morgan-Richards, M., S. A. Trewick, and S. Dunavan. 2008. When is it coevolution? The case of ground weta and fleshy fruits in New Zealand. New Zealand Journal of Ecology 32:108-112.

Morgan, D., J. Waas, and J. Innes. 2009. An inventory of mammalian pests in a New Zealand city. New Zealand Journal of Zoology 36:23-33. 
Morrison, E. B., and C. A. Lindell. 2012. Birds and bats reduce insect biomass and leaf damage in tropical forest restoration sites. Ecological Applications 22:1526-1534.

Moss, K., and M. Sanders. 2001. Advances in New Zealand mammalogy 1990-2000: hedgehog. Journal of the Royal Society of New Zealand 31:31-42.

Murphy, E., and P. Bradfield. 1992. Change in diet of stoats following poisoning of rats in a New Zealand forest. New Zealand Journal of Ecology 16:137-140.

Murphy, E. C., and J. E. Dowding. 1995. Ecology of the stoat in Nothofagus forest: home range, habitat use and diet at different stages of the beech mast cycle. New Zealand Journal of Ecology 19:97-109.

Nelson, G. H., F. E. Smith, and L. B. Slobodkin. 1960. Community Structure, Population Control, and Competition. The American Naturalist 94:421-425.

New, T. R. 2007. Beetles and conservation. Journal of Insect Conservation 11:1-4.

New, T. R. 2008. Insect conservation and islands. Springer Science \& Business Media. $247 \mathrm{pp}$.

Newman, D. G. 1994. Effects of a mouse, Mus musculus, eradication programme and habitat change on lizard populations of Mana Island, New Zealand, with special reference to McGregor's skink, Cyclodina macgregori. New Zealand Journal of Zoology 21:443-456.

Newman, D. G., and I. McFadden. 1990. Seasonal fluctuations of numbers, breeding, and food of kiore (Rattus exulans) on Lady Alice Island (Hen and Chickens group), with a consideration of kiore: tuatara (Sphenodon punctatus) relationships in New Zealand. New Zealand Journal of Zoology 17:55-63.

Nijhout, H. 2003. The control of body size in insects. Developmental Biology 261:1-9. 
Norton, D. A., and B. Warburton. 2015. The potential for biodiversity offsetting to fund effective invasive species control. Conservation Biology 29:5-11.

Notman, P. 1989. A review of invertebrate poisoning by compound 1080. New Zealand Entomologist 12:67-71.

O'Donnell, C. F., and J. M. Hoare. 2012. Quantifying the benefits of long-term integrated pest control for forest bird populations in a New Zealand temperate rainforest. New Zealand Journal of Ecology:131-140.

O’Donnell, C. F., J. Christie, B. Lloyd, S. Parsons, and R. Hitchmough. 2013. Conservation status of New Zealand bats, 2012. New Zealand Threat Classification Series 6:12.

Oksanen, J., F. G. Blanchet, M. Friendly, R. Kindt, P. Legendre, D. McGlinn, P. R. Minchin, R. B. O'Hara, G. L. Simpson, P. Solymos, M. H. H. Stevens, E. Szoecs, and H. Wagner. 2018. Community Ecology Package. Package 'vegan' 2.4-6. Page 292.

Oliver, I., and A. J. Beattie. 1996a. Designing a cost-effective invertebrate survey: A test of methods for rapid assessment of biodiversity. Ecological Applications 6:594607.

Oliver, I., and A. J. Beattie. 1996b. Invertebrate morphospecies as surrogates for species: a case study. Conservation Biology 10:99-109.

OSPRI. 2012. TBFree: Rimutaka aerial possum control completed. Retrieved from http://www.tbfree.org.nz

Power, M. E. 1992. Top-down and bottom-up forces in food webs: do plants have primacy. Ecology 73:733-746. 
Powlesland, R., I. Stringer, and D. Hedderley. 2005. Effects of an aerial 1080 possum poison operation using carrot baits on invertebrates in artificial refuges at Whirinaki Forest Park, 1999-2002. New Zealand Journal of Ecology 29:193-205.

Pryde, M. A., C. F. O’Donnell, and R. J. Barker. 2005. Factors influencing survival and long-term population viability of New Zealand long-tailed bats (Chalinolobus tuberculatus): implications for conservation. Biological Conservation 126:175185.

Ramsay, G. 1978. A review of the effect of rodents on the New Zealand invertebrate fauna. Pages 89-95. Department of Lands and Survey Wellington, New Zealand.

Rate, S. R. 2009. Does rat control benefit forest invertebrates at Moehau, Coromandel Peninsula? Report. Pub. Team. Department of Conservation, New Zealand. 26 pp. Rice, W. R. 1989. Analyzing Tables of Statistical Tests. Evolution 43:223-225.

Rogers, H., J. H. R. Lambers, R. Miller, and J. J. Tewksbury. 2012. 'Natural experiment'demonstrates top-down control of spiders by birds on a landscape level. PloS one 7:e43446.

Root, R. B. 1973. Organization of a Plant-Arthropod Association in Simple and Diverse Habitats: The Fauna of Collards (Brassica Oleracea). Ecological Monographs 43:95-124.

Rosseel, Y., D. Oberski, J. Byrnes, L. Vanbrabant, V. Savalei, E. Merkle, M. Hallquist, M. Rhemtulla, M. Katsikatsou, M. Barendse, M. Chow, and T. Jorgensen. 2017. Latent Variable Analysis. Page 92.

Rufaut, C. G., and G. W. Gibbs. 2003. Response of a tree weta population (Hemideina crassidens) after eradication of the Polynesian rat from a New Zealand island. Restoration Ecology 11:13-19. 
Ruggiero, A., P. Sackmann, A. G. Farji-Brener, and M. Kun. 2009. Beetle abundanceenvironment relationships at the subantarctic-patagonian transition zone. Insect Conservation and Diversity 2:81-92.

Ruscoe, W. 2001. Advances in New Zealand mammalogy 1990-2000: house mouse. Journal of the Royal Society of New Zealand 31:127-134.

Ruscoe, W. A., D. S. Ramsey, R. P. Pech, P. J. Sweetapple, I. Yockney, M. C. Barron, M. Perry, G. Nugent, R. Carran, and R. Warne. 2011. Unexpected consequences of control: competitive vs. predator release in a four-species assemblage of invasive mammals. Ecology Letters 14:1035-1042.

Ruscoe, W. A., P. J. Sweetapple, M. Perry, and R. P. Duncan. 2013. Effects of Spatially Extensive Control of Invasive Rats on Abundance of Native Invertebrates in Mainland New Zealand Forests. Conservation Biology 27:74-82.

Ruscoe, W. A., D. Wilson, L. McElrea, G. McElrea, and S. J. Richardson. 2004. A house mouse (Mus musculus) population eruption in response to rimu (Dacrydium cupressinum) seedfall in southern New Zealand. New Zealand Journal of Ecology 28:259-265.

Russell, J. C. 2012. Spatio-temporal patterns of introduced mice and invertebrates on Antipodes Island. Polar Biology 35:1187-1195.

Sabu, T. K., and R. T. Shiju. 2010. Efficacy of pitfall trapping, Winkler and Berlese extraction methods for measuring ground-dwelling arthropods in moistdeciduous forests in the Western Ghats. Journal of Insect Science 10:Available online: insectscience.org/10.98.

Santorufo, L., C. A. Van Gestel, A. Rocco, and G. Maisto. 2012. Soil invertebrates as bioindicators of urban soil quality. Environmental Pollution 161:57-63. 
Saunders, A., and D. Norton. 2001. Ecological restoration at mainland islands in New Zealand. Biological Conservation 99:109-119.

Schadewinkel, R. B., A. M. Senior, D. J. Wilson, and I. G. Jamieson. 2014. Effects on South Island robins (Petroica australis) from pest control using aerially applied 1080 poison. New Zealand Journal of Ecology 38:315-321.

Schowalter, T. D. 2011. Insect ecology: an ecosystem approach. Academic Press, Burlington, MA. pp.

Schwarz, C. J. 2014. Chapter 2: Analysis of BACI experiments. Page 104 Course Notes for beginning and intermediate statistics, Department of Statistics and Actuiarial Science, Simon Fraser University, Canada.

Seldon, D. S., and J. R. Beggs. 2010. The efficacy of baited and live capture pitfall traps in collecting large-bodied forest carabids. New Zealand Entomologist 33:30-37.

Shaw, R. C., N. J. Boogert, N. S. Clayton, and K. C. Burns. 2015. Wild psychometrics: evidence for 'general'cognitive performance in wild New Zealand robins, Petroica longipes. Animal Behaviour 109:101-111.

Sherley, G. H. 1985. The breeding system of the South Island Rifleman (Acanthisitta chloris) at Kowhai Bush, Kaikoura, New Zealand. PhD Thesis. University of Canterbury, New Zealand. 224 pp.

Sherley, G. H., I. A. N. Stringer, G. R. Parrish, and I. Flux. 1998. Demography of two landsnail populations (Placostylus ambagiosus, Pulmonata: Bulimulidae) in relation to predator control in the far north of New Zealand. Biological Conservation 84:83-88.

Simberloff, D. 2008. Successes, failures, and challenges in protecting biodiversity: DOC and the next 20 years. Page 14 in Conserv-Vision conference. A celebration of 20 
years of conservation by New Zealand's Department of Conservation The University of Waikato Hamilton, New Zealand

Simberloff, D. 2010. Invasive species. Pages 131-152 in N. S. Sodhi and P. R. Ehrlich, editors. Conservation biology for all. Oxford University press, Unite States.

Sinclair, L., J. McCartney, J. Godfrey, S. Pledger, M. Wakelin, and G. Sherley. 2005. How did invertebrates respond to eradication of rats from Kapiti Island, New Zealand? New Zealand Journal of Zoology 32:293-315.

Smith, R. K., A. S. Pullin, G. B. Stewart, and W. J. Sutherland. 2010. Effectiveness of predator removal for enhancing bird populations. Conservation Biology 24:820829.

Speight, M. R., M. D. Hunter, and A. D. Watt. 1999. Ecology of insects: concepts and applications. Blackwell Science Ltd. 641 pp.

Spurr, E., and K. Drew. 1999. Invertebrates feeding on baits used for vertebrate pest control in New Zealand. New Zealand Journal of Ecology 23:167-173.

Spurr, E., S. Rod, and K. Tranter. 2011. Food preferences of the bellbird (Anthornis melanura) in native forest remnants on the Port Hills, Banks Peninsula, New Zealand. Notornis 58:139-157.

Spurr, E. B., and P. H. Berben. 2004. Assessment of non-target impact of 1080-poisoning for vertebrate pest control on weta (Orthoptera: Anostostomatidae and Rhaphidophoridae) and other invertebrates in artificial refuges. New Zealand Journal of Ecology 28:63-72.

St Clair, J. J. 2011. The impacts of invasive rodents on island invertebrates. Biological Conservation 144:68-81. 
Stavert, J. R., B. A. Drayton, J. R. Beggs, and A. C. Gaskett. 2014a. The volatile organic compounds of introduced and native dung and carrion and their role in dung beetle foraging behaviour. Ecological Entomology 39:556-565.

Stavert, J. R., A. C. Gaskett, D. J. Scott, and J. R. Beggs. 2014b. Dung beetles in an aviandominated island ecosystem: feeding and trophic ecology. Oecologia 176:259-271.

Stoler, A. B., and R. A. Relyea. 2013. Bottom-up meets top-down: leaf litter inputs influence predator-prey interactions in wetlands. Oecologia 173:249-257.

Stringer, I., and R. Chappell. 2008. Possible rescue from extinction: transfer of a rare New Zealand tusked weta to islands in the Mercury group. Journal of Insect Conservation 12:371-382.

Stringer, I., and R. Hitchmough. 2012. Assessing the conservation status of New Zealand's native terrestrial invertebrates. New Zealand Entomologist 35:77-84.

Sutherland, W. J. 2006. Ecological census techniques: a handbook. Cambridge University Press, UK. 450 pp.

Sweetapple, P. J., and G. Nugent. 2007. Ship rat demography and diet following possum control in a mixed podocarp — hardwood forest. New Zealand Journal of Ecology 31:186-201.

Sweetapple, P. J., and G. Nugent. 2011. Chew-track-cards: a multiple-species small mammal detection device. New Zealand Journal of Ecology 35:153-162.

Taylor-Smith, B. 2015. Evolution of diversity: Analysis of species and speciation in Hemiandrus ground weta. PhD Thesis. Massey University, New Zealand. 226 pp. Taylor-Smith, B. L., M. Morgan-Richards, and S. A. Trewick. 2013. New Zealand ground wētā (Anostostomatidae: Hemiandrus): descriptions of two species with notes on their biology. New Zealand Journal of Zoology 40:314-329. 
Taylor-Smith, B. L., S. A. Trewick, and M. Morgan-Richards. 2016. Three new ground wētā species and a redescription of Hemiandrus maculifrons. New Zealand Journal of Zoology 43:363-383.

Thoresen, J. J., D. Towns, S. Leuzinger, M. Durrett, C. P. H. Mulder, and D. A. Wardle. 2017. Invasive rodents have multiple indirect effects on seabird island invertebrate food web structure. Ecological Applications 27:1190-1198.

Towns, D. R. 2002. Interactions between geckos, honeydew scale insects and host plants revealed on islands in northern New Zealand, following eradication of introduced rats and rabbits. Pages 329-335 in C. Veitch and M. Clout, editors. Turning the tide: the eradication of invasive species. IUCN SCC Invasive Species Specialist Group, IUCN, Gland, Switzerland \& Cambridge, UK.

Towns, D. R., P. J. Bellingham, C. P. Mulder, and P. O. B. Lyver. 2012. A research strategy for biodiversity conservation on New Zealand's offshore islands. New Zealand Journal of Ecology 36:1-20.

Towns, D. R., D. Simberloff, and I. A. Atkinson. 1997. Restoration of New Zealand islands: redressing the effects of introduced species. Pacific Conservation Biology 3:99-124.

Towns, D. R., D. A. Wardle, C. P. Mulder, G. W. Yeates, B. M. Fitzgerald, G. Richard Parrish, P. J. Bellingham, and K. I. Bonner. 2009. Predation of seabirds by invasive rats: multiple indirect consequences for invertebrate communities. Oikos 118:420-430.

Trewick, S. A., and K. J. Bland. 2012. Fire and slice: palaeogeography for biogeography at New Zealand's North Island/South Island juncture. Journal of the Royal Society of New Zealand 42:153-183. 
Trewick, S. A., and M. Morgan-Richards. 2015. Weta Geta, A comprehensive guide to New Zealand Orthoptera. Retrieved from http://soilbugs.massey.ac.nz/insecta.php Tscharntke, T., and B. A. Hawkins. 2002. Multitrophic level interactions. Cambridge University Press. 284 pp.

Van Aarde, R., S. Ferreira, and T. Wassenaar. 2004. Do feral house mice have an impact on invertebrate communities on sub-Antarctic Marion Island? Austral Ecology 29:215-224.

Vandewalle, M., F. De Bello, M. P. Berg, T. Bolger, S. Dolédec, F. Dubs, C. K. Feld, R. Harrington, P. A. Harrison, and S. Lavorel. 2010. Functional traits as indicators of biodiversity response to land use changes across ecosystems and organisms. Biodiversity and Conservation 19:2921-2947.

Veltman, C. J., and I. M. Westbrooke. 2011. Forest bird mortality and baiting practices in New Zealand aerial 1080 operations from 1986 to 2009. New Zealand Journal of Ecology 35:21-29.

Walker, T. J. 1957. Ecological studies of the arthropods associated with certain decaying materials in four habitats. Ecology 38:262-276.

Watt, J. C. 1983. Beetles (Coleoptera) of Auckland. Tane 29:31-50.

Watts, C., R. Empson, D. Thornburrow, and M. Rohan. 2012a. Movements, behaviour and survival of adult Cook Strait giant weta (Deinacrida rugosa; Anostostomatidae: Orthoptera) immediately after translocation as revealed by radiotracking. Journal of Insect Conservation 16:763-776.

Watts, C., I. Stringer, G. Sherley, G. Gibbs, and C. Green. 2008. History of weta (Orthoptera: Anostostomatidae) translocation in New Zealand: lessons learned, islands as sanctuaries and the future. Journal of Insect Conservation 12:359-370. 
Watts, C., D. Thornburrow, V. Cave, and J. Innes. 2014. Beetle community changes following pest mammal control at two biodiversity sanctuaries in Wellington, New Zealand. Journal of the Royal Society of New Zealand 44:61-87.

Watts, C., D. Thornburrow, and J. Innes. 2012b. Monitoring invertebrates in communityled sanctuaries. Kararehe Kino - Vertebrate Pest Research 20:16-17.

Watts, C. H., D. P. Armstrong, J. Innes, and D. Thornburrow. 2011. Dramatic increases in weta (Orthoptera) following mammal eradication on Maungatautari-evidence from pitfalls and tracking tunnels. New Zealand Journal of Ecology 35:261-272.

Weaver, S. 2003. Policy implications of 1080 toxicology in New Zealand. Journal of Rural and Remote Environmental Health 2:46-59.

Wellington City Council. 2017. Predator Free Wellington. Retrieved from http://wellington.govt.nz/your-council/projects/predator-free-wellington

Williams, K. S. 1993. Use of terrestrial arthropods to evaluate restored riparian woodlands. Restoration Ecology 1:107-116.

Wilson, E. O. 1987. The little things that run the world (the importance and conservation of invertebrates). Conservation Biology 1:344-346.

Woodcock, B. A. 2005. Pitfall trapping in ecological studies. Pages 37-57 in S. Leather, editor. Insect sampling in forest ecosystems. Blackwell Publishing, UK.

Wootton, J. T. 1994. The nature and consequences of indirect effects in ecological communities. Annual Review of Ecology and Systematics 25:443-466.

Wright, J. 2011. Evaluating the use of 1080: predators, poisons and silent forests. Report. New Zealand. 85 pp.

Zavaleta, E. S., R. J. Hobbs, and H. A. Mooney. 2001. Viewing invasive species removal in a whole-ecosystem context. Trends in Ecology \& Evolution 16:454-459. 
8. APPENDIX 
APPENDIX TABLE 8.1 Taxonomic composition and total abundance of invertebrate communities inside $(\mathrm{Z})$ and outside $(\mathrm{O})$ the fenced reserve, ZEALANDIA, in 2014 and 2015.

\begin{tabular}{|c|c|c|c|c|c|c|c|c|}
\hline Taxonomic level & & & Guilds $^{a}$ & 2014 & & 2015 & & \\
\hline Class & Order & Family & & $\mathrm{Z}$ & $\mathrm{O}$ & $\mathrm{Z}$ & $\mathrm{O}$ & Total \\
\hline \multirow[t]{23}{*}{ Insecta } & Coleoptera & Carabidae & $\mathrm{P}$ & 43 & 12 & 47 & 9 & 111 \\
\hline & & Scarabaeidae & $\mathrm{D} / \mathrm{H}$ & 6 & 0 & 3 & 0 & 9 \\
\hline & & Curculionidae & $\mathrm{H}$ & 3 & 7 & 10 & 10 & 30 \\
\hline & & Chrysomelidae & $\mathrm{H}$ & 0 & 0 & 0 & 1 & 1 \\
\hline & & Staphylinidae & $\mathrm{P} / \mathrm{D}$ & 10 & 99 & 23 & 159 & 291 \\
\hline & & Pselaphidae & $\mathrm{P}$ & 1 & 0 & 5 & 1 & 7 \\
\hline & & Tenebrionidae & $\mathrm{D}$ & 1 & 0 & 0 & 0 & 1 \\
\hline & & Lucanidae & D & 0 & 0 & 0 & 2 & 2 \\
\hline & & Elateridae & $\mathrm{H} / \mathrm{P}$ & 0 & 0 & 6 & 2 & 8 \\
\hline & & Mordellidae & $\mathrm{H}$ & 0 & 0 & 1 & 0 & 1 \\
\hline & & Other beetles & - & 8 & 17 & 16 & 21 & 62 \\
\hline & Orthoptera & $\begin{array}{l}\text { Rhaphidophoridae } \\
\text { (CW) }\end{array}$ & $\mathrm{O}$ & 4 & 5 & 9 & 5 & 23 \\
\hline & & $\begin{array}{l}\text { Anostostomatidae } \\
\text { (GW) }\end{array}$ & $\mathrm{O}$ & 0 & 0 & 0 & 1 & 1 \\
\hline & & $\begin{array}{l}\text { Anostostomatidae } \\
\text { (TW) }\end{array}$ & $\mathrm{O}$ & 0 & 0 & 2 & 0 & 2 \\
\hline & & Other Orthoptera & - & 0 & 0 & 0 & 4 & 4 \\
\hline & Diptera & & $\mathrm{D}$ & 8 & 9 & 39 & 66 & 122 \\
\hline & Hemiptera & & $\mathrm{H}$ & 3 & 5 & 5 & 9 & 22 \\
\hline & Hymenoptera & Formicidae & $\mathrm{O}$ & 7 & 2 & 46 & 21 & 76 \\
\hline & & Others Hymenoptera & - & 6 & 4 & 9 & 15 & 34 \\
\hline & Psocoptera & & $\mathrm{D}$ & 4 & 4 & 5 & 1 & 14 \\
\hline & Dermaptera & & $\mathrm{O}$ & 0 & 0 & 1 & 0 & 1 \\
\hline & & Other insects & - & 1 & 2 & 0 & 2 & 5 \\
\hline & Archaeognatha & & $\mathrm{H} / \mathrm{D}$ & 0 & 1 & 0 & 1 & 2 \\
\hline Diplura & & & $\mathrm{P}$ & 0 & 1 & 2 & 48 & 51 \\
\hline Collembola & & & $\mathrm{D}$ & 93 & 502 & 143 & 93 & 831 \\
\hline \multirow[t]{4}{*}{ Arachnida } & Acari & & $\mathrm{P} / \mathrm{D}$ & 21 & 27 & 37 & 49 & 134 \\
\hline & Araneae & & $\mathrm{P}$ & 78 & 98 & 64 & 81 & 321 \\
\hline & Opiliones & & $\mathrm{P} / \mathrm{D}$ & 7 & 9 & 19 & 36 & 71 \\
\hline & Pseudoscorpiones & & $\mathrm{P}$ & 12 & 3 & 9 & 0 & 24 \\
\hline Diplopoda & & & $\mathrm{D}$ & 19 & 22 & 38 & 77 & 156 \\
\hline Chilopoda & & & $\mathrm{P}$ & 2 & 1 & 2 & 4 & 9 \\
\hline \multirow[t]{2}{*}{ Crustacea } & Isopoda & & $\mathrm{D}$ & 3 & 3 & 14 & 15 & 35 \\
\hline & Amphipoda & & $\mathrm{D}$ & 149 & 149 & 396 & 322 & 1016 \\
\hline \multirow[t]{3}{*}{ Gastropoda } & & (Snail) & $\mathrm{H}$ & 3 & 7 & 6 & 10 & 26 \\
\hline & & $\begin{array}{l}\text { Others (flatworms } \\
\text { etc.) }\end{array}$ & - & 6 & 8 & 6 & 9 & 29 \\
\hline & & Total & & 498 & 997 & 963 & 1074 & 3532 \\
\hline
\end{tabular}

${ }^{a} \mathrm{P}=$ Predator; $\mathrm{D}=$ Detritivores; $\mathrm{H}=$ Herbivorous; $\mathrm{O}=$ Omnivorous. $\mathrm{CW}=$ cave weta, $\mathrm{GW}=$ ground weta, $\mathrm{TW}=$ tree weta 

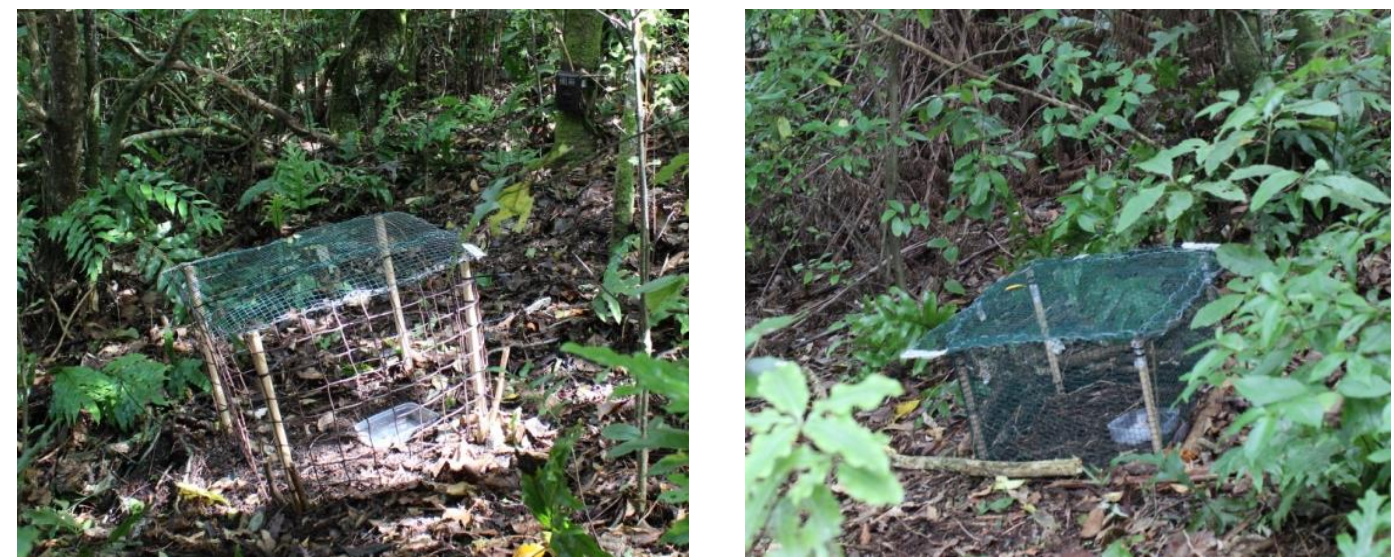

a

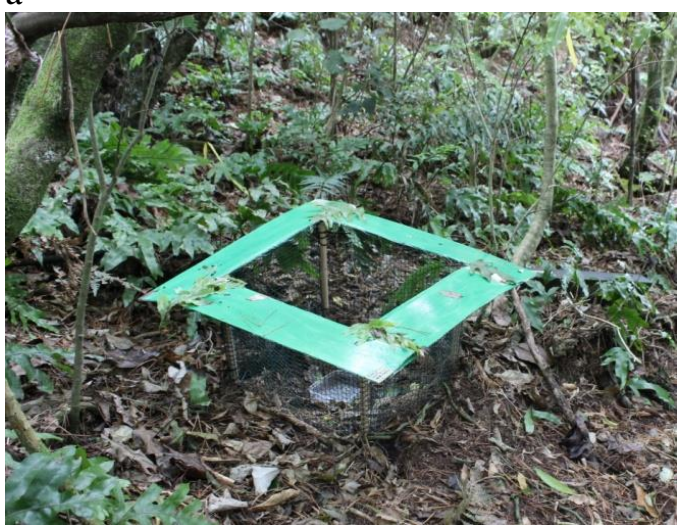

c

b

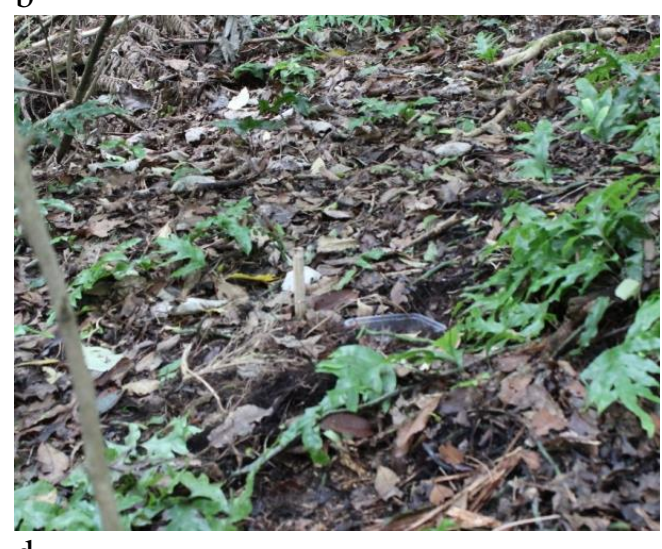

d

APPENDIX FIGURE 8.1 Details of each treatment and control for predation pressure experiment inside and outside the fenced reserve. a) Bird-reduced entry treatment (BE), b) bird and mammal exclusions (BME), c) mammal exclusion (ME) and d) control.
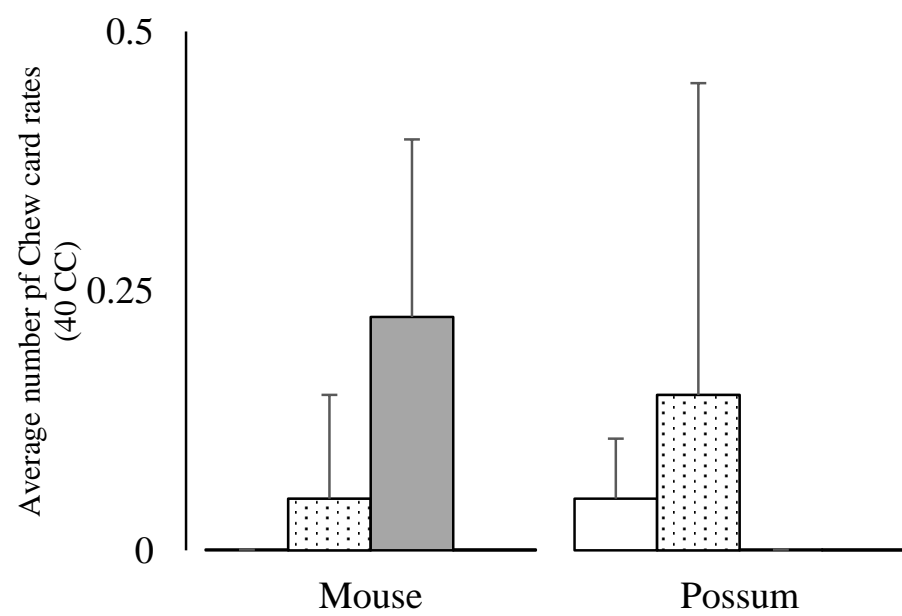

$\square$ Outside 2014

$\square$ Outside 2015

$\square$ Inside 2014

๑Inside 2015

APPENDIX FIGURE 8.2 Detection average $( \pm \mathrm{SD})$ rate of mammals inside (closed patterns) and outside (white patterns) the fenced reserve using chew card devices for 2014 and 2015. 


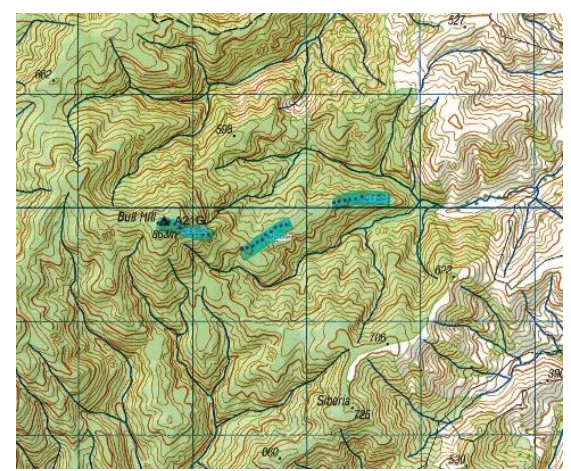

Bull hill (BUL) 440-860m, Aorangi

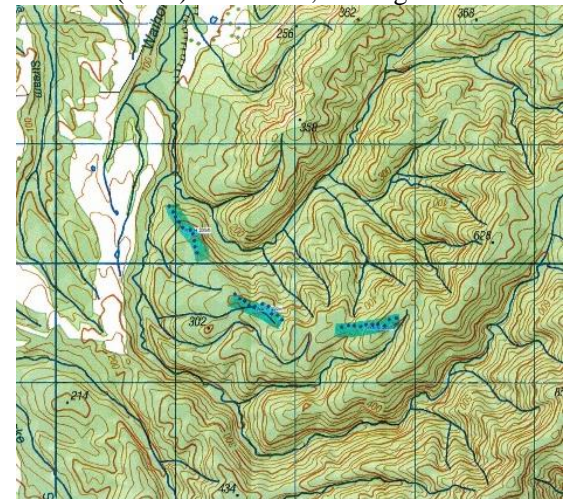

Waihora (WAI) 260-510m, Aorangi

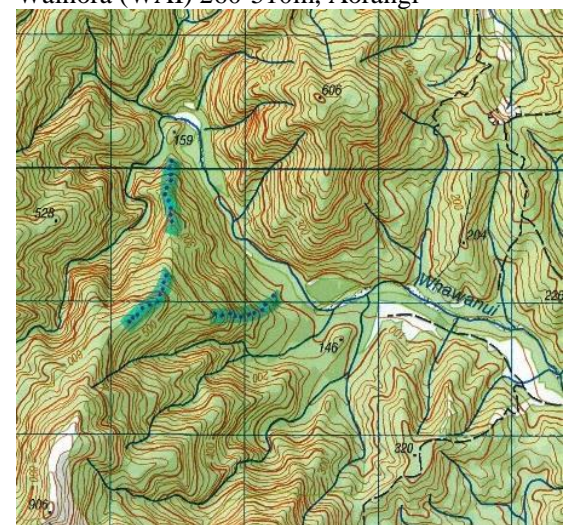

Whawanui-Homeburn (WHA) 160-580m, Aorangi

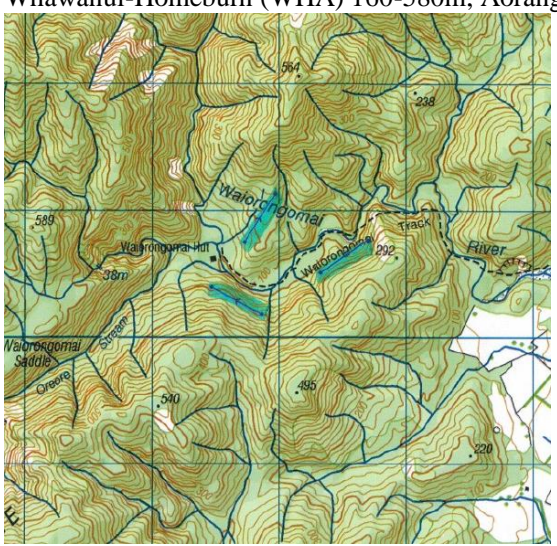

Wairongomai (East) (WRM) 120-260m, Remutaka

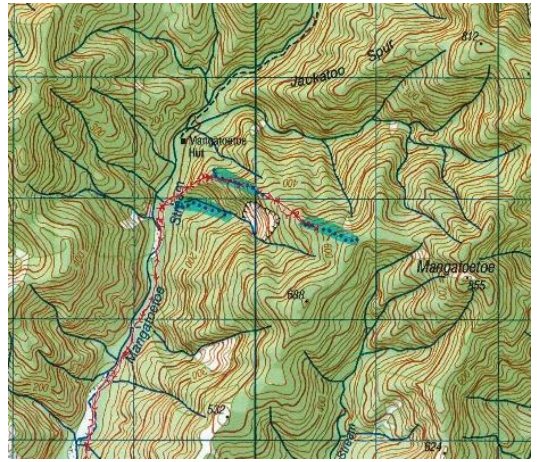

Mangatoetoe (MAN) 100-660m, Aorangi

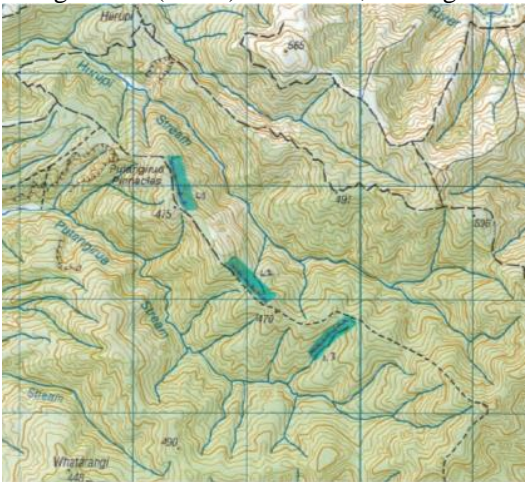

Pinnacles (PIN) 380-440m, Aorangi

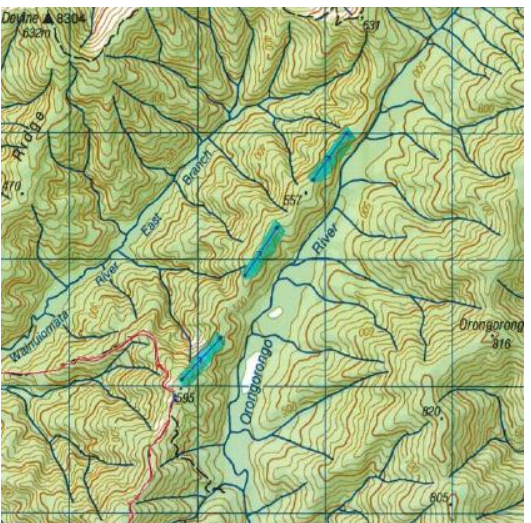

Orongorongo (West) (ORO) 460-590m, Remutaka

APPENDIX FIGURE 8.3 Details of monitoring lines at each site in the Aorangi and Remutaka

Forests. 
Appendix Table 8.2 Taxonomic composition and total abundance of invertebrates in Aorangi and Remutaka Forests from November 2013 to November 2015. AF=

Aorangi Forest, RF= Remutaka Forest; Preference: Epi= Epigeous, F= Foliage, $\mathrm{M}=$ mainly, GDW= Ground-dwelling; Guilds: $\mathrm{P}=$ Predator, H= Herbivore, $\mathrm{D}=\mathrm{Detritivore}$,

$\mathrm{O}=$ Omnivore.

\begin{tabular}{|c|c|c|c|c|c|c|c|c|c|c|c|c|c|c|c|c|c|c|c|c|}
\hline \multicolumn{3}{|c|}{ Taxonomic level } & \multirow[b]{2}{*}{ Species } & \multirow[b]{2}{*}{ Preference } & \multirow[b]{2}{*}{ Guilds $^{a}$} & \multirow{2}{*}{\begin{tabular}{|c|} 
Novv-12 \\
AF \\
\end{tabular}} & \multirow{2}{*}{\begin{tabular}{|c|} 
Feb-13 \\
$\mathrm{AF}$
\end{tabular}} & \multicolumn{2}{|c|}{ Nov-2013 } & \multicolumn{2}{|c|}{ Feb-2014 } & \multicolumn{2}{|c|}{ Nov-2014 } & \multicolumn{2}{|c|}{ Feb-2015 } & \multicolumn{2}{|c|}{ Nov-2015 } & \multicolumn{2}{|c|}{ Total } & \multirow[t]{2}{*}{ Total } \\
\hline Class & Order & Family & & & & & & $\mathbf{A F}$ & RF & $\mathbf{A F}$ & RF & $\mathbf{A F}$ & $\mathbf{R F}$ & $\mathbf{A F}$ & $\mathbf{R F}$ & $\mathbf{A F}$ & $\mathbf{R F}$ & $\mathbf{A F}$ & RF & \\
\hline Collembola & & & & Epi-soil & D & - & & 198 & 39 & 175 & 17 & 933 & 268 & 2065 & 1027 & 2995 & 51 & 6366 & 1402 & 7768 \\
\hline \multirow[t]{22}{*}{ Insecta } & Coleoptera & Carabidae & & Epi-Gdw & $\mathrm{P}$ & - & & 14 & 88 & 61 & 54 & 28 & 14 & 41 & 37 & 27 & 129 & 171 & 322 & 493 \\
\hline & & & Ctenognathus sp1 & Epi-Gdw & $P$ & - & - & 0 & 33 & 10 & 17 & 8 & 6 & 19 & 7 & 0 & 34 & 37 & 97 & 134 \\
\hline & & & Ctenognathus sp2 & Epi-Gdw & $P$ & - & - & 1 & 42 & 2 & 25 & 1 & 6 & 8 & 20 & 0 & 84 & 12 & 177 & 189 \\
\hline & & & Mecodema sp1 & Epi-Gdw & $P$ & - & - & 1 & 2 & 6 & 2 & 1 & 0 & 0 & 0 & 1 & 1 & 9 & 5 & 14 \\
\hline & & & Mecodema sp2 & Epi-Gdw & $P$ & - & & 0 & 2 & 0 & 2 & 1 & 1 & 0 & 0 & 0 & 0 & 1 & 5 & 6 \\
\hline & & & Megadromus sp1 & Epi-Gdw & $P$ & - & - & 1 & 0 & 11 & 0 & 4 & 0 & 7 & 2 & 4 & 0 & 27 & 2 & 29 \\
\hline & & & Megadromus sp2 & Epi-Gdw & $P$ & - & - & 0 & 2 & 0 & 3 & 0 & 0 & 0 & 2 & 2 & 6 & 2 & 13 & 15 \\
\hline & & & Pentagonica vittipennis & Epi-Gdw & $P$ & - & - & 0 & 0 & 2 & 0 & 0 & 1 & 0 & 3 & 1 & 0 & 3 & 4 & 7 \\
\hline & & & Psegmatopterus? sp1 & Epi-Gdw & $\mathrm{P}$ & - & - & 1 & 0 & 4 & 0 & 1 & 0 & 3 & 0 & 0 & 1 & 9 & 1 & 10 \\
\hline & & & Morphospecies 3 & Epi-Gdw & $P$ & - & - & 3 & 3 & 9 & 3 & 7 & 0 & 1 & 1 & 3 & 0 & 23 & 7 & 30 \\
\hline & & & Morphospecies 4 & Epi-Gdw & $\mathrm{P}$ & - & - & 4 & 1 & 7 & 0 & 0 & 0 & 0 & 1 & 2 & 0 & 13 & 2 & 15 \\
\hline & & & Morphospecies 9 & Epi-Gdw & $P$ & - & - & 0 & 0 & 0 & 0 & 2 & 0 & 0 & 1 & 0 & 0 & 2 & 1 & 3 \\
\hline & & & Morphospecies 13 & Epi-Gdw & $P$ & - & - & 0 & 0 & 0 & 2 & 0 & 0 & 0 & 0 & 0 & 0 & 0 & 2 & 2 \\
\hline & & & Morphospecies 16 & Epi-Gdw & $P$ & - & - & 3 & 0 & 10 & 0 & 3 & 0 & 3 & 0 & 14 & 3 & 33 & 3 & 36 \\
\hline & & & Morphospecies 17 & Epi-Gdw & $P$ & - & - & 0 & 3 & 0 & 0 & 0 & 0 & 0 & 0 & 0 & 0 & 0 & 3 & 3 \\
\hline & & Scarabaeidae & Saphobius spp. & Epi-Gdw & $\mathrm{D}^{\mathrm{a}}$ & - & - & 79 & 51 & 384 & 30 & 107 & 57 & 97 & 230 & 73 & 40 & 740 & 408 & 1148 \\
\hline & & Curculionidae & & Epi-Gdw & $\mathrm{H}$ & - & - & 3 & 5 & 5 & 4 & 2 & 3 & 12 & 7 & 6 & 1 & 28 & 20 & 48 \\
\hline & & Chrysomelidae & & Fol & $\mathrm{H}$ & - & - & 0 & 0 & 0 & 0 & 0 & 0 & 3 & 0 & 0 & 1 & 3 & 1 & 4 \\
\hline & & Staphylinidae & & Epi-Gdw & $\mathrm{P} / \mathrm{D}$ & - & - & 10 & 3 & 81 & 7 & 16 & 5 & 43 & 11 & 3 & 4 & 153 & 30 & 183 \\
\hline & & $\begin{array}{l}\text { Pselaphidae } \\
\end{array}$ & & Epi-Gdw & $P$ & - & - & 0 & 0 & 8 & 1 & 1 & 1 & 2 & 1 & 3 & 2 & 14 & 5 & 19 \\
\hline & & Tenebrionidae & & Epi-Gdw & D & - & - & 0 & 0 & 1 & 0 & 0 & 0 & 0 & 0 & 0 & 0 & 1 & 0 & 1 \\
\hline & & Lucanidae & & Epi-Gdw & $\mathrm{D}$ & - & - & 1 & 0 & 1 & 0 & 0 & 0 & 0 & 0 & 0 & 0 & 2 & 0 & 2 \\
\hline
\end{tabular}




\begin{tabular}{|c|c|c|c|c|c|c|c|c|c|c|c|c|c|c|c|c|c|c|c|c|}
\hline & & Elateridae & & Fol & $\mathrm{H} / \mathrm{P}$ & - & - & 2 & 7 & 2 & 0 & 15 & 0 & 2 & 1 & 1 & 6 & 22 & 14 & 36 \\
\hline & & Other Beetles & & - & - & - & - & 7 & 13 & 46 & 5 & 25 & 9 & 63 & 25 & 42 & 12 & 183 & 64 & 247 \\
\hline & Orthoptera & Rhaphidophoridae & & Epi-Gdw & $\mathrm{O}$ & 1 & 21 & 9 & 11 & 28 & 13 & 9 & 17 & 53 & 33 & 7 & 23 & 128 & 97 & 225 \\
\hline & & Anostostomatidae & Hemiandrus spp. & Epi-Gdw & $\mathrm{O}$ & 8 & 210 & 26 & 20 & 95 & 1 & 18 & 4 & 158 & 30 & 20 & 0 & 535 & 55 & 590 \\
\hline & Diptera & & & Fol & $\mathrm{D}$ & - & - & 205 & 182 & 789 & 118 & 743 & 310 & 1126 & 413 & 1547 & 142 & 4410 & 1165 & 5575 \\
\hline & Hemiptera & & & Fol & $\mathrm{H}$ & - & - & 3 & 2 & 25 & 5 & 6 & 18 & 42 & 33 & 11 & 13 & 87 & 71 & 158 \\
\hline & Hymenoptera & & & M Epi-Gdw & $\mathrm{O}$ & - & - & 42 & 37 & 149 & 31 & 85 & 39 & 225 & 63 & 57 & 8 & 558 & 178 & 736 \\
\hline & Blattodea & (cockroaches) & & Epi-Gdw & $\mathrm{O}$ & - & - & 3 & 0 & 7 & 0 & 0 & 1 & 5 & 0 & 0 & 0 & 15 & 1 & 16 \\
\hline Arachnida & Acari & & & Epi/soil & $\mathrm{P} / \mathrm{D}$ & - & - & 134 & 29 & 83 & 9 & 105 & 31 & 357 & 100 & 550 & 58 & 1229 & 227 & 1456 \\
\hline & Araneae & & & Epi-Gdw & $P$ & - & - & 62 & 29 & 165 & 68 & 57 & 19 & 193 & 74 & 78 & 26 & 555 & 216 & 771 \\
\hline & Opiliones & & & Epi-Gdw & $\mathrm{P} / \mathrm{D}$ & - & - & 78 & 30 & 95 & 22 & 55 & 42 & 144 & 66 & 73 & 49 & 445 & 209 & 654 \\
\hline & Pseudoscorpiones & & & Epi-Gdw & $P$ & - & - & 3 & 0 & 0 & 1 & 2 & 0 & 6 & 1 & 8 & 1 & 19 & 3 & 22 \\
\hline Diplopoda & & & & Epi-Gdw & $\mathrm{D}$ & - & - & 3 & 4 & 11 & 3 & 5 & 8 & 4 & 11 & 13 & 2 & 36 & 28 & 64 \\
\hline Chilopoda & & & & Epi-Gdw & $P$ & - & - & 6 & 1 & 4 & 2 & 3 & 1 & 4 & 3 & 4 & 0 & 21 & 7 & 28 \\
\hline Crustacea & Isopoda & & & Epi-Gdw & $\mathrm{D}$ & - & - & 7 & 3 & 3 & 1 & 6 & 7 & 9 & 3 & 5 & 3 & 30 & 17 & 47 \\
\hline & Amphipoda & & & Epi-Gdw & $\mathrm{D}$ & - & - & 26 & 30 & 53 & 28 & 40 & 22 & 76 & 89 & 28 & 22 & 223 & 191 & 414 \\
\hline Gastropoda & & & & Epi-Gdw & - & - & - & 2 & 1 & 12 & 8 & 7 & 5 & 8 & 4 & 13 & 1 & 42 & 19 & 61 \\
\hline & & & & & Total & 9 & 231 & 923 & 585 & 2283 & 428 & 2268 & 881 & 4738 & 2262 & 5564 & 594 & 16016 & 4750 & 20766 \\
\hline
\end{tabular}



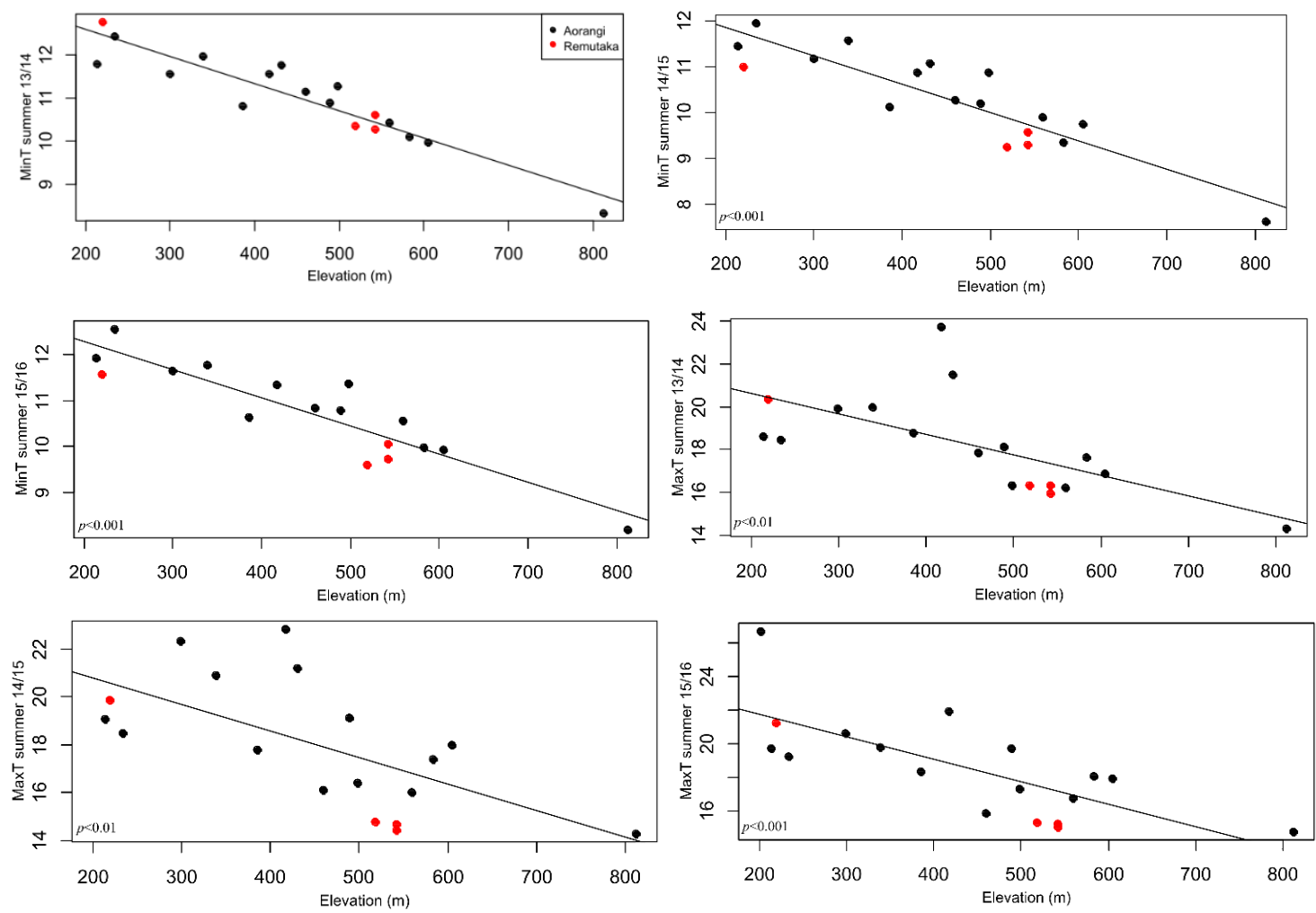

APPENDIX FigURE 8.4 Mean daily minimum temperature (MinT) and mean daily maximum temperatures (MaxT) as a function of Elevation (m) in Aorangi and Remutaka Forests for Summer 2013/2014, 2014/15, 2015/16. Circles denotes average number per pitfall trap plot for Aorangi (black) and Remutaka (red) monitoring sites. 
Aorangi Forest

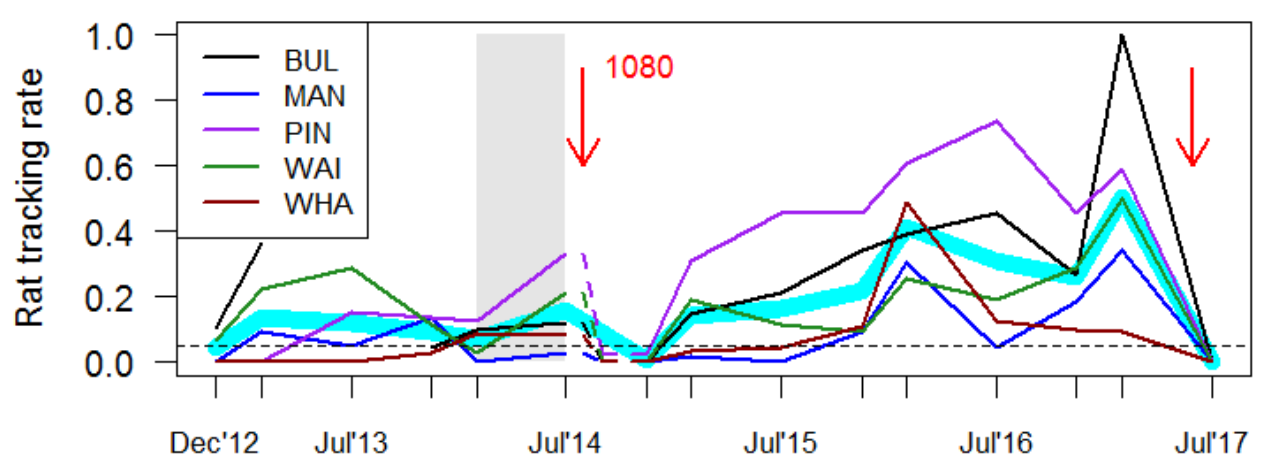

Remutaka Forest

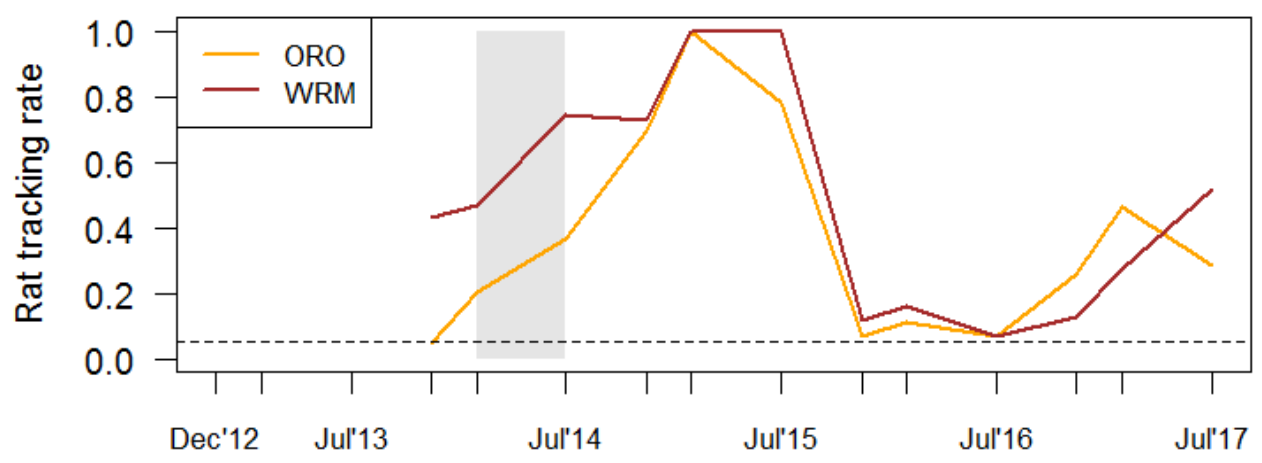

a) 


\section{Aorangi Forest}

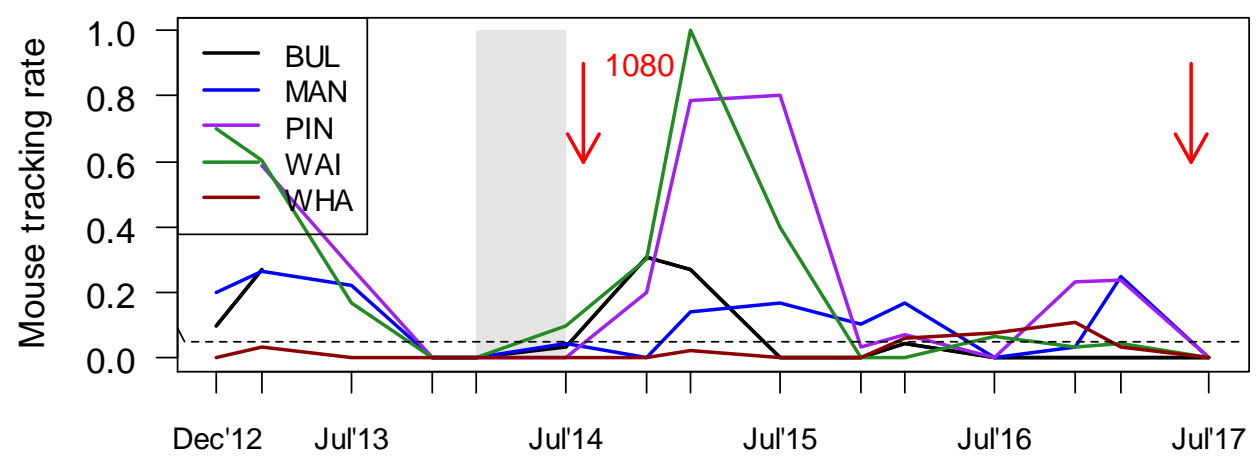

Remutaka Forest

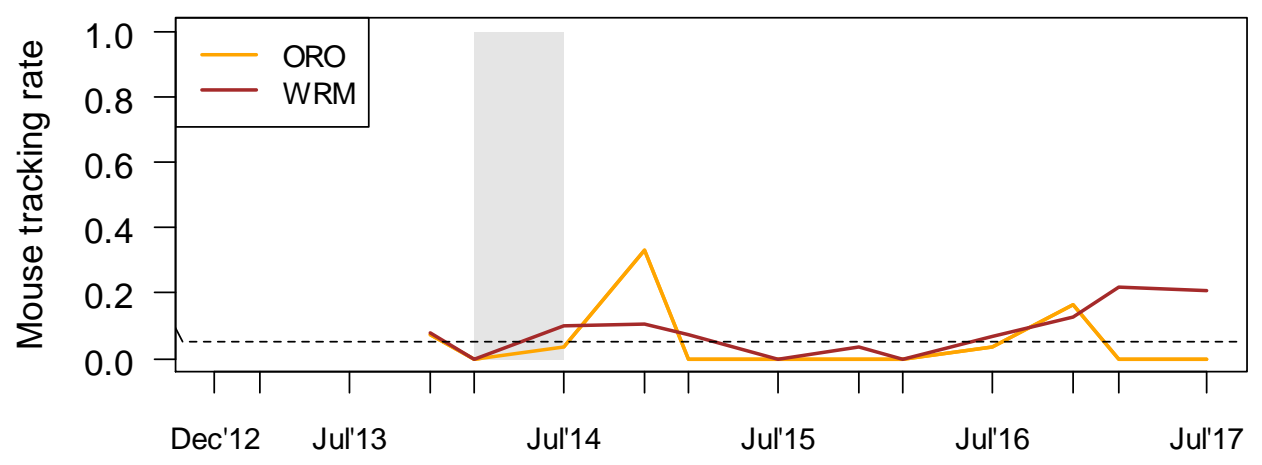

b)

APPENDIX FigURE 8.5 Detection rates of a) rats and b) mice across the Aorangi and Remutaka monitoring sites. Results are shown separately by site (see Chapter 3 ). The average for the detection rates of rats in the Aorangi Forest as a whole is shown by a thick blue line. Rat tracking rates have been transformed to equal those expected from the standard operating protocols of the Department of Conservation, New Zealand (one-night with peanut butter at both ends) and adjusted to account for possum interference. The horizontal dashed line indicates a $5 \%$ tracking rate. The grey band between February and July 2014 represents a heavy mast year with abundant beech seed on the ground. Red arrows indicate the timing of aerial 1080 drops in the Aorangi (August 2014 and June 2017). Extracted from Hartley (2017). 


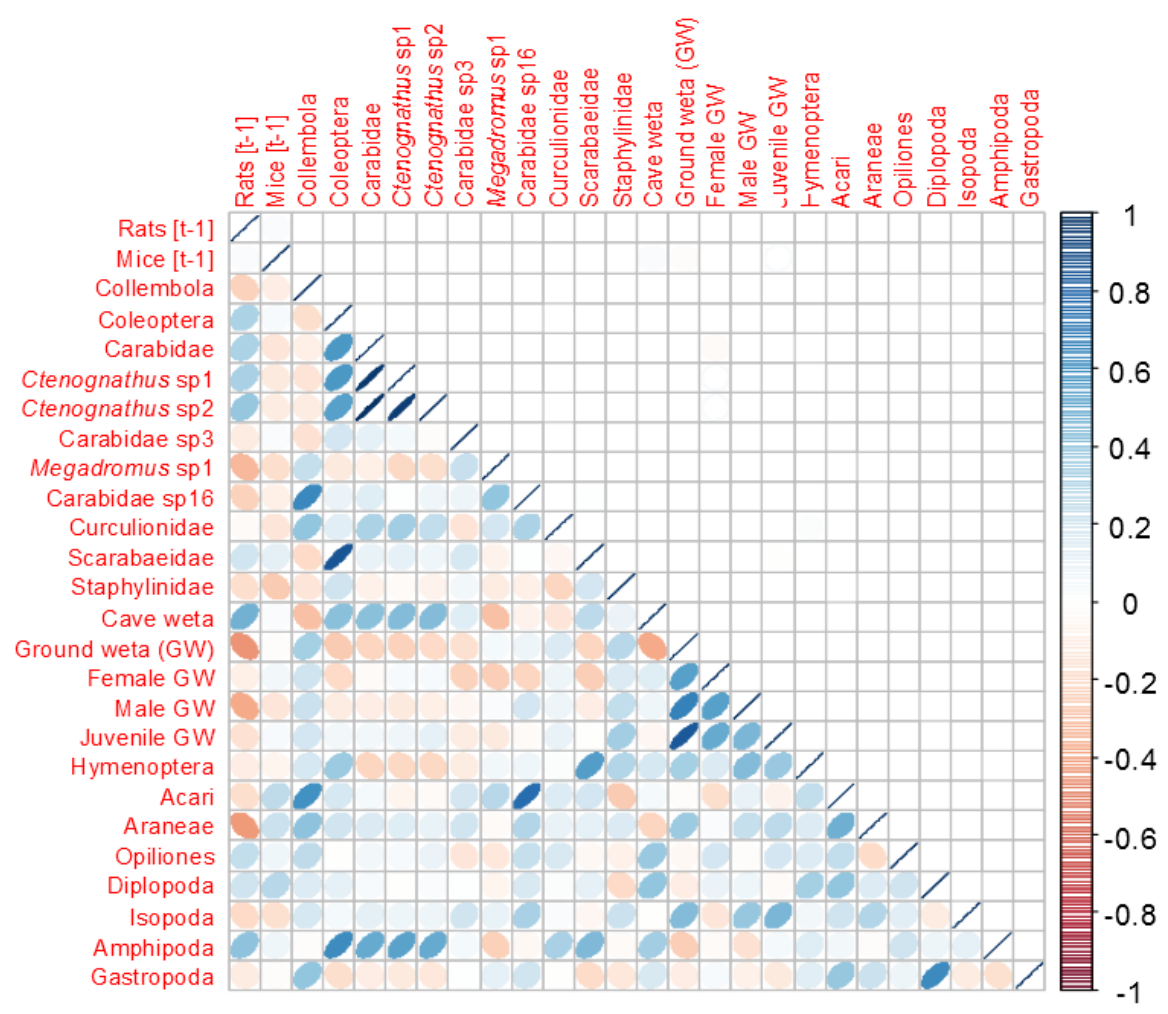

APPENDIX FIGURE 8.6 Matrix of all possible correlations between abundance of rats and mice from the previous season [t-1] and invertebrate abundance [t] in Aorangi and Remutaka Forests. Colours and slope represent coefficient intervals for positive, neutral or negative relationships. 

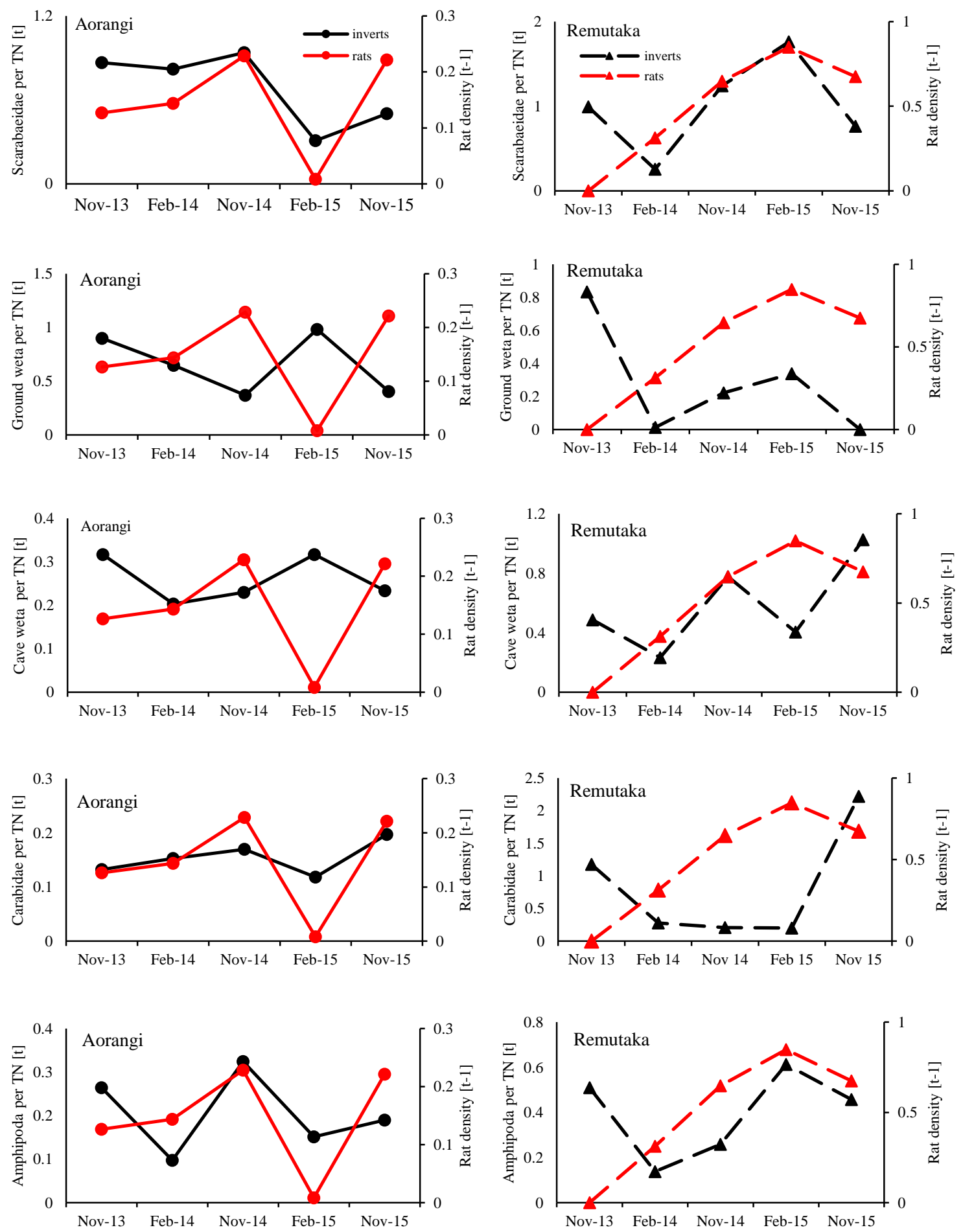

APPENDIX FIGURE 8.7 Mean number of invertebrate abundance per TN [ $\mathrm{t}$ ] and rat density [t-1] per site in the Aorangi and Remutaka across seasons. Note that values of rat abundance are expressed here as the density from the previous season, then comparisons show be done for a particular season. 


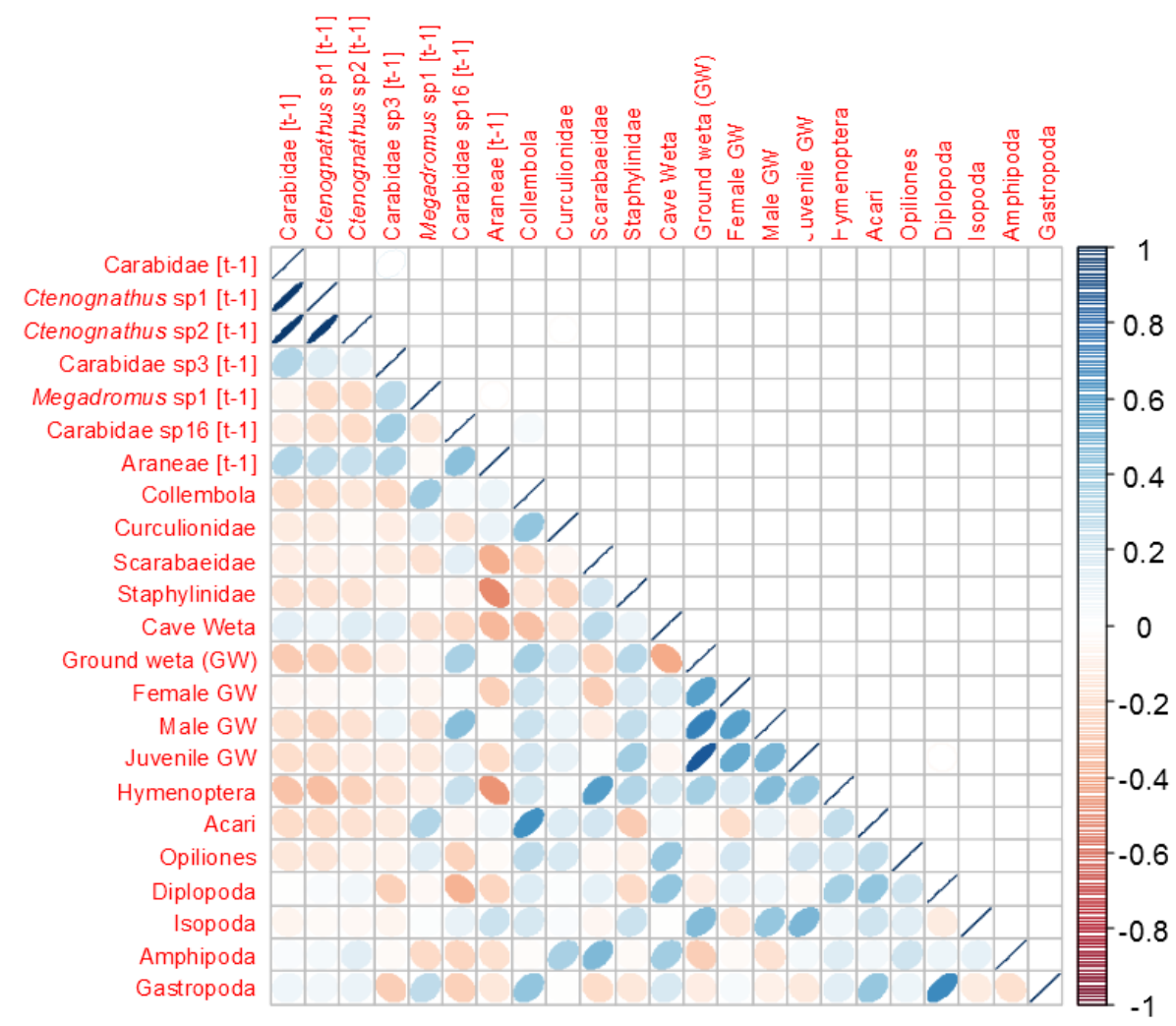

APPENDIX FigURE 8.8 Matrix of all possible correlations between abundance of invertebrate predators from the previous season [t-1] and invertebrate prey abundance in Aorangi and Remutaka Forests. Colours and slope represent coefficient intervals for positive, neutral or negative relationships. 


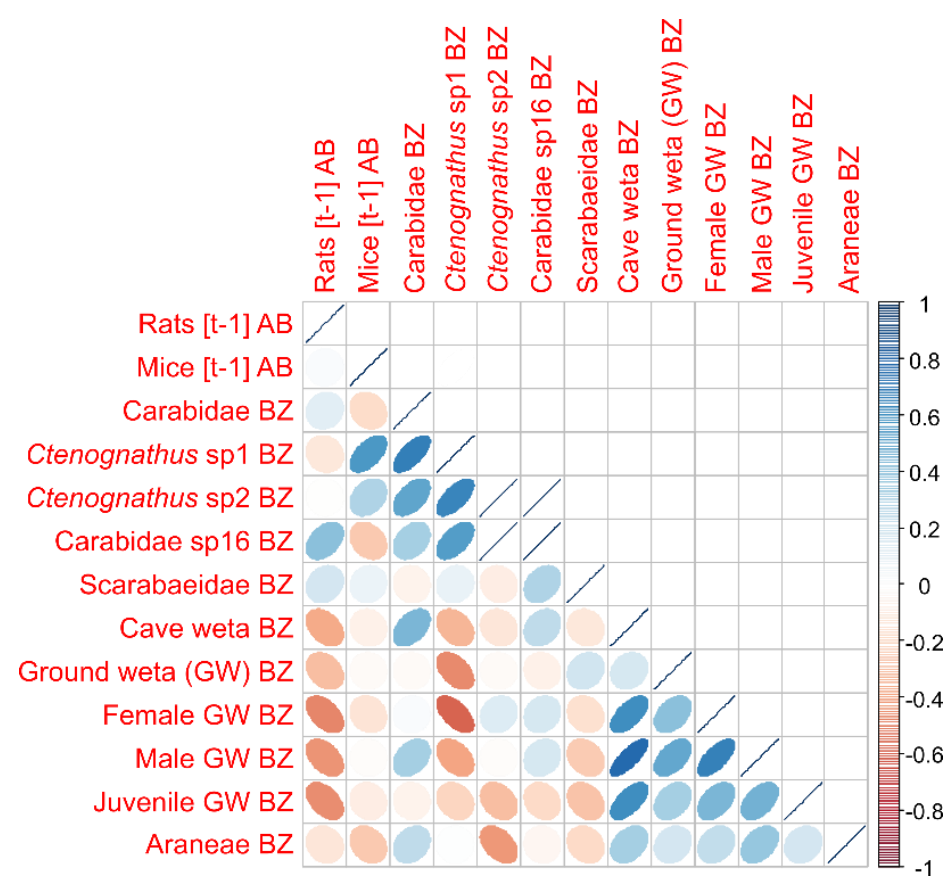

APPENDIX FigURE 8.9 Matrix of all possible correlations between abundance (AB) of rats and mice from the previous season [t-1] and invertebrate body sizes (BZ) in Aorangi and Remutaka Forests. Colours and slope represent coefficient intervals for positive, neutral or negative relationships. 
APPENDIX TABLE 8.3 Structural Equation Modelling (SEM) summary of the best model for invertebrate abundance.

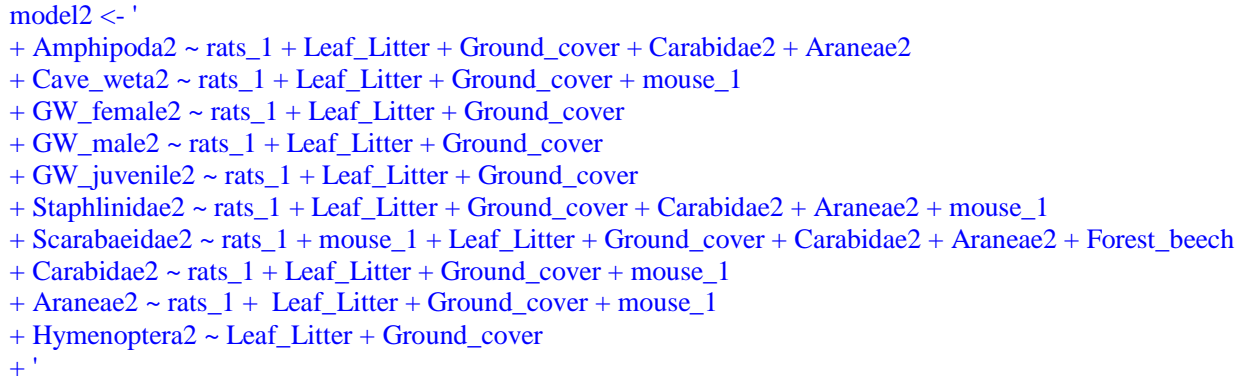

Model test baseline model:

Minimum Function Test Statistic

Degrees of freedom

User model versus baseline model:

Comparative Fit Index (CFI)

Loglikelihood and Information Criteria:

Loglikelihood user model (H0) $\quad 27.319$

Loglikelihood unrestricted model (H1) $\quad 41.521$

Number of free parameters $\quad 109$

Akaike (AIC) $\quad 163.362$

Bayesian (BIC)

Sample-size adjusted Bayesian (BIC) 93.007

Root Mean Square Error of Approximation:
RMSEA
0.032
90 Percent Confidence Interval $0.000 \quad 0.091$
$\mathrm{P}$-value RMSEA $<=0.05$ 0.629

Standardized Root Mean Square Residual:

SRMR

0.046

Parameter estimates:

$\begin{array}{lr}\text { Information } & \text { Observed } \\ \text { Standard Errors } & \text { Standard }\end{array}$

Estimate Std.err Z-value $\mathrm{P}(>|\mathrm{z}|)$ Std.lv Std.all

Regressions:

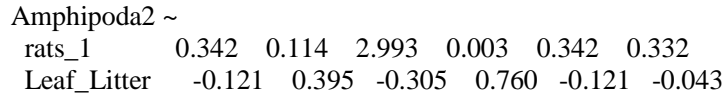




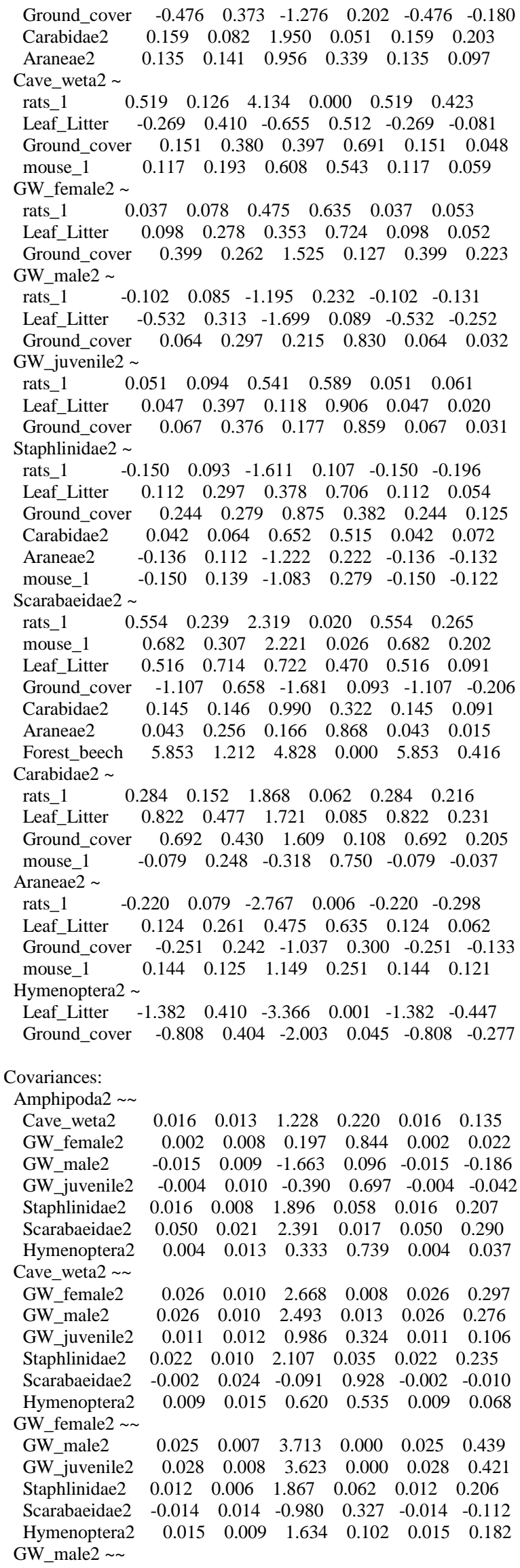




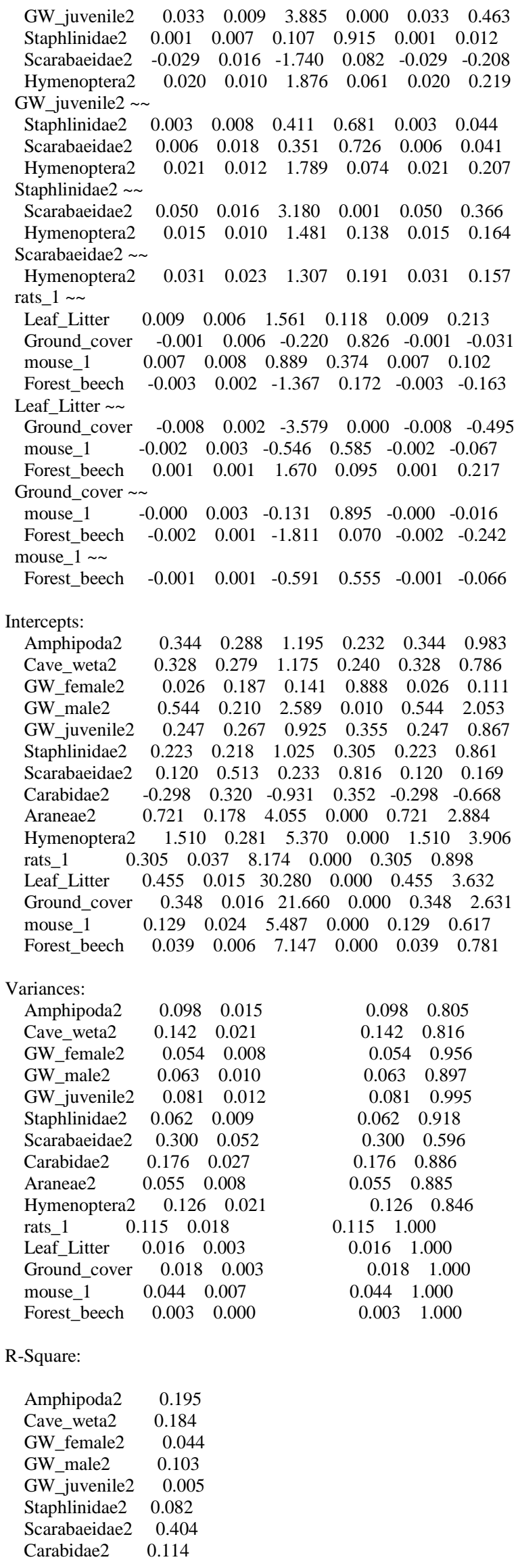




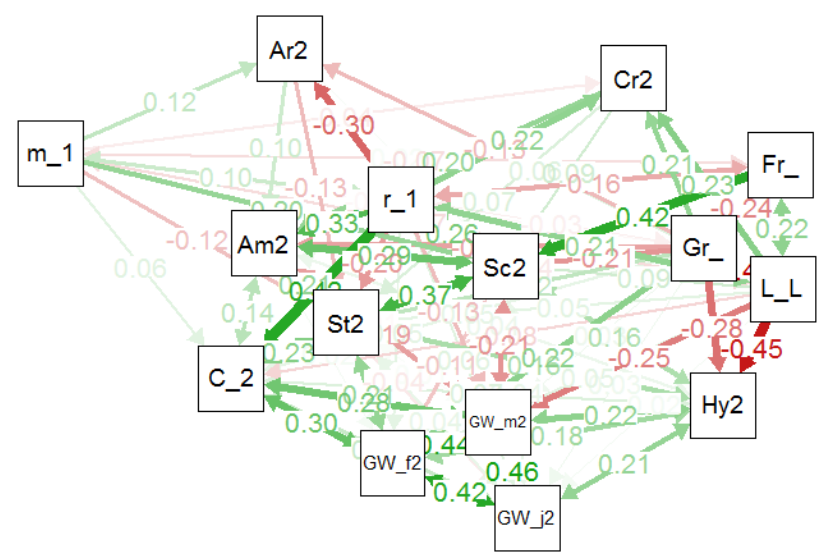

Chi Square Difference Test

Df AIC BIC Chisq Chisq diff Df diff $\operatorname{Pr}(>$ Chisq) fit0 14350.59576 .5717 .672

$\begin{array}{lllll}\text { fit1 } 17440.15696 .26 & 17.672 & 0.0001 & 3 & 1.0000\end{array}$ fit2 $26163.36437 .0528 .403 \quad 10.7316 \quad 9 \quad 0.2946$ 